\title{
Natural buffer placement and downstream flood mitigation in rural Hawkes Bay, New Zealand
}

\author{
John Ballinger \\ A thesis submitted in fulfilment of the requirements for the degree of Masters of Science in \\ Physical Geography, at Victoria University of Wellington, New Zealand \\ School of Geography, Environment and Earth Sciences \\ Victoria University of Wellington
}

March 2011 


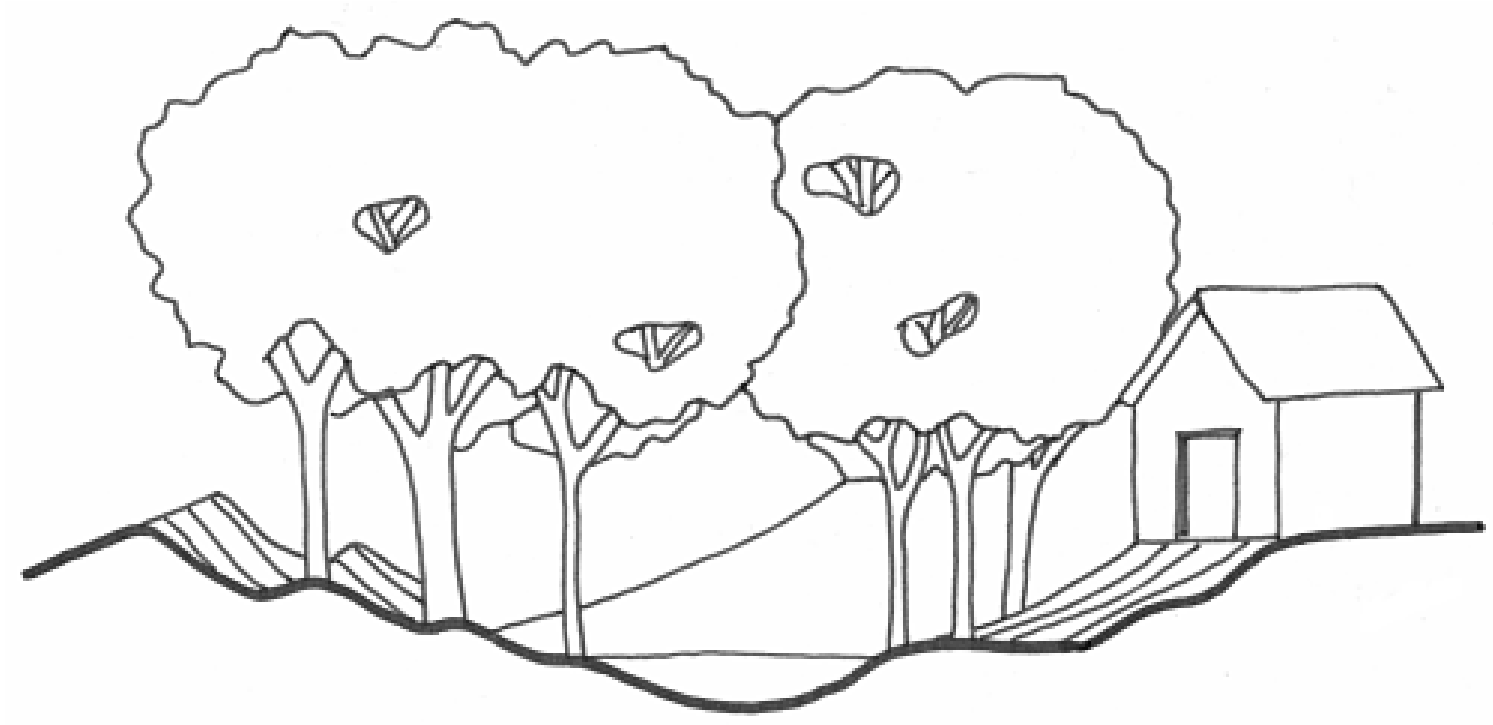

"If you're going to live by the river, make friends with the crocodile" Indian proverb 


\section{Abstract}

Small scale field studies from around the world have shown that agricultural land management has a significant effect on the timing and magnitude of flood peaks. One land management technique called 'soft' engineering utilises strategically planted trees, wetlands, and other natural buffers to temporarily store flood water in upland catchments. This helps mitigate lowland flooding by delaying the release of water into the river system which dampens the peaky response and therefore reduces the pressure on urban areas downstream. With these issues in mind, this MSc thesis examines the landscape benefits arising from both existing and optimally located natural buffers within the Hawkes Bay region of New Zealand, quantifying their capacity to mitigate flooding under varying soil and climatic conditions through;

a) Collating existing data and knowledge;

b) Collecting further targeted data on buffer impacts; and

c) Using this data to inform and apply a flood mitigation model to examine options for buffer placement and simulate flow response times under different land management scenarios.

The ability of any model to make practical predictions is largely dependent on the quality of data input. This research established that the nationally available $25 \mathrm{~m}$ Digital Elevation Models (DEMs) are not suitable for detailed hydrological modelling at the farm scale. A $10 \mathrm{~m}$ DEM was the coarsest resolution considered appropriate. In addition, the nationally available soil information while generally appropriate benefited from moderate "ground truthing" to better represent the soils "true" hydraulic properties. Further targeted data relating to the influence of trees on soil infiltration and storage capacity was collected. Measurements of hydraulic conductivity found that soil under individual populous spp. trees and a Cupresses macrocarpa shelterbelt were 3.1 and 5.5 times as conductive respectively as soil under pasture at $10 \mathrm{~m}$ from the trees. The soil was also less compacted near the trees when the livestock were excluded. This improved the structure and thus water storage capacity of soil. These results informed the buffer assumptions when simulating rainfall-runoff under the different land management scenarios.

The modelling results suggest that the capacity of natural buffers to reduce quickflow is strongly influenced by soil antecedent conditions. Under very wet soil conditions the buffers had little extra capacity to store water when subjected to large rainfall events. In drier soil conditions large rainfall events were absorbed by the buffers with considerable reductions in quickflow. This suggests that buffers occupying a relatively small amount of land but sited in areas of high flow accumulation could prove very effective at mitigating intense rainfall, especially in drier summer months e.g. subtropical storms. Although the results from the modelling are speculative, the outcome is never the less encouraging. Results from both the model simulations and field measurements of hydraulic conductivity suggest that strategically placed ponds and small scale planting can be used to improve the infiltration and water storage capacity of extensive areas of grazed pasture. This will likely reduce runoff and erosion rates and thereby improve stream water quality and farm productivity at both the farm and wider catchment scale. Considering that flooding is the most frequent and costly natural hazard worldwide, natural buffers with their low maintenance costs and recognized ecosystem co-benefits could offer a cost effective and sustainable solution as part of future flood management planning. 


\section{Acknowledgments}

There are a number of people and organisations that I would like to thank for their support and assistance in the completion of this MSc thesis:

- Firstly I would like to thank my supervisor Bethanna Jackson. You provided me with an immense level of support, guidance and insight throughout this thesis. Thank you for stimulating my interest in sustainable land use and introducing me to the wonderful (and sometimes trying) world of hydrological modelling.

- I would also like to thank the staff at Hawkes Bay Regional Council. In particular Gary Clode from Flood Protection, and Chris Perley, Neil Faulknor, and Warwick Hesketh from the Land Management team for their enthusiasm towards my research and assistance in finding suitable study sites. Further help was provided by the Hydrology team with Rob Waldron and Kim Coulson supplying me with hydrological data for the modelling. Additional thanks to Craig Goodier for providing the LiDAR data and Darrel Hall for compiling the relevant GIS data.

- I am very grateful to the landowners of Takapau and Mananui farms, William Foley, Graeme Chapman, and Neville Twist, for allowing me onto their farms. In particular, a big thanks to William Foley and his head shepherd for pulling the university ute out of the mud.

- I would also like to thank my field assistants Richard Taylor, Hamish McKoy, and William Ries. The field work was made all the more enjoyable thanks to your good humour and enthusiasm. Further thanks must be given to William who provided me with countless hours of assistance during the GIS analysis.

- Additional technical support and advice was provided by Gigi Woods and Andrew Rae.

- Thank you to all my friends and colleagues at Victoria University for your encouragement, proof reading and words of support.

- Last but not least, the success of this research would not have been possible without the love and support of my family, friends and significant other Ilse Corkery. Thank you. 


\section{Table of contents}

Abstract

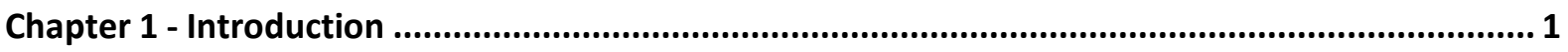

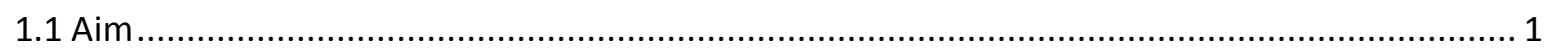

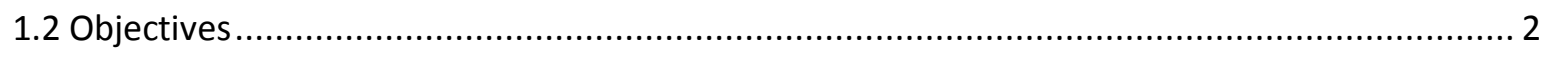

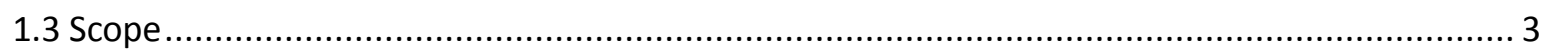

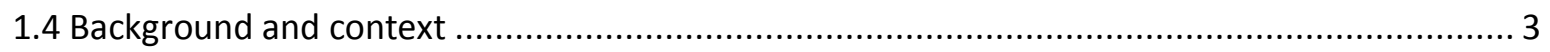

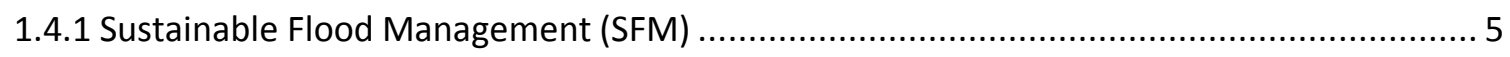

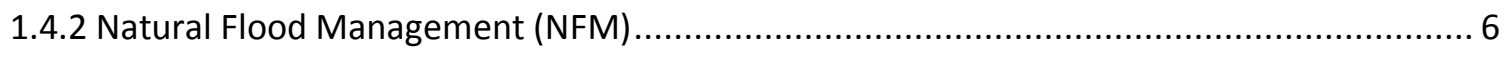

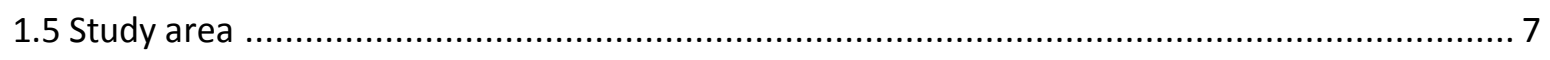

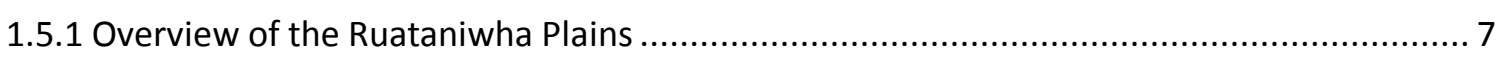

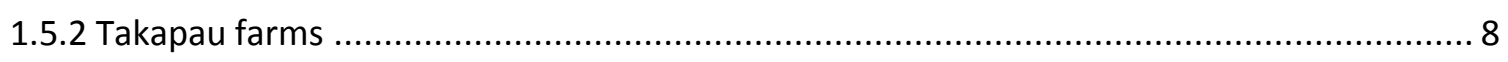

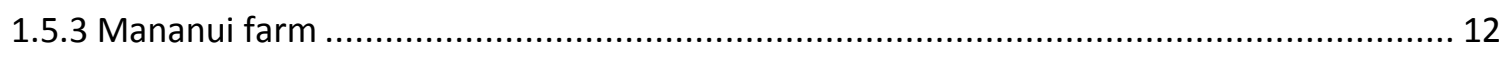

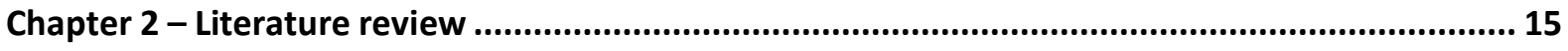

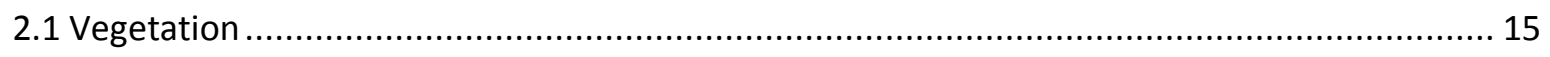

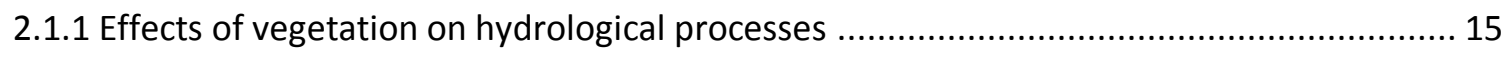

2.1.2 The effects of trees on hydraulic conductivity ............................................................. 17

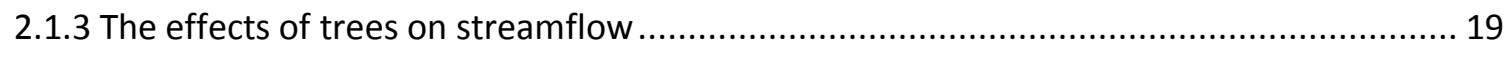

2.1.4 The effects of vegetation on sediment yield and erosion ............................................... 25

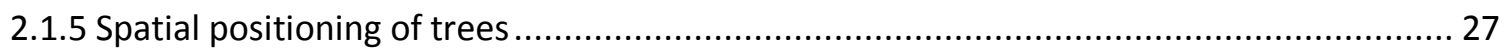

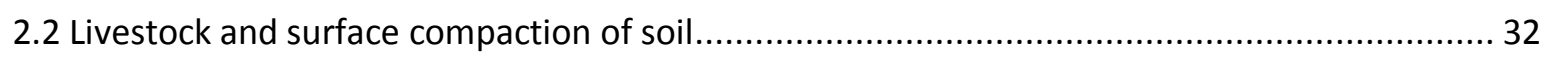

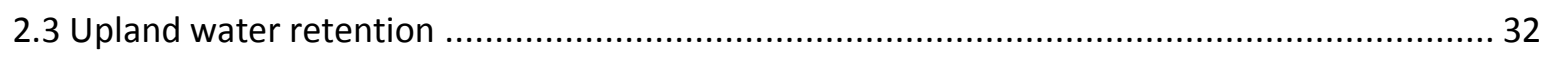

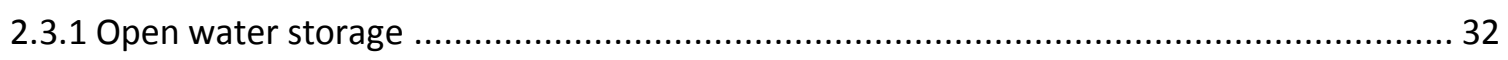

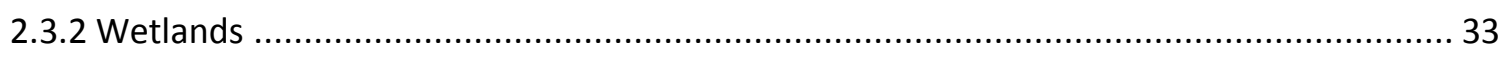

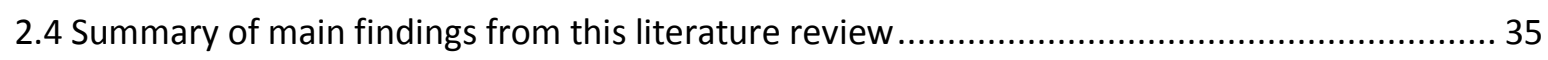

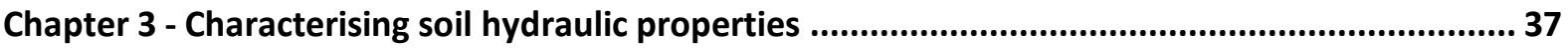




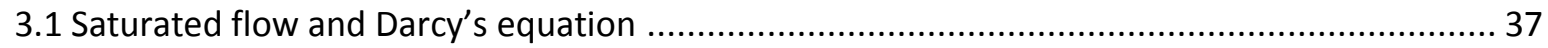

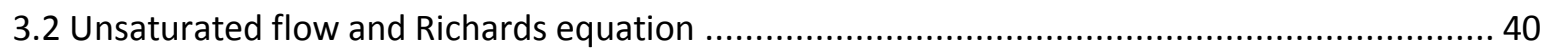

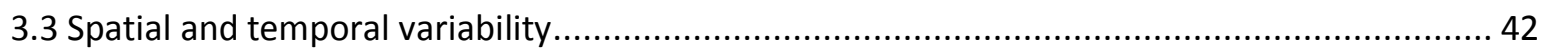

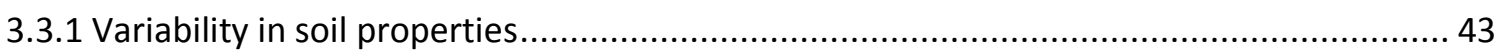

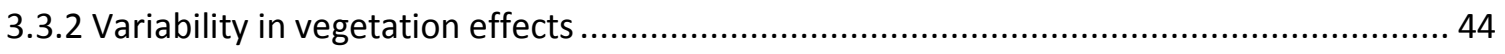

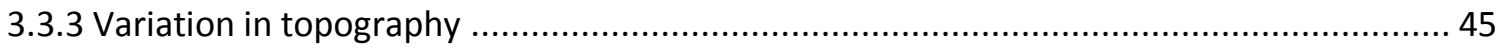

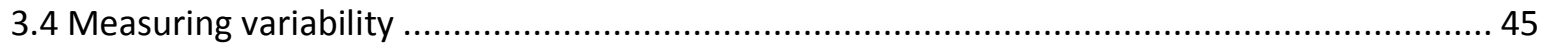

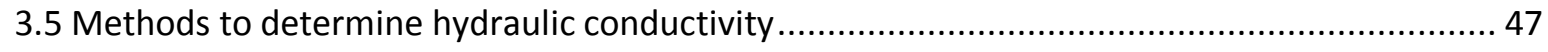

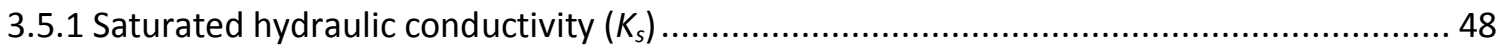

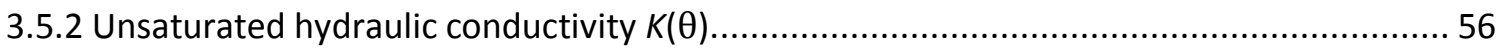

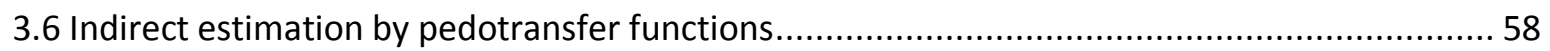

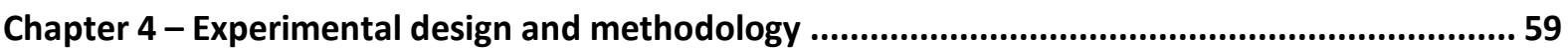

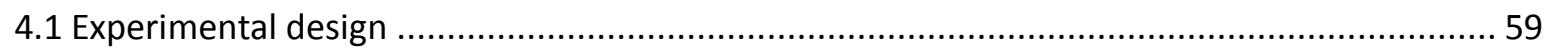

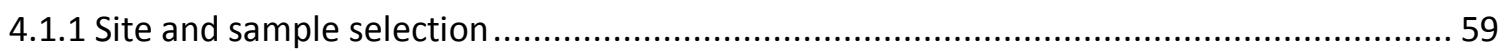

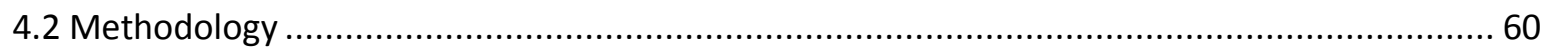

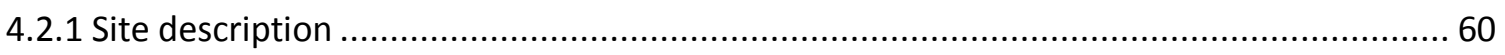

4.2.2 Rationale for choosing the field based Guelph Permeameter ......................................... 60

4.2.3 Measuring saturated hydraulic conductivity with the Guelph Permeameter................... 61

4.2.4 Measuring dry bulk density using the driving hammer technique ..................................63 63

4.2.5 Soil texture analysis using the laser diffraction and sieve method...................................64

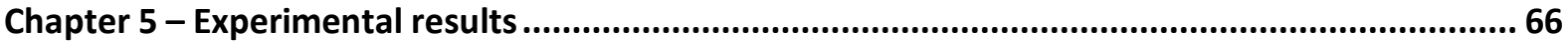

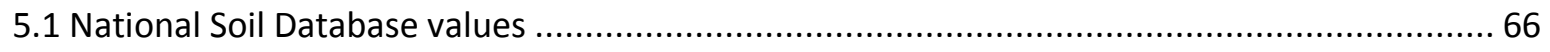

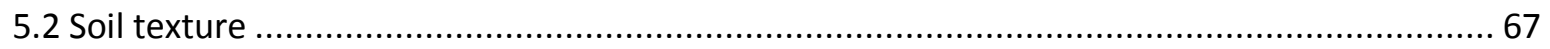

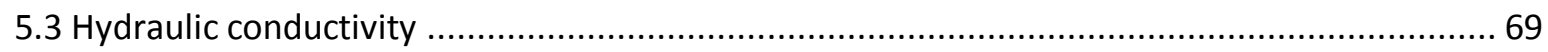

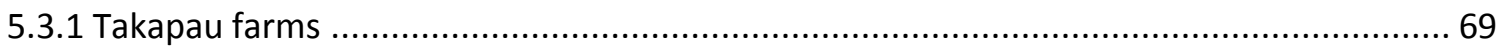

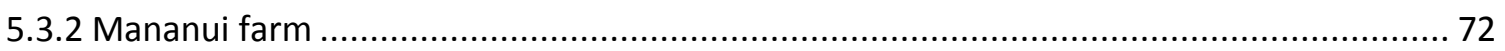

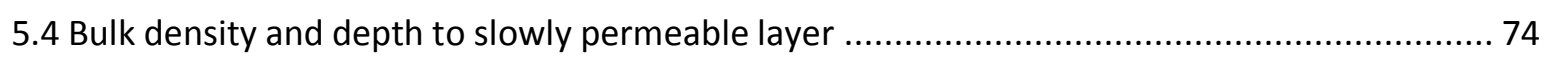

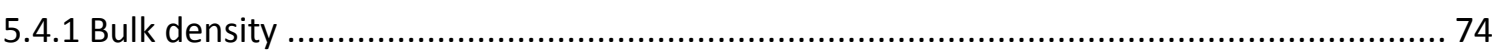

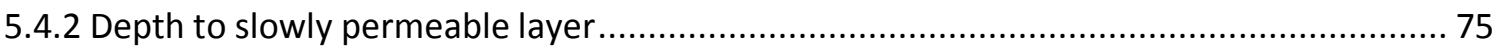

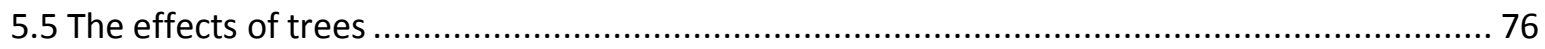

5.5.1 Macrocarpa (Cupressus macrocarpa) shelterbelt.............................................................. 76

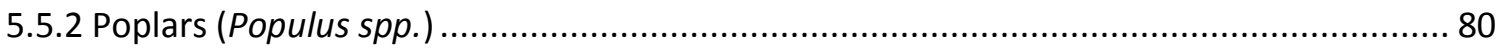

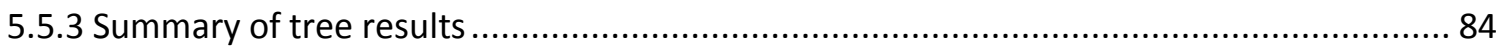

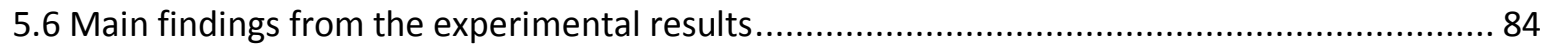




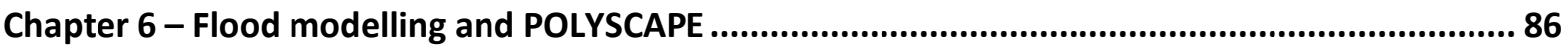

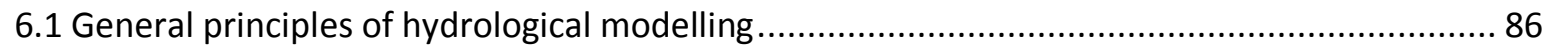

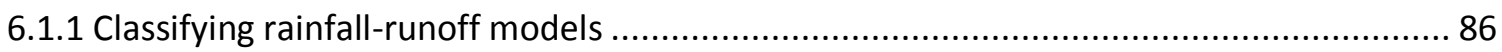

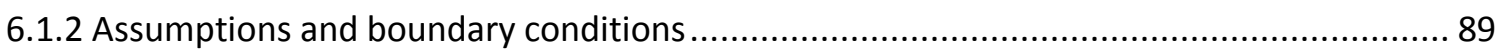

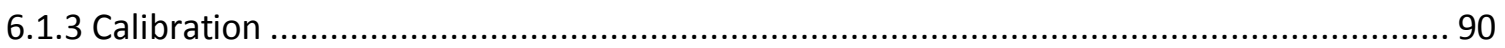

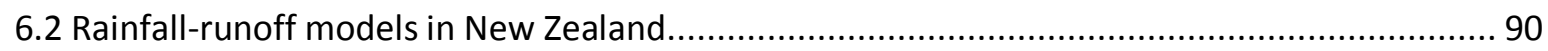

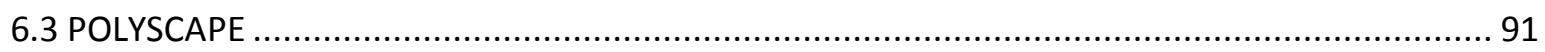

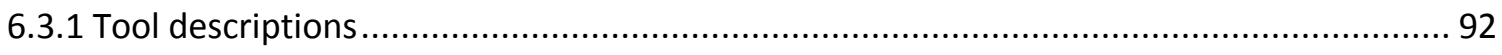

6.4 Using POLYSCAPE to determine the optimum locations for flood mitigation ......................... 93

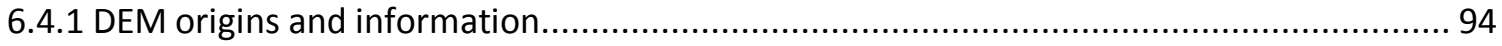

6.4.2 Comparing output between different resolution DEMs .............................................. 95

6.5 Predicting the impacts of land use change using POLYSCAPE............................................. 99

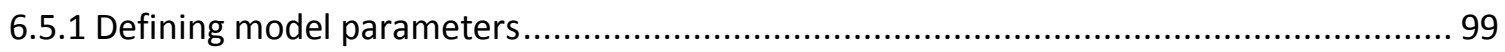

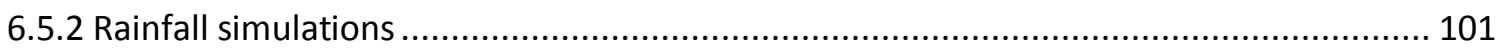

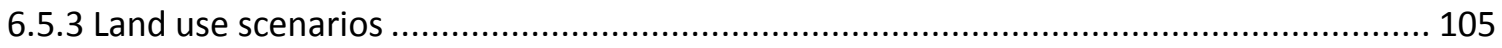

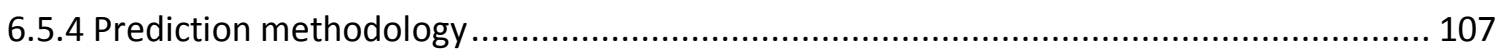

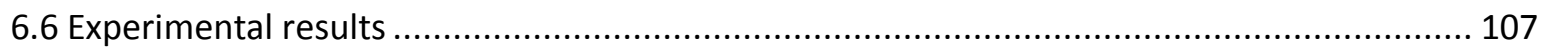

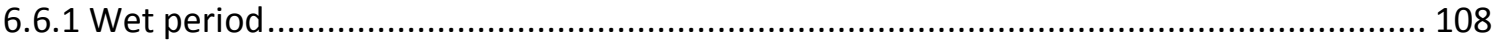

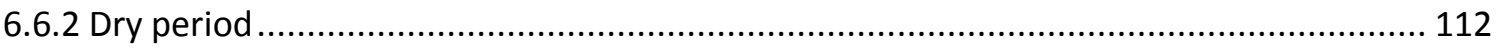

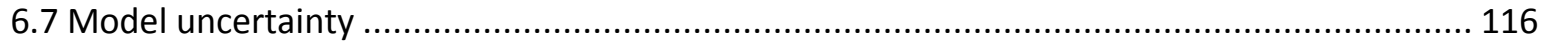

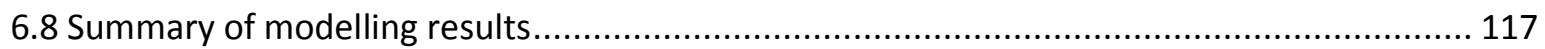

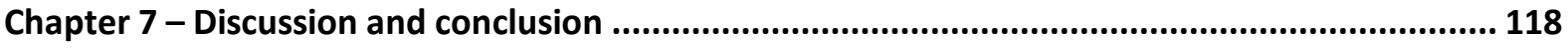

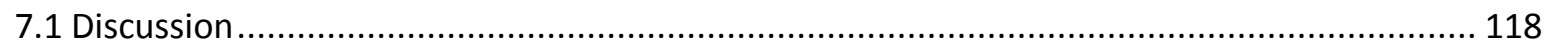

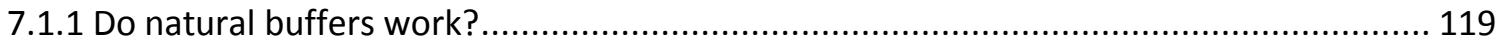

7.1.2 Implementing Natural Flood Management techniques ................................................ 121

7.1.3 Is the national scale land, soil and elevation data appropriate for hydrological modelling at

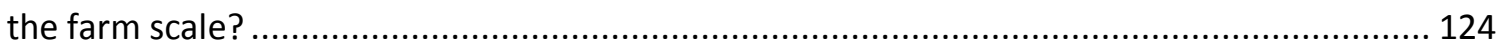

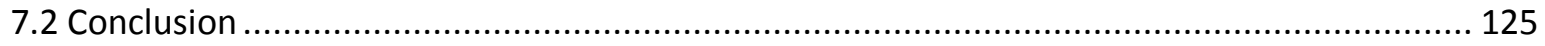

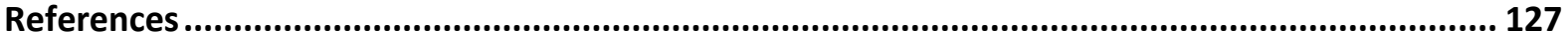

Appendix A - Original and adjusted bulk density ..................................................................... 143

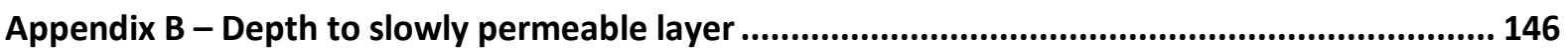




\section{List of Figures}

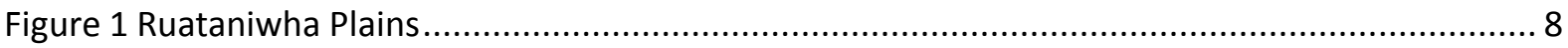

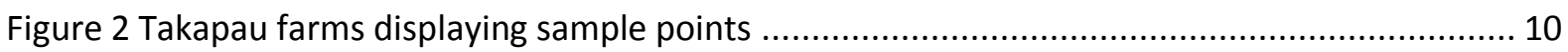

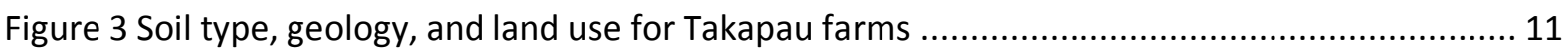

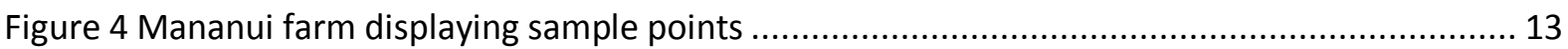

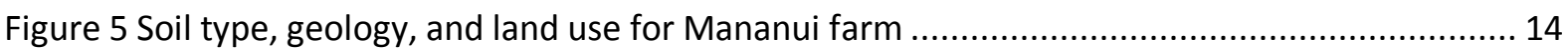

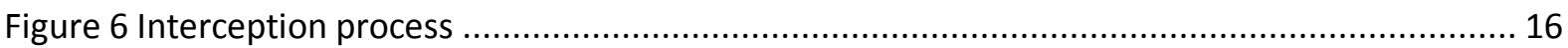

Figure 7 Modelled soil moisture storage beneath pasture and pine forest ................................... 22

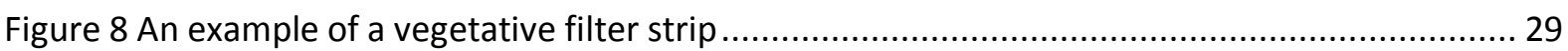

Figure 9 Soil infiltartion rates between planted und unplanted areas ............................................ 31

Figure 10 Water release characteristics for soils of different textures ......................................... 41

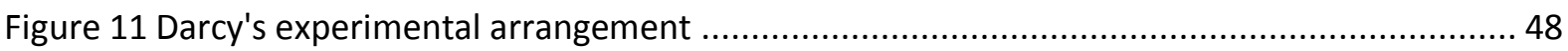

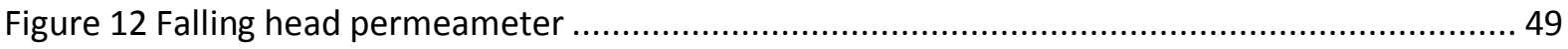

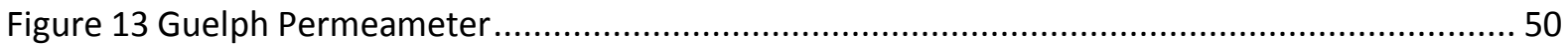

Figure 14 Infiltration through a ring infiltrometer onto a restricting layer ......................................5 54

Figure 15 Infiltration over a large inundated area into a soil with a restricting layer......................... 55

Figure 16 Measuring $K_{s}$ with the Guelph Permeameter at Takapau farms ................................... 63

Figure 17 Bulk density core, stainless steel cylinder and hammer used for extracting soil cores ....... 64

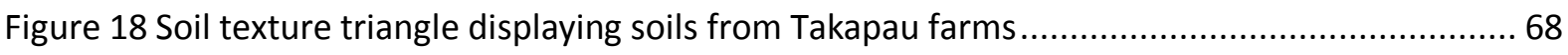

Figure 19 Soil texture triangle displaying soils from Mananui farm .............................................. 68

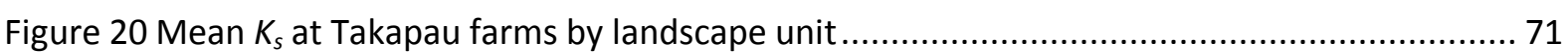

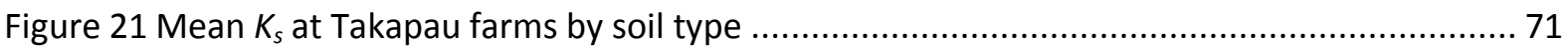

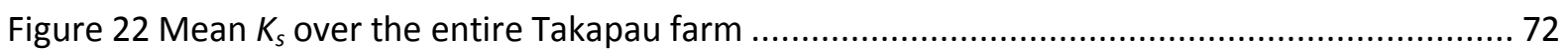

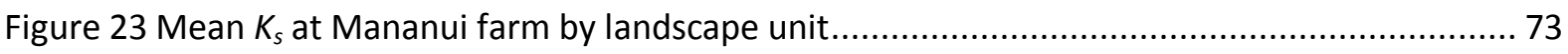

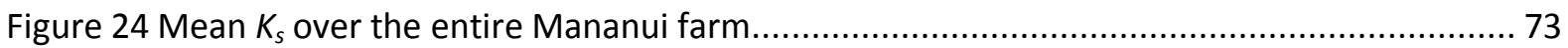

Figure 25 Mean bulk density at Takapau farms at different soil horizons. ........................................ 74

Figure 26 Mean bulk density at Mananui farm at different soil horizons. ........................................ 75

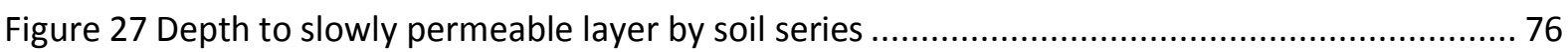

Figure 28 Mean hydraulic conductivity at 1, 5 and $10 \mathrm{~m}$ spacing from macrocarpa shelterbelt. ........ 78

Figure 29 Mean bulk density at 1, 5 and 10m spacing from macrocarpa shelterbelt........................ 78

Figure 30 Measuring $K_{s}$ at $1 \mathrm{~m}$ from trunk of tree; height of trees at southern end of shelterbelt ..... 79

Figure 31 Measuring $K_{s}$ and bulk density at $5 \mathrm{~m}$ from the base of the macrocarpa shelterbelt .......... 80

Figure 32 Mean hydraulic conductivity at 1,5 and $10 \mathrm{~m}$ spacing from poplar trees.......................... 81

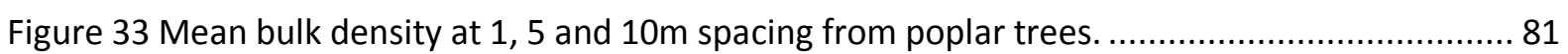

Figure $34 K_{s}$ near macrocarpas and poplars at distances of 1,5, and $10 \mathrm{~m}$ from the base of the trees

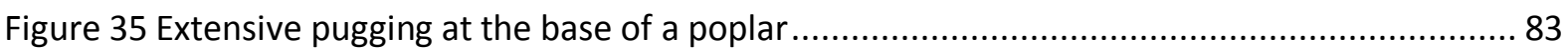

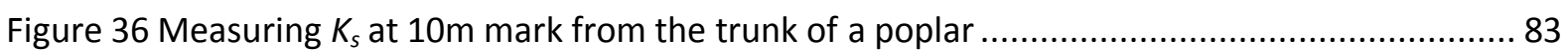

Figure 37 Comparison of output from the POLYSCAPE flood mitigation layer using a variety of digital elevation data..

Figure 38 Differences in elevation between a high resolution $(1 \mathrm{~m})$ reference DEM and DEMs of varying resolution and source data

Figure 39 Original "wet" rainfall followed by the differences in rainfall quantity between the original record and the $1^{\circ} \mathrm{C}$ and $2^{\circ} \mathrm{C}$ record. 
Figure 40 Cumulative "wet" rainfall for the original record and the $1^{\circ} \mathrm{C}$ and $2^{\circ} \mathrm{C}$ increase in atmospheric temperature.

Figure 41 Original "dry" rainfall followed by the differences in rainfall quantity between the original and the $1^{\circ} \mathrm{C}$ and $2^{\circ} \mathrm{C}$ record.

Figure 42 Cumulative "dry" rainfall for the original record and the $1^{\circ} \mathrm{C}$ and $2^{\circ} \mathrm{C}$ increase in atmospheric temperature.

Figure 43 The three land use scenarios used in the POLYSCAPE modelling.... 106

Figure 44 Hydrograph showing 'original' rainfall and quickflow response from the different land use scenarios during the largest 'wet' rainfall event.

Figure 45 Hydrograph showing 'original' rainfall and quickflow response from the different land use scenarios during the $2^{\text {nd }}$ largest 'wet' rainfall event.

Figure 46 Hydrograph showing 'original' rainfall and quickflow response from the different land use scenarios during the $3^{\text {rd }}$ largest 'wet' rainfall event.

Figure 47 Cumulative quickflow from the different land use and rainfall scenarios over the entire 'wet' rainfall period.

Figure 48 Hydrograph showing 'original' rainfall and quickflow response from the different land use scenarios during the largest 'dry' rainfall event.

Figure 49 Hydrograph showing 'original' rainfall and quickflow response from the different land use scenarios during the $2^{\text {nd }}$ largest 'dry' rainfall event.

Figure 50 Hydrograph showing 'original' rainfall and quickflow response from the different land use scenarios during the $3^{\text {rd }}$ largest 'dry' rainfall event.

Figure 51 Cumulative quickflow from the different land use and rainfall scenarios over the entire 'wet' rainfall period.

Figure 52 Vegetative buffer zone along an ephemeral stream channel and; an example of a planting profile using endemic plants 


\section{List of Tables}

Table 1 Ratio of $K_{s}$ of the A-horizon under trees to that under adjacent pasture ............................. 18

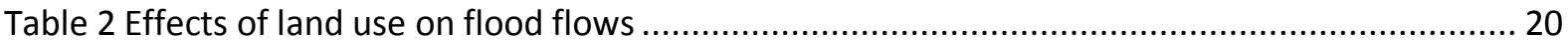

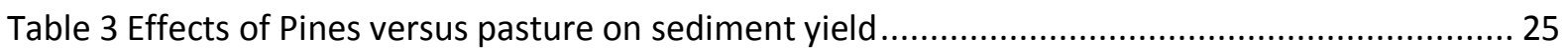

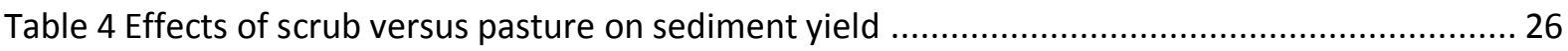

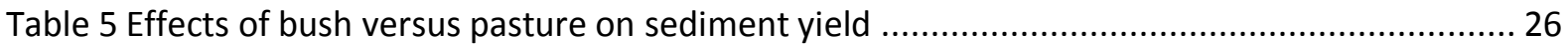

Table 6 Guide for selecting manning's roughness coefficients for natural channels and flood plains 28

Table 7 Indicative hydraulic conductivities based on texture and other soil properties .................... 39

Table 8 Examples of deterministic and random views of hydrological variability ............................ 45

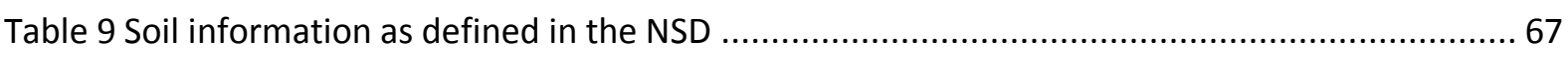

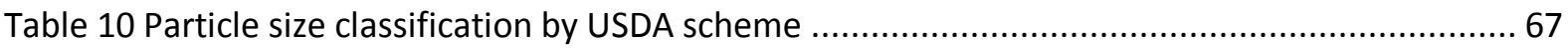

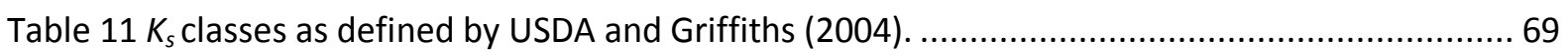

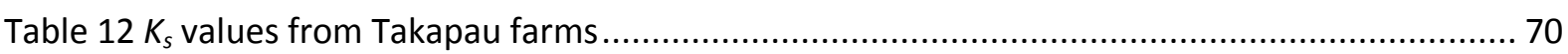

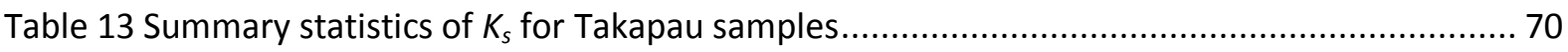

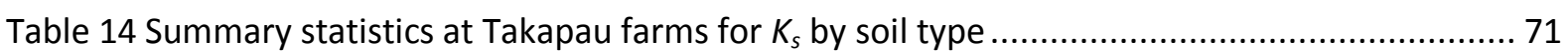

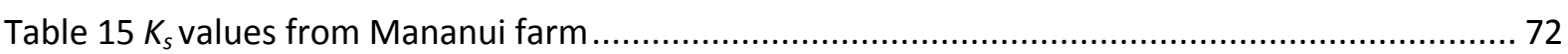

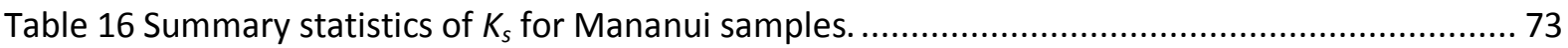

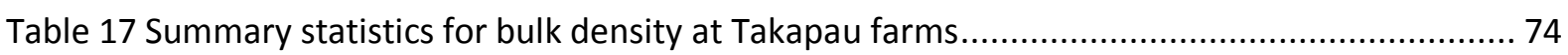

Table 18 Summary statistics for bulk density at Mananui farm ..................................................... 74

Table 19 Summary statistics for depth to slowly permeable layer by soil series .............................. 75

Table 20 Summary statistics and test of normality of mean hydraulic conductivity at 1,5 and $10 \mathrm{~m}$

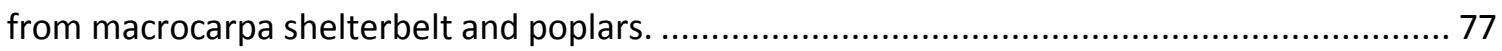

Table 21 Summary statistics and test of normality for mean bulk density at 1, 5 and 10m from macrocarpa shelterbelt and poplars.

Table 22 Differences in elevation between a high resolution reference DEM $(1 \mathrm{~m})$ and five DEMs of varying resolution.

Table $23 K_{s}$, depth to slowly permeable layer, profile total available water values assigned to soil types..

Table 24 Change in rainfall quantities between the original record, and a $1^{\circ} \mathrm{C}$ and $2^{\circ} \mathrm{C}$ increase in atmospheric temperature.

Table 25 Total cumulative rainfall for the wet and dry periods and \% change between the original record, and $1^{\circ} \mathrm{C}$ and $2^{\circ} \mathrm{C}$ increase in atmospheric temperature. 103

Table 26 Ratio of pasture versus buffer cover resulting in amount of flood prone land protected/mitigated.

Table 27 Total quickflow generated during the largest 'wet' rainfall event................................... 109

Table 28 Total quickflow generated during the $2^{\text {nd }}$ largest 'wet' rainfall event ................................ 109

Table 29 Total quickflow generated during the 3rd largest 'wet' rainfall event.............................. 110

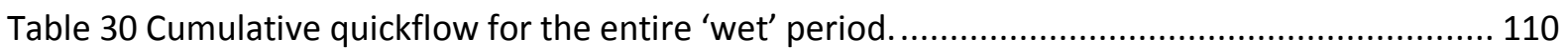

Table 31 Total quickflow generated during the largest 'dry' rainfall event.................................... 113

Table 32 Total quickflow generated during the $2^{\text {nd }}$ largest 'dry' rainfall event ............................... 113

Table 33 Total quickflow generated during the $3^{\text {rd }}$ largest 'dry' rainfall event................................. 114

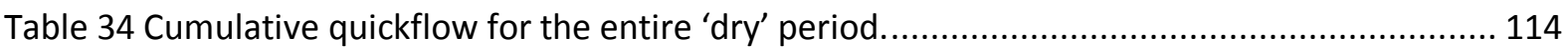




\section{List of Equations}

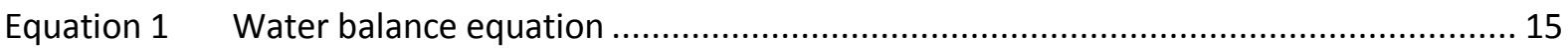

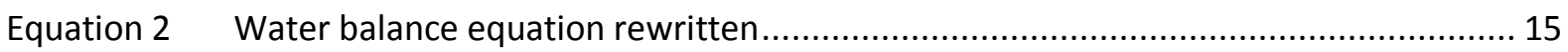

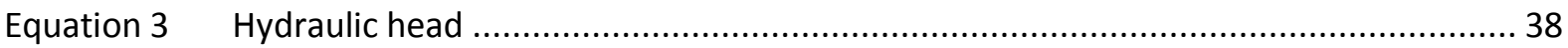

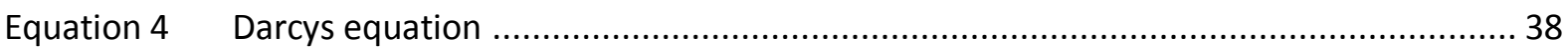

Equation 5 The van Genuchten water retention curve relationship ........................................ 40

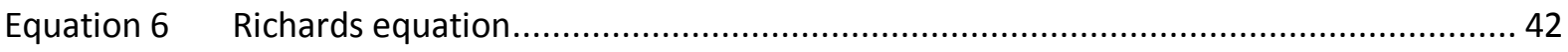

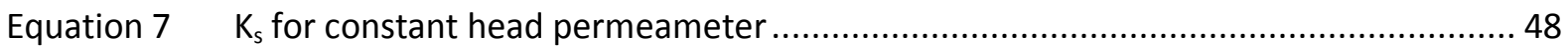

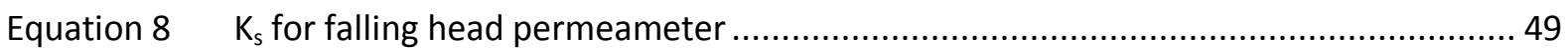

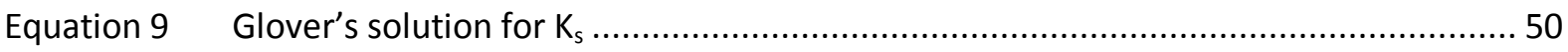

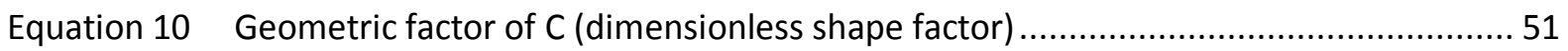

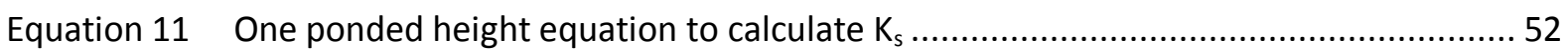

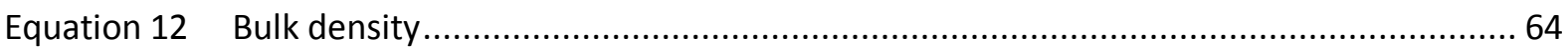

Equation 13 Soil volumetric water content, soil water filled pore space, soil porosity ................. 64

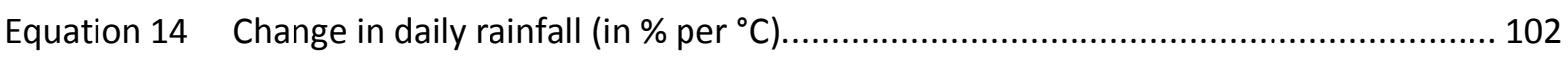




\section{Chapter 1 - Introduction}

Flooding is the most frequent and costly natural hazard worldwide (Morris et al. 2010). In the future, the frequency and magnitude of floods can be expected to increase due to the influence of climate change, land management, and further development of flood plains and coastal lowlands (Smith and Ward 1998). It is estimated that extreme rainfall in the period 1985 to 2008 has been responsible for USD 700 billion of damages including indirect costs (Morris et al. 2010). Although the largest share of economic loss is borne by urban communities, agricultural land represents large proportions of flood producing areas (Morris et al. 2010). Small scale field studies from around the world have shown that agricultural land management has a significant effect on the timing and magnitude of flood peaks (see Chapter 2). This is because agricultural practises influence soil hydraulic properties (storage capacity and hydraulic conductivity) and therefore strongly affect the local generation of surface and subsurface runoff ( $\mathrm{O}^{\prime} \mathrm{C}$ onnell et al. 2006). One land management technique called 'soft' engineering utilises strategically planted trees, wetlands, and other natural buffers to temporarily store flood water in upland catchments. This helps mitigate lowland flooding by delaying the release of water into the river system. In turn, this dampens the peaky response and therefore reduces the pressure on urban areas downstream. With this in mind this thesis applies a flood mitigation model from the POLYSCAPE toolbox (described in Chapter 6 section 6.3) to an upland farm in central Hawkes Bay to predict rainfall-runoff under nine different land use and rainfall scenarios. Particular emphasis was given to the placement of natural buffers within the landscape when quantifying their flood mitigation effectiveness.

\subsection{Aim}

The aim of this research is to examine the landscape benefits arising from both existing and optimally located natural buffers within the Hawkes Bay region of New Zealand, quantifying their capacity to mitigate flooding under varying soil and climatic conditions through;

a) Collating existing data and knowledge;

b) Collecting further targeted data on buffer impacts; and

c) Using this data to inform and apply a flood mitigation model to examine options for buffer placement and simulate flow response times under different land management scenarios.

The flood mitigation tool is a semi-distributed, spatially explicit model which requires data describing catchment elevation, rainfall, evaporation, discharge, land use and soil type to accurately model rainfall-runoff. Field work measuring soil hydraulic conductivity, texture, and bulk density augmented nationally available land and soil information. One important factor in the wide scale 
application of the flood mitigation tool, or indeed any flood risk prediction model is the cost associated with obtaining the necessary data to accurately apply the model. This is especially difficult for local authorities who manage large areas but have limited financial resources. In New Zealand the national scale data is of coarse resolution. The cost of obtaining finer resolution data can be significant. Therefore an important question is to what degree and in what environments can the national scale data (notably DEM and land and soil information) be relied upon to produce sufficiently accurate output for the flood management process? Furthermore, if the data is unreliable or not reliable in all environments, then what would be required to address this issue, and is this feasible? Hence, a fourth sub-aim is to provide guidance on what might be required for future applications.

\subsection{Objectives}

To achieve the aim this research was broken into the following objectives:

1. Ground truth the national scale land and soil information held in the New Zealand Land Resource Inventory (NZLRI) and National Soil Database (NSD) by digging soil pits and collecting samples from selected sites within the Ruataniwha Plains in Hawkes Bay based on land type, topography, soil and geology. Measure the hydraulic conductivity, soil texture, bulk density, and the depth to slowly permeable layer at each sample location and compare to the national data. This data is used to assess the extent to which the national data can be used for detailed flood modelling and management at the farm scale.

2. As tree shelterbelts are proposed as natural flood buffers, measure the changes in soil hydraulic properties at a distance of 1,5 and 10 metres from the trunk of two commonly found species of trees on New Zealand farms: a Cupressus macrocarpa shelterbelt and individual Populus spp. trees.

3. Collect elevation, rainfall, evaporation, and soil moisture data from Hawkes Bay Regional Council and NIWA's National Climate Database (Cliflo).

4. To maximise flood mitigation benefits, calculate the optimal or near optimal locations for natural buffer placement using the flood mitigation tool within POLYSCAPE. Compare model output using six Digital Elevation Models (DEMs) of differing resolutions. These include two national scale DEMs $(25 \mathrm{~m})$ created by GeographX and Landcare Research, and four DEMs $(25 \mathrm{~m}, 10 \mathrm{~m}, 5 \mathrm{~m}, 1 \mathrm{~m})$ created from Light Detection and Ranging (LiDAR) data. This is to determine both the limits of DEM resolution appropriate for effective prediction of flood 
buffering effects at the farm scale, and to show the differences between the same resolution DEMs from different data sources.

5. Explore the flood mitigating effectiveness of natural buffers by simulating runoff response for nine different land use and rainfall scenarios. The land use layers include the farm under current land use (existing buffers); the farm with existing buffers removed; and the farm with additional strategically placed buffers. The rainfall simulations include a representative "wet" and "dry" record and the same records modified for a $1^{\circ} \mathrm{C}$ and $2^{\circ} \mathrm{C}$ change following national guidance (MfE 2010) to reflect potential climate change impacts.

\subsection{Scope}

This thesis is broken down into the following chapters. The remainder of this chapter briefly discusses historical floods and future flood frequency trends before considering Natural Flood Management (NFM) as a complimentary approach to traditional engineered solutions. It concludes with a description of the study areas. In Chapter 2, a literature review looks for evidence from peerreviewed studies for changes in flood risk caused by changes in vegetation and open water storage basins. In Chapter 3, the fundamental principles of soil water movement are explained before the challenges associated with measuring hydraulic conductivity and other hydraulic properties are discussed. This is followed by a brief overview of different measurement methods with a detailed description of the field based constant head Guelph Permeameter method. A detailed description of the experimental methodology is presented in Chapter 4, with the results and discussion in Chapter 5. For the rainfall-runoff modelling, a spatially explicit physically based hydrological model is applied and the results from the different land management and rainfall scenarios discussed in Chapter 6 . Chapter 7 concludes the thesis with a discussion of main findings and recommendations for future research.

\subsection{Background and context}

Floods are a natural landscape forming process responsible for the development of river valleys, floodplains, and a rich diversity of aquatic and riparian habitats (Meissner 2003). Towns and cities have developed on floodplains because they provide flat, fertile land with access to fresh water, and historically provided inexpensive transport via the river. However, with floodplain exploitation comes the risk of destructive flooding to homes, infrastructure and livelihood, and in extreme events the loss of life. Despite advances in technology and investment in flood control works, flood occurrence and the resulting hardship have been steadily increasing (Kundzewicz 2002). Indeed, 
flooding is the most frequent and costly natural hazard worldwide and leads all other natural disasters in the number of people affected and in resultant economic losses (Morris et al. 2010).

How vulnerable a society is to flooding is a function of the exposure to the hazard and their adaptive capacity (Hennessy et al. 2007). Both have increased through time but exposure is increasing faster than adaptive capacity and therefore society's vulnerability is increasing also. Loster's (1999) analysis of the world's great flood disasters found that the number of flood disasters over the period 1990 to 1998 were three times greater than the previous three and a half decades from 1950 to 1985 . Since then, many more damaging floods have occurred including wide spread flooding across Europe in 2002, the inundation of New Orleans by Hurricane Katrina in 2005 , the heavy monsoonal rains in Pakistan in 2010, and most recently the suffering caused by river flooding in Queensland, Australia 2011. Between 1920 and 1983, New Zealand experienced 935 damaging floods with total flood damage costs averaging NZ \$120 million/yr from 1968 to 1998 (NZIER 2004).

A paper published recently in Nature has proven the link between anthropogenic climate change and rainfall intensification in the Northern Hemisphere (Min et al. 2011). This is because a warmer atmosphere can hold more water causing the intensity and/or duration of rainfall to increase. To date the contribution of climate change to flood events in the Southern Hemisphere has been hard to distinguish given other sources of climatic variability such as El Nino-Southern Oscillation (ENSO) (Hennessy et al. 2007), but since the world shares one atmosphere it is likely this effect is occurring in the Southern Hemisphere also.

Perhaps a more significant factor contributing to flood exposure is human management of rivers and their catchments. It is generally thought that agricultural intensification over the last five decades has led to more frequent and intense floods following heavy rainfall (Morris et al. 2010). This is attributed to the "improvement" of drainage systems by draining wetlands so water can be discharged quickly from agricultural land, and clearing of natural vegetation from floodplains and hill country. This has reduced the capacity of catchments to store and slowly release water producing flashy flow regimes (Kundzewicz 2002). Furthermore, continued floodplain development has straightened and confined rivers within narrow channels, disconnecting them from their floodplains. Now water has nowhere to go in times of flood and will either overtop local flood defences, or be transmitted downstream as a wave increasing flood risk in lower catchments (Johnson et al. 2008). In industrialized countries the traditional approach to this problem has been to build higher flood defences, but as McConchie (2000) notes, it is usually economically impossible to provide protection 
against the maximum possible flood ${ }^{1}$. The issue of engineering failure was demonstrated in the USA (one of the wealthiest nations on earth) when the levees containing the Mississippi River failed to protect New Orleans from Hurricane Katrina and the resultant storm surge in 2005. In most industrialized countries natural flow regimes have been replaced by engineered solutions whereas developing countries lack the financial resources to build and maintain them. Instead, they rely on more basic approaches using traditional knowledge to cope with flood waters (Johnson et al. 2008). For an in-depth discussion of this fundamental dichotomy in flood management see Ogtrop et al.(2005).

\subsubsection{Sustainable Flood Management (SFM)}

The combination of engineered projects, degradation of natural buffering systems, and development on floodplains coupled with greater consideration for the environment has meant a more sustainable approach to flood management is required (Johnson et al. 2008). Hard engineering is appropriate in some cases, but it often only deals with the symptoms and not the causes of the flood. General "Sustainable Flood Management" (SFM) works with the entire river catchment and deals with flooding at the source in the upper catchment (WWF 2007). The paradigm shift from hard engineering to a more sustainable approach began to gain momentum in the 1990s e.g. Adams and Perrow (1999). There are many approaches to SFM which generally embrace economic, environmental, and social objectives. One of these approaches is cited by Johnson et al.(2008:2) who suggests that SFM include the following eight components:

1. Floods legislation driven by good science, policy and planning;

2. Flood monitoring networks and warning systems;

3. Flood data for trend analysis and investigating flood generation processes;

4. Protecting, benefiting and involving communities;

5. Engineered flood protection schemes;

6. Economics including capital costs, maintenance costs, environmental and social benefits;

7. Protecting, restoring and enhancing the natural environment; and

8. Natural flood management in functional flood control areas, involving restoration of natural features and natural processes, and catchment land use planning.

\footnotetext{
${ }^{1}$ Derived from the upper end of flood frequency curves. The upper end can be evaluated by the recorded maximum floods in the region. If a frequency curve shows a flood in excess of anything experienced in the region and the frequency is not supported by data near that level, then the upper end of the curve is questionable (Riggs 1985).
} 


\subsubsection{Natural Flood Management (NFM)}

SFM is an approach with an integrated set of procedures covering an entire physical catchment from the upland source areas down to the lowland depositional areas. Of interest to this project is component 8, Natural Flood Management (NFM), which aims to reduce run-off rates in the uplands by restoring or enhancing natural buffers in key flood control areas to reduce downstream flooding. Many of the recommended management procedures are already part of best practices in farming, forestry, river and natural habitat management. The key components of NFM encompasses the set of techniques used, their location within the landscape, and their effectiveness in both the short and long term (Johnson et al. 2008). The set of techniques used in NFM are described in (WWF 2007) and include:

- Reforestation of hillslopes;

- Planting dense woodlands in gulleys;

- Modifying agricultural practices;

- Restoring upland wetlands, lowland wetlands and flood plains;

- Restoring river channel meanders;

- Controlling excessive erosion; and

- Management of large woody material in watercourses.

National initiatives such as "Making Space for Water" (England and Wales) and "Room for Rivers" (Netherlands) are investigating these techniques for floodplain management (Morris et al. 2010). These techniques offer opportunities for multiple benefits which include improved flood mitigation, amenity, protection against soil erosion, and increased bio-diversity and habitat connectivity. Such areas might also provide alternative sources of income for landowners through compensation for lost agricultural productivity, or by selective harvesting of timber/flood buffering trees. Before such programs are established, it is important to quantify the effectiveness of natural buffers under varying soil and climatic conditions. This is because vegetation affects soil water storage capacity, which in turn is sensitive to soil antecedent moisture levels. If the soil is near saturated (such as in winter) then its water storage capacity is less. If the soil is very dry (as in summer) then its water storage capacity is greater. With this in mind, this research utilises the flood mitigation tool within POLYSCAPE (described in Chapter 6 section 6.3) to explore how vegetated buffer areas affect soil storage and thus runoff under varying antecedent conditions. 


\subsection{Study area}

The combination of lithology, relief and climate make Hawkes Bay susceptible to periodic flooding. This research is being assisted by Hawkes Bay Regional Council (HBRC) and therefore the objective was to find a suitable catchment within Hawkes Bay whose land owners would permit research to be carried out over the period of the project. The criterion for catchment selection was that it must be within rural Hawkes Bay, be readily accessible by vehicle, and have sufficient capacity to generate flow to downstream areas. Of critical importance was the availability of high resolution LiDAR elevation data. While the Ruataniwha Plains have good coverage, the surrounding hill country which is the source area for downstream flooding is poorly represented. Despite this, two areas (Takapau farms and Mananui farm) bordering the Ruataniwha Plains in central Hawkes Bay satisfied all criteria and hence were selected.

\subsubsection{Overview of the Ruataniwha Plains}

The Ruataniwha Plains lie in an inter-montane basin between the Ruahine range in the west and the Ruakawa Range in the east. The western ranges create a rain shadow over the plains producing an average yearly rainfall of $800 \mathrm{~mm}$ increasing to $1000 \mathrm{~mm}$ moving east to west (Pollock 2010). Four large rivers, the Waipawa, Tukituki, Makaretu, and Tukipo Rivers as well as minor streams have gradually filled the basin with sediment over the last 200,000 years. The Ruataniwha Plains is an important horticultural region for the Hawkes Bay. There are a wide diversity of soils ranging from heavy clays to gravels, from shallow to deep, and from waterlogged to well drained (Griffiths 2004). Traditional agriculture is giving way to widespread intensification with large water storage and irrigation schemes proposed for the future (Tonkin \& Taylor Ltd 2009). 


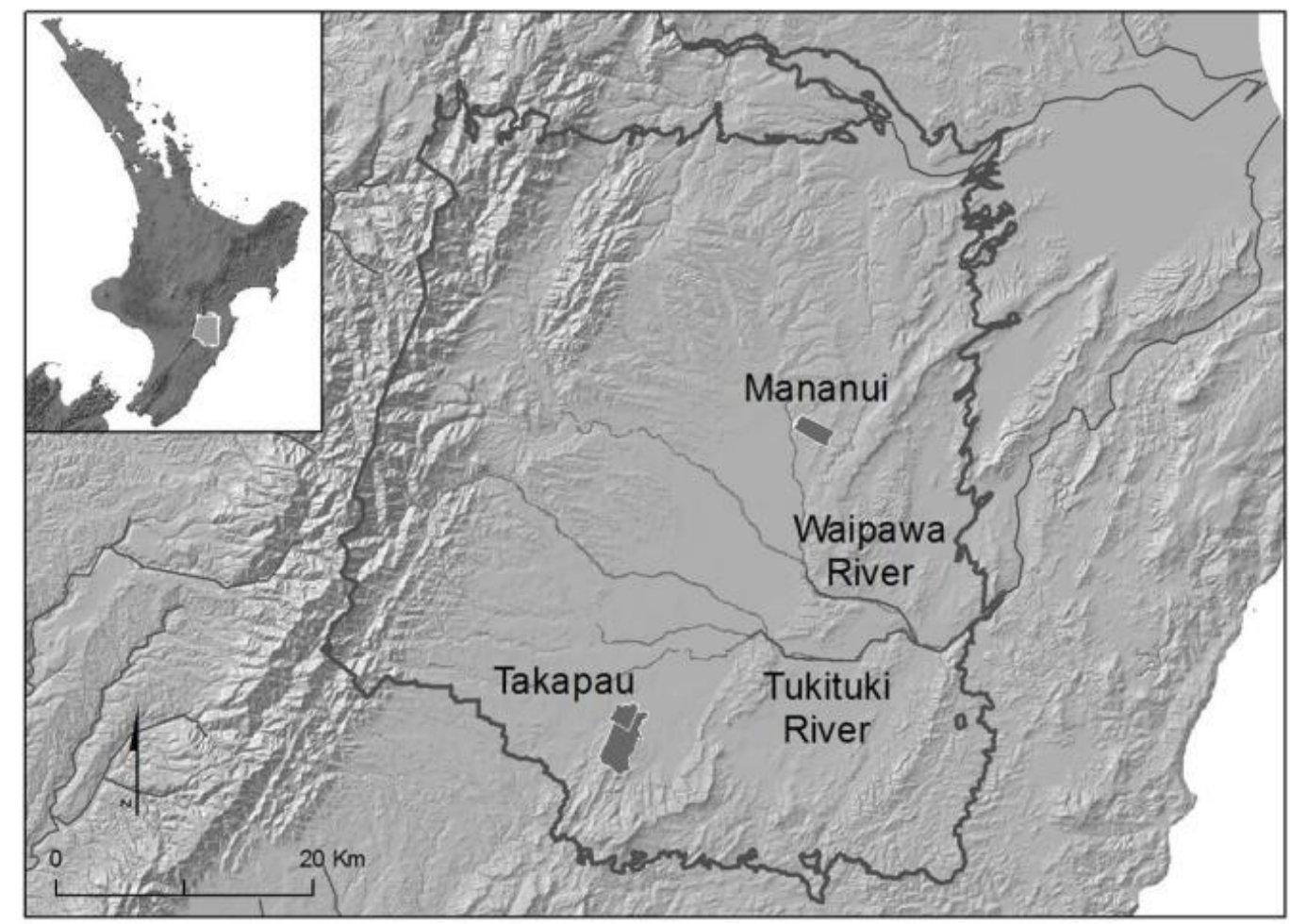

Figure 1 Ruataniwha Plains showing the Takapau and Mananui study areas (dark grey). Two major rivers, the Waipawa and Tukituki join and then drain to the northwest

Flood protection for the Ruataniwha Plains is provided by the 'Upper Tukituki Flood Control Scheme' which is designed to contain a 1 in 100 year flood. The scheme protects approximately 130,000ha of potentially floodable land including some 200ha of urban land in Waipawa and Waipukurau (Woodward-Clyde 1998).

\subsubsection{Takapau farms}

Site one is located on the southern border of the Ruantaniwha Plains near Takapau and extends across two farming properties (covering a combined area of $12.6 \mathrm{~km}^{2}$ ); the first belonging to William Foley, and the second to Graeme Chapman. HBRC undertook extensive soil mapping in the area culminating in the Griffiths (2004) "Soils of the Ruataniwha Plains" management guide. This information is included in the National Soils Database (NSD). On Mr Foley's farm these maps were further improved by Stokes (2006) as part of an environmental plan for the Foley Bros properties. The farms have a variety of features within the landscape. To the north is Ruataniwha Plains alluvium sitting on intermediate and low-lying terraces. South of the alluvium is limestone hill country which trends in a north-east/south-west direction. At the southern part of the study area is mudstone hill country, and to the south east, a steep greywacke outcrop. The limestone, mudstone and greywacke hill country surround rolling loess downlands with a basin drained by the Awanui Stream. The three predominant soil types are silt loams (Matapiro, Mangapakeha and Atua) whose extent has been defined by the underlying geology. A further three soils (Okawa sandy loam, 
Taihape silt loam, and Takapau stony loam) are present in small quantities on the farm boundaries. The soils are termed 'pallic' which means they occur where there is a water deficit in summer and surplus in winter. They are all derived from Tongariro ash on loess and are typically shallow with $20 \mathrm{~cm}$ ash on gleyed silt loam (loess) on a fragipan at $35-60 \mathrm{~cm}$. The pan layers are cemented to a greater or lesser extent by silica weathered from volcanic ash which can be exacerbated by ploughing which can cause finer silts and clays to clog the coarse pores creating slow rates of drainage. Griffiths (2004) notes that although the infiltration rate is moderate, permeability is very slow with water perching on the pan. Land use is primarily pastoral with winter cropping on the downlands. The livestock are sheep and cattle. The only wooded regions of note are a macrocarpa shelterbelt (Cupressus macrocarpa) dividing the two farms and a pine plantation (Pinus radiata) located on the greywacke outcrop on Mr Chapman's property. Throughout the two properties are a number of farm dams with the largest reservoir located at the northern end of Mr Foley's property. Of note on Mr Foley's property is an old Maori pa site located at the summit of one of the limestone hills. This area is fenced off and local iwi must be consulted before any work is undertaken here. The relative complexity of the Takapau landscape led to the bulk of the field work ( 47 study sites) and all of the hydrological modelling being carried out here. 


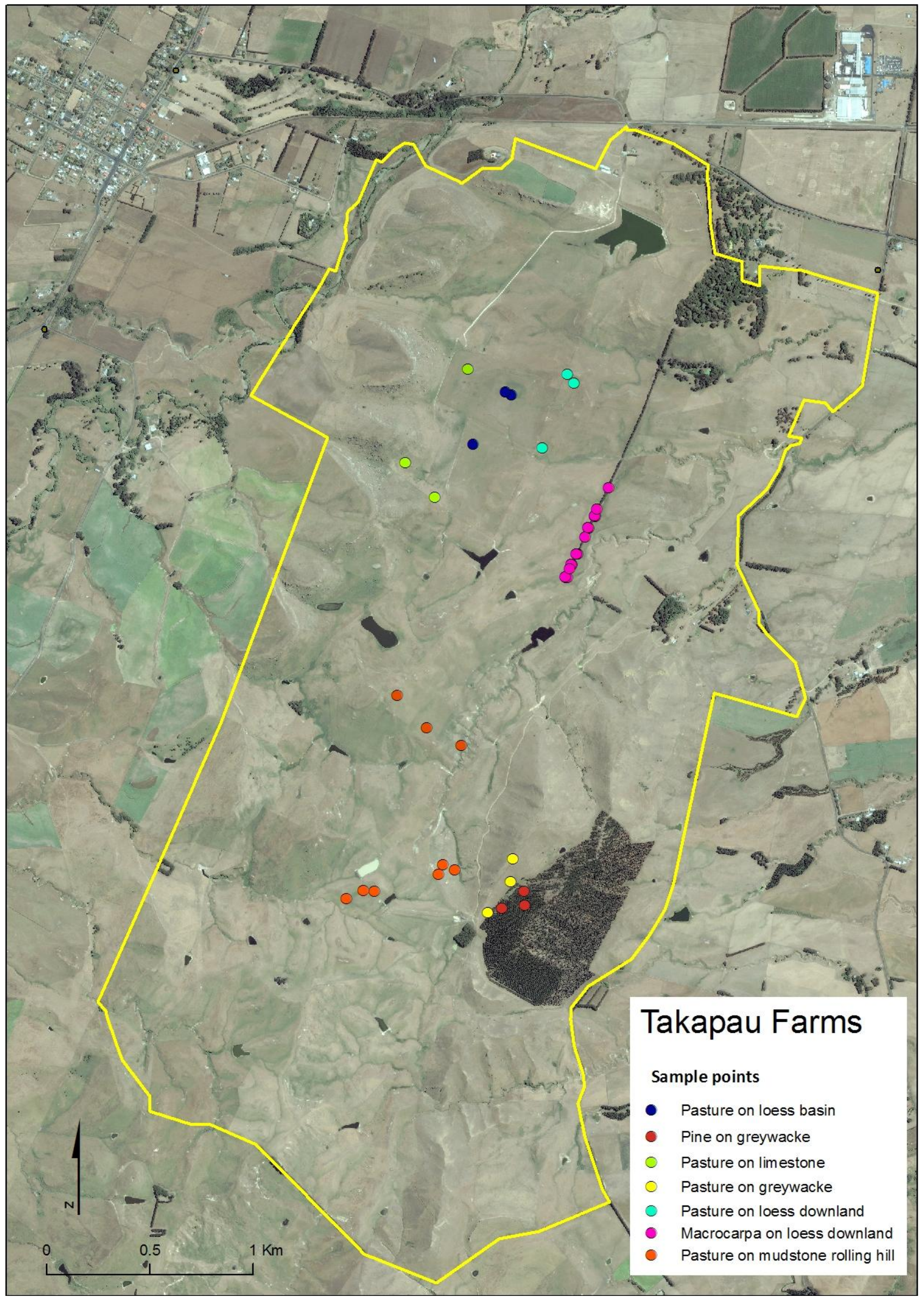

Figure 2 Takapau farms displaying sample points. Map was created from property data and satellite photography supplied by HBRC. 


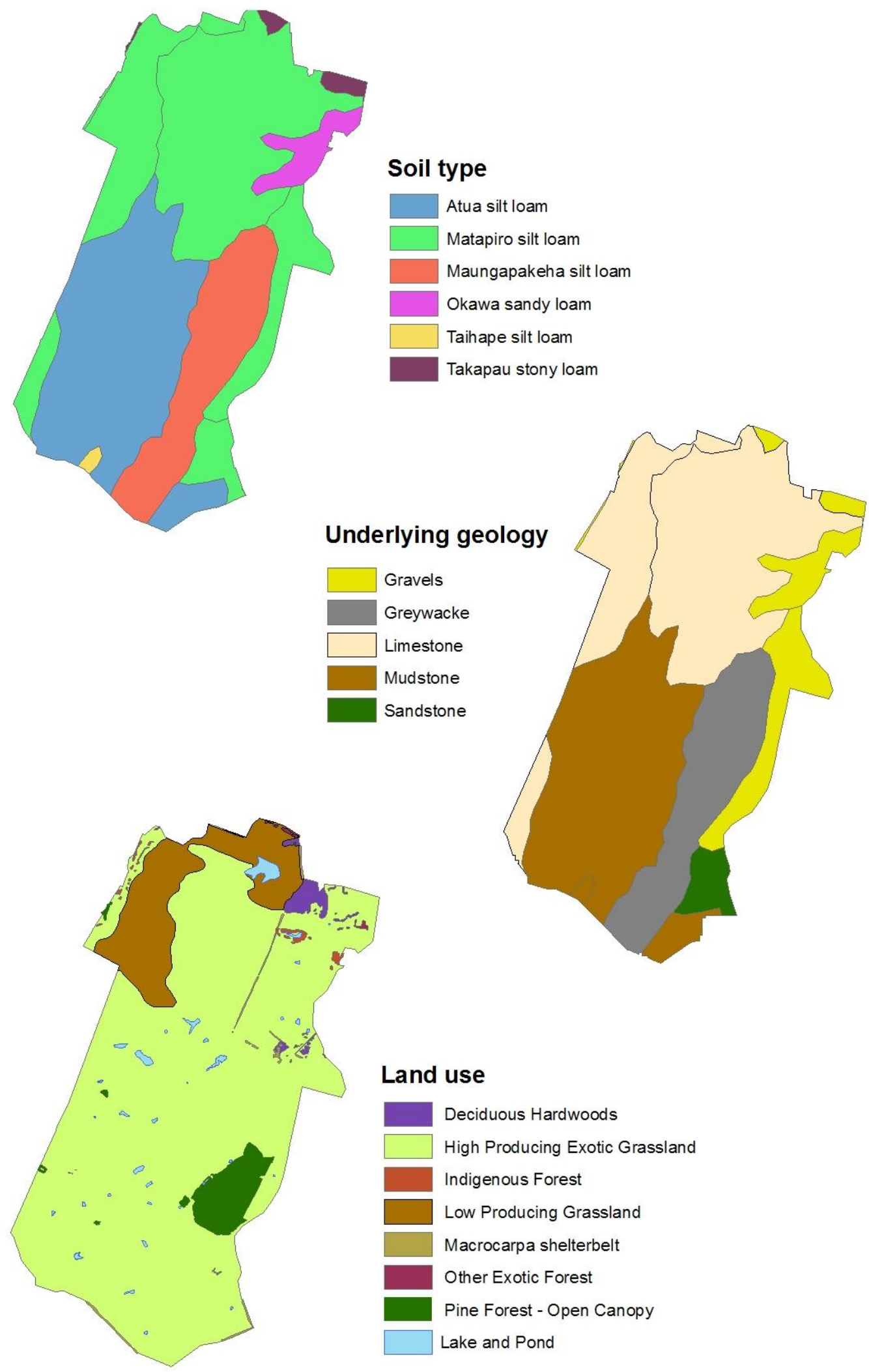

Figure 3 Soil type, geology, and land use for Takapau farms. Map was created with data from the New Zealand Land Resource Inventory (NZLRI) although the data for the land use section was improved through field investigations and digitizing from aerial photography. 


\subsubsection{Mananui farm}

Site 2 is located on the north-eastern boundary of the Ruataniwha Plains and is owned and farmed by Neville Twist. The farm area is $4 \mathrm{~km}^{2}$ and consists of rolling land on an eroded high terrace. At the northern end of the farm is a neighbouring property which includes a large wetland/reservoir. The western boundary is Argyll Road and to the south an adjacent farm. Three small tributaries, one named Karawa Stream, drain to the plains on the eastern border where the Mangaonuka Stream flows south to the Waipawa River. The high terrace consists of red gravels with a small amount of limestone and sandstone at the eastern edge of the farm. Overlying the red gravels is the pallic Mangatahi sandy loam. The sandy loam is quite shallow in places with typical depths ranging between 7 and $50 \mathrm{~cm}$. In addition, a small amount of Matapiro silt loam overlays the limestone and sandstone. The land use is exclusively pastoral with few trees on the property apart from some poplars (Poplar spp.) in the gullies to provide shade for stock. The livestock are sheep and cattle. Due to similar geology, soil type, and land use throughout the farm fewer field measurements (30) were carried out here. However, this relative homogeneity made it possible to investigate how changes in slope angle might affect soil hydraulic properties. Furthermore, the national soil data for Mananui was "ground truthed" and the influence of poplar trees on hydraulic conductivity was measured which helped answer some of the objectives of the wider study. Time constraints, more buffers and greater farmer interest at Takapau farms led to the decision to run POLYSCAPE at Takapau only. However, with more time Mananui could be modelled also. 


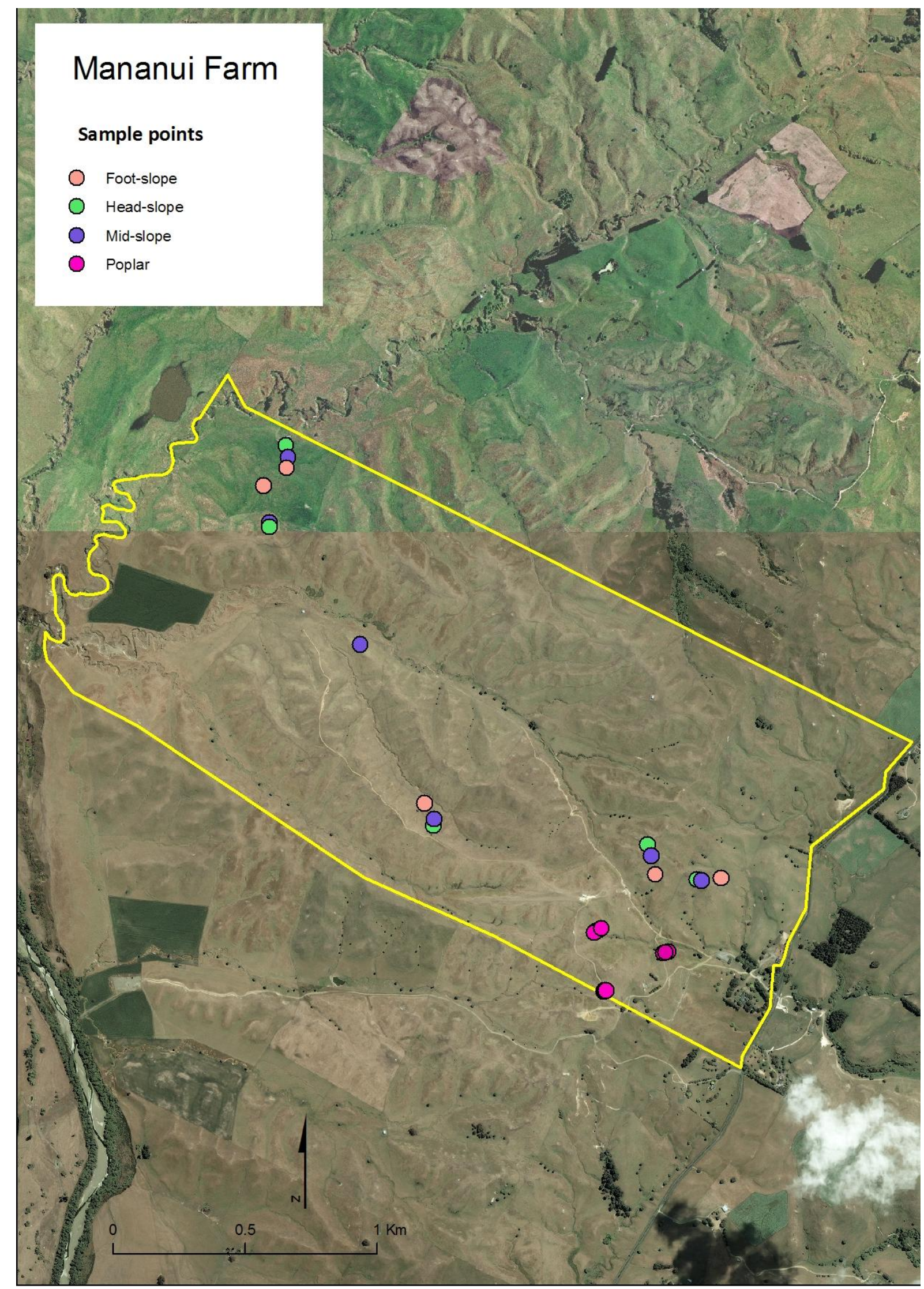

Figure 4 Mananui farm displaying sample points. Map was created from property data and aerial and satellite photography supplied by HBRC. 


\section{Soil type}

Mangatahi sandy loam

Matapiro silt loam

\section{Underlying geology}
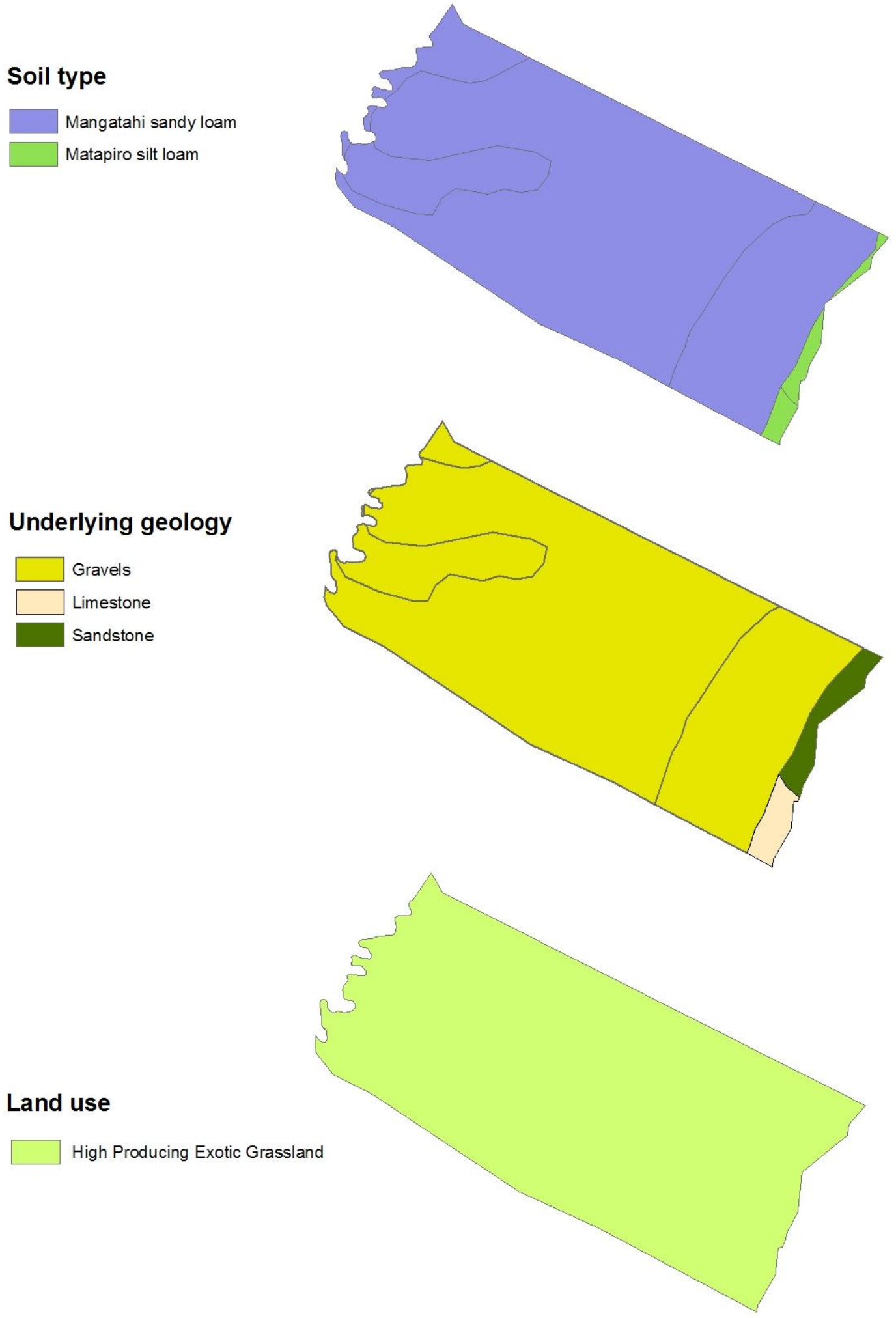

Figure 5 Soil type, geology, and land use for Mananui farm. Map was created with data from the New Zealand Land Resource Inventory (NZLRI). 


\section{Chapter 2 - Literature review}

This chapter summarizes studies investigating the impacts of vegetation (trees, scrub, pasture) and upland water retention (ponds, small dams, wetlands) on the hydraulic and sediment regime of upland watersheds. Although this study is paying particular attention to flooding, the effect of land use on sediment erosion and deposition is also considered as it has important implications for landscape flood capacity (discussed in section 2.1.4). When compiling this review an emphasis was given to New Zealand studies but where there was a lack of information from New Zealand international examples were used.

\subsection{Vegetation}

\subsubsection{Effects of vegetation on hydrological processes}

The physical effects of planting or clearing forests have been studied by water resource managers, foresters and hydrologists around the world. Vegetation affects streamflow primarily through interception, evapotranspiration and infiltration processes. Fahey, et al. (2004) describe the effects of land use change on streamflow within the context of the water balance equation:

Equation $1 \quad Q=P-E-\Delta S$,

where $Q$ is runoff, $P$ is precipitation, $E$ is evapotranspiration, and $\Delta S$ is change in water stored within the soil profile and as groundwater. Over a year the changes in soil moisture and groundwater storage are likely to be small and therefore changes in total annual runoff associated with land use conversion are usually caused by changes in evaporation (Fahey and Rowe 1992). Therefore, the annual water balance equation can be rewritten as:

Equation $2 \quad Q=P-\left(E_{i}+E_{t}+E_{u}\right)$,

where $E_{i}$ is rain which is intercepted on leaves and branches before it hits the ground and is evaporated back into the atmosphere (wet canopy evaporation), $E_{t}$ is water extracted from the soil and transpired (dry canopy evaporation), and $E_{u}$ is transpiration from the understory vegetation and evaporation from the soil (Fahey et al. 2004). Increasing the vegetation canopy cover increases interception and therefore wet canopy evaporation.

Dry canopy evaporation loss (transpiration) is very similar between pasture and plantation forestry with pasture loss typically greater if water supply is unlimited (Davie and Fahey 2005). The main difference between the two vegetation types is greater wet canopy evaporation losses (interception) experienced by the taller vegetation. This is due to two factors. Firstly, the larger leaf/needle area is 
more capable of intercepting and evaporating rainfall compared to grass leaf area. The second and more important reason is increased canopy roughness and faster wind speed at height which results in greater turbulence above the canopy. This helps the evaporated water mix easily with the drier air above leading to higher wet canopy evaporation (see Figure 6) (Davie and Fahey 2005).

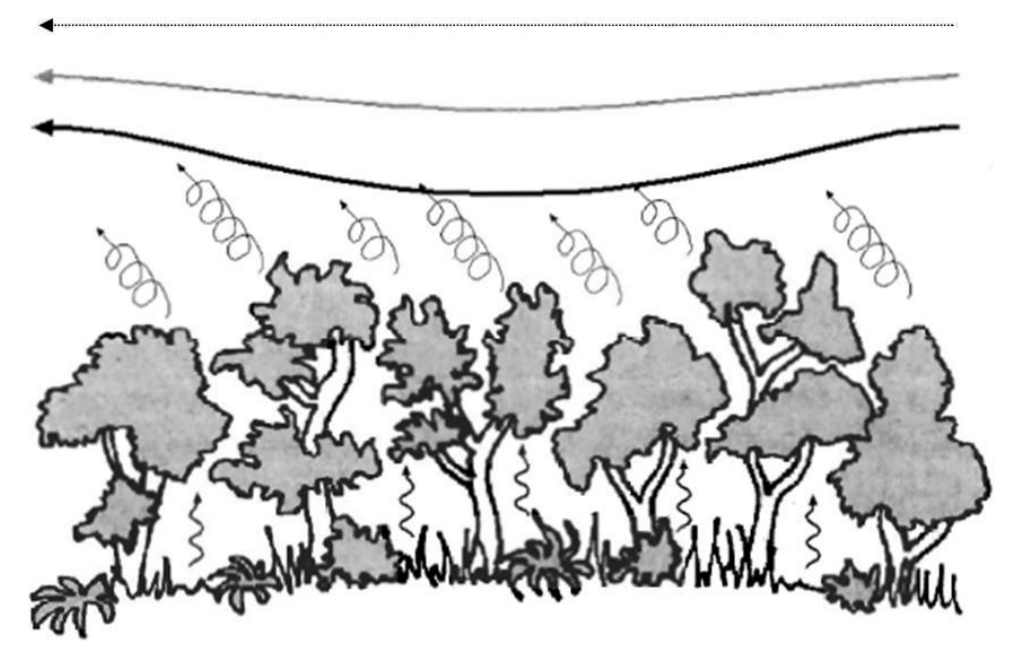

Figure 6 Interception process. The capacity of leaves to intercept rainfall and efficient mixing of water vapour with drier air above lead to high evaoprative, or interception loss. Source (Davie and Fahey 2005)

Rowe et al. (2002) used maximum values from New Zealand and international studies to summarize the effects of native vegetation and plantation forests on streamflow. They found that kanuka and manuka scrub was able to intercept as much as $42 \%$ of rainfall, beech-podocarp forests up to $30 \%$, Douglas fir plantations up to $29 \%$, and radiata pine plantations as much as $23 \%$. In areas with lower annual rainfall transpiration losses (dry canopy evaporation) can be greater than interception losses (wet canopy evaporation). For example, a study by Fahey et al. (2001) found transpiration losses from young Douglas fir, old Douglas fir, and mature radiata pine plantations on the Canterbury Plains were $47 \%, 58 \%$ and $42 \%$ of gross rainfall respectively, compared with interception losses of between $20 \%$ and $29 \%$. Kelliher et al. (1986) have shown that understory transpiration can also contribute substantially to total water loss from a forest. In areas where canopy is frequently wet then $E_{i}$ can be as high as $70 \%$ of total evaporative loss for forests. For this reason, changes in streamflow are often associated with changes in interception loss following afforestation or harvesting (Fahey et al. 2004). Although interception is a very significant part of the overall water balance, it is usually less significant in large floods due to intensive rainfall overwhelming canopy storage (Nisbet and Thomas 2006). However, it should be noted that between rainfall events increased wet canopy evaporation can increase available storage before the next event. 
In terms of flood buffering capacity, a more significant effect than evaporation loss is vegetations ability to increase water infiltration into the soil through cracks around the stem, trunk, and roots, as well as protecting the soil against rainsplash and direct sunlight. In the long term, increased organic matter from vegetation can improve soil structure which increases storage capacity. All these processes help dampen peak flow as water is either extracted and transpired by plants or moves as slower subsurface flow rather than quickflow. By increasing surface roughness and delaying the movement of water, vegetation and leaf litter can increase the total amount of infiltration; and by transpiring and drying the soil, can increase initial infiltration rates (Jones 1997). Infiltration and permeability rates are highly influenced by rooting depth with a worldwide review by Schenk and Jackson (2002) showing that average rooting depth for grassland in a forest zone is $40 \mathrm{~cm}$ compared to $121 \mathrm{~cm}$ for warm temperate forest. Trees can also improve infiltration through compacted subsoils in urban environments as part of stormwater management. Experiments by Bartens et al. (2008) showed that black oak (Quercus velutina Lam.) and red maple (Acer rubrum L.) tree roots penetrated compacted subsoil increasing infiltration rates by an average of $153 \%$ compared to an unplanted control. All these processes can slow or decrease the movement of water through the catchment system. However, the overall impact on the flood peak depends on the interaction of the processes mentioned above with the greatest effect in source areas such as headwater catchments.

\subsubsection{The effects of trees on hydraulic conductivity}

Many studies look for the hydrological effect of trees by measuring streamflow at the catchment outlet. As there is a lack of historical streamflow data from the study area this research will assess the impact of trees by comparing hydraulic conductivity at trees (Cupressus macrocarpa, populous spp.) with pasture located $5 \mathrm{~m}$ and $10 \mathrm{~m}$ from the base of the trunk (Objective 2). While having localised flow data is helpful for model calibration, measuring hydraulic conductivity at trees directly has its advantages. This is because it is difficult to untangle the effects of trees from other influences on streamflow data. Therefore measuring hydraulic conductivity directly means the differences in infiltration between trees and pasture can be isolated.

Hydraulic conductivity $(K)$ represents the ease of water movement through the soil relative to a potential gradient and depends on the permeability of the soil and the degree of saturation. Hydraulic conductivity together with the sorptivity of the soil (capacity of the soil to absorb water) controls the soil infiltration rate (McLaren and Cameron 1996). Although it is generally accepted that saturated hydraulic conductivity $\left(K_{s}\right)$ of forest soils is higher than soils under other vegetation types (Pritchett and Fisher 1987; McCulloch and Robinson 1993), there are few published studies investigating how safe this assumption is. A review by Chandler and Chappell (2008) found that the 
majority of research supported the hypothesis that trees increase $K_{s}$ relative to other vegetation types. Table 1 displays the ratio of $K_{s}$ between different species of trees and pasture in particular soils. The wide variety of results shows that soil condition plays a dominant role in determining hydraulic conductivity. For example, separate studies investigating the same species of tree in different soil types found that Eucalyptus spp. were between 2.5 (Burch et al. 1987), and 140 (Wood 1977) times as conductive as pasture in the same areas. However, some studies have found that the assumption of greater hydraulic conductivity under forest soils is not always true. For example, a study of reforestation on degraded land in Nigeria found that out of 6 plantations, only one had significant increase in $K_{s}$ compared to pasture (Jaiyeoba 2001). Furthermore, three studies found that $K_{s}$ was actually greater under pasture than forest soils (Yeates and Boag 1995; Giertz et al. 2005; Chappell and Franks 1996). As stated in Chandler and Chappell (2008), these conflicting results clearly show a need for further research into how trees affect $K_{s}$, including consideration of the possible mechanisms which allow them to influence soils. Some of these characteristics include rooting depth and abundance, the chemistry of their leaves, and whether they are evergreen or deciduous. These traits themselves are influenced by such things as climate (e.g. temperate versus tropical) and geomorphic regime (e.g. underlying sediment and depth to hardpan).

Table 1 Ratio of saturated hydraulic conductivity of the A-horizon under trees to that under adjacent pasture. Adapted from Chandler and Chappell (2008)

\begin{tabular}{|l|l|l|l|}
\hline F/G & Soil type $^{\text {b }}$ & Tree type $^{\text {c }}$ & Reference \\
\hline 2.5 & $\mathrm{nk}$ & Eucalyptus spp. $^{\text {a }}$ & Burch et al. (1987) \\
$1.1-3.1^{\text {a }}$ & Alfisol & Populus spp. & This study \\
$3.4^{\mathrm{d}}$ & Gleysoil & Quercus robur & Chandler and Chappell (2008) \\
4.8 & $\mathrm{nk}$ & Pinus insularis & Costalles (1979) \\
5.2 & $\mathrm{nk}$ & Pinus halepensis & Berglund et al. (1981) \\
$4.5-5.5^{\mathrm{a}}$ & Alfisol & Cupressus macrocarpa & This study \\
$4.5-7.2$ & Cambisol & Quercus robur & Burt et al. (1983) \\
$2.3-12$ & Ferralsol & Eucalyptus/Gravillea spp. & Wood (1977) \\
14 & Nitisol & Hibiscus elatus & Ternan et al. (1987) \\
20 & Andosol & Podocarp & Jackson (1973) \\
$23-41$ & nk & Quercus spp. & Molchanov (1960) \\
50 & Ultisol & Quercus spp. & Hoover (1949) \\
60 & Mollisol & Betula spp./Frangula alnus/Prunus spinosa & Carroll et al. (2004) \\
$17-140$ & Cambisol & Eucalyptus spp. & Wood (1977) \\
\hline
\end{tabular}

$\mathrm{F} / \mathrm{G}=$ ratio of the topsoil saturated hydraulic conductivity under trees to that under pasture (ranked by magnitude).
(nk) not known.
a At 5 and $10 \mathrm{~m}$ from Tree
b FAO-UNESCO classification
c Dominant or representative tree species. d Reported as 'dark grey soils'.

The review by Chandler and Chappell (2008:1226) cites several studies describing the mechanisms that might increase or decrease $K_{s}$ near trees. These include: 


\section{a) Positive effects of trees on $K_{s}$}

- Macroflow around the roots which can increase flow through the soil matrix by many orders of magnitude (Aubertin 1971; Beven and Germann 1982). In this way $K_{s}$ can be very sensitive to small changes in the abundance of macropores (Aubertin 1971; Buttle and House 1997). As many root systems extend beyond the crown radius (Florence 2004; Friend et al. 1990; Fogel 1983), macroflow might account for increased $K_{s}$ many metres beyond the tree (Chandler and Chappell 2008).

- Compared to pasture, the topsoil under trees is generally drier due to wet canopy evaporation (David et al. 2006) and root abstraction to support transpiration (Katul et al. 1997). In very dry periods soil cracks can open which either do not close, or close very slowly with subsequent rewetting and as a consequence maintain elevated levels of $K_{s}$ (Holden and Burt 2003).

- The accumulation of leaf litter and other organic material beneath trees can positively affect aggregate structure (Chaney and Swift 1984; Graham et al. 1995; Chappell et al. 1999) thereby increasing $K_{s}$ (Wood 1977).

\section{b) Negative effects of trees on $K_{s}$}

- The weight of the tree along with the movement of roots during windy conditions can compress the soil over centimetre-scales to reduce $K_{s}$ (Campbell et al. 1996).

- The soil can become more acidic under some species of trees due to increased dissolution of soil minerals (Augusto et al. 2000), acidic leaf-litter (Muys et al. 1992), or acidic sap (Nilsson et al. 1982). This can reduce soil structure stability and therefore pore space as aggregates collapse reducing $K_{s}$ (Baumgartl and Horn 1991). The acidity of soils can also negatively affect soil fauna such as worms (Neirynck et al. 2000) whose activity improves soil stability and creates macropores through worm holes (Beven and Germann 1982). A reduction in worms would negatively affect $K_{s}$ (Chandler and Chappell 2008).

- Isolated trees can have an indirect influence on $K_{s}$ due to livestock sheltering beneath them from rain, wind or sun. The congregation of animals, particularly during wet conditions can lead to surface compaction of soil which reduces $K_{s}$ (Drewry et al. 2000).

\subsubsection{The effects of trees on streamflow}

\section{a) Small catchment studies}

Internationally and within New Zealand, the links between land use change and streamflow have mostly been studied at the small catchment scale. Data on the effect of vegetation clearance has 
been gathered from around the world, often through paired catchment studies. International reviews by Bosch and Hewlett (1982), Hornbeck et al. (1993), Sahin and Hall (1996), Stednick (1996), Robinson et al. (2003), and Brown et al. (2005) present general relationships between decreased forest cover and increased annual runoff although the proportional change in runoff is catchment, vegetation and climate specific.

New Zealand studies have been summarised by Waugh (1980), Fahey and Rowe (1992), Maclaren (1996), Fahey et al. (2004) and most recently Blaschke et al. (2008). Blaschke's et al. (2008) report offers a very good summary of the previous four New Zealand reviews with the key findings presented in tables for floods, water yield, and low flows. It is important to note that these studies have been undertaken in small catchments that have either been entirely forested, allowed to revert to scrub, or have been completely cleared. These studies have not considered strategically planted or mixed vegetation catchments. The following section presents results for afforestation affects on flooding only.

Table 2 is compiled from the review by Blaschke et al. (2008) of small catchment studies in New Zealand and suggests large decreases in flood peaks after afforestation although there is considerable variation in the magnitude of decreases from different parts of the country. Blaschke et al. (2008:7) found that flood peak reductions are in the range $30 \%$ to $>90 \%$ for small floods; $50 \%$ to $70 \%$ for annual floods; and $20 \%$ to $50 \%$ for large floods. A point to note about Table 2 is that there is no consistency in the nature of published flood reduction values. While some figures are for annual floods, others are for small frequent floods that occur each year while others again are for large floods that occur infrequently. In addition, record lengths range between 2 to $10+$ years, but with the exception of Purukohukohu and Moutere, are too short for statistically reliable flood frequency analyses. Hence, although all the authors have considered a time series of flood peaks they have analysed them differently making comparisons difficult. Blaschke et al. (2008) also draw attention to the fact that reduced flood peaks do not necessarily imply a reduced volume of flow. They note that some publications indicate afforested catchments discharge the same volume of water but over longer periods of time creating broader, lower flood peaks, while other publications make no reference to the issue.

Table 2 Effects of land use on flood flows. Source (Blaschke et al. 2008)

\begin{tabular}{|l|l|l|l|l|l|}
\hline Catchments & Regions & Comparison & $\begin{array}{l}\% \\
\text { change }\end{array}$ & Source & Comments \\
\hline Purukohukohu & $\begin{array}{l}\text { Volcanic } \\
\text { plateau }\end{array}$ & Pines vs pasture & -50 & $\begin{array}{l}\text { (Rowe et al. 2002) } \\
\text { - based on (Dons } \\
1987)\end{array}$ & $\begin{array}{l}\text { Small floods (less than } \\
\text { annual) }\end{array}$ \\
\hline Purukohukohu & $\begin{array}{l}\text { Volcanic } \\
\text { plateau }\end{array}$ & Bush vs pasture & $>90$ & $\begin{array}{l}\text { (Rowe } \text { et al. 2002) } \\
\text { - based on (Dons }\end{array}$ & $\begin{array}{l}\text { Large floods (greater } \\
\text { than annual) }\end{array}$ \\
\hline
\end{tabular}




\begin{tabular}{|c|c|c|c|c|c|}
\hline & & & & 1987) & \\
\hline Purukohukohu & $\begin{array}{l}\text { Volcanic } \\
\text { plateau }\end{array}$ & Bush vs pasture & -89 & (Dons 1987) & Averaged peak flows \\
\hline Taita & Wellington & Pines vs pasture & $\begin{array}{l}-35 \text { to } \\
-80\end{array}$ & $\begin{array}{l}\text { (Claridge 1980; } \\
\text { Jackson 1973) }\end{array}$ & $\begin{array}{l}\text { Averaged peak flows, } \\
\text { all floods each year }\end{array}$ \\
\hline Taita & Wellington & Bush vs pasture & -7 & $\begin{array}{l}\text { (Claridge 1980; } \\
\text { Jackson 1973) }\end{array}$ & $\begin{array}{l}\text { Averaged peak flows, } \\
\text { all floods each year }\end{array}$ \\
\hline Moutere & Nelson & Pines vs pasture & -80 & (Duncan 1995) & $\begin{array}{l}\text { Small floods (less than } \\
\text { annual) }\end{array}$ \\
\hline Moutere & Nelson & Scrub vs pasture & -65 & (Duncan 1995) & $\begin{array}{l}\text { Averaged peak flow, } \\
\text { annual floods }\end{array}$ \\
\hline Moutere & Nelson & Pines vs pasture & -50 & (Duncan 1995) & 50 year flood \\
\hline Kikiwa & Nelson & Pines vs pasture & 40 & (McKerchar 1980) & $\begin{array}{l}\text { Averaged peak flows, } \\
\text { record length one } \\
\text { year }\end{array}$ \\
\hline Kikiwa & Nelson & Bush vs pasture & 12 & (McKerchar 1980) & $\begin{array}{l}\text { Averaged peak flows, } \\
\text { record length one } \\
\text { year }\end{array}$ \\
\hline Berwick & Otago & Pines vs pasture & -67 & (Smith 1987) & $\begin{array}{l}\text { Averaged peak flow, } \\
\text { annual floods }\end{array}$ \\
\hline Glendhu & Otago & Pines vs tussock & -50 & $\begin{array}{l}\text { (Fahey and } \\
\text { Jackson 1997) }\end{array}$ & $\begin{array}{l}\text { Averaged peak flow, } \\
\text { annual floods }\end{array}$ \\
\hline Maimai & West Coast & Bush & -37 & $\begin{array}{l}\text { (Rowe and Pearce } \\
\text { 1994) }\end{array}$ & $\begin{array}{l}\text { Pre vs post clearance, } \\
\text { small floods* }\end{array}$ \\
\hline Maimai & West Coast & Bush & -23 & $\begin{array}{l}\text { (Rowe and Pearce } \\
\text { 1994) }\end{array}$ & $\begin{array}{l}\text { Pre vs post clearance, } \\
\text { large floods* }\end{array}$ \\
\hline Big Bush & Nelson & Bush & $\begin{array}{l}-34 \text { to } \\
-44\end{array}$ & $\begin{array}{l}\text { (Fahey and } \\
\text { Jackson 1997) }\end{array}$ & $\begin{array}{l}\text { Pre vs post clearance, } \\
\text { small floods* }\end{array}$ \\
\hline Big Bush & Nelson & Bush & marked & $\begin{array}{l}\text { (Fahey and } \\
\text { Jackson 1997) }\end{array}$ & $\begin{array}{l}\text { Pre vs post clearance, } \\
\text { large floods* }\end{array}$ \\
\hline
\end{tabular}

* Expressed as reversal of authors \% flood peak increase

Overall, New Zealand research suggests that afforestation has a considerable effect on reducing flood peaks. Although it is generally thought that this effect is greatest for small floods, Duncan's (1995) study found floods with a 50-year return period are reduced by half under pine forest compared to pasture. He attributes this to interception during storms and reduced soil moisture underneath the forest canopy. Davie and Fahey (2005) use soil and rainfall data from Duncan (1995) to illustrate why different soil moisture levels under pine and pasture, combined with the timing of a peak flood is important. The main difference in soil moisture storage occurs in late autumn and early winter when interception and greater rooting depth by pines causes a delay in refilling the soil moisture store. If a storm event occurs its effect will be lessened underneath the forested catchment. In the modelled scenarios (Figure 7) up to $60 \mathrm{~mm}$ of rain falling in the May-June period could be absorbed by the forest covered soil that is not available under the cover of pasture. Later in winter when soil moisture storage is similar under both vegetation types, the difference in stormflow is likely to be significantly less. 
Davie (1996), through the amalgamation of several models investigating land use and forest growth suggested that the greatest changes in storm runoff occurred during the period of canopy closure. This suggests that forest growth can cause a rapid change within a short period of time (Davie 1996). Once the forest canopy is closed the response under different aged forests is relatively consistent (Davie and Fahey 2005).

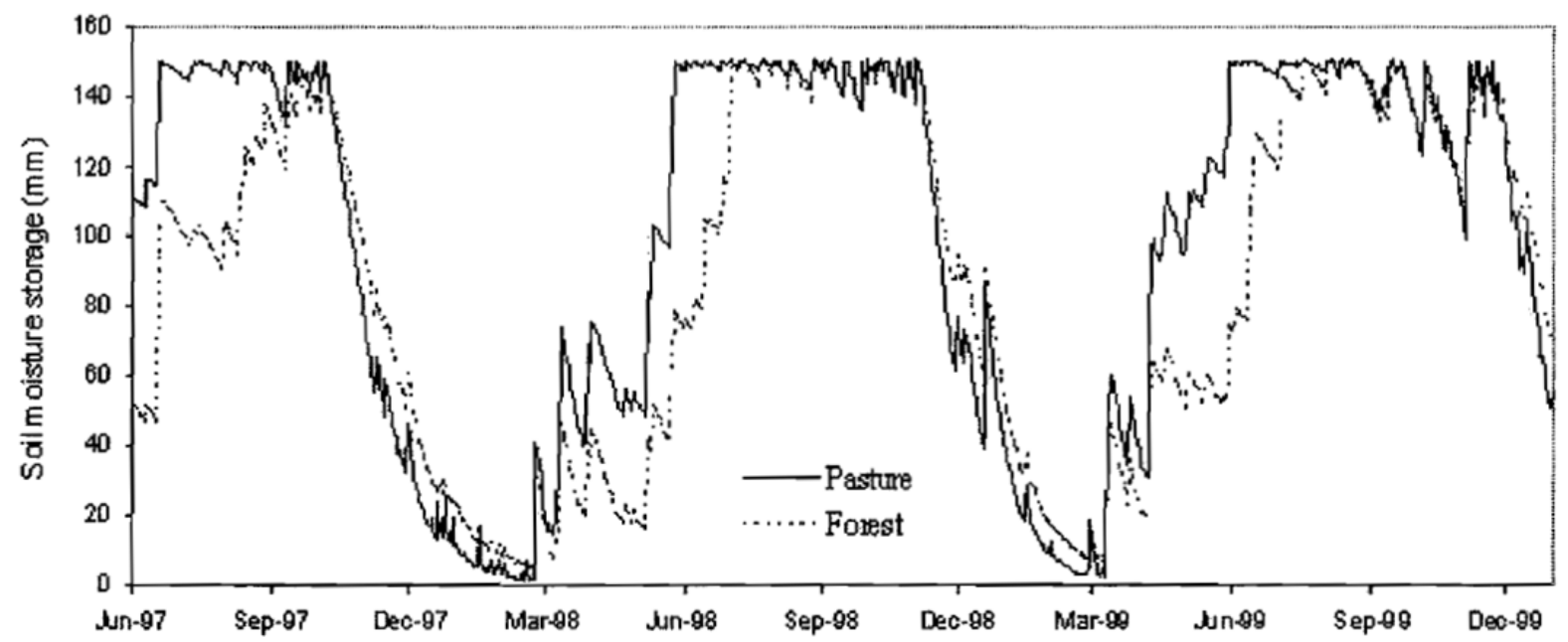

Figure 7 Modelled soil moisture storage beneath pasture and pine forest canopy using soil and rainfall data from Moutere gravels in Motueka catchment, Nelson. Note, the modelled values of soil storage agree well with measured values using neutron probes. Source (Davie and Fahey 2005:6).

Blaschke et al. (2008) state the findings of the New Zealand research suggest that afforestation or reversion from pasture or deforested land will result in a large reduction in flood peaks. However, they quote Maclaren (1996) who, after discussing several New Zealand extrapolations of research data to large, partly forested catchments, states:

"Vegetation may have a trivial influence on hydrological characteristics, compared with topography, the extent and influence of precipitation, and the structure of the soil and parent rock. Certainly, considerable caution needs to be exercised when extrapolating findings from one catchment to another...

To summarise: the benefit of forests in mitigating floods should not be overstated. Floods are common even in catchments of undisturbed native vegetation. Forests clearly can provide some smoothing of flood peaks in certain situations, but only in relatively small storm events and generally for small catchments and in areas close to afforested sub-catchments. Their main benefit lies in their ability to reduce sedimentation, if appropriate management practices are used". 


\section{b) Large catchment studies}

Small catchment studies have shown that different land use types can either amplify or dampen the effects of extreme flood events. However, there is little evidence of the cumulative effects of watershed flood peaks as they converge downstream at the broader catchment scale. This does not mean there is no effect, but rather that the evidence has been hard to distinguish given other sources of natural variability e.g. climate and landscape heterogeneity (O'Connell et al. 2006). Despite this, there have been a few large-catchment studies into the effects of afforestation on river flow in New Zealand. Don (1986) measured a 13\% decrease in annual water yield from the $900 \mathrm{~km}^{2}$ Tarawera catchment after 28\% was converted from scrub and bush to pine between 1964 and 1981. Don (1986) attributed only $5 \%$ of the decrease to deforestation and the other $8 \%$ to decreased rainfall. In the Mangatu and Waipaoa sub-catchments on the East coast, Pearce et al. (1987) estimated a $30 \%$ reduction in yield from a partly afforested catchment ( $36 \%$ of total $120 \mathrm{~km}^{2}$ ). Pearce et al. (1987) method involved subtracting evapotranspiration rates from rainfall records.

Mulholland (2006) forecast changes in flood flows under proposed deforestation of $225 \mathrm{~km}^{2}$ in Waikato sub-catchments between Wairakei and Atiamuri. He used two methods (flood frequency curves and runoff modelling) to predict increases in peak discharge resulting from a $100 \%$ and $57 \%$ conversion from forest to pasture. Under the $100 \%$ scenario, method 1 forecast a $550 \%$ increase in flood runoff while method 2 predicted a rise of $900 \%$. Under a scenario where $57 \%$ of the forest was removed, an increase in flood runoff of $230 \%$ (method 1) and 228\% (method 2) was predicted. For the second scenario this is equivalent to an increase of $110-131 \mathrm{~m}^{3} \mathrm{~s}^{-1}$ in a 20 -year flood, and 222$239 \mathrm{~m}^{3} \mathrm{~s}^{-1}$ in a 100 -year flood into the Waikato River. Mulholland's (2006) predictions were made by applying changes in flood runoff from the Purukohukohu experimental basins and applying them to flow records from the Mangakara and Waiotapu catchments. Blaschke et al. (2008:12) claim "the forecast flood results appear substantial (an additional 1 cumec per $\mathrm{km}^{2}$ of deforested area in a 100year flood), but need to be scaled back (in proportion to the ratio of surface to subsurface floodwater contributions) before that can be applied to larger Waikato sub-catchments."

Blaschke et al. (2008:13) explain why it would be unwise to extrapolate absolute flows or percentage reductions in flows from small research catchments which have been entirely afforested or allowed to revert, to the entire area of a medium or large catchments. They use a hypothetical example where:

"one-fifth of the sub-catchment is afforested, and the flood peak out of the afforested area reduces by $50 \%$ then flood peak from the farmed four-fifths of the sub-catchment remains at $100 \%$ at the sub-catchment's outlet reduces by $10 \%$ overall. What actually happens to a flood 
wave passing down a large river is somewhat more complex, because its catchment's flood response is not uniform. Quite apart from any vegetation effect, how fast a flood wave accumulates in the main channel, is influenced by:

- Catchment shape (rounded, narrow, or regular);

- Flow network topology (tributary branches numerous or sparse; long or short; junctions at wide or closely-spaced intervals);

- Rainfall pattern (heavy rain falling on some sub-catchments but not others); and

- Hydro-geology (infiltration and storage of rainfall by soil and underlying rock, enabling either slow release of sub-surface runoff to channels, or fast surficial runoff)."

In addition, whether the partially afforested sub-catchment affects flood peaks in the main channel is dependent on whether:

- "The sub-catchment is a large or a small part of the total catchment area;

- Its water enters the main channel close to other tributary junctions or tens of kilometres apart;

- Rain in the sub-catchment is heavy or light relative to what falls elsewhere; and

- The sub-catchment geology delays runoff to a greater degree than in other tributaries." (Blaschke et al. 2008:13)

Rowe et al. (2003) and Blaschke et al. (2008) draw attention to the spatial placement of afforestation within a catchment. In small to medium size floods rainfall is usually concentrated in the mountainous headwaters due to orographic effects. In this situation targeted planting of headwater sub-catchments could significantly diminish flood peaks as they pass down the main channel of a large catchment in small to medium events (1 to 10-year flood). In larger floods however ( $>10$ year return period), rainfall is often associated with large, moisture laden storms which drop heavy rain on the middle-catchment, downstream locations, as well as headwater areas. In this situation afforestation in the middle-catchment or downstream areas should have a similar effect. But as Blaschke et al. (2008:13) comment:

"Regrettably, because of the other factors that determine passage of a large floodwave down a main channel, the vegetation effect will be quite small. This is so even where a significant proportion of the catchment is afforested." 


\subsubsection{The effects of vegetation on sediment yield and erosion}

Terrestrial erosion reduces water storage within the landscape by removing soil from the slopes which reduces soil depth and thus storage capacity. The eroded material can then fill natural storage basins such as valley bottoms, ponds or wetlands which further exacerbate flood risk. Sediment yield measures the amount of material eroded from the land that is delivered to waterways. High yields affect the level of rivers through sediment deposition which reduces channel flood capacity (Ghosh 2006; Blaschke et al. 2008).

A rivers sediment yield includes measurements of coarse sediment (gravel and sand particles bouncing along its bed) called bedload, and fine sediment (silts and clays) which float within the water called suspended load. Bedload typically accounts for $10-20 \%$ of total sediment yield but is particularly hard to measure and therefore suspended load is discussed in most studies (Blaschke et al. 2008).

As with the hydrology section, Blaschke et al. (2008) have reviewed New Zealand investigations and summarised the differences in sediment yield from paired catchment studies between pine, scrub and bush versus pasture in Tables 3, 4 and 5 .

Table 3 Effects of Pines versus pasture on sediment yield. Source (Blaschke et al. 2008)

\begin{tabular}{|c|c|c|c|c|c|}
\hline Catchments & Region & Comparison & $\begin{array}{l}\% \\
\text { change }\end{array}$ & Author & Comments \\
\hline $\begin{array}{l}\text { Glenbervie vs } \\
\text { Scotsman }\end{array}$ & $\begin{array}{l}\text { Northland- } \\
\text { Waikato }\end{array}$ & Pines vs pasture & -51 & (Hicks 1990) & $\begin{array}{l}\text { Average annual yield } \\
\text { difference* }\end{array}$ \\
\hline $\begin{array}{l}\text { Topuni vs } \\
\text { Kokopu }\end{array}$ & Northland & Pines vs pasture & -59 & (Hicks 1990) & $\begin{array}{l}\text { Average annual yield } \\
\text { difference* }\end{array}$ \\
\hline $\begin{array}{l}\text { Upper } \\
\text { Waitemata }\end{array}$ & North Auckland & Pines vs pasture & -27 to -96 & $\begin{array}{l}\text { (Van Roon } \\
\text { 1983) } \\
\end{array}$ & Annual yield differences \\
\hline Tairua & Coromandel & Pines vs logged & 466 & (Lowe 1998) & Annual yield differences \\
\hline Purkohukohu & $\begin{array}{l}\text { Volcanic } \\
\text { Plateau }\end{array}$ & Pines vs pasture & -93 & (Hicks 1990) & $\begin{array}{l}\text { Average annual yield } \\
\text { difference }\end{array}$ \\
\hline Pakuratahi & Hawkes Bay & Pines vs pasture & -68 to -87 & (Black 1998) & Annual yield differences \\
\hline Pakuratahi & Hawkes Bay & Pines vs pasture & -55 & (Fahey 1999) & $\begin{array}{l}\text { Average annual yield } \\
\text { difference }\end{array}$ \\
\hline Moutere & Nelson & Pines vs pasture & -95 & (Hicks 1990) & $\begin{array}{l}\text { Average annual yield } \\
\text { difference }\end{array}$ \\
\hline Pigeon & Nelson & Pines vs logged & 2 & (Hicks 1990) & $\begin{array}{l}\text { Average annual yield } \\
\text { difference }\end{array}$ \\
\hline Ashley & $\begin{array}{l}\text { North } \\
\text { Canterbury }\end{array}$ & Pines vs logged & 0 & (Jackson 1998) & Annual yield differences \\
\hline Berwick & Otago & Pines vs pasture & -36 & (Hicks 1990) & $\begin{array}{l}\text { Average annual yield } \\
\text { difference }\end{array}$ \\
\hline
\end{tabular}

* Re-calculated from author's Glenbervie-Kokopu comparison 
Notes: Record lengths vary from 2 to $20+$ years. Most catchments were either adjacent or had similar terrain and were generally less than $5 \mathrm{~km}^{2}$. For 8 out of the 11 catchment studies, sediment yields were measured for standing forest vs pasture or tussock.

Table 4 Effects of scrub versus pasture on sediment yield. Source (Blaschke et al. 2008)

\begin{tabular}{|l|l|l|l|l|l|}
\hline Catchments & Region & Comparison & $\begin{array}{l}\% \\
\text { change }\end{array}$ & Author & Comments \\
\hline Puketurua & Northland & $\begin{array}{l}\text { Scrub vs } \\
\text { pasture }\end{array}$ & -39 to -65 & $\begin{array}{l}\text { (Schouten } \\
1976)\end{array}$ & $\begin{array}{l}\text { Annual yield } \\
\text { differences* }\end{array}$ \\
\hline Tairua & Coromandel & $\begin{array}{l}\text { Scrub vs cleared } \\
\text { for forestry }\end{array}$ & -40 & $\begin{array}{l}\text { (Swales and } \\
\text { Hume 1998) }\end{array}$ & $\begin{array}{l}\text { Average annual yield } \\
\text { differences }\end{array}$ \\
\hline Otutira & $\begin{array}{l}\text { Volcanic } \\
\text { Plateau }\end{array}$ & $\begin{array}{l}\text { Scrub vs } \\
\text { pasture }\end{array}$ & -51 & $\begin{array}{l}\text { (Selby 1972; } \\
\text { Selby and } \\
\text { Hosking 1973) }\end{array}$ & $\begin{array}{l}\text { Event yields, runoff } \\
\text { plots }\end{array}$ \\
\hline Tararua & Manawatu & $\begin{array}{l}\text { Scrub vs } \\
\text { pasture }\end{array}$ & -70 & (Reenes 1976) & $\begin{array}{l}\text { Annual yield } \\
\text { difference** }\end{array}$ \\
\hline Moutere & Nelson & $\begin{array}{l}\text { Scrub vs } \\
\text { pasture }\end{array}$ & $\begin{array}{l}-98 \text { to - } \\
100\end{array}$ & (Scarf 1970) & $\begin{array}{l}\text { Annual yield } \\
\text { differences, runoff plots }\end{array}$ \\
\hline
\end{tabular}

*Scrub cleared for pasture conversion. $\quad * *$ Record for one year only

Table 5 Effects of bush versus pasture on sediment yield. Source (Blaschke et al. 2008)

\begin{tabular}{|l|l|l|l|l|l|}
\hline Catchments & Region & Comparison & $\begin{array}{l}\text { \% } \\
\text { change }\end{array}$ & Author & Comments \\
\hline $\begin{array}{l}\text { Upper } \\
\text { Waitemata }\end{array}$ & North Auckland & Bush vs pasture & -86 to -88 & $\begin{array}{l}\text { (Van Roon } \\
\text { 1983) }\end{array}$ & Annual yield differences \\
\hline Hapuakohe & Waikato & Bush vs pasture & -50 to -75 & (Selby 1976) & Event yield differences \\
\hline Whatawhata & Waikato & Bush vs pasture & -90 & $\begin{array}{l}\text { (Quinn and } \\
\text { Stroud 2002) }\end{array}$ & Annual yield differences \\
\hline Purukohukohu & $\begin{array}{l}\text { Volcanic } \\
\text { Plateau }\end{array}$ & Bush vs pasture & -63 & (Dons 1987) & $\begin{array}{l}\text { Average annual yield } \\
\text { difference }\end{array}$ \\
\hline Tararua & Manawatu & Bush vs pasture & -91 & $\begin{array}{l}\text { (Bargh 1977, } \\
1978)\end{array}$ & $\begin{array}{l}\text { Annual yield difference } \\
\text { (record length one } \\
\text { year) }\end{array}$ \\
\hline
\end{tabular}

Results from small-catchment studies suggest afforesting or reverting close to $100 \%$ of small catchments can reduce average sediment yields by at least $50 \%$ and in most cases greater than $80 \%$. However, Blaschke et al. (2008) make the following points when comparing the variable sediment yields from different catchment studies. First, as both annual and average sediment yields are influenced by the frequency of storms, short records may not include the extreme events that produce a lot of a catchments sediment yield. Second, catchments with low mean annual rainfall also have fewer storms and thus less erosion. Geology is a third factor because hard stratum is more resistant to erosion which restricts sediment supply to streams. Despite these limitations, the studies confirm a general principle, that sediment yield reductions are substantial, though variable when comparing pine, scrub and bush against pasture (Blaschke et al. 2008). 
Reducing sediment yields will eventually lead to greater capacity within river channels and surface storage areas. This has a positive effect on floods as the bank is higher relative to water level reducing the likelihood of overtopping; and tributaries can discharge during large flows if the water in the main channel is lower. This stops water backing up behind stopbanks. However, increasing channel capacity can also increase flood risk if a degrading river undermines and breaches a stopbank (Blaschke et al. 2008).

The benefits of reduced sediment yield are not restricted to reduced flood risk alone. Blaschke et al. (2008:32) list other benefits as including:

- Improved water quality (fewer occasions when high suspended sediment prevents water take for irrigation, stockwater, industrial or urban supply);

- Improved aquatic habitat (more suitable for recreation and fisheries);

- Less sediment in reservoirs storage (maintains storage capacity); and

- Less sediment in estuaries and harbours (maintains navigation).

For a detailed classification of erosion and sedimentation effects see Krausse et al. (2001), Parkyn and Wilcock (1992), and Buchan et al. (2006).

New Zealand studies of sediment yields in medium to large catchments were reviewed by Hicks, et al. (1996). They concluded that high sediment loads in rivers are associated with high rainfall and unstable geology. In addition, relative reductions in yields greater than $50 \%$ can only be achieved if afforestation occurs in areas with historically high sediment loads. Blaschke et al. (2008) claim where high rainfall and unstable geology exists:

"Afforesting or reverting fairly small percentages of a catchment's area can result in proportionately much larger percentage reductions in the catchment's sediment yield."

\subsubsection{Spatial positioning of trees}

There is evidence suggesting trees can lower peak flows substantially at the smaller sub-catchment scale. Although numerous studies have investigated the hydrological implications of large scale afforestation within single catchments, there is a lack of quantitative data on the spatial positioning of vegetation within the landscape and its effect on runoff. What evidence exists is mainly concerned with either riparian vegetation, or contoured hedgerows comprising grasses, shrubs and trees designed to limit nutrient and sediment loss from agricultural areas. The following is a summary of those studies. 


\section{a) Riparian vegetation and floodplain forest}

Riparian vegetation and forest can delay the progression of flood flows down a river. This is due to increases in hydrological roughness created by woody debris dams within stream channels and the resistance from trees, shrubs and deadwood on the floodplain (Nisbet and Thomas 2006). Table 6 lists the hydraulic roughness values (Manning's coefficient) of different vegetation types found on floodplains. It shows that trees create more of a physical barrier than other vegetation types mostly because the later flatten down during high flows whereas trees generally do not. Shah et al. (2009:11) lists other factors which influence the hydraulic roughness of trees. These include "the spacing and layout of trees, smoothness of trunks, presence of lower branches, and level of undergrowth and amount of dead wood on the forest floor." The combination of these factors slows flow velocities and enhances out of bank flow, thereby increasing water storage on the floodplain and thus lowering downstream flood peaks (Shah et al. 2009).

Table 6 Guide for selecting manning's roughness coefficients for natural channels and flood plains. Source (Arcement and Schneider 1990)

\begin{tabular}{|l|l|}
\hline Channel & Hydraulic Roughness (Manning's $\mathbf{n}$ ) \\
\hline Pasture (no scrub) - short grass (long grass) & $0.030(0.035)$ \\
\hline Mature field crops & 0.040 \\
\hline Scattered scrub, heavy weeds & 0.050 \\
\hline Medium to dense scrub in winter (summer) & $0.070(0.100)$ \\
\hline $\begin{array}{l}\text { Heavy stand of timber, a few down trees, little } \\
\text { undergrowth, flood stage below branches }\end{array}$ & 0.100 \\
\hline As above but with flood stage reaching branches & 0.120 \\
\hline Dense willows, straight, summer & 0.150 \\
\hline
\end{tabular}

Hydraulic modelling in Southwest England indicated that floodplain forest reduces water velocities by $50 \%$ or more and increased local upland flood waters in a 1 in 100 year flood event. This created additional flood storage of $71 \%$ and decreased and delayed the downstream progression of the flood peak by 2 hours and 20 minutes (Thomas and Nisbet 2006). Darby (1999) modelled flow resistance from flexible and non-flexible vegetation. When parameters such as wetted perimeter, vegetation height and density were increased, flood flows were delayed at the locality. However, hydraulic modelling by Anderson et al. (2006) showed the vegetative resistance effect of delaying flood peaks is moderated by the size of the flood with smaller floods more sensitive to vegetation roughness than larger floods. While riparian and floodplain vegetation can hold back water, it can also enhance the risk of upstream flooding due to backing up of flood waters. In relation to this is the potential for washouts of debris dams which can damage bridges and other important infrastructure in downstream towns and cities (Robb 1992). On balance however it appears the risks associated with 
these methods are outweighed by the additional downstream protection provided and greater time for flood warnings. In summary, riparian vegetation can increase local flood water storage, but there is a need for greater understanding of the role of vegetation over a floodplain and its ability to temporarily hold back water (Johnson et al. 2008).

\section{b) Vegetative filter strips}

Filter strips are areas of vegetated land situated between a potential pollutant source area and a surface water body that receives runoff (Figure 8). Contoured filter strips (sometimes called contoured hedgerows) are positioned in areas of runoff accumulation and are used to intercept pollutants as mitigation in cropping systems. There are few published studies from New Zealand investigating the effects of vegetative filter strips on flooding and soil erosion. One study by McKergow et al. (2008) assessed the effectiveness of grass filter strips for nutrient interception from agricultural areas in the Rotorua Lakes catchment. The study found grass filter strips intercepted nitrogen $(N)$ and phosphorus $(P)$ attached to suspended sediment within surface runoff. The main removal processes including deposition, physical filtering, and infiltration. Although reductions in surface runoff were not directly mentioned, the reductions in nutrient runoff through increased infiltration would mean smaller volumes of overland flow were reaching the flow gauges.

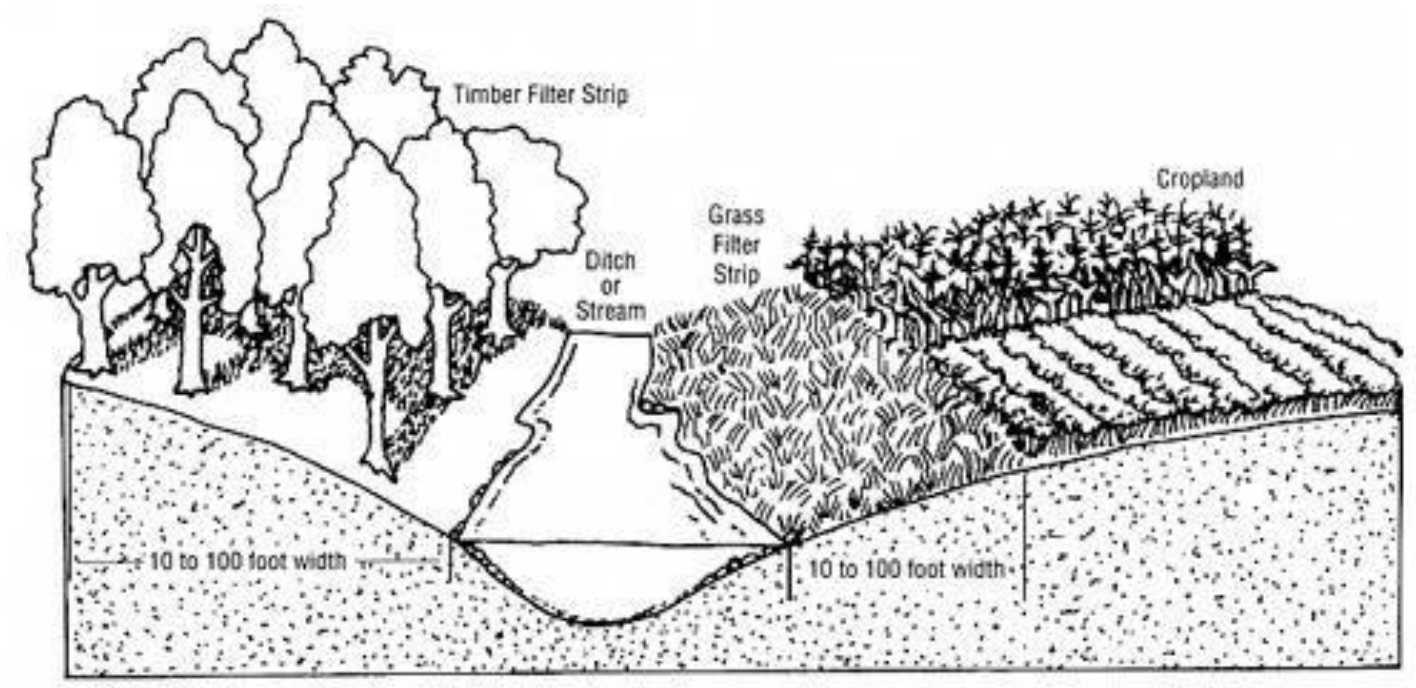

Figure 8 Vegetative filter strips have the potential for integrated runoff control to reduce flood risk, pollution and erosion. Source (Leeds et al. 2010).

An earlier study near Hamilton found riparian zones were a net sink for $\mathrm{P}$ and $\mathrm{N}$, except under storm conditions which scoured out nutrient rich sediment (Cooke and Cooper 1988; Cooke 1988). This suggests that to increase the effectiveness of filter strips during larger floods might require vegetative placement further from the stream in less saturated areas. A similar study from the USA 
also measured reductions in P (50\%), N (20-50\%) and sediment (50-89\%) although like the New Zealand studies, actual runoff volumes were not measured directly (Daniels and Gilliam 1996).

The majority of studies directly measuring runoff volumes from vegetative filter strips have been situated in the humid tropical regions. In the Philippines, a series of experiments measured overland and subsurface runoff to quantify surface hydrologic response under different land types (forested, tilled, slash/mulch, pasture). Forest had the highest rainfall threshold and lowest annual runoff response at $3 \%$. In contrast pasture had the greatest runoff response at $76 \%$ of annual rainfall with the lowest thresholds. A modified version of the pasture field was pasture with contour-filter strips which demonstrated greater infiltration and rainfall thresholds with runoff accounting for $31 \%$ of annual rainfall (Chandler and Walter 1998).

Hedgerow intercropping systems were introduced to China in the early 1990's. Sun et al. (2008) reviewed their effectiveness in water and soil conservation from studies across China. They found decreases in surface flow and soil loss ranging between $26-60 \%$ and $97 \%$ respectively in the Jinsha Basin (Sun et al. 1999; Sun et al. 2001; He et al. 2000; He et al. 2001). Runoff was reduced by $18 \%$ and soil loss by $90 \%$ in Guizhou compared with slopelands without hedgerows (Yin et al. 1996; Yin et al. 2001). Xu et al. (2000) reported that runoff and soil loss from contour hedgerow intercropping were only $24.8 \%$ and $16.9 \%$ of that from agriculture slopelands under traditional management in the Three Gorges area. In the loess slopelands in temperate mountains (Wang 2000) found that contour hedges can reduce runoff by more than $30 \%$ and soil loss by more than $50 \%$. In addition, runoff and soil loss were reduced by $66.2 \%$ and $\mathbf{7 7 . 2} \%$ in the Loess Plateau of Shanxi by planting hedgerows (Zhou et al. 1997).

A six year study in the humid tropics of Peru found contour cropping hedgerows conserved $83 \%$ and 93\% more water and soil than from sole cropping alone. In addition hedgerow plots maintained higher soil nutrients and the soil physical properties were improved compared to sole cropping (Alegre and Rao 1996). McDonald et al. (2002) compared changes in runoff and erosion after secondary forest removal under three different land types (bare soil, agriculture, agroforestry) and compared it to a forest plot in the Blue Mountains of Jamaica. As expected, forest provided good protection against surface runoff and erosion. Agriculture caused a seven-fold increase in surface runoff and 21-fold increase in soil erosion. However, agroforestry, which contained crops and contoured hedgerows, was effective in conserving water with a $45 \%$ reduction in runoff and $35 \%$ reduction in soil erosion compared to agriculture. McDonald et al. (2002:1) concluded that: 
"This low-input, contour-tree-hedgerow technology is effective at soil and water conservation through the sieve-barrier effect and increased water infiltration and has the potential to enhance the sustainability of this land-use system at a plot scale."

In the United Kingdom a highly instrumented, multi-scale experimental programme was established in mid-Wales to investigate the effectiveness of strategically placed trees in reducing flood peaks on undulating farmland. The modelled and measured results, summarised in Carroll et al. (2004), Jackson et al. (2008) and Marshall et al. (2009), found that strategically placed tree shelter belts established on grazed permanent pastures can greatly increase water infiltration (Figure 9a) thereby reducing flood peaks by as much as $40 \%$ at the field scale. They found infiltration rates can change very quickly with significant increases in infiltration within just 2 years (Figure 9b). This led Carroll et al. (2004) to suggests that:

"Strategically placed, small scale planting of trees for shelter can be used to improve the infiltration capacity of extensive areas of grazed permanent pasture. This is likely to have positive impacts on runoff rates, erosion and stream water quality at both farm and landscape scales."

These results are particularly relevant for New Zealand as Wales has both a similar climate and pastoral hill farming.
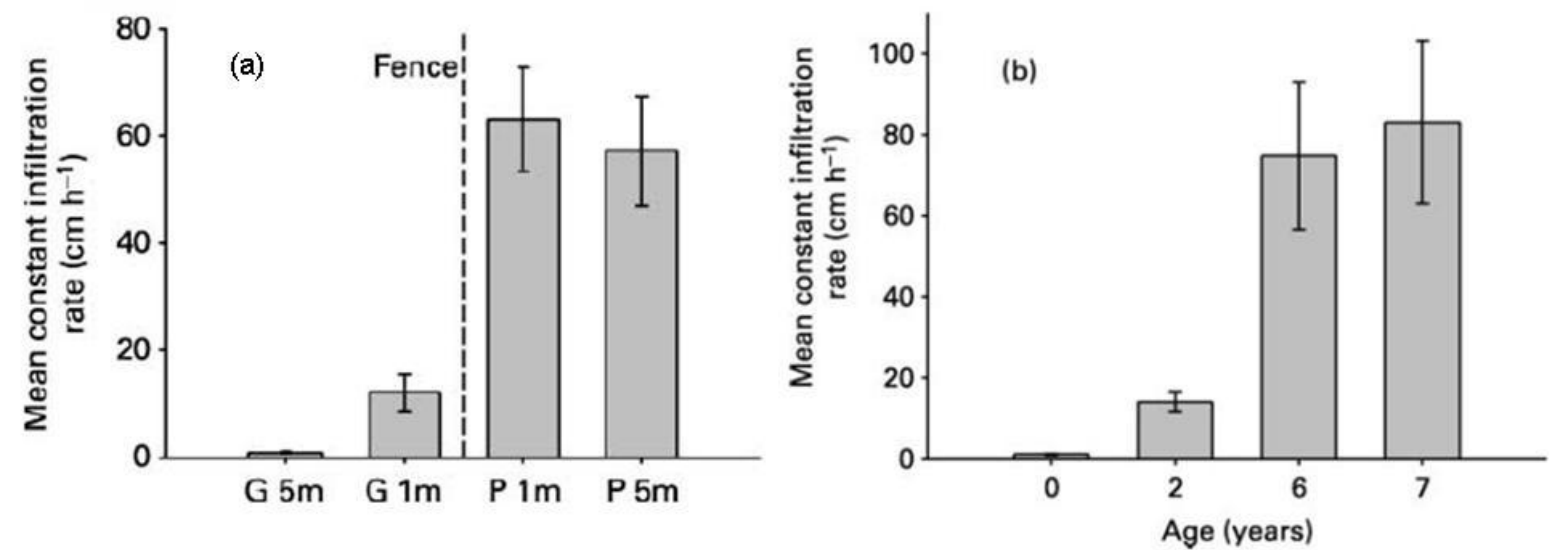

Figure 9 (a) Measured infiltration rates for different transect positions for the grazed (G) and planted (P) areas. Bars give one standard error of the mean. (b) Infiltration rate at the $5 \mathrm{~m}$ position for shelterbelts of different ages. Bars give one standard error of the mean. Source (Carroll et al. 2004). 


\subsection{Livestock and surface compaction of soil}

A further consequence of forest conversion to pasture is soil compaction from livestock treading. The degree of compaction is a function of the state of the soil and the weight of the animal. Intensive grazing of livestock can change soil hydraulic properties by decreasing soil infiltration rates, porosity, hydraulic conductivity, and bulk density (Marshall et al. 2009). Treading is most pronounced in wet conditions and has been shown to be more severe on cattle farms compared to sheep farms (Drewry et al. 2000). Studies from New Zealand include work by Mulholland and Fullen (1991) who reported $21 \%$ greater bulk density on areas heavily trampled by cattle compared to areas less trampled. Climo and Richardson (1984) found that reductions in macroporosity from sheep treading depended on soil texture, soil drainage, and stocking rate. Singleton and Addison (1999) measured soil properties from three Waikato dairy farms and found a decline in hydraulic conductivity, proportion of pores, and aggregate size in normally grazed and previously pugged areas compared to never trodden areas. Other studies from New Zealand reporting similar trends include work by Brown (1968); Drewry et al. (2000); Edmond (1974, 1958); Gradwell (1968); Greenwood and McNamara (1992); Nguyen et al. (1998); Scott (1963); Zegwaard et al. (1998). Marshall et al. (2009) cites studies from around the world which have linked intensive grazing and soil degradation to increased runoff rates at the plot scale (Elliot et al. 2002; Heathwaite et al. 1990; James and Roulet 2007; Nguyen et al. 1998). Heathwaite et al. (1990) measured surface runoff rates between plots of heavily grazed hillslope, ungrazed temporary grassland and cereal plots, with runoff rates of $53 \%, 5 \%$, and $7 \%$ respectively. Furthermore, the reduction in vegetation from grazing can lead to decreases in interception, rooting depth, and soil porosity which further exacerbates runoff rates (Marshall et al. 2009).

\subsection{Upland water retention}

\subsubsection{Open water storage}

A lake can be defined as a "body of standing water occupying a basin and lacking continuity with the sea" (Lowe and Green 1987). A pond is similar but is usually smaller than a lake. Often small farm dams are constructed for irrigation and stock drinking water or detention dams for the control of short intense rainfall events in catchments vulnerable to flooding and erosion. Detention dams are usually only full for 24 hours or so and are used together with other methods of soil conservation such as land retirement and re-vegetation (Everitt 2006). If an artificial pond or lake were carefully positioned to intercept runoff with sufficient storage then a number of co-benefits could result. These include: 
- Holding back runoff during intense rainfall to buffer floods;

- Storage of water for irrigation, or stock drinking water;

- Maintaining ecological low flows during dry periods;

- Recreation opportunities (boating, shooting, fishing);

- Capturing nutrients and sediment from farm runoff (improved water quality downstream);

- Potential ecosystem improvement (If stock excluded and riparian planting established).

However, small dams can also have negative impacts such as:

- Decreased water quality (especially if stock have access);

- Decreased water quantity (especially with many small dams);

- Flow regime change (can effect ecological integrity of stream);

- Restricting sediment supply (creates erosion downstream);

- Cumulative impacts of many dams at larger catchment scale (affects wider hydraulic regime and ecological integrity).

Beavis and Howden (1996) reviewed studies from both Australia and abroad and provide detailed information on the impacts of farm dams. Few studies from New Zealand exist on the impacts from small dams. One by Maxted et al. (2005) compared six small constructed ponds in the Auckland region and found they had poorer water quality than the streams they replaced. The degree of water quality decline was related to pond size, retention time, and catchment land use with the most degraded conditions found in rural ponds with large surface areas and long retention times.

\subsubsection{Wetlands}

Definitions of a 'wetland' are as wide and varied as the different wetland types themselves. Generally, wetlands are considered as the interface between dry land and a readily identified water body such as a lake, pond or the ocean. In other cases they may be solely linked to groundwater and appear quite isolated, such as a freshwater spring. Typically a wetland area is either permanently or intermittently wet with fluctuating land-water margins. These areas include bogs, swamps, seeps, lagoons, fens, and wet margins of a lake, river, stream or drain (TRC 2010).

There has been considerable debate within the literature regarding the role of wetlands in attenuating floods or acting as source areas for runoff (Fahey et al. 1998). A long standing generalization is that wetlands reduce floods, promote groundwater recharge, and regulate river flows (Bullock and Acreman 2003). Certainly in lowland areas extensive wetlands can act like spill areas for flood waters given enough storage thereby reducing the hazard from large floods 
(Campbell and Jackson 2004). In this way they are similar to lakes or ponds. As an example, the Lake Waikare-Whangamarino Wetland flood control scheme located in the Waikato region can store up to 94.8 million cubic metres of water and is worth $\$ 917,189$ annually for its flood mitigation role alone (Schuyt and Brander 2004; DOC 2007). Johnson et al. (2008) and WWF (2002) cite many more examples where wetland and floodplain restoration has significantly reduced flood damages in Europe.

In headwater catchments wetlands have traditionally been thought of as important for attenuating flood peaks and sustaining baseflows in dry periods by absorbing water like a sponge and slowly releasing it into the stream. Early work by Davoren (1978) and Bonnell et al. (1990) investigating hillslope runoff processes in a headwater catchment in Glendhu, Otago supported this hypotheses. Fahey et al. (1998) and Bowden et al. (2001) studied the same area and concluded that the bog and hillslope responded as a unit during storm events making it unlikely they attenuated flood peaks. They also reported that during post storm recessions, "unsaturated flow from the surrounding hillslopes may contribute as much water to baseflow as the bog itself"(Fahey et al. 1998:157). This means that wetlands, rather than storing and releasing water, could simply link the hillslopes and streams that drain them. Another study in the Pakihi wetlands near Reefton found that the water table rose very quickly in response to rainfall with runoff dominated by quickflow $(70 \%$ of $1600 \mathrm{~mm}$ annual runoff). It was also reported that Pakihi was incapable of maintaining substantial baseflows with only $10 \mathrm{~mm}$ of water yield over a 20 day dry period (Jackson 1987). Campell and Jackson (2004:20.8) used these studies to claim that:

"In reality wetlands remain wet because their soils generally have such low hydraulic conductivity that they release water only slowly, or because they receive water inputs from surrounding hillslopes or aquifers. Because they remain close to saturation for much of the time, wetland soils have a very limited capacity to store additional water from rainfall, let alone flood waters flowing in from outside."

Bullock and Acreman (2003) undertook a comprehensive worldwide review of 439 published statements from 169 wetland hydrology studies. They found that only 83 of the 439 statements (19\%) concluded that a wetland's influence on the water cycle was neutral or insignificant. The majority concluded that wetlands either increase or decrease a component of the hydrological cycle. When assessing impacts on flooding most studies (23 of 28 ) showed that lowland wetlands reduced or delayed floods. This relationship was also seen in headwater wetlands, but to a much lesser degree (30 of 66 ). A considerable number ( 27 of 66 ) of headwater wetlands increased flood peaks. The outcome of this study led Bullock and Acreman (2003:368) to conclude that: 
"There is no simple relationship between wetland types and the hydrological functions they perform... almost invariably; some data needs to be collected at a site to identify its functional role. Consequently, generalised and simplified statements of wetland function are discouraged because they demonstrably have little practical value".

The ability of a wetland to buffer runoff is largely controlled by the amount of available water storage. If the water table rises above the ground surface and is still contained within the boundaries of the surrounding topography then the wetland can hold water back before releasing it into the stream. To this extent it behaves like a pond. But if the wetland has little vertical storage and the soil becomes saturated, then overland flow will occur turning the wetland into a runoff source. With this in mind, careful positioning of a wetland to maximise storage could create an effective buffer.

\subsection{Summary of main findings from this literature review}

- Studies comparing hydraulic conductivity between trees and pasture show that in general, forest soils are significantly more conductive than pasture soils. However, some conflicting results show there is a need for further research into how trees affect hydraulic conductivity, including consideration of the possible mechanisms which allow them to influence soils. The significance of the tree effect is influenced by such things as species characteristics, climate, and geomorphic regime.

- Evidence suggests that targeted afforestation in smaller upland catchments can significantly decrease and delay flood peaks as they pass downstream in small to medium size events (1 to 10 -year flood).

- There is debate in the literature surrounding the significance of forest on flood peaks in larger catchments. The predominant thinking is that in larger floods (>10-year), when heavy rain falls in the lower, middle and upper catchments, the cumulative effect of vegetation is small. However, every catchment is unique with the propagation of flood waves through large catchments moderated by a complex interaction of factors. These include: catchment geometry, channel network, rainfall pattern, hydraulic properties of soil/geology, area of contributing sub-catchments, and the timing and distance apart of tributaries. To better understand how local scale flood effects combine to affect flooding at larger scales new multiscale monitoring and modelling research is required.

- Sediment and erosion studies of upland forestry catchments report significant decreases in erosion rates and sediment yield when compared to deforested catchments. This helps 
maintain upland storage areas by restricting the supply of sediment to river channels and flood plains.

- Although there are few studies from temperate areas, results from tropical and sub-tropical regions have shown strategically placed contoured vegetative filter strips can greatly reduce surface runoff and sediment loss at the plot scale. Further work quantifying changes in runoff quantity and timing are required to better assess their effectiveness for flood mitigation.

- Riparian and floodplain vegetation have been shown to delay flood peaks through increased surface roughness and thus resistance to flow creating more water storage in upper catchments. More research is required into the degree of resistance created by different vegetation types and their location and density on the floodplain.

- Surface treading by stock decreases infiltration which increases runoff. Treading is greatest with heavy stock and wet soil conditions and therefore excluding stock from shelterbelts should help maximize their flood buffering capacity.

- Some quantitative data exists to support the restoration of wetlands and the reconnection of floodplains for managing flood waters. However, the effectiveness of wetlands can vary significantly so some data must be collected to identify a wetlands functional role before it is used for flood mitigation.

- Open water storage such as dams or ponds can significantly lower surface and sediment runoff if positioned carefully within the landscape to maximize storage. However, open water storage can also have negative environmental effects which need to be carefully considered before a pond or dam is installed. 


\section{Chapter 3 - Characterising soil hydraulic properties}

Characterising the soil hydraulic properties at Takapau and Mananui farms is an important step when developing an understanding of the runoff generation processes and parameterising the POLYSCAPE hydrological model. In particular, most studies using physically-based hydrological models identified saturated hydraulic conductivity as an especially sensitive input parameter (Davies et al. 1999). This chapter introduces some fundamental principles of water transport in soil including movement in saturated and unsaturated conditions. An objective of this study is to analyse the hydrological response of different soils to rainfall at various spatial and temporal scales. For this reason the issues of scale and variability are briefly discussed, including the important topic of matrix versus macroflow (preferential flow paths). The remainder (and bulk) of this chapter provides an overview of different techniques for measuring hydraulic conductivity in preparation for the following chapter (Chapter 4, Experimental design and methodology).

\subsection{Saturated flow and Darcy's equation}

A soil is saturated when all available pore space is filled with water and negligible air is present. This usually occurs after prolonged rainfall or irrigation. In reality, soils normally have some air trapped within them and rarely reach a fully saturated state. For most soils "saturation' is usually a temporary state as drainage allows air back into the soil through the largest spaces called macropores. The matric potential of the soil at saturation is zero. Once the application of water has stopped then the macropores rapidly drain (usually within 48 hours) leaving the soil at field capacity (McLaren and Cameron 1996). Field capacity can be loosely described as "the state of the soil after rapid drainage has effectively ceased and the soil water content has become relatively stable" (McLaren and Cameron 1996:82). Some soils such as clays can take longer than 48 hours to reach field capacity due to low permeability and adhesive and osmotic binding which gives clays a greater ability to hold water (Or and Wraith 2000).

Soils have different textures and structures with varying amounts of pore sizes. How well these are connected, the range of sizes, and the water content have dominant influences on the rate of drainage through the soil. Gardiner and Miller (2004:84) list some factors that control the rate of infiltration through the soil:

- Percentage of sand, silt, and clay: Sands generally permit rapid infiltration when saturated, or close to saturation. Clays have slow infiltration, especially after swelling in response to added water. 
- Soil structure: Fine-textured soils with granular structure have greater infiltration rates than massive structureless soils.

- Organic matter: In general, the greater the amount of organic material and the coarser it is, the more readily water enters the soil.

- Depth of soil to hardpan, bedrock, or other impervious layer: Shallow soils have less storage capacity and therefore cannot absorb as much water as deep soils.

- Amount of water in the soil: Infiltration rates are generally highest when soils are dry and decrease through time as the soil wets up eventually reaching a constant minimum infiltration rate. This is because pores or cracks are fewer and smaller as clays become moist and swollen. Also, as dry underlying soil becomes wet, the matric potential gradient from top to lower layers disappears.

- Soil temperature: Warm soils take in water faster than cool soils. Also, frozen soils may or may not take in water depending on porosity and water content when freezing took place.

- Compaction: Soil compaction can occur due to vehicles or heavy grazing and reduces pore space and slows infiltration. A measure of soil compactness is bulk density i.e. mass to volume ratio.

Collectively these characteristics define how easily water percolates through a soil, a property called soil permeability. The most commonly used indicator of soil permeability is hydraulic conductivity. The hydraulic conductivity $(K)$ of a soil is a measure of the soil's ability to transmit water when subjected to a hydraulic gradient and is the constant proportionality in Darcy's equation (1856). Henry Darcy was a French hydraulic engineer who conducted experiments to determine the flow rate of water through sand filters. His experiments calculated the rate of discharge $Q\left[\mathrm{~m}^{3}\right]$ through a sand filled column with a bulk cross-sectional area $A\left[\mathrm{~m}^{2}\right]$ maintained at constant hydraulic head $h$ $\left[\mathrm{m}^{2}\right]$. Hydraulic head is the driving force made from gravitational and pressure potential. When these are expressed per unit weight, they are known as elevation head $z[\mathrm{~m}]$, and pressure head $\Psi$ $[\mathrm{m}]$ respectively. Therefore, total hydraulic head $h[\mathrm{~m}]$ is the sum of both components,

Equation $3 \quad h=z+\Psi$

Consequently, for any one soil, the quantity of water flowing through an area over a given time is directly proportional to the driving force (hydraulic head) and inversely proportional to the resistance to flow (soil and fluid properties). Thus, Darcy's equation can be written as:

Equation $4 \quad Q=-K_{S} A\left(\frac{\Delta h}{l}\right)$, 
where $Q$ is the volume of discharge $\left[\mathrm{m}^{3}\right]$ through a cross sectional area $A\left[\mathrm{~m}^{2}\right] ; K_{s}$ is the hydraulic conductivity of the saturated porous medium; and $\left(\frac{\Delta h}{l}\right)$ is the change in hydraulic head $(\Delta h)$ with distance along the direction of flow $(l)$. The negative sign indicates flow from high to low hydraulic head (McLaren and Cameron 1996; White 2006; Youngs 2001). Darcy found that the amount of discharge changed when he used different types of sand. This was related to the hydraulic conductivities of the sands which were influenced by the amount of water in their pores and its viscosity, as well as the porosity, pore size distribution, tortuosity and surface roughness (White 2006). For this reason, saturated hydraulic conductivity $K_{s}$ is an important measure of the drainage capacity of a soil. Typical values of $K_{s}$ are found in numerous texts such as Brassington (2007), Gardiner and Miller (2004) and McLaren and Cameron (1996). The US Department of Agriculture (2010) collated results from a number of studies to define typical $K_{s}$ values which range between very rapid $\left(>250 \mathrm{~mm} / \mathrm{h}^{-1}\right)$ in coarse sandy soils down to very slow, or near impermeable rates $\left(<1 \mathrm{~mm} / \mathrm{h}^{-1}\right)$ in some compacted soils (Table 7$)$. Darcy's equation is most valid when both hydraulic head and resistance to flow are constant over time. This occurs in laminar flow conditions through a homogenous non-swelling soil. Table 7 displays $K_{s}$ values based on soil structure and texture however the presence of macropores or fissures (discussed in section 3.3.1) can significantly increase bulk $K_{s}$. Furthermore, the swelling and shrinking of clays can cause cracks within the soil which can also increase hydraulic conductivity (Batey 2001). Methods for measuring $K_{s}$ are reviewed in section 3.5.

Table 7 Indicative hydraulic conductivities based on texture and other soil properties. Source (USDA 2010; McLaren and Cameron 1996)

\begin{tabular}{|l|l|l|l|l|}
\hline Texture & Textural class & General & $\mathbf{K}_{\mathbf{s}}$ class & $\mathbf{K}_{\mathbf{s}} \mathbf{r a t e}\left(\mathbf{m m} / \mathbf{h}^{-1}\right)$ \\
\hline Coarse sand & Coarse & Sandy & Very rapid & $>250$ \\
\hline $\begin{array}{l}\text { Sands } \\
\text { Loamy sands }\end{array}$ & Coarse & $\begin{array}{l}\text { Sandy } \\
\text { Loamy }\end{array}$ & Rapid & $125-250$ \\
\hline $\begin{array}{l}\text { Sandy loam } \\
\text { Fine sandy loam }\end{array}$ & Moderately coarse & Loamy & Moderately rapid & $60-125$ \\
\hline $\begin{array}{l}\text { Very fine sandy loam } \\
\text { Loam } \\
\text { Silt loam } \\
\text { Silt }\end{array}$ & Medium & Loamy & Moderate & $20-60$ \\
\hline $\begin{array}{l}\text { Clay loam } \\
\text { Sandy clay loam } \\
\text { Silt clay loam }\end{array}$ & Moderately fine & Loamy & Moderately slow & $5-20$ \\
\hline $\begin{array}{l}\text { Sandy clay } \\
\text { Silty clay } \\
\text { Clay }\end{array}$ & Fine and very fine \\
\hline \begin{tabular}{l} 
Cd horizon Natric \\
\hline
\end{tabular} & Clayey & & Slow & \\
\hline
\end{tabular}




\subsection{Unsaturated flow and Richards equation}

In unsaturated conditions $K$ is dependent on soil water content $(\theta)$ with water movement controlled by unsaturated hydraulic conductivity $K(\theta)$. In these conditions, except when very close to saturation, matric forces or tension dominate. Tension refers to negative pressure and is a measure of how much suction the soil pore exerts on water. As suction increases large pores empty and fill with air as water is confined to progressively smaller pores. Water columns within the soil become more tortuous as pathways between pores are disconnected. Eventually water is held very tightly as hydroscopic, or residual water within micropores $(<30 \mu \mathrm{m}$ diameter) making it unavailable to plants. The overall result is that $K$ decreases considerably from its maximum at $K_{s}$ (Gardiner and Miller 2004). In an unsaturated soil water will always try and equalise by moving from areas of high potential to low potential (wetter to dry areas). Sometimes this driving force is greater than the gravitational force so water, as well as moving downwards, can also flow upwards or sideways depending on matric potential (McLaren and Cameron 1996).

Most studies describing water movement through unsaturated porous media are based on Richards equation. To solve this equation a water retention curve (WRC) is required which describes the relationship between pressure head $(\Psi)$ and water content $(\theta)$. Soils release water at different suctions depending on the pore size distribution with the relationship defined by the WRC. Figure 10 shows typical WRCs for soils of different textures. One commonly employed empirical equation for determining $K$ in unsaturated soil is the van Genuchten (1980) WRC curve combined with the Mualem (1986a) hydraulic conductivity function. The van Genuchten (1980) WRC relationship is given by:

Equation $5 \quad S_{e}=\left(\frac{\theta-\theta_{r}}{\theta_{s}-\theta_{r}}\right)=\frac{1}{(1+\alpha|\Psi| n) m}$

Where,

$S_{e}=$ Effective saturation (=1 at saturation)

$\theta_{r}=$ Residual water content at which $K$ is negligibly small (volumetric, \% or fraction)

$\theta_{s}=$ Saturated water content (volumetric, $\%$ or fraction)

$\Psi=$ pressure head $[\mathrm{m}]$ 
$\alpha, n, m$ are empirical fitting parameters (values obtained using the measured water release characteristic). Usually, $\mathrm{m}$ is set to be dependent on $\mathrm{n}$ where,

$$
m=1-\left(\frac{1}{n}\right)
$$

When combined with a hydraulic conductivity function proposed by Mualem (1986a), the hydraulic conductivity relationship becomes:

$$
K=K_{s} S e^{L}\left(1-\left(1-S e^{1 / m}\right)^{m}\right)^{2}
$$

Where,

$K_{s}=$ Saturated hydraulic conductivity $\left[\mathrm{m} / \mathrm{s}^{-1}\right]$

$L$ is a dimensionless parameter, which accounts for pore tortuosity and connectivity (usually taken to be 0.5).

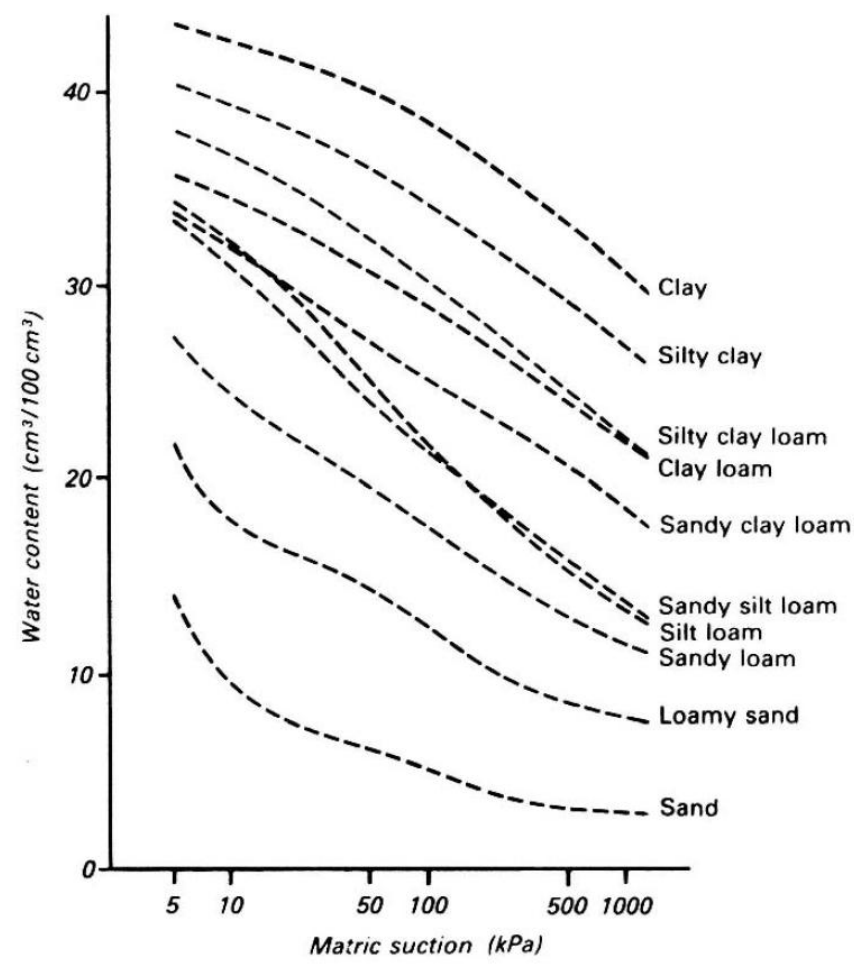

Figure 10 Water release characteristics for soils of different textures. Source (Townend et al. 2000)

This process is complicated by a phenomenon called hysteresis where the curves are different for a drying soil compared to a rewetted soil. Townend et al. (2000) cites models that attempt to account for hysteresis (Haverkamp and Parlange 1986; Tietje and Tapkenhinrichs 1993; Viaene et al. 1994). Generally in practice however, only the drying rate is measured and hysteresis is ignored. Although hysteresis affects both the WRC and $\mathrm{K}$ curves, the most important control on the shape of the curves 
is soil composition (Townend et al. 2000). Further information on flow within unsaturated soil can be found in Dirksen (2001), Gardiner and Miller (2004), and White (2006).

To describe water movement in unsaturated non-swelling soils, Richards (1931) applied a continuity requirement to Darcy's equation. This gave the following non-linear equation which for onedimensional vertical flow, can be expressed as:

Equation $6 \quad \partial \theta / \partial t=\frac{\partial}{\partial z}\left[K(\theta)\left(\frac{\partial \Psi}{\partial z}+1\right)\right]$

Where $t$ is time $[\mathrm{s}]$ and $z$ is vertical distance $[\mathrm{m}]$.

Richards equation is highly non-linear and is usually solved using numerical methods (Phoon et al. 2007). Unsaturated hydraulic conductivity is very difficult to measure accurately because it can vary over many orders of magnitude, both between soils and for the same soil due to different water contents (Dirksen 2001). This variability occurs over a range of spatial and temporal scales and is not confined to hydraulic conductivity alone. Indeed, all hydrological information has some degree of variability which must be recognised when attempting to understand or solve a hydrological problem.

\subsection{Spatial and temporal variability}

The use of physically-based distributed hydrological models to predict the effects of change has highlighted the need to improve the representation of variability. Spatially distributed models are becoming increasingly sophisticated and require higher resolution data to improve their performance. Scale in this context is the spatial measure over which a hydrological variable is being measured. In this case, it could be at a point, a field, or a catchment. The treatment of spatial variability in hydrology is becoming more sophisticated but is being held back by the difficulties of obtaining data at suitable scales and covering large enough areas (Woods 2005). While spatial variability relates to changes over distance, temporal variation in hydrological phenomena (e.g. soil moisture, river flow, groundwater levels) is usually caused by weather and climate variability. Although hydrological systems can dampen or amplify hydrological phenomena the predominant driver is usually changes in precipitation and evaporation. The other main source of temporal variability is human management of land and water. Temporal variability occurs over a wide range of rhythmic scales ranging from seconds, minutes, and hours, up to daily, monthly, and inter-annual cycles. Variability at fine time scales is often accounted for using high resolution data. Where this is impractical or inappropriate, a longer timescale is chosen for analysis (Woods 2005). An example of this is calculating return periods for extreme events such as floods. Although flow and rainfall data 
are often recorded at the minute timescale, the year to year change in flood magnitude is often represented statistically where the maximum annual flood record from a few decades worth of data is extrapolated to calculate return periods for over a century (Woods 2005).

This research addresses the variability issue in two ways. The first assesses the spatial accuracy of nationally available input data by ground truthing soil and land use information and comparing model output between different resolution DEMs. The second assesses the temporal variability in soil moisture (which affects quickflow generation) by using time-varying rainfall and evaporation data as boundary conditions.

\subsubsection{Variability in soil properties}

Soils are developed by the interaction between climate, geology, topography, vegetation and biological processes. Soils can also be affected by human agricultural activity such as ploughing or stocking rates (McLaren and Cameron 1996). Because of the numerous factors that affect soil formation, soils typically have complex spatial patterns. Within the soil profile soil layers (horizons) are distinguished by (amongst other things) changes in porosity and permeability with depth with the boundaries between horizons varied in distinctness and shape. The horizons are an important control on hydrology because they can slow or limit vertical flow and redirect water downslope. In hill country the soils on upper slopes are generally lighter and shallower than those found at the bottom, which are usually deeper, heavier and wetter. After descending a few centimetres or metres through the soil the layers become thicker and eventually form a hardpan or connect with the underlying bedrock (McLaren and Cameron 1996). A hardpan is a dense impervious layer usually found under the uppermost topsoil. Some hardpans are formed by deposits in the soil which fuse and bind soil particles together, while others can be formed by compaction from repeated ploughing (Gibbs 1980). Shallow impervious soil layers can create areas of rapid flow and transport with the locations and extent of these areas important for runoff intensity (Woods 2005).

One complicating factor in the measurement of hydraulic conductivity is preferential flow through macropores. Preferential flow (sometimes called macroflow) refers to the rapid flow of water through pathways such as worm holes, root channels, and cracks, thereby bypassing the soil matrix. This results in uneven wetting of the soil profile. Their influence on hydrology is determined by their size and connectivity, as well as capillary tension. Under preferential flow conditions Darcy's equation for laminar flow through a homogenous porous soil does not apply. The importance of macroflow on storm discharge has been a cause of debate in the literature. Noguchi et al. (1999) cites studies from the Maimai research catchment in New Zealand with an initial study concluding that macroflow through the subsurface was the main contributor to storm runoff (Mosley 1979). 
Following this, Sklash et al. (1986) evaluated the roles of old and new water using natural isotopes to claim that old water was the main contributor and that macroflow was not significant. A later study by McDonnell (1990) concluded that new invading water mixed with the older stored water and that both were discharged from macropores during storm events. The significance of macroflow varies in time. When clay swells in response to water, pore spaces become blocked. This decreases infiltration and increases runoff. With this in mind one might assume that a stream would be more responsive during winter when soils are wetter than in summer when soils are drier. However, Robinson and Beven (1983) discovered that a pasture with mole drains became more responsive in summer due to clay cracking which created quicker flow paths to the mole drains. Similarly, when $K_{s}$ was measured in a cracking clay soil in Sicily, the mean $K_{s}$ values were 1 to 3 orders of magnitude greater than might be expected for a clayey texture (Bagarello et al. 1999). Alternatively, the development of macroflow can sometimes stimulate deep percolation to groundwater storage which can help buffer storm flow (Marshall et al. 2009). The influence of macroflow is greatest under saturated conditions and rapidly decreases with less water content. It is difficult to determine the spatial occurrence and connectivity of macropores which is a major impediment for hydrological modelling (Bonell 1993).

Woods (2005) claims that trying to define soil properties using core or point measurements as a method of obtaining highly resolved soil data is rarely practical. While acknowledging remote sensing he claims hydrologists usually use generalized soil maps to define soil within a region. Of importance to this study is the varying hydraulic conductivity and capacity for water storage of soils within the Takapau and Mananui sub-catchments. The soil properties for these areas were downloaded from the National Soils Database (NSD) and had varying levels of reliability which depended on how the information was collected. This varying level of reliability prompted the ground truthing of the soil data (for results see Chapter 5 ).

\subsubsection{Variability in vegetation effects}

As discussed in Chapter 2, vegetation significantly affects the hydrological system and notably the spatial distribution of soil water. Vegetation can affect soil properties and soil water at scales ranging from a centimetre up to kilometres. At finer scales vegetation influences infiltration through flow paths around the roots and improves soil structure by adding organic matter which increases storage capacity. A trees canopy intercepts rainfall which gets evaporated back into the atmosphere, while the roots extract soil water for evapotranspiration which reduces moisture levels between rainfall events (see Chapter 2 section 2.1.1). Vegetation can also affect soil properties up to kilometres by forming communities of particular species which create unique environments. At larger scales plant composition tends to reflect the climate and physiography which they live in (Woods 2005). The 
degree to which trees affect the above processes can alter with the seasons. For example, trees in spring and summer are rapidly growing and draw significant amounts of water and nutrients from the soil to maintain photosynthesis (Wullschleger et al. 1998). By winter, the production of new growth slows dramatically and deciduous trees drop their leaves which decreases the interception and evapotranspiration effect (Xiao and McPherson 2002). Of particular interest for this study is to what degree can trees, occupying a relatively small land area, influence soil properties and thus be used as a flood mitigation measure (for results see Chapters 5 and 6 ).

\subsubsection{Variation in topography}

Water flows downhill under the influence of gravity and pressure head with the sum of both parts equalling hydraulic head (see section 3.1). With higher elevation comes greater hydraulic head leading to increased discharge. Hydrology interacts with topography at scales ranging from "microtopography (1-1000mm depressions and rills), hillslopes (10-1000m wide), and stream environments (0.1-1000km wide), up to extensive channel networks (1-10,000km long)." Each has unique hydrological processes and spatial complexity (Woods 2005:12). Today's topographical data is usually in the form of topographical maps or Digital Elevation Models (DEMs). The later combined with GIS software has vastly improved our ability to investigate spatial detail in some areas and has been used to predict the spatial patterns of other variables which are more difficult to measure e.g. precipitation (Chell 2007; Woods 2005). This research compares model output using six DEMs of differing resolutions. This is to determine both the limits of DEM resolution appropriate for effective prediction of flood buffering effects at the farm scale, and to show the differences between the same resolution DEMs from different data sources (for results see Chapter 6 section 6.4.2).

\subsection{Measuring variability}

Hydrological measurements are usually made to improve the understanding of hydrological processes, quantify a resource such as stream gauging, or for compliance reasons such as water quality measurement (Western et al. 2005). Another reason is to constrain parameters in models used for prediction and for hypothesis testing. Woods (2005) provides some examples of the approaches taken to conceptualize and quantify hydrological processes in space and time.

Table 8 Examples of deterministic and random views of hydrological variability. Source (Woods 2005)

\begin{tabular}{|l|l|l|}
\hline & Deterministic & Random/statistical \\
\hline Temporal & $\bullet \quad$ Time series (for many variables) & $\bullet \begin{array}{l}\text { Sudden, intense \& localised rainfall } \\
\text { (rain bursts) }\end{array}$ \\
& $\begin{array}{l}\text { Constant value (e.g. temperature of } \\
\text { deep groundwater) }\end{array}$ & $\begin{array}{l}\text { Occurrence and magnitude of storm } \\
\text { events. }\end{array}$ \\
& $\begin{array}{l}\text { Diurnal cycle (e.g. solar radiation, } \\
\text { evaporation, snowmelt) }\end{array}$ & \begin{tabular}{l} 
Occurrence and magnitude of floods \\
\hline
\end{tabular}
\end{tabular}




\begin{tabular}{|c|c|c|}
\hline & $\begin{array}{l}\text { - Annual cycle (e.g. soil moisture, } \\
\text { snowmelt, streamflow) }\end{array}$ & $\begin{array}{ll} & \text { and droughts } \\
\text { - Interannual variability }\end{array}$ \\
\hline Spatial & $\begin{array}{l}\text { - Map (where possible, e.g. vegetation } \\
\text { type, topographic elevation) } \\
\text { - Constant value } \\
\text { - Transect along hillslope catena } \\
\text { - Transect across mountain range } \\
\text { (orographic uplift and rain shadow) }\end{array}$ & $\begin{array}{l}\text { - } \text { Climate statistics } \\
\text { - Soil } \\
\text { - Geology } \\
\text { - Microtopography }\end{array}$ \\
\hline
\end{tabular}

When designing a measurement program one must consider the phenomena to be measured, the key spatial and temporal scales of interest, the required accuracy, and the available resources (Western et al. 2005). Once the objectives have been defined a sampling strategy can be designed. Thompson (2002) provides guidance on how to establish statistically sound sampling techniques which are based on some prior knowledge of the variables behaviour. Blöschl and Sivapalan (1995) recognized that changing the scale of observation can result in a change in perceived variability. This is relevant when drawing conclusions from model output obtained using discrete times and locations. For this reason Blöschl and Sivapalan (1995) defined a 'scale-triplet' sampling method. The scale triplet consists of the spacing (distance between samples), the extent (total coverage of data in space and time), and the support (size of sample). All three components are needed to define the unique spatial and temporal extent of measurement. The representative elementary volume (REV) is the smallest volume from which a measurement can be made to represent a larger whole. To establish the hydraulic properties of a particular soil requires measurements taken from samples of that soil. If the sample size is too small then the readings tend to fluctuate. As sample size increases the fluctuations dampen and eventually when the sample size is large enough, the readings become consistent. This sample size is the representative elementary volume. Iwata et al. (1995) compiled a list of studies which investigate the number of sample sizes required to determine REV in various porous media.

Determining the REV for a soils hydraulic conductivity is made difficult by the presence of preferential flow. As previously noted, the hydraulic conductivity of soils can vary by several orders of magnitude, even in areas of the same geological formation (Oosterbaan and Nijland 1994). Therefore, many measurements are required in order to determine accurate estimates of $K$ for an area. These measurements themselves are also subject to uncertainty through potential methodological error and indeed, Chappell and Ternan (1997) claim that this uncertainty can be greater than the spatial variability itself. Uncertainty in measurements of $K$ relate to both: (i) precision errors, and (ii) systematic (or technique) errors (Chappell and Ternan 1997). Precision errors relate to the level of exactness (e.g. number of decimal points), and in the case of measuring $K$ on soil cores would include timing and dimensional errors (Zhang 2010). Systematic errors are much 
harder to quantify and might include such things as disturbance of the soil core, artificial compaction, or soil loss from the core (Chell 2007).

Due to time, cost, and equipment constraints there is often a trade off between great accuracy and a few points, and less accuracy and many points. Western et al. (2005) suggests an optimum strategy would involve some combination of a few highly accurate point measurements to test surrogate relationships and calibrations, and many points of lower accuracy to measure spatial and temporal variability.

An important part of the error checking process is the validation of $K_{s}$ measurements. This is difficult because there is no set standard to compare against. Rather there exists a variety of allegedly "representative" $K_{s}$ values in the literature as cited in section 3.1. In addition to representative $K_{s}$ values, laboratory methods on soil cores (section 3.5.1) are often used as a standard to compare other methods by. Comparative studies have shown that there can be significant differences in $K_{s}$ estimates between measurement techniques (Lauren et al. 1988; Lee et al. 1985; Munoz-Carpena et al. 2002; Paige and Hillel 1993). The differences in results between each technique are a function of both the theoretical basis of the various methods, and the scale that the method is applied to (Davis et al. 1999). Durner and Lipsius (2005) cite Jury's (1985) extensive review of published field measurement data which found large disparities in hydraulic conductivity between studies. He attributed this in part to apparent variability caused by the fitting of oversimplified functions to the data. However, Durner and Lipsius (2005) provide multiple reasons including soil disturbance, biological, chemical and physical processes to the pore matrix, and temporal and spatial variability, as reasons why absolute comparisons of accuracy between different techniques is not possible.

\subsection{Methods to determine hydraulic conductivity}

Multiple techniques for measuring hydraulic conductivity exist. These can be carried out in the laboratory or in-situ within the field. Although accurate measurement of hydraulic conductivity is important when predicting water movement in soil, in practice substantial error is associated with all measurement techniques. The following section provides a brief overview of the methodologies commonly used and includes an in-depth discussion on the field based constant head technique. For additional methods and more detailed introductions to these techniques see, Dirkson (2001), Youngs (2001), and Durner and Lipsius (2005). 


\subsubsection{Saturated hydraulic conductivity $\left(K_{s}\right)$}

\section{a) Laboratory methods}

These methods involve taking a relatively "undisturbed" soil core from the field and essentially repeating Darcy's experiments where the core is saturated in the laboratory and flow and pressure head are measured over time. In these experiments $K_{s}$ is defined by "the rate of flow per unit-cross section area per unit hydraulic head gradient" (Youngs 2001:9). The most commonly used tool for measuring $K_{s}$ is called a permeameter. The two main methods are the constant head, and falling head permeameters. In addition to these methods there are others which involve wetting an unsaturated sample to zero soil water pressure (saturation). These methods apply infiltration theory to achieve $K_{s}$ from measurements on the rate of uptake of water by the soil (Youngs 2001). For more information see Clothier (2001). Additionally, Durner and Lipsius (2005), and Youngs (2001) list a collection of less common techniques for determining soil hydraulic properties.

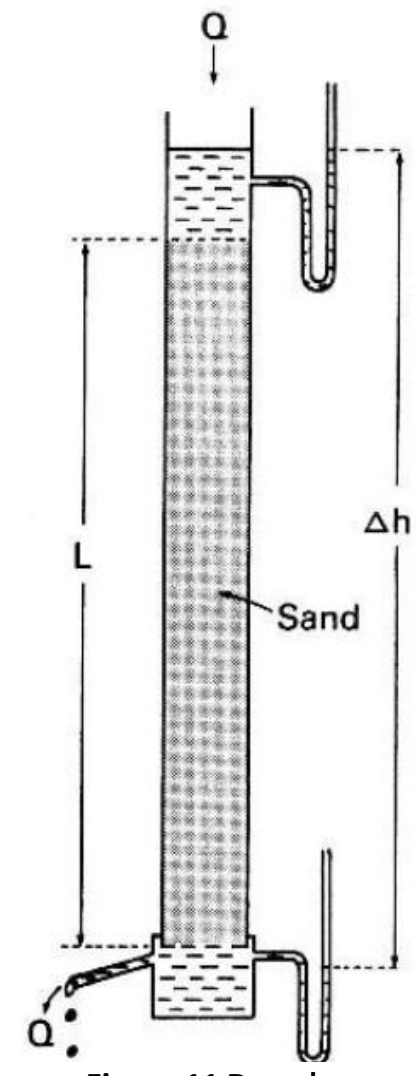

Figure 11 Darcy's

experimental arrangement.

Source (Youngs 2001)

\section{i. Constant head permeameter}

The constant head permeameter uses the same arrangement as Darcy's experiment in 1856 (depicted in Figure 11). Water percolates through the column from a constant head of water on the surface, and is collected for measurement at the outlet at the base (Youngs 2001). The hydraulic conductivity is given from the measurements by:

Equation $7 \quad K=\frac{Q L}{A \Delta h}$

Where,

$Q=$ flow rate $\left[\mathrm{m}^{3} \mathrm{~s}^{-1}\right]$

$L=$ length of the column
$A=$ cross sectional area $\left[\mathrm{m}^{2}\right]$

$\Delta h=$ head difference causing flow $[\mathrm{m}]$

Durner and Lipsius (2005) note the limitations to this method are related to small or inadequate sample size, soil disturbance during core collection, and preferential boundary flow through macropores along the core wall. In addition, the commonly used smaller soil cores $(6.3 \mathrm{~cm} \times 7.3 \mathrm{~cm})$ are often too small to adequately represent macropore extent within a profile (Davis et al. 1999). 
That said however, the method is simple, inexpensive, and convenient, and despite these limitations remains one of the most popular methods for measuring $K_{s}$. In addition, it is often used as a reference point for evaluating other methods (Durner and Lipsius 2005).

\section{ii. Falling head permeameter}

This technique is often used to determine $K_{s}$ for samples with low permeability because it utilizes a high hydraulic gradient when compared to the constant head method (Durner and Lipsius 2005). The falling head method is similar to the constant head except that once water is applied it is not held constant, but rather allowed to drain and the changing level of head observed (Figure 12). To read the rate of fall it is magnified within a manometer tube of smaller diameter than the soil sample. Thus, the hydraulic conductivity $(K)$ equation can be expressed as:

Equation $8 \quad K=\frac{a L}{A t} \operatorname{In} \frac{h_{o}}{h_{1}}$

Where,

$A=$ cross sectional area of sample $\left[\mathrm{m}^{2}\right]$

$a=$ cross sectional area of manometer $\left[\mathrm{m}^{2}\right]$

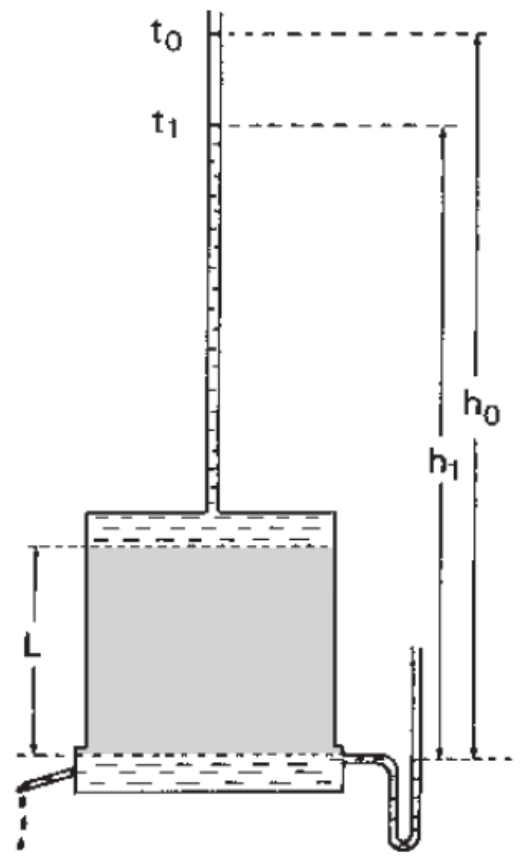

Figure 12 Falling head permeameter.

Source (Youngs 2001)

$L=$ length of soil sample

$h_{0}=$ initial head difference $[\mathrm{m}]$

$h_{1}=$ final height of water $=h_{0}-\Delta h[\mathrm{~m}]$

$\mathrm{t}=$ time required to get head drop of $\Delta h\left(t_{1}-t_{0}\right)$

The falling head method is subject to the same conditions as the constant head method however care must also be taken when applying head gradients well in excess of those experienced in the field as large gradients can disturb the soil structure.

\section{b) Field methods}

Although laboratory methods have the advantage of being quick and precise, collection and transport to the laboratory can alter a soil's physical properties making results unrepresentative for field conditions. Field methods have the advantage of measuring soil under natural conditions leading Durner and Lipsius (2005:11) to claim that "direct in-situ measurements of hydraulic and retention properties still provides perhaps the most reliable, and often, the only means of determining hydraulic properties, despite their high costs and extreme time demands." However, 
field as well as laboratory measurements are subject to small scale heterogeneity between samples. Therefore a large number of measurements are required in order to get an adequate evaluation of hydraulic conductivity at any given site (Durner and Lipsius 2005). Field methods can broadly be divided into those above the water table, and those below the water table. Those below the water table are typically used when estimating groundwater flow into or out of wells (Youngs 2001). Methods above the water table are most relevant to this study and are described here.

\section{i. Borehole permeameter}

The Guelph Permeameter (GP) is a constant head well permeameter that measures in-situ hydraulic conductivity. The GP was developed using the theory of borehole permeability (Hooghoudt 1934) and was the chosen method for measuring $K_{s}$ (see section 4.2 .2 for the rationale for choosing the GP). For this reason, a relatively detailed account of the theory is explained in order to provide background for the results and discussion of GP results in Chapter 5.

The GP uses a Mariotte bottle to maintain a constant water level inside a hole augured to a selected depth in an unsaturated soil. First, the hole is augured and the GP placed. Then the water from the permeameter slowly fills the hole to a set height and infiltrates the soil. Flow migrates quasispherically from the infiltration surface creating a saturated bulb and wetting zone (Figure 13). Once the saturated bulb has formed and remains constant, out-flow is at steady state while the wetting front continues to percolate. The steadystate flow is measured and together with the diameter and water level within the auger hole, is used to determine field saturated hydraulic conductivity $K_{s}$ (Durner and Lipsius 2005).

Early work by Glover (1953) modelled steady state flow from a well into unsaturated soil. Glover's solution is based on Laplace's equation which ignores capillarity and assumes the surrounding soil is saturated and draining at the rate of $K_{s}$. This assumes that it is purely pressure head $H$ that generates flow $Q$. Thus, Glover's solution for hydraulic conductivity can be written as:

Equation $9 \quad K=\frac{C Q}{2 \pi H^{2}}$

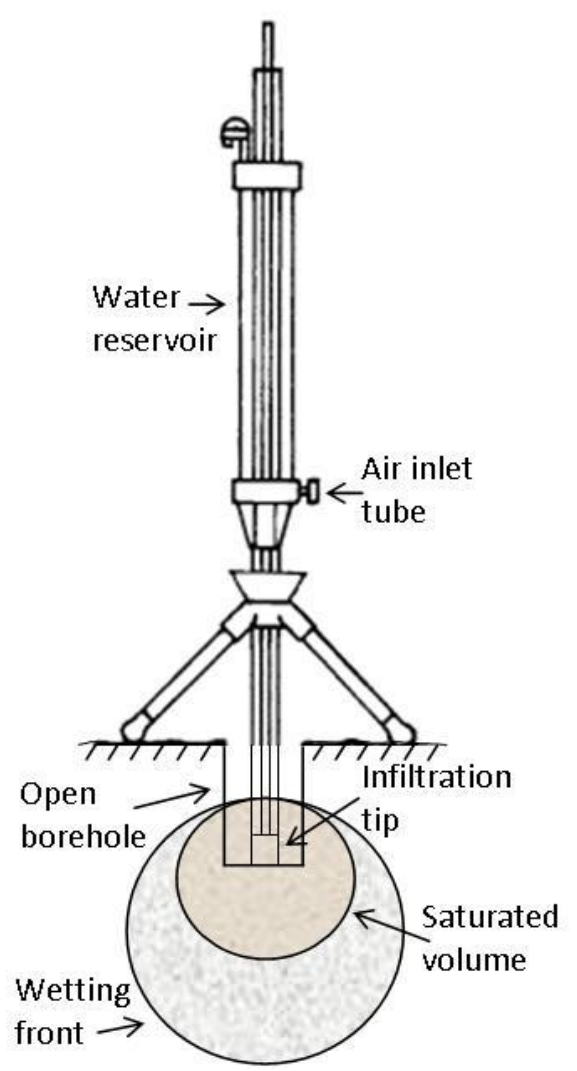

Figure 13 Guelph Permeameter, principle of the method. Adapted from (Beims et al. 2007; Soilmoisture 2008) 
Where the geometric factor of $\mathrm{C}$ (dimensionless shape factor) is given by:

Equation $10 \quad C=\sin ^{-1}\left(\frac{H}{a}\right)-\sqrt{\left(\frac{a}{H}\right)^{2}}+1+\frac{a}{H}$

Thus, by auguring a small hole of radius $a$, and using a Mariotte bottle to maintain constant head $H$, it is possible to measure $Q$ and ascertain field saturated hydraulic conductivity $K_{s}$ (Clothier 2001). Some advantages to this technique are the ease in which the equipment can be transported, assembled, and operated by one person. Measurements typically take 0.5 to 2 hours depending on the soil type, and the GP only requires about 2.5Ltr of water (Beims et al. 2007). However, Clothier (2001) warns that care must be taken when creating the hole to ensure no smearing or sealing of the walls occurs. This is because the surface of the walls in the well strongly affects $Q$, and any smearing will retard flow.

Later work by Phillip (1985) showed that ignoring capillarity when calculating $K_{s}$ can lead to results which are an order of magnitude higher, especially in fine textured soils where the matrix flux potential is large. Capillarity controls the size of the saturated bulb around the well and in part determines flow $Q$ (Clothier 2001). For this reason, first Stephens and Neuman (1982) and then both Phillip (1985), and Reynolds et al. (1985) developed independent theories for the role of capillarity in determining steady flow $Q$ from a well. Stephens and Neuman (1982) based their empirical analysis on the unsaturated-saturated flow regime of Richards equation rather than Laplace's equation (Clothier 2001; Elrick and Reynolds 1992). Later, Phillip (1985) and Reynolds et al. (1985) developed different but comparable, approximate analytical solutions based on Richards equation for measuring flow from a well above the water table. Elrick and Reynolds (1992) claim that subsequent investigations of all three methods (i.e. Stephens and Neuman 1982; Phillip 1985; Reynolds et al. 1985) give comparable results when predicting the steady state flow from a well.

The Reynolds et al. (1985) solution uses the GP and two consecutive pressure head measurements, $H_{1}$ and $H_{2}$ (typically 5 and $10 \mathrm{~cm}$ ). Their solution separates the gravity (saturated) and capillarity (unsaturated) components of flow using Richards equation. The two measurements of flow from the well allowed for simultaneous equations to calculate field saturated hydraulic conductivity $\left(K_{s}\right)$ and matrix flux potential $\left(\Phi_{m}\right)\left[\mathrm{m}^{2} \mathrm{~s}^{-1}\right]$. As an alternative to $K_{s}$, matrix flux potential $\Phi_{m}$ can be used to describe unsaturated flow in soil and offers some advantages under certain conditions. These are water transport under steep potential gradients, and when determining analytical solutions for steady-state multidimensional flow problems. Matrix flux potential is a direct function of the soil water content, but is only indirectly related to pressure head (Dirksen 2001). 
The Reynolds et al. (1985) method can give unrealistic negative $K_{s}$ or $\Phi_{m}$ values when significant soil heterogeneity such as large macropores or a continuous layer boundary is encountered in the change in saturated bulb between the two $H$ levels. If the heterogeneity is caused by a boundary layer Reynolds and Elrick (1986) suggest altering the H-levels so that it does not fall between them. If only an approximate $K$ value is required, then they suggest substituting the two-ponded height (simultaneous equation) for the simpler and less labour intensive one-ponded height (fixed $\alpha^{*}$ ) method which requires only one $\mathrm{H}$-level.

Numerous field studies have experienced repeated problems with negative $K_{s}$ and $\Phi_{m}$ values when using the GP and the two-ponded head method (Amoozegar 1989; Chell 2007; Elrick et al. 1989; Lilly 1994; Salverda and Dane 1993; Vieira et al. 1988; Wilson and Jardine 1989). Elrick's et al. (1989) solution was to use the one-ponded height method suggested by Reynolds and Elrick (1986) to calculate $K_{s}$ using Richard's equation, and the parameter $\alpha^{*}$ (unsaturated slope) to represent capillarity. To derive $\alpha^{*}$ Elrick's et al. (1989) evaluated the soil texture and structure and assigned the following values: for coarse sands and highly structured soils they considered $\alpha^{*}$ to be $35 \mathrm{~m}^{-1}$, most structured soils and medium to fine sands $12 \mathrm{~m}^{-1}$, unstructured fine-textured soils $4 \mathrm{~m}^{-1}$, and compacted clays $1 \mathrm{~m}^{-1}$. Thus, the one-ponded height (fixed $\alpha^{*}$ ) method can calculate $K_{s}$ by the following relationship (Elrick and Reynolds 1992):

Equation $11 \quad K_{S}=\frac{C Q}{\left(2 \pi^{2}\right)+\left(\pi a^{2} C\right)+\left(\frac{2 \pi^{2}}{\alpha^{*}}\right)}$

Where,

$K_{s}=$ Field saturated hydraulic conductivity $\quad Q=$ Steady state recharge $\left[\mathrm{m}^{3} \mathrm{~s}^{-1}\right]$

$A=$ well radius $[\mathrm{m}] \quad h=$ steady depth of water in well $[\mathrm{m}]$

$C=$ dimensionless shape factor (see Glover's solution above)

$a^{*}=$ measure of soils capillarity (ability to absorb water) $\left[\mathrm{m}^{-1}\right]$

As an alternative to applying $\alpha^{*}$ in the one-ponded technique, Elrick et al. (1989) suggests using the Laplace analysis, which assumes all flow from an unlined well to be saturated. However, Lilly (1994) notes that $K_{s}$ values calculated by this method are generally greater than those calculated by Richards equation.

Lilly (1994) used the GP to look for relationships between land use and hydraulic conductivity at various locations across Scotland. Of the 210 measurements made using the two-ponded head technique, only 72 (34\%) met the validity criteria set in Reynolds et al. (1992) i.e. positive values for 
$K_{s}$ and $\Phi_{m}$, and a calculated $\alpha$ value between 1 and $100 \mathrm{~m}$. For this reason, Lilly (1994) used the oneponded technique. Elrick and Reynolds (1989) reported that $75 \%$ of their two-ponded head measurements were positive, while Vieira et al. (1988), Chell (2007), and Salverda and Dane (1993) had far less positive values with a mere $27 \%, 20 \%$ and $60 \%$ respectively. Salverda and Dane (1993) found that the simultaneous approach worked best in coarser homogenous soils, and on finer homogenous soils if smearing during well preparation was kept to a minimum. These conditions are not found in soils whose physical properties vary with depth, or soils overlaying an impervious layer, such as a clay pan, bedrock, or permafrost (Hayashi and Quinton 2004). Thus, the aforementioned soil heterogeneity commonly found in nature led Salverda and Dane (1993:420) to conclude:

"Since it has been shown theoretically and experimentally that GP results, obtained by the multiple head analysis, are often unreliable, this method should not be recommended as a standard procedure to measure the soil's hydraulic properties. A possible alternative to the multiple head analysis of the GP could be the single head analysis".

\section{ii. Ring infiltrometer}

Ring infiltrometers are probably the most commonly used instrument for measuring field infiltration rates. Like the Guelph Permeameter, infiltrometers are used in-situ to estimate field-saturated hydraulic conductivity $K_{s}$ and matrix flux potential $\Phi_{m}$. Water can be applied at either falling or constant head conditions, but the constant head method is usually preferred due to the ease of analysis and setup (Durner and Lipsius 2005). In the constant head method water is ponded at positive pressure head $h_{0}$ using a Mariotte bottle which allows for a wide range of $h_{0}$ values (Durner and Lipsius 2005). Both single and double rings can be used. In the single ring method, a ring is driven into the soil to a selected depth, being careful to minimize disturbance to the soil. The ring confines the flow to the vertical thereby minimising lateral flow caused by capillary action. For extra assurance, a double ring system can be used to attempt to eliminate lateral flow. Under this system flow through the outer ring should guarantee one-dimensional vertical flow through the inner ring with measurements of $K_{s}$ taken from the inner ring only (Durner and Lipsius 2005). In saturated conditions flow from the ring is at positive pressure head. This is controlled by $K_{s,}$ which allows for gravity and matric flux potential. Common size ratios of the inner and outer rings is $20 \mathrm{~cm}$ for the inner and 30cm for the outer (Radcliffe and Rasmussen 2000).

Applying to the same ring two positive hydraulic heads enables the simultaneous solving of the resulting equations for $K_{s}$ and $\Phi_{m}$ (Durner and Lipsius 2005). As with the Guelph Permeameter, this method can cause a large percentage of negative or unrealistic results for $K_{s}$ and $\Phi_{m}$, particularly in highly heterogeneous and/or low permeability soils. In this situation, Durner and Lipsius (2005) 
suggest replacing the one dimensional steady state flow analysis with a transient analysis using a nonlinear least-squares inversion method. Another method employed by Parkin et al. (1999) uses the constant head experiment as before, but once steady state flow is achieved the head is allowed to fall and the rate measured as a function of time. Other suggestions for characterizing hydraulic properties within slowly permeable soils include the methods listed in Fallow et al. (1994) which involves measuring early-time infiltration under both falling and constant head. Further methods have been developed which combine TDR and ring infiltrometers to measure hydraulic properties in unsaturated soils (Parkin et al. 1995).

Since both the ring infiltration and Guelph Permeameter methods are based on infiltration theory the sources of error are similar, and often caused by soil heterogeneity. Effects that often compromise analysis include impeding layers either at the surface, such as compaction from animals or farm equipment, or in the sub-surface such as a clay pan or bedrock. Restricting layers at the surface impede infiltration through to the underlying layer which consequently will not be fully wetted up and so the infiltration rate can only be related to unsaturated hydraulic conductivity. These restricting layers can be expressed in terms of hydraulic impedance $\left(R_{r}\right)$ which consists of the layers thickness $\left(L_{r}\right)$ divided by its hydraulic conductivity $\left(K_{r}\right)$. In contrast, impeding layers at depth can cause lateral flow creating higher $K_{s}$ value than would occur if the entire surface was saturated and water had to flow through the impeding layer (Figures 14 and 15). Additionally, the presence of macropores and cracks can create preferential flow creating a non-uniform wetting pattern thereby increasing $K_{s}$ values (see section 3.3.1). The effect of the impeding layer is greatest when the ring size is small with errors of several hundred percent possible. If $K_{s}$ is being measured in the upper soil profile (above the restricting layer) then an underestimate of $K_{s}$ can occur (Bouwer 1986).

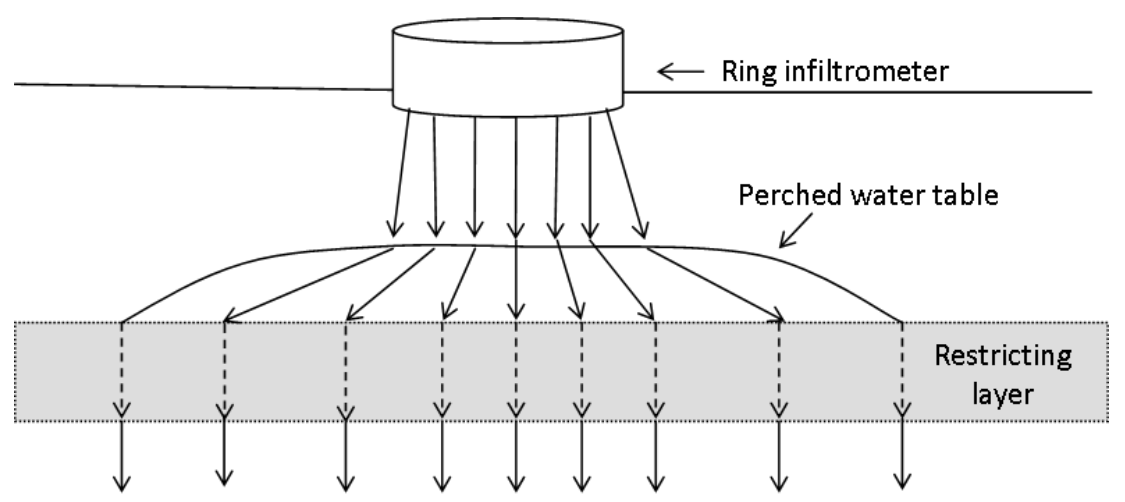

Figure 14 Infiltration through a ring infiltrometer onto a restricting layer creating a perched water table. Adapted from Bouwer (1986). 


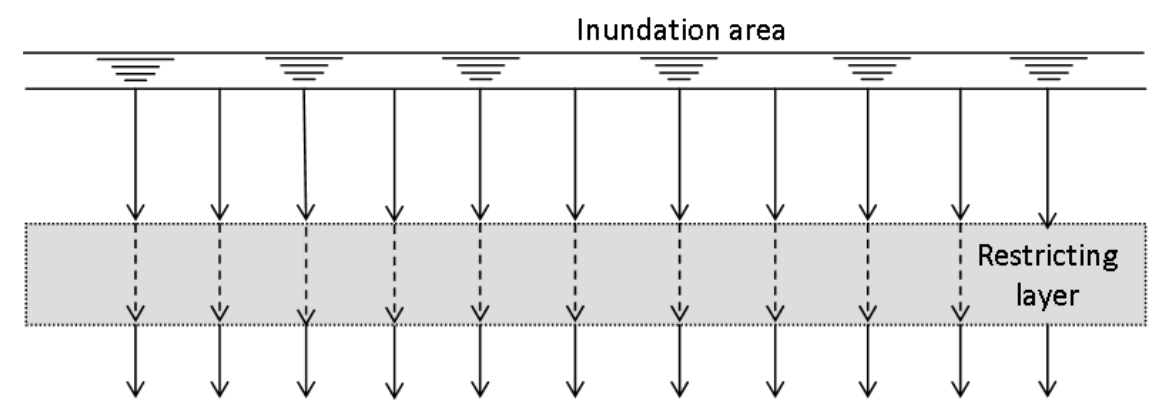

Figure 15 Infiltration over a large inundated area into a soil with a restricting layer. Reproduced from Bouwer (1986).

To counter ring size error a ring should be chosen that is adequately sized to represent the soil. Obviously, the larger the ring the better, however practicality often dictates which size is used. Other sources of error include disturbance during ring insertion which can either decrease $K_{s}$ by compacting the soil, or increase $K_{s}$ by fracturing the soil and creating preferential flow paths down the sides of the ring. Another significant measurement error is blocked flow paths associated with entrapped air beneath the advancing wetting front. If air cannot escape to the surface then pressure head increases at the wetting front thereby decreasing infiltration rates. Further error can result from fingered flow where the wetting front infiltration is uneven due to water repellancy, a process created by decaying organic matter plus humic and fulvic acids. Soils in such a condition are said to be hydrophobic; this is most commonly observed in dry soils (Clothier 2001). In reality it is rare that soil becomes fully saturated. Bouwer (1986) claims that measured $K_{s}$ might be as low as half of real $K_{s}$ (noting that $K$ can vary by several orders of magnitude depending on water content).

\section{iii. Pressure Infiltrometer}

The Pressure Infiltrometer (PI) method was developed by Reynolds and Elrick (1990) especially for the measurement of $K_{s}$ in low permeability soils. It is a variant of the Guelph Permeameter and uses a single ring which is driven into the soil to a depth of about one radius. Positive pressure head is maintained in the head space of the ring with water fed into the soil through a sealed top lid connected to a capillary tube which is also used as a measuring device (Youngs 2001). The PI was designed to mitigate the problem of achieving two, sufficiently separated H-levels in heterogeneous soils. Either the single head method (using the $a^{*}$ parameter to represent capillarity), or a double head method which measures both $K_{s}$ an $a^{*}$, can be used. In the later case, the heads should be sufficiently different to avoid the problems of negative values as commonly experienced with the Guelph Permeameter method (Chell 2007). Reynolds et al. (2000) adds that the PI method has relatively simple and rapid measurements, allows larger heads for less permeable soils, and the absence of an augerhole means the dangers of smearing are eliminated. Possible sources of error 
are the same as those experienced with the ring infiltrometer. An additional error is the small diameter of the ring $(100 \mathrm{~mm})$, which raises the issue of whether the sample size is sufficient to be a fair representative of the soil (Chell 2007; Reynolds et al. 2000). Reynolds et al. (2000) claims that the pressure infiltrometer is well suited for measuring $K_{s}$ but it has received little field testing or comparison with other methods.

\section{iv. Disk permeameters (Tension infiltrometers)}

Methods for measuring in-situ infiltration such as ring infiltrometers only measure flow under ponded saturated conditions. In soils with distinct macropores preferential flow will dominate thereby bypassing the soil matrix. For this reason disk permeameters (or tension infiltrometers in the USA) were developed to create negative potential (tension) on water flow. This excludes macropores from the flow process and measures soil matrix flow only. The modern disk permeameter was developed by Perroux and White (1988), and evolved from the sorptivity tube of Clothier and White (1981). The disk permeameter is set at head $h_{0}$ on a smooth surface of contact sand and the unconfined infiltration is observed by the drop in water level in the reservoir, or automatically using pressure transducers. The relative effects of macropores can be measured by altering the pressure head with a sudden drop in conductivity observed with a drop in head (Clothier 2001).

\subsubsection{Unsaturated hydraulic conductivity $K(\theta)$}

Unsaturated flow (introduced in section 3.2) can be very difficult to measure and indeed, no single method is best suited to all conditions (Dirksen 2001). There are many papers reviewing techniques for determining $K(\theta)$ including (Klute and Dirksen 1986; Kool et al. 1987; Mualem 1986a; Van Genuchten et al. 1992, 1999). Methods for measuring unsaturated flow can be divided into steady state and transient. Steady state methods are more accurate than transient and usually use less sophisticated equipment. Their main disadvantage is they can take much more time. These methods are further divided into laboratory and field measurements. The following section briefly reviews steady state methods. Further information on a variety of techniques can be found in Dirksen (2001) and Klute and Dirksen (1986).

\section{a) Steady-state laboratory methods}

\section{i. Head controlled}

This method uses Darcy's head controlled method (defined in section 3.5.1) to make measurements on a soil column at a range of hydraulic heads. Soil water content can be measured non- 
destructively by weighing or using sensors for dielectric measurements, and tensiometers for matric potential measurements. The experimental setup can give a high degree of accuracy and therefore Dirksen (2001) suggests it should be used as the standard method for measuring $K(\theta)$.

\section{ii. Flux controlled}

Rather than controlling hydraulic head, this method controls the flux density at the input end of a soil column by using a device that can deliver small, uniform, steady state water flux densities over an extended time period (Dirksen 2001). Dirksen and Matula (1994) have developed a device that can deliver steady average fluxes down to $0.1 \mathrm{~mm} \mathrm{~d}^{-1}$. Unfortunately, this method can take several days to reach steady state making it an unattractive option if time constraints are an issue.

\section{iii. Regulated evaporation}

The regulated evaporation method achieves steady state when soil water supplied at constant negative pressure head is evaporated at a constant rate at the soil surface. The flux density throughout the soil is steady while the water content and thus hydraulic conductivity decrease towards the surface. The hydraulic conductivity gained will be some form of average for the range of water contents (Dirksen 2001).

\section{b) Steady-state field method}

\section{i. Sprinkling infiltrometer}

The sprinkling infiltrometer is the field version of the laboratory based flux controlled experiment. This method is often used in erosion studies where the impacts of rain splash can be simulated. Measurements can extend over days, or even weeks depending on the range of water contents covered. Over these periods temperature can fluctuate significantly which affects water transport processes. For this reason, all field measurements should minimize temperature changes as much as possible (Dirksen 2001).

\section{ii. Disk permeameters (Tension infiltrometers)}

This method uses the same setup as described in the saturated flow version. The disk supplies water at constant pressure head to the surface of an unconfined homogeneous soil. Initially, flow is one dimensional and is controlled by sorptivity. Once steady state is reached (usually a few hours) capillary and gravity forces can be separated and hydraulic conductivity measured (Dirksen 2001). 


\subsection{Indirect estimation by pedotransfer functions}

As a result of the cost and difficulty of measuring hydraulic properties, other more easily analysed soil properties have been used to obtain these relationships indirectly. These estimation methods are called pedo-transfer functions (ptfs). Tietje and Tapkenhinrichs (1993) divides ptfs into three categories:

\section{i. Point regression models}

Water content is estimated over a range of matric potentials using regression analysis on large data sets of soil samples which contain information on soil texture, organic content, and bulk density. The regression equations estimate water content at different matric potentials depending on the structural makeup of the other soil properties (Townend et al. 2000).

\section{ii. Physical model methods}

The water release curve is estimated from particle size distribution. Assumptions are made about the shape of particles, packing, and capillary attraction of water in different size pores to estimate hydraulic conductivity (Townend et al. 2000). This approach has developed over the last decade due to advances in instrumental techniques and computer technology (Blunt and Hilpert 2001), however these techniques are currently used more for research into process rather than practical determination of hydraulic properties (Durner and Lipsius 2005).

\section{iii. Functional parameter regression methods}

An equation describing the water release curve is formulated and the parameters of the curve are determined for a particular soil using regression analysis with measured values on a water release curve (Townend et al. 2000). A commonly used empirical equation for determining $K$ in unsaturated soil is the van Genuchten (1980) WRC curve combined with the Mualem (1986a) hydraulic conductivity function (section 3.2).

There are a large number of reviews that compare the various pedo-transfer functions (Danalatos et al. 1994; Felton and Nieber 1991; Haverkamp and Parlange 1986; Nandagiri and Prasad 1997; Rawls et al. 1991; Schaap 2005; Tietje and Tapkenhinrichs 1993; Vereecken et al. 1989; Viaene et al. 1994; Wagner et al. 2001; Wosten et al. 2001). In many of these studies the van Genuchten (1980) and Mualem (1986a) model appears to give accurate results, but this method does require at least five measurements to fit it (Townend et al. 2000). 


\section{Chapter 4 - Experimental design and methodology}

For this MSc thesis saturated hydraulic conductivity $\left(K_{s}\right)$, bulk density $(\rho)$ and soil texture (described in sections 4.2.4 and 4.2.5) were measured on soils at two locations (Takapau farms and Mananui farm) bordering the Ruataniwha Plains in Central Hawkes Bay. The constant head Guelph Permeameter was used for measuring $K_{s}$, the driving hammer for $\rho$, and laser diffraction and sieve techniques for soil texture. This chapter outlines the experimental design and site selection followed by the rationale for choosing the field based constant head permeameter. This is followed by the methodologies and principal sources of error.

\subsection{Experimental design}

Western et al. (2005:1) states that before designing any measurement program it is important to ascertain the objectives of the data collection. This provides the basics for a sampling strategy which includes the objectives of the research; key spatial and temporal scales of interest; required accuracy, and available resources. The aim of chapter 4 is to design a methodology for achieving objectives 1 and 2, which as stated in the introduction are:

1. Ground truth the national scale land and soil information held in the New Zealand Land Resource Inventory (NZLRI) and National Soil Database (NSD) by digging soil pits and collecting samples from selected sites within the Ruataniwha Plains in Hawkes Bay based on land type, topography, soil and geology. Measure the hydraulic conductivity, soil texture, bulk density, and the depth to slowly permeable layer at each sample location and compare to the national data. This will be used to assess the extent to which the national data can be used for detailed flood modelling and management at the farm scale.

2. As tree shelterbelts are proposed as natural flood buffers, measure the changes in soil hydraulic properties at a distance of 1,5 and 10 metres from the trunk of two commonly found species of trees on New Zealand farms: a Cupressus macrocarpa shelterbelt and individual Populus spp. trees.

\subsubsection{Site and sample selection}

For objective 1, evidence was sought to test whether there were any differences in soil texture, bulk density, and $K_{s}$ values between sample sites. It was recognised that only a limited study of spatial variability would be possible due to the limited time available. A comprehensive analysis of spatial variability would require many more measurements. Despite this, it was thought that an indicative 
assessment of the influence of elevation, geology, soil type, and land use were obtainable objectives given available time.

To represent Takapau farms the area was divided into 7 landscape units and at least 3 measurements taken for each unit. The landscape units included pine forest and pasture overlaying greywacke, pasture and macrocarpa on loess downlands, pasture on mudstone, and pasture on loess basin and limestone. Unlike Takapau farms, Mananui farm has similar geology, soil type and land use throughout (gravels, sandy loam, pasture). The reduced number of variables provided an opportunity to compare $K_{s}$ at different slope angles along a transect. Each transect had 3 points corresponding to head slope, mid-slope and foot slope (see Milne et al. (1991) for a definition) with a total of 5 transects ( $16 K_{s}$ points) measured overall.

\subsection{Methodology}

\subsubsection{Site description}

Once a sample site was selected the soils and site location were described as per the methodology defined in the 'Soil Description Handbook' by Milne et al. (1991). The location was calculated by the average of three GPS points taken using a handheld Garmin GPS. Soil texture samples were collected by digging pits down to the slowly permeable layer. This layer was usually a fragipan (A dense, subsurface layer of hard soil with relatively slow permeability to water, mostly because of its extreme density or compactness rather than its high clay content or cementation), but in a few cases samples were obtained down to bedrock or underlying gravels. Bulk density cores and sediment samples were collected at different soil layers and boundaries. Hydraulic conductivity measurements were made in the A horizon at approximately 12 to $20 \mathrm{~cm}$ depth.

\subsubsection{Rationale for choosing the field based Guelph Permeameter}

The best technique for measuring soil hydraulic properties is not always clear. Some authors such as Dirksen (2001) proclaim the multiple benefits of carrying out measurements in the laboratory stating it is good practice unless there are overriding reasons to perform them in-situ. In contrast, Durner and Lipsius (2005) claim that field measurements offer the most reliable, and often, only means of determining hydraulic properties. The major disadvantage of using laboratory methods was the practical difficulties in successfully obtaining an "undisturbed" soil core and safely transporting it back to the laboratory, some $250 \mathrm{~km}$ away. The low soil moisture levels during the first collection period (late summer) made the soil less likely to hold together, and when combined with the steep and undulating nature of the field sites coupled with the long distance back to laboratory facilities 
back in Wellington, it was feared that the cores would be disturbed in transit. Even if collection was delayed until soil moisture levels were higher, disturbance was still likely to occur. This was the primary reason why it was decided that in-situ field measurements would be most appropriate for this study.

The major limiting factor when choosing a field technique was the available equipment. The field based equipment belonging to Victoria University of Wellington were ring infiltrators and a Guelph Permeameter (GP). Clothier (2001) provides a table that ranks the relative merits of eight different field infiltration devices via a usefulness score. Overall the ring infiltrometer scored the highest due to its low cost, ease of use and data analysis, and lack of technical skills required by the operator. However, it scored poorly in the disturbance category due to ring insertion. The Guelph Permeameter also rated highly coming second behind the ring infiltrometer. It scored slightly less because it costs more and requires greater operator experience. However, the GP outscored the rings due to fewer disturbances to the soil and greater information able to be obtained from the measurements. These benefits prompted its selection for this project. The standard equation for the GP measures $K_{s}$ using Reynolds et al. (1985) two-ponded head method. However, negative values obtained using this method prompted the use of the one-ponded head technique (Elrick et al. 1989) outlined in section 3.6.1.

\subsubsection{Measuring saturated hydraulic conductivity with the Guelph Permeameter}

Saturated hydraulic conductivity was measured on site using the Guelph Permeameter (GP). The GP was operated in accordance with the operating instructions (Soilmoisture 2008). What follows is the step by step procedure employed when using the GP.

\section{1) Site preparation}

Upon arrival at the site an evaluation of the topography and general soil appearance was made in order to select a representative point for the study area.

\section{2) Well preparation}

The well was prepared by auguring a borehole to a selected depth (typically $15-20 \mathrm{~cm}$ ). The Soil Auger was used to remove the bulk of the soil while the Sizing Auger was used as a finishing tool to produce a well hole of uniform geometry and to clean debris from the bottom of the well hole. In moist soils and fine or medium textured soils the process of auguring a well hole can create a smear layer on the wall of the well blocking the natural flow of water into the surrounding soil. In this situation the Well Prep Brush was used to remove the smear layer. 


\section{3) Placement of permeameter}

The GP was assembled and mounted within the tripod and the stopper in the reservoir cap removed and both reservoirs filled with water using the plastic water container. Once filled, the stopper was replaced in the fill hole and the neoprene tube from the vacuum port checked to make sure it was folded over and closed with the clamping ring. Then the tripod was centred over the well hole and the GP lowered being careful not to knock any debris off the sides of the well into the hole. The flexibility of the tripod base allowed the legs to be adjusted to accommodate variation in slope. When the slope angle was particularly steep the adjustable 'Heavy Duty Guelph Stand' was used to stabilise the GP.

\section{4) Making a reading}

After the GP was assembled, filled and placed within the well measurements were taken using the following procedure.

Step 1 - First, to verify that both reservoirs were connected, the notch on the reservoir valve was turned up. Then the well height indicator and well head scale were checked to make sure they were down flush against the reservoir cap.

Step 2 - The well head height $\left(H_{1}\right)$ was established by raising the air tube either 5 or $10 \mathrm{~cm}$ being careful to raise it slowly thereby reducing turbulence and erosion as well as potential overflow from the surge effect. The combination reservoir was used and the rate of fall $(R)$ observed at 2 minute intervals. If it was too slow to easily distinguish the rate of fall between consecutive readings then the inner reservoir only was used. Additionally, the time between readings could be made longer for slowly permeable soils (e.g. $5 \mathrm{~min}$ ), or shorter for faster permeable soils (e.g. $1 \mathrm{~min}$ ).

Step 3 - Outflow was measured at the chosen time interval from the rate of fall $(R)$ as read against the scale stamped on the selected reservoir. $R$ was monitored until a steady rate of fall is reached. A steady rate is achieved when $R$ is the same for three consecutive readings $\left(R_{1}\right)$. The rate of fall for each interval is determined by dividing the change in water level within the reservoir in centimetres by the time interval in seconds.

Step 4 - The field saturated hydraulic conductivity $\left(K_{s}\right)$, was then calculated using Elrick and Reynolds (1992) equation listed in Chapter 3 section 3.5.1 (i). 


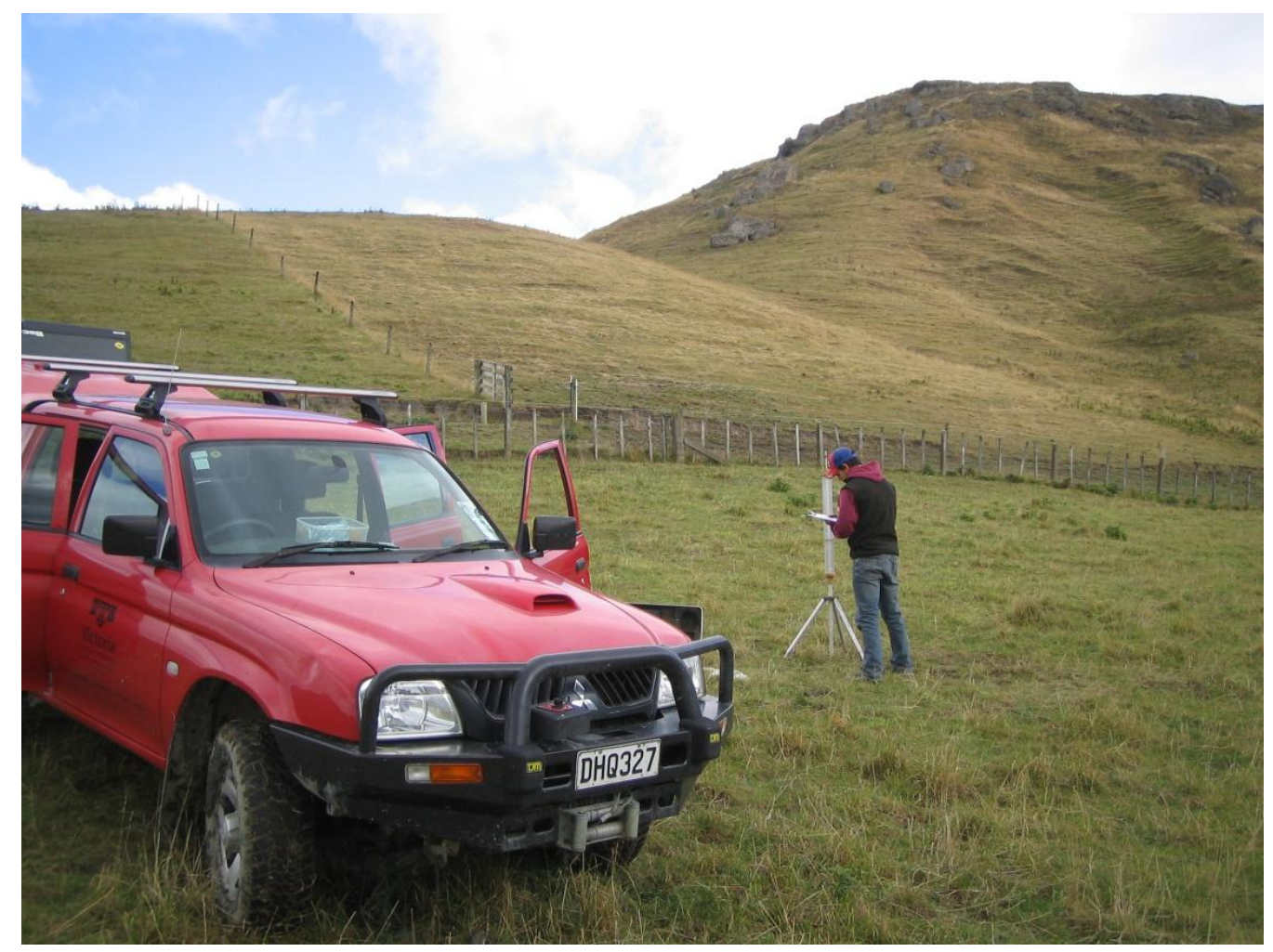

Figure 16 Measuring $K_{s}$ with the Guelph Permeameter at Takapau farms

\subsubsection{Measuring dry bulk density using the driving hammer technique}

The bulk density $(\rho)$ of soil is the ratio of the soil mass to its volume and is inversely related to the porosity of the same soil, i.e. the more space in the soil, the lower the value of bulk density (Gerrard 2003). Values of $\rho$ generally range from $<1 \mathrm{~g} / \mathrm{cm}^{3}$ for highly organic soils, $1.0-1.4 \mathrm{~g} / \mathrm{cm}^{3}$ for wellaggregated loamy soils, and $1.2-1.8 \mathrm{~g} / \mathrm{cm}^{3}$ for sands and compacted horizons in clay soils (White 2006). The first stage in measuring bulk density involved obtaining a soil core while trying to minimise disturbance to the soil during the process. This was achieved through driving a stainless steel cylinder containing a core into the ground to selected depths and horizons. A hammer was used to carefully drive the cylinder into the ground, which was made easier by the cutting edge of the cylinder. Once the cylinder was extracted and the core removed, the usual procedure recommends leaving approximately $2 \mathrm{~cm}$ of soil protruding from the base and trimming it off in the lab. However, in mid-march 2010 when most of the samples were collected the soil was very dry which caused some of the ends to break off during transport. For this reason ends were trimmed in the field and then the core tapped up within a plastic bag. This way if any soil fell out in transit, it could still be included with the core when calculating bulk densities in the lab. 


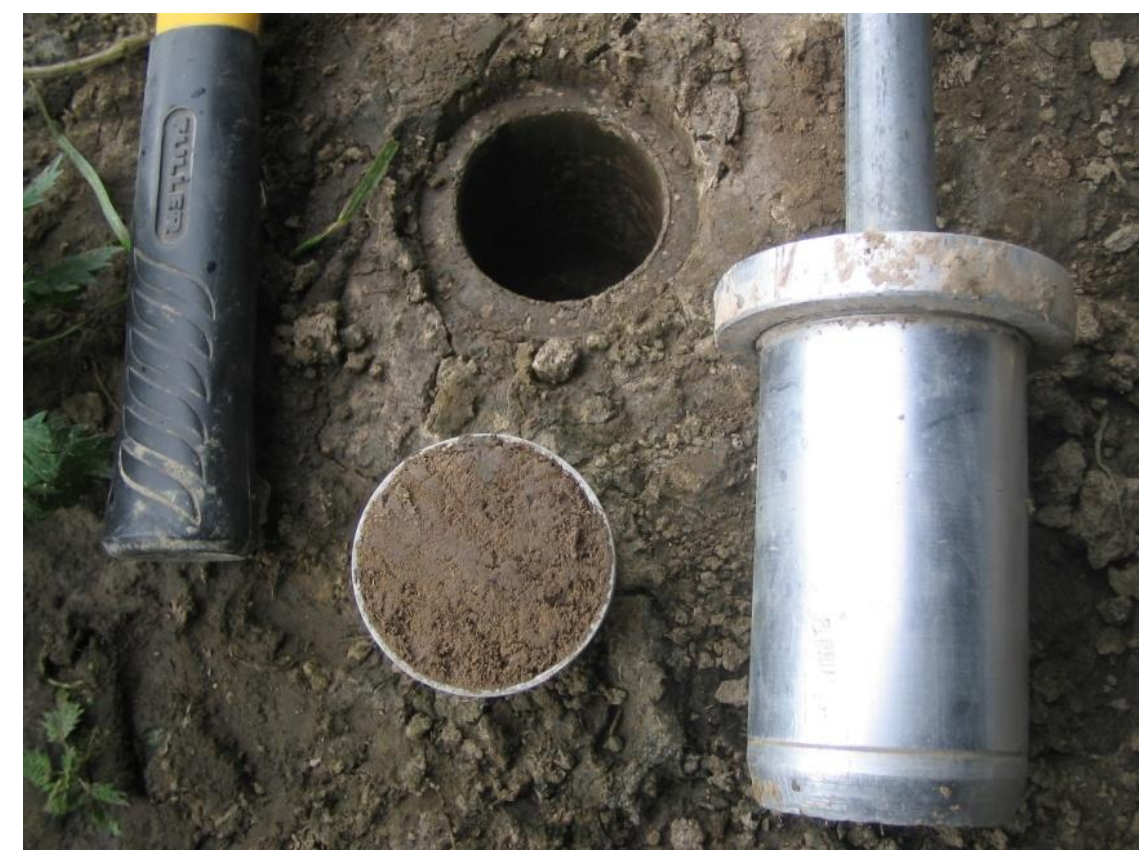

Figure 17 Bulk density core, stainless steel cylinder and hammer used for extracting soil cores

Once in the laboratory the core volume was calculated (60 mm length; $40.5 \mathrm{~mm}$ diameter) then both the tube and soil were weighed in grams. The core was oven dried at $105^{\circ} \mathrm{C}$ for 24 hours then removed and cooled in a desiccator. The oven dried core was weighed and then the soil removed and the empty core weighed again. From this process bulk density $(\rho)\left[\mathrm{g} / \mathrm{cm}^{3}\right]$ was calculated by dividing the weight of the soil alone $\left(M_{s}\right)[g]$ by the volume of the core $\left(V_{t}\right)[g]$.

Equation $12 \quad \rho=\frac{\text { weight of soil alone }}{\text { volume of the core }}$

In addition the soil volumetric water content $\left(W_{v}\right)[g]$ was calculated by the difference in core weight [g] between dry and wet sample using the equation defined in (USDA 2010):

Equation $13 \quad W_{v_{[g]}}=\frac{\text { weight of moist soil }- \text { weight of soil alone }}{\text { volume of the core }}$

$$
\begin{aligned}
& \text { Soil water filled pore space }[\%]=\frac{W v \times 100}{\text { soil porosity }} \\
& \text { Volumetric water content }\left[\mathrm{g} / \mathrm{cm}^{3}\right]=w_{v} \times \rho \\
& \text { Soil porosity }(\%)=1-\frac{\rho}{2.65}
\end{aligned}
$$

\subsubsection{Soil texture analysis using the laser diffraction and sieve method}

Soil samples are composed of various proportions of fine $(<0.5 \mathrm{~mm}$; sands, silts and clays) and coarse sediment $(>0.5 \mathrm{~mm}$; gravel). The distribution of particles is a significant determiner of the hydraulic characteristics within a soil. To establish the distribution of particle size for each sample two 
methods were used. For those samples with fine sediment only, a Laser Particle Size Analyzer (LPSA) was used. For samples with both fine and coarse material both the LPSA and sieving were used.

\section{a) Laser particle size analyser}

Particle size of soil samples $<0.5 \mathrm{~mm}$ were calculated using the LS 13320 Laser Particle Size Analyser made by Beckman Coulter. The laser diffraction method relies on analysis of the 'halo' of diffracted light when the laser beam passes through a dispersion of particles within water. The angle of diffraction increases as particle size decreases (Wedd 2003). Operation of the LPSA was followed using the methodology outlined in the LPSA manual (Beckman Coulter 2003). Only a small part of each soil sample is required to run through the LPSA. This was selected in part by the coning and quartering method outlined by Pitard (1993). Although this approach is not a highly accurate representation of the sample, it is deemed accurate enough where site variation, such as soils, is high (Pitard 1993). After the sample was cut into four, one quarter was randomly selected and ground gently in calgon using a pestle and mortar to separate the particles. This was then sonicated within a test tube and a sub-sample extracted with a pipette and run through the LPSA. However, early results showed a bias for selecting sands when using the pipette due to the settling process. Soils that were known silt loams were coming out as sand loams. This issue was overcome by randomly selecting a small sub-sample from the original quartered sample and separating the aggregates as before. Then the entire sub-sample was run through the LPSA thereby removing any bias from using the pipette. This method gave results more in line with expectations.

\section{b) Sieve analysis}

Out of the 147 samples collected, 30 contained coarse aggregates ( $>1.5 \mathrm{~mm}$ in diameter). While the finer aggregates were run through the LPSA, the coarser gravels required sieving. This method involved drying and weighing the entire sample to give total weight, then 'wet sieving' to remove the finer particles and drying the remainder and weighing again. This gave relative proportions of fine versus coarse material within the total sample. The remaining coarse sediment was sieved through different size mesh and weighed at each stage. The results from the sieving were combined with results from the laser diffraction and the distribution of particle size established via a percentage breakdown. 


\section{Chapter 5 - Experimental results}

Chapter 5 presents the results and discussion from the experimental methodology in Chapter 4 . The aim of this chapter is to complete objectives 1 and 2 by breaking it down into 3 sections. The first section lists the soil properties as found in the National Soil Database (NSD) so they can be compared with the measured values. The second section compares the measured values (soil texture, hydraulic conductivity, bulk density, depth to slowly permeable layer) against the NSD at Takapau and Mananui farms using confidence intervals and statistical tests where appropriate. The third section presents results from a study into the changes in soil hydraulic properties at a macrocarpa shelterbelt on Takapau farms and poplars at Mananui at a distance of 1, 5 and 10 metres from the trees. In total, $70 K_{s}$ readings, 114 bulk density cores, and 145 soil texture distributions were measured and analysed.

\subsection{National Soil Database values}

Table 9 displays the properties of the soils in both study areas as listed in the NSD. Within the NSD is a field "EST_values". These describe the origin of the value and to what extent they can be relied upon for accuracy. The NSD Matapiro silt loam values are derived from actual measurements of the soil (class m). The Takapau, Taihape, and Mangatahi loams have NSD values estimated from relationships with other soils (class $r$ ) but the estimate is considered reliable. The Maungapakeha silt loam values were also estimated from relationships with other soils but with an unknown level of accuracy (class $u$ ). The NSD values for the Atua silt loam were estimated from General Soil Survey Data (scale 1:253,440) (class uf), which in general is considered less reliable than the ' $u$ ' class above. Three soils on Takapau farms (Takapau, Taihape, Okawa) were present in small quantities and for this reason the field studies were restricted to the Atua, Mangapakeha, and Matipiro silt loams only.

No statistical test was suitable for comparing the data measured in the field with the NSD. This is because the NSD values are classified in classes which encompass a range of values e.g. $K_{s}$ classes (slow $=1$ to $4 \mathrm{~mm} / \mathrm{h}^{-1}$, moderate $=4-71 \mathrm{~mm} / \mathrm{h}^{-1}$ etc, see Table 9). Therefore the field data was analysed using $95 \%$ confidence intervals and then compared to see if it matched the classes assigned to the same area in the NSD. 
Table 9 Soil information as defined in the NSD. The moderate class $=4$ to $71 \mathrm{~mm} / \mathrm{h}^{-1}$.

\begin{tabular}{|l|l|c|c|}
\hline Farm & Soil type & $\begin{array}{c}\text { Hydraulic conductivity } \\
\left(\mathbf{m m} / \mathbf{h}^{-1}\right)\end{array}$ & $\begin{array}{c}\text { Depth to slowly permeable } \\
\text { layer }(\mathbf{m})\end{array}$ \\
\hline Takapau & Atua silt loam & moderate & $\min 1.5, \max 3.0$, mid 2.25 \\
& Mangapakeha silt loam & moderate & $\min 1.5, \max 3.0$, mid 2.25 \\
& Matapiro silt loam & moderate & $\min 0, \max 0.44$, mid 0.22 \\
& Takapau stony loam & moderate & $\min 1.5$, max 3.0, mid 2,25 \\
& Taihape silt loam & moderate & $\min 0.45, \max 0.89$, mid 0.67 \\
& Okawa sandy loam & moderate & $\min 0.45, \max 0.59$, mid 0.52 \\
\hline Mananui & Mangatahi sandy loam & moderate & $\min 1.5, \max 3.0$, mid 2.25 \\
\hline
\end{tabular}

\subsection{Soil texture}

The method for measuring soil texture distributions is described in detail in Chapter 4 (section 4.2.5). Particle size was classified using the United States Department of Agriculture (USDA) scheme (Table 10). The measured soil textures were very similar to those held in the NSD. The NSD classes the soil at Takapau farms as silt loam. Of the 88 samples analysed from Takapau farms, 69 (78.4\%) were classed as silt loams with 8 of those samples also containing some gravels. The remaining 19 samples (21.6\%) were classed silt and were located at depths ranging from 20 to $70 \mathrm{~cm}$ (Figure 18). At Mananui farm the NSD defines the soil as sandy loam. Of the 57 samples collected 48 (84.2\%) were classed sandy loams, with 17 of those samples also containing some gravels. The remaining samples were either loamy sand 6 (10.5\%), or silt loam 3 (5.3\%) (Figure 19).

In summary, $78.4 \%$ of the samples at Takapau were silt loam which matched the values held in NSD. The remaining 21\% was silt which came from the Mudstone hill country at depth. At Mananui $84.2 \%$ were sandy loam which matched the values held in the NSD. The remainder were closely related as either loamy sand or silt loam. When dealing with a highly variable substance such as soil it is common to find large differences in soil properties (Elkateb et al. 2003), even at the hillslope scale (Sivapalan 2003). The slight variation in soil textures found across both study sites is consistent with this and it can be concluded that the NSD is suitable for predicting soil texture at the study sites.

Table 10 Particle size classification by USDA scheme. Note: samples with gravels $>15 \%$ and $<50 \%$ are termed gravelly. Samples with $>50 \%$ gravels are termed very gravelly.

\begin{tabular}{ccccc}
\hline Sediment size & clay & silt & sand & gravel \\
\hline$\mu \mathrm{m}$ & 2 & $2-50$ & $50-2000$ & $2000-315,000$ \\
$\mathrm{~mm}$ & $<0.002$ & $0.002-0.05$ & $0.05-2.0$ & $2.0-31.5$ \\
\hline
\end{tabular}




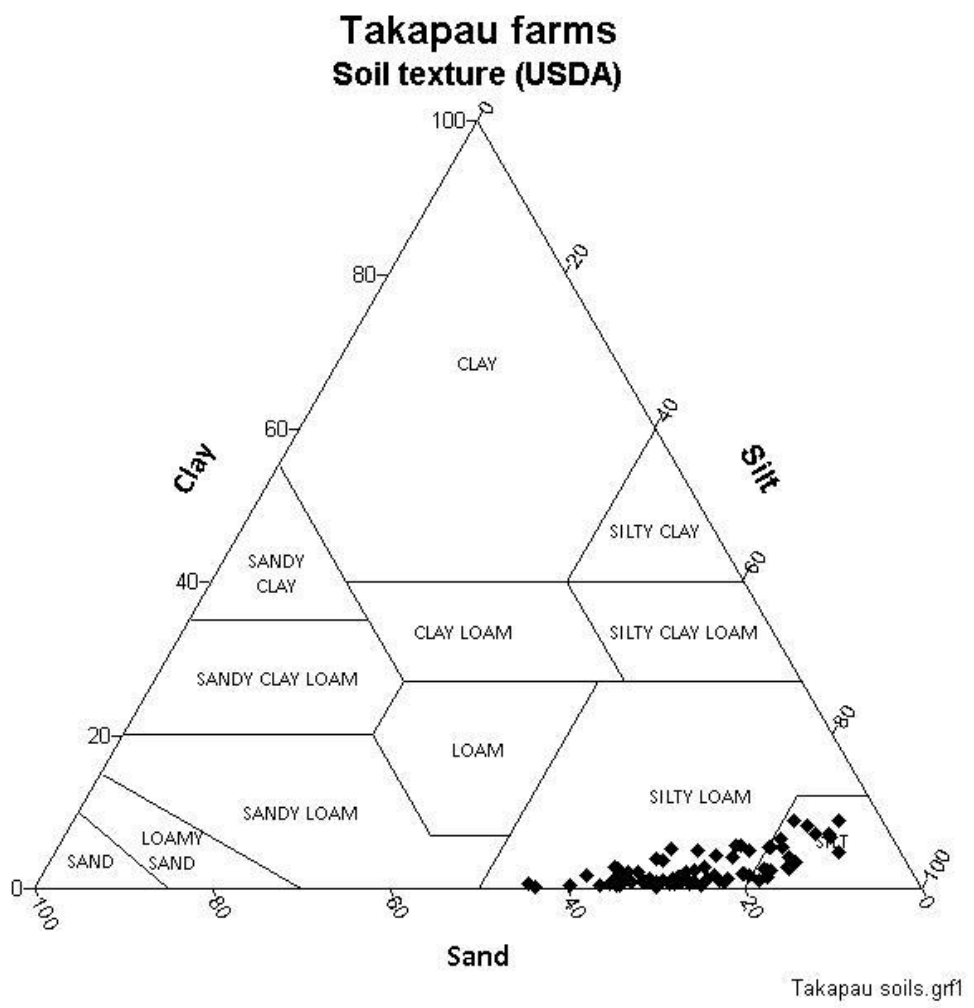

Figure 18 Soil texture triangle displaying soils from Takapau farms classified by \% sand, silt and clay. Of the 88 samples, 69 are silt loams and 19 are silt.

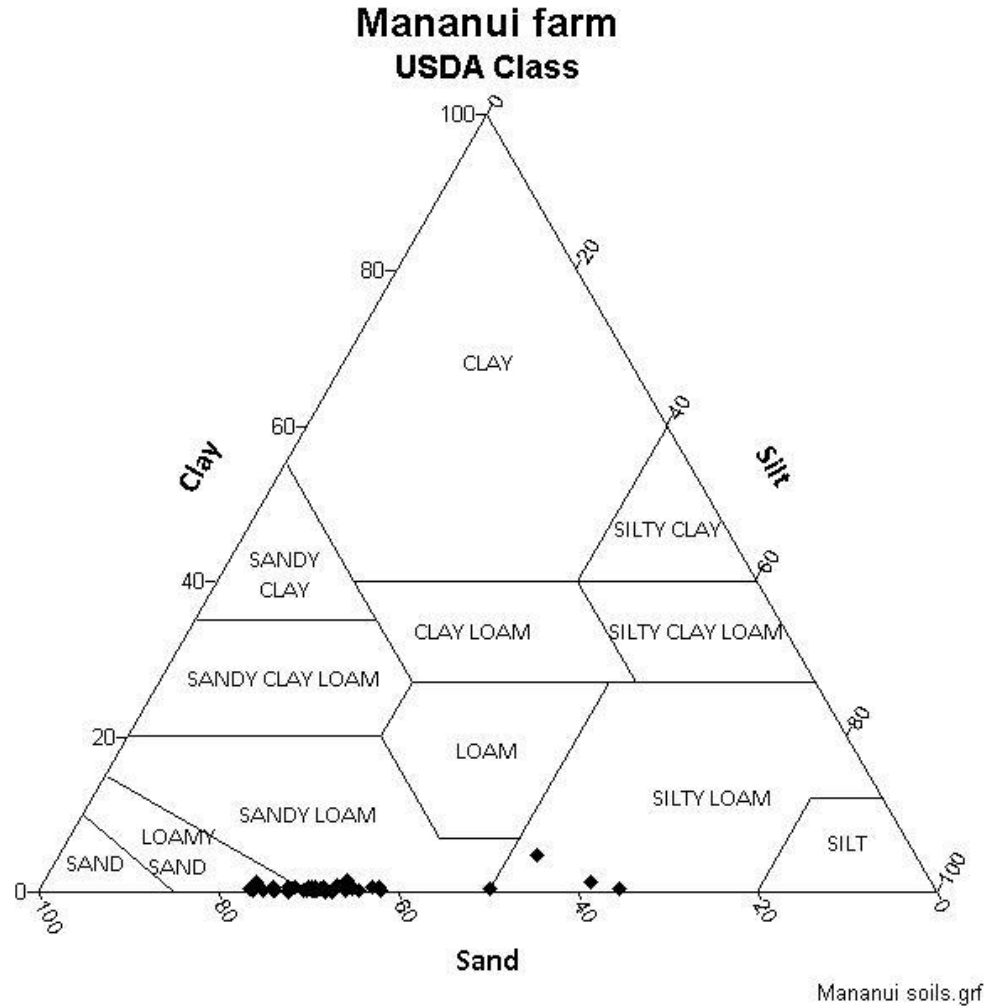

Figure 19 Soil texture triangle displaying soils from Mananui farm classified by \% sand, silt and clay. Of the 57 samples, 48 are either sandy loams, or gravelly sandy loams. The remaining 9 are loamy sand and silt loam. 


\subsection{Hydraulic conductivity}

Saturated hydraulic conductivity $\left(K_{s}\right)$ was measured using the field based Guelph Permeameter. The presence of a fragipan (see section 4.2.1 for a definition) at reasonably shallow depths (section 5.4.2), and the limited time available for field work meant that all $70 K_{s}$ measurements were taken in the A-horizon only. Forty three of these were distributed throughout the landscape to provide some idea of spatial variability. The remaining 27 were used to determine whether $K_{s}$ is greater near trees (specifically a macrocarpa shelterbelt and poplars) compared to the same soil in pasture. The initial calculation method for inferring $K_{s}$ from the measurements was the standard two-ponded head technique (Reynolds et al. 1985), however this method gave negative values. As an alternative the one-ponded height method (Reynolds et al. 1992) was applied to calculate $K_{s}$. This used the average of the two separate calculations of $K_{s}$ obtained using two hydraulic heads (50 and $100 \mathrm{~mm}$ ) from the two-ponded technique. For a detailed description of the negative value problem and both the one and two-ponded head techniques see Chapter 3 section 3.5.1. (b). The NSD categorizes $K_{s}$ using the classes listed in Griffiths (2004) which for comparison are displayed below the USDA classes (Table 11).

Table $11 K_{s}$ classes as defined by USDA and Griffiths (2004).

\begin{tabular}{|l|c|c|c|c|c|c|c|}
\hline Class & \multicolumn{7}{|c|}{ Hydraulic conductivity $\left(\mathrm{mm} / \mathbf{h}^{-1}\right)$} \\
\hline USDA & $\begin{array}{c}\text { very } \\
\text { slow }\end{array}$ & slow & $\begin{array}{c}\text { moderately } \\
\text { slow }\end{array}$ & moderate & $\begin{array}{c}\text { moderately } \\
\text { rapid }\end{array}$ & rapid & very rapid \\
& $<1$ & $1-5$ & $5-20$ & $20-60$ & $60-125$ & $125-250$ & $>250$ \\
\hline $\begin{array}{l}\text { (Griffiths } \\
\text { 2004) }\end{array}$ & $\begin{array}{c}\text { very } \\
\text { slow } \\
<1\end{array}$ & slow & \multicolumn{2}{|c|}{ moderate } & \multicolumn{2}{c|}{ rapid } & $\begin{array}{c}\text { very } \\
\text { rapid } \\
\end{array}$ \\
\hline
\end{tabular}

\subsubsection{Takapau farms}

As discussed in Chapter 4, section 4.1.1, at Takapau farms the landscape was divided into units based on geology, soil type, and land use. Table 12 displays measured $K_{s}$ values for each landscape unit with their associated class, with Table 13 displaying the summary statistics. The pasture on limestone had the highest mean $K_{s}\left(11.4 \mathrm{~mm} / \mathrm{h}^{-1}\right)$ and the slowest was the pasture on loess basin $\left(3.2 \mathrm{~mm} / \mathrm{h}^{-1}\right)$. Interestingly, the pasture on greywacke had higher $K_{s}\left(8.1 \mathrm{~mm} / \mathrm{h}^{-1}\right)$ than the adjacent pines on greywacke $\left(4.3 \mathrm{~mm} / \mathrm{h}^{-1}\right)$. In both locations the soil overlaying the bedrock was very shallow $(6-30 \mathrm{~cm})$ but in the pasture the greywacke was more fractured with large cracks. These cracks can create macroflow which could explain the higher hydraulic conductivity at the pasture. The mean values for all landscape units fell within the moderate category as defined in Griffiths (2004), apart from pasture on loess basin which was classed as slow. When sorting $K_{s}$ by soil type the high and low values were reduced with mean values for the Atua silt loam $5.5 \mathrm{~mm} / \mathrm{h}^{-1}$, Matapiro silt loam 
$6.9 \mathrm{~mm} / \mathrm{h}^{-1}$, and Mangapakeha silt loam $6.2 \mathrm{~mm} / \mathrm{h}^{-1}$ (Table 13). Mean $K_{s}$ for the entire Takapau farm is $8.46 \mathrm{~mm} / \mathrm{h}^{-1}$ (moderate) which is consistent with the classification it is given in the NSD.

Table $12 K_{s}$ values from Takapau farms in $\mathrm{mm} / \mathrm{h}^{-1}$

\begin{tabular}{|c|c|c|c|c|c|}
\hline \multirow{2}{*}{ Takapau farms } & \multirow{2}{*}{$\begin{array}{c}\text { Sample } \\
\text { id. }\end{array}$} & \multirow{2}{*}{$\begin{array}{c}\text { Depth of } \\
\text { well }(\mathrm{mm})\end{array}$} & \multirow{2}{*}{$\kappa_{s}\left(\mathrm{~mm} / \mathrm{h}^{-1}\right)$} & \multicolumn{2}{|c|}{$K_{s}$ Class } \\
\hline & & & & (USDA) & (Griffiths 2004) \\
\hline $\begin{array}{l}\text { Pasture on loess } \\
\text { basin }\end{array}$ & $\begin{array}{l}1 / \mathrm{A} 1 \\
1 / \mathrm{A} 2 \\
1 / \mathrm{A} 3\end{array}$ & $\begin{array}{l}170 \\
170 \\
180\end{array}$ & $\begin{array}{l}2.9 \\
2.5 \\
4.1\end{array}$ & $\begin{array}{l}\text { slow } \\
\text { slow } \\
\text { slow }\end{array}$ & $\begin{array}{l}\text { slow } \\
\text { slow } \\
\text { moderate }\end{array}$ \\
\hline $\begin{array}{l}\text { Pine on } \\
\text { greywacke }\end{array}$ & $\begin{array}{l}1 / \mathrm{B} 1 \\
1 / \mathrm{B} 2 \\
1 / \mathrm{B} 3\end{array}$ & $\begin{array}{l}200 \\
120 \\
160\end{array}$ & $\begin{array}{l}5.8 \\
4.5 \\
2.5 \\
\end{array}$ & $\begin{array}{l}\text { moderately slow } \\
\text { slow } \\
\text { slow }\end{array}$ & $\begin{array}{l}\text { moderate } \\
\text { moderate } \\
\text { slow }\end{array}$ \\
\hline $\begin{array}{l}\text { Pasture on } \\
\text { limestone }\end{array}$ & $\begin{array}{l}1 / \mathrm{C} 1 \\
1 / \mathrm{C} 2 \\
1 / \mathrm{C} 3 \\
\end{array}$ & $\begin{array}{l}150 \\
170 \\
190 \\
\end{array}$ & $\begin{array}{c}7.6 \\
19.9 \\
6.6 \\
\end{array}$ & $\begin{array}{l}\text { moderately slow } \\
\text { moderately slow } \\
\text { moderately slow }\end{array}$ & $\begin{array}{l}\text { moderate } \\
\text { moderate } \\
\text { moderate }\end{array}$ \\
\hline $\begin{array}{l}\text { Pasture on } \\
\text { greywacke }\end{array}$ & $\begin{array}{l}1 / \mathrm{D} 1 \\
1 / \mathrm{D} 2 \\
1 / \mathrm{D} 3 \\
\end{array}$ & $\begin{array}{l}130 \\
130 \\
150 \\
\end{array}$ & $\begin{array}{c}3.3 \\
13.0 \\
8.1 \\
\end{array}$ & $\begin{array}{l}\text { slow } \\
\text { moderately slow } \\
\text { moderately slow }\end{array}$ & $\begin{array}{l}\text { slow } \\
\text { moderate } \\
\text { moderate } \\
\end{array}$ \\
\hline $\begin{array}{l}\text { Pasture on loess } \\
\text { downland }\end{array}$ & $\begin{array}{l}1 / E 1 \\
1 / E 2 \\
1 / E 3\end{array}$ & $\begin{array}{l}150 \\
170 \\
160\end{array}$ & $\begin{array}{l}2.1 \\
5.2 \\
7.0\end{array}$ & $\begin{array}{l}\text { slow } \\
\text { moderately slow } \\
\text { moderately slow }\end{array}$ & $\begin{array}{l}\text { slow } \\
\text { moderate } \\
\text { moderate }\end{array}$ \\
\hline $\begin{array}{l}\text { Macrocarpa on } \\
\text { loess downland }\end{array}$ & $\begin{array}{l}1 / \mathrm{F} 1 \\
1 / \mathrm{F} 2 \\
1 / \mathrm{F} 3 \\
1 / \mathrm{M} 1 \\
1 / \mathrm{M} 2 \\
1 / \mathrm{M} 3 \\
1 / \mathrm{M} 4 \\
1 / \mathrm{M} 5 \\
\end{array}$ & $\begin{array}{l}150 \\
180 \\
150 \\
160 \\
160 \\
170 \\
150 \\
160 \\
\end{array}$ & $\begin{array}{c}3.1 \\
9.5 \\
6.9 \\
7.1 \\
6.7 \\
9.2 \\
10.4 \\
7.1 \\
\end{array}$ & $\begin{array}{l}\text { slow } \\
\text { moderately slow } \\
\text { moderately slow } \\
\text { moderately slow } \\
\text { moderately slow } \\
\text { moderately slow } \\
\text { moderately slow } \\
\text { moderately slow }\end{array}$ & $\begin{array}{l}\text { slow } \\
\text { moderate } \\
\text { moderate } \\
\text { moderate } \\
\text { moderate } \\
\text { moderate } \\
\text { moderate } \\
\text { moderate } \\
\end{array}$ \\
\hline $\begin{array}{l}\text { Pasture on } \\
\text { mudstone rolling } \\
\text { hill }\end{array}$ & $\begin{array}{l}1 / \mathrm{G} 1 \\
1 / \mathrm{G} 2 \\
1 / \mathrm{G} 3 \\
1 / \mathrm{H} 1 \\
1 / \mathrm{H} 2 \\
1 / \mathrm{H} 3 \\
1 / 11 \\
1 / 12 \\
1 / 13\end{array}$ & $\begin{array}{l}150 \\
150 \\
160 \\
170 \\
160 \\
160 \\
150 \\
150 \\
170\end{array}$ & $\begin{array}{c}3.5 \\
6.1 \\
4.6 \\
7.9 \\
4.5 \\
1.9 \\
10.7 \\
4.3 \\
6.0\end{array}$ & $\begin{array}{l}\text { slow } \\
\text { moderately slow } \\
\text { slow } \\
\text { moderately slow } \\
\text { slow } \\
\text { slow } \\
\text { moderately slow } \\
\text { slow } \\
\text { moderately slow }\end{array}$ & $\begin{array}{l}\text { slow } \\
\text { moderate } \\
\text { moderate } \\
\text { moderate } \\
\text { moderate } \\
\text { slow } \\
\text { moderate } \\
\text { moderate } \\
\text { moderate }\end{array}$ \\
\hline
\end{tabular}

Table 13 Summary statistics of $K_{s}$ for Takapau samples. Note, values for areas (G, H, I) have been averaged together to represent pasture on mudstone rolling hill.

\begin{tabular}{|l|c|c|c|c|c|c|c|}
\hline \multicolumn{1}{|c|}{$\boldsymbol{K}_{\boldsymbol{s}} \mathbf{m m} / \mathbf{h}^{-\mathbf{1}}$} & id & $\mathbf{n}$ & mean & $\boldsymbol{K}_{\boldsymbol{s}}$ class & $\mathbf{S D}$ & $\mathbf{S E}$ & $\begin{array}{c}\mathbf{9 5 \%} \mathbf{~ C l} \text { of } \\
\mathbf{M e a n}\end{array}$ \\
\hline Pasture on loess basin & 1A & 3 & 3.2 & slow & 0.83 & 1.09 & 1.14 to 5.26 \\
Pine on greywacke & 1B & 3 & 4.3 & moderate & 1.66 & 1.31 & 0.18 to 8.42 \\
Pasture on limestone & 1C & 3 & 11.4 & moderate & 7.41 & 3.90 & -7.01 to 29.81 \\
Pasture on greywacke & 1D & 3 & 8.1 & moderate & 4.85 & 2.87 & -3.95 to 20.15 \\
Pasture on loess downland & 1E & 3 & 4.8 & moderate & 1.88 & 0.52 & 1.22 to 3.5 \\
Macrocarpa on loess downland & 1F & 8 & 7.5 & moderate & 2.27 & 1.20 & 5.6 to 9.40
\end{tabular}




\begin{tabular}{|l|c|c|c|c|c|c|c|} 
Pasture on mudstone rolling hill & $1 \mathrm{G}$ & $\mathbf{9}$ & 5.5 & moderate & 2.59 & 0.86 & 3.51 to 7.49 \\
Takapau sub-catchment & - & $\mathbf{3 2}$ & $\mathbf{6 . 4}$ & moderate & $\mathbf{3 . 6 7}$ & $\mathbf{0 . 6 5}$ & $\mathbf{5 . 0 7}$ to $\mathbf{7 . 7 2}$ \\
\hline
\end{tabular}
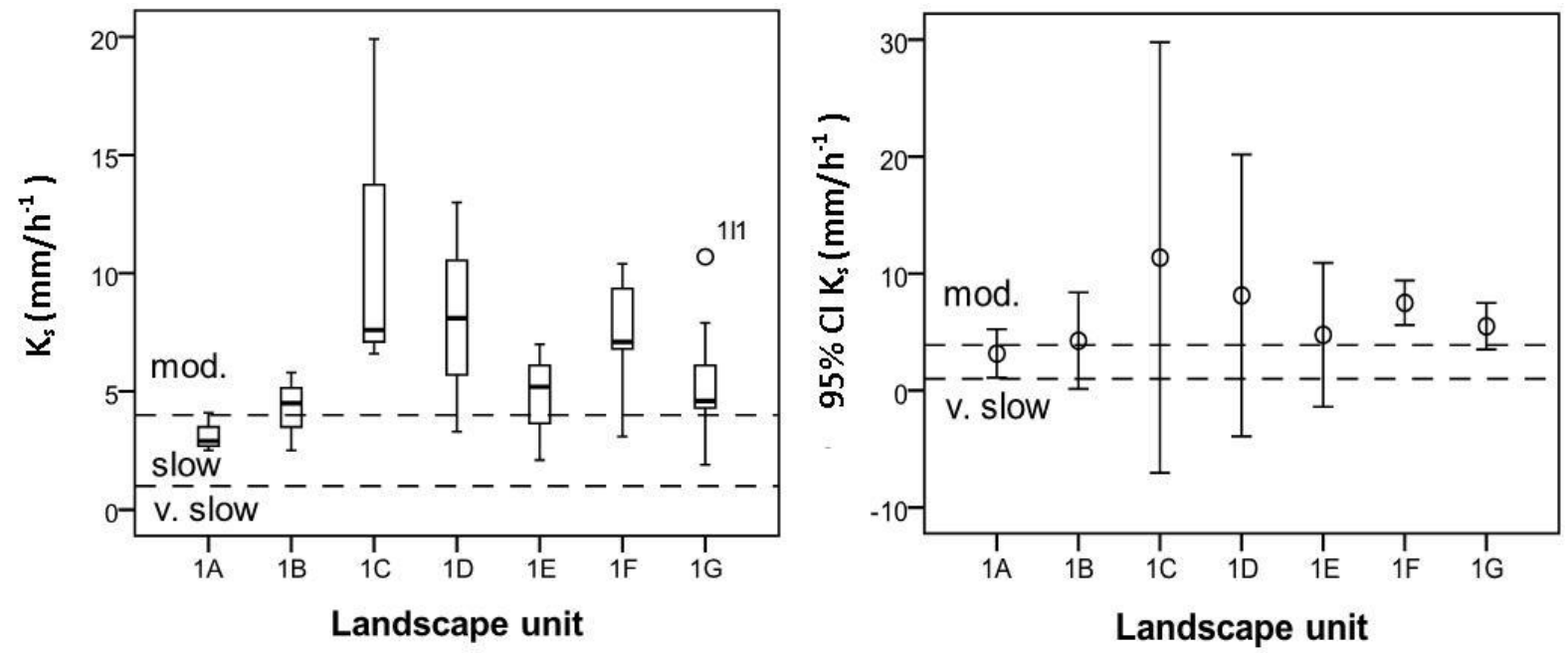

Figure 20 Mean $K_{s}$ at Takapau farms by landscape unit. Box and whisker plot shows the distribution of values ( $\min$, LQR, Med, UQR, Max) and where they lie in relation to the $K_{s}$ classes as defined in Griffiths (2004). The small circle shows any outliers. The second plot displays the mean for each landscape unit at the $95 \% \mathrm{Cl}$.

Table 14 Summary statistics at Takapau farms for $K_{s}$ by soil type

\begin{tabular}{|l|c|c|c|c|c|c|}
\hline \multicolumn{1}{|c|}{ Soil series/type } & $\mathbf{n}$ & mean $\boldsymbol{K}_{\boldsymbol{s}}$ & $\boldsymbol{K}_{\boldsymbol{s}}$ class & $\mathbf{S D}$ & $\mathbf{S E}$ & $\mathbf{9 5 \%} \mathbf{C l}$ of Mean \\
\hline Atua silt loam & 9 & 5.5 & moderate & 2.59 & 0.86 & 3.51 to 7.49 \\
Matapiro silt loam & 17 & 6.9 & moderate & 4.17 & 1.01 & 4.80 to 9.08 \\
Mangapakeha silt loam & 6 & 6.2 & moderate & 3.87 & 1.58 & 2.14 to 10.26 \\
\hline
\end{tabular}
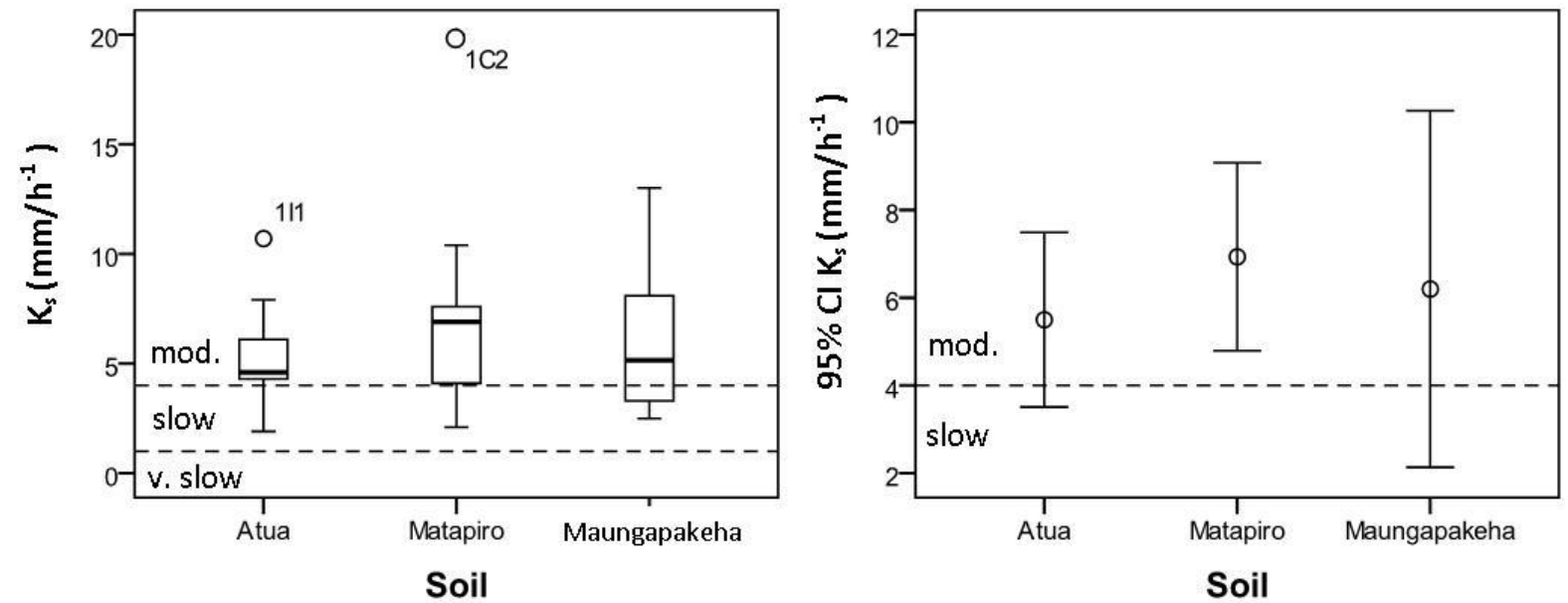

Figure 21 Mean $K_{s}$ at Takapau farms by soil type displayed as a box and whisker plot and $95 \% \mathrm{Cl}$. 

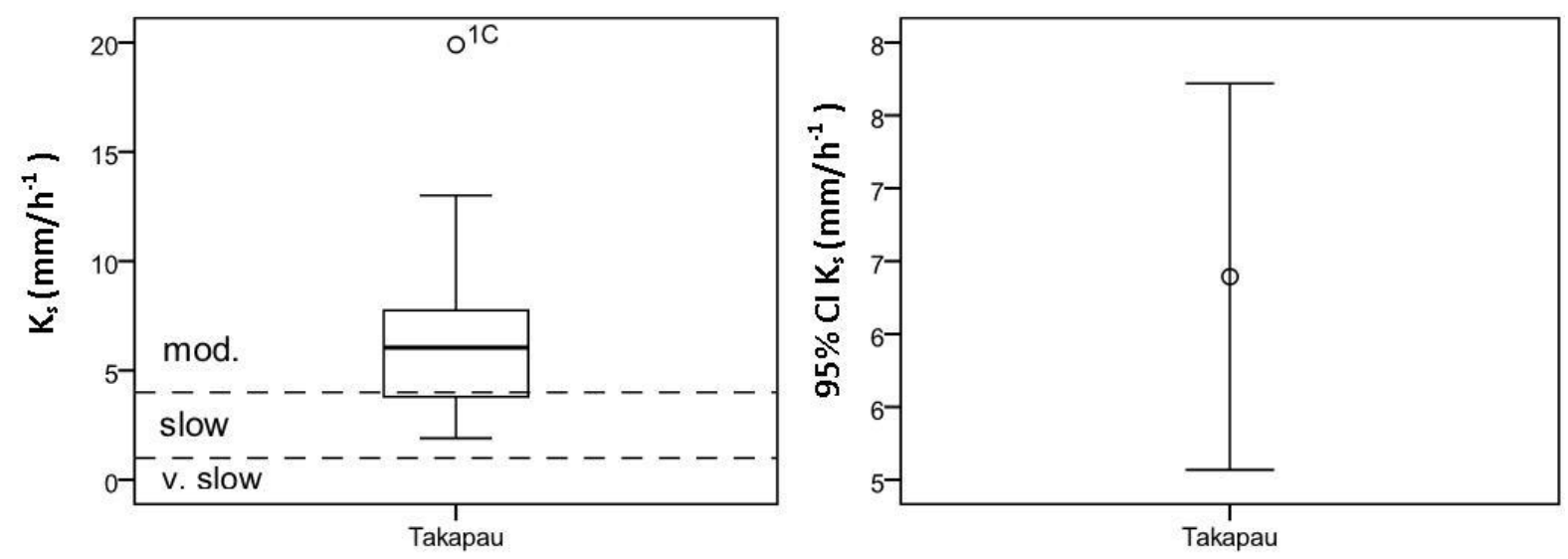

Figure 22 Mean $K_{s}$ over the entire Takapau farm displayed as a box and whisker plot and $95 \% \mathrm{Cl}$.

\subsubsection{Mananui farm}

Mananui farm had the same soil type, underlying geology, and land use throughout and so provided an opportunity to compare $K_{s}$ between slope angles. This was achieved by measuring $K_{s}$ along 5 transects which were divided into three sections (footslope, mid-slope, headslope) based on slope definitions in Milne et al. (1991) (Table 15). Table 16 displays the summary statistics with the head slope having the lowest mean $\left(4.86 \mathrm{~mm} / \mathrm{h}^{-1}\right)$ which was probably due to the shallow soil depth (low storage) and low slope angle (elevation head). While the mid-slope had the shallowest soil depth, its steep slope angle resulted in the highest mean $K_{s}\left(11.84 \mathrm{~mm} / \mathrm{h}^{-1}\right)$. The mean $K_{s}$ at the foot slope $\left(8.67 \mathrm{~mm} / \mathrm{h}^{-1}\right)$ fell between the first two due to a deeper soil profile which had more storage, but shallower slope angle which had less pressure potential. However, when comparing mean $K_{s}$ between slope angles using the one-way ANOVA test, a P-value of 0.164 was calculated indicating the differences were not significant at the $5 \%$ significance level. The mean values for all three slope units fell into the moderate category as did mean $K_{s}$ for the entire Mannaui farm $\left(8.4 \mathrm{~mm} / \mathrm{h}^{-1}\right)$. This range of values associated with the moderate class matched those listed in the NSD.

Table $15 K_{s}$ values from Mananui farm in $\mathrm{mm} / \mathrm{h}^{-1}$

\begin{tabular}{|l|c|c|c|l|l|}
\hline $\begin{array}{c}\text { Mananui } \\
\text { farm }\end{array}$ & $\begin{array}{c}\text { Sample } \\
\text { no. }\end{array}$ & $\begin{array}{c}\text { Depth of } \\
\text { well }(\mathbf{m m})\end{array}$ & $\boldsymbol{K}_{s}\left(\mathbf{m m} / \mathbf{h}^{-1}\right)$ & \multicolumn{2}{|c|}{$\boldsymbol{K}_{s}$ Class } \\
(USDA 2010) & \multicolumn{1}{|l|}{ (Griffiths 2004) } \\
\hline Foot slope & 2/A1 & 160 & 8.5 & moderately slow & moderate \\
& 2/A2 & 160 & 3.0 & slow & slow \\
& 2/A3 & 180 & 0.3 & very slow & very slow \\
& 2/A4 & 170 & 15.7 & moderately slow & moderate \\
& 2/A5 & 150 & 11.7 & moderately slow & moderate \\
& 2/A6 & 150 & 12.8 & moderately slow & moderate \\
\hline Mid-slope & 2/B1 & 160 & 3.9 & slow & slow \\
& 2/B2 & 150 & 9.5 & moderately slow & moderate \\
& 2/B3 & 150 & 19.1 & moderately slow & moderate \\
& 2/B4 & 160 & 9.7 & moderately slow & moderate \\
\hline
\end{tabular}




\begin{tabular}{|l|l|l|c|l|l|}
\hline & 2/B5 & 140 & 17.0 & moderately slow & moderate \\
\hline Head slope & $2 / \mathrm{C} 1$ & 200 & 5.2 & moderately slow & moderate \\
& 2/C2 & 160 & 1.2 & slow & slow \\
& 2/C3 & 170 & 2.7 & slow & slow \\
& 2/C4 & 160 & 4.6 & slow & slow \\
& 2/C5 & 140 & 10.6 & moderately slow & moderate \\
\hline
\end{tabular}

Table 16 Summary statistics of $\boldsymbol{K}_{s}$ for Mananui samples.

\begin{tabular}{|l|c|c|c|c|c|c|c|}
\hline \multicolumn{1}{|c|}{$\boldsymbol{K}_{\boldsymbol{s}} \mathbf{~} \mathbf{m} / \mathbf{h}^{\mathbf{- 1}}$} & id & $\mathbf{n}$ & mean & $\boldsymbol{K}_{\boldsymbol{s}}$ class & $\mathbf{S D}$ & $\mathbf{S E}$ & $\mathbf{9 5 \%} \mathbf{C l}$ of Mean \\
\hline Foot slope & 2A & 6 & 8.67 & moderate & 5.96 & 2.43 & 2.41 to 14.93 \\
Mid-slope & 2B & 5 & 11.84 & moderate & 6.17 & 3.02 & 4.18 to 19.51 \\
Head slope & 2C & 5 & 4.86 & moderate & 3.58 & 1.69 & 0.42 to 9.30 \\
Mananui & - & $\mathbf{1 6}$ & $\mathbf{8 . 4 6}$ & moderate & $\mathbf{5 . 7 9}$ & $\mathbf{1 . 4 5}$ & $\mathbf{5 . 3 8}$ to $\mathbf{1 1 . 5 6}$ \\
\hline
\end{tabular}
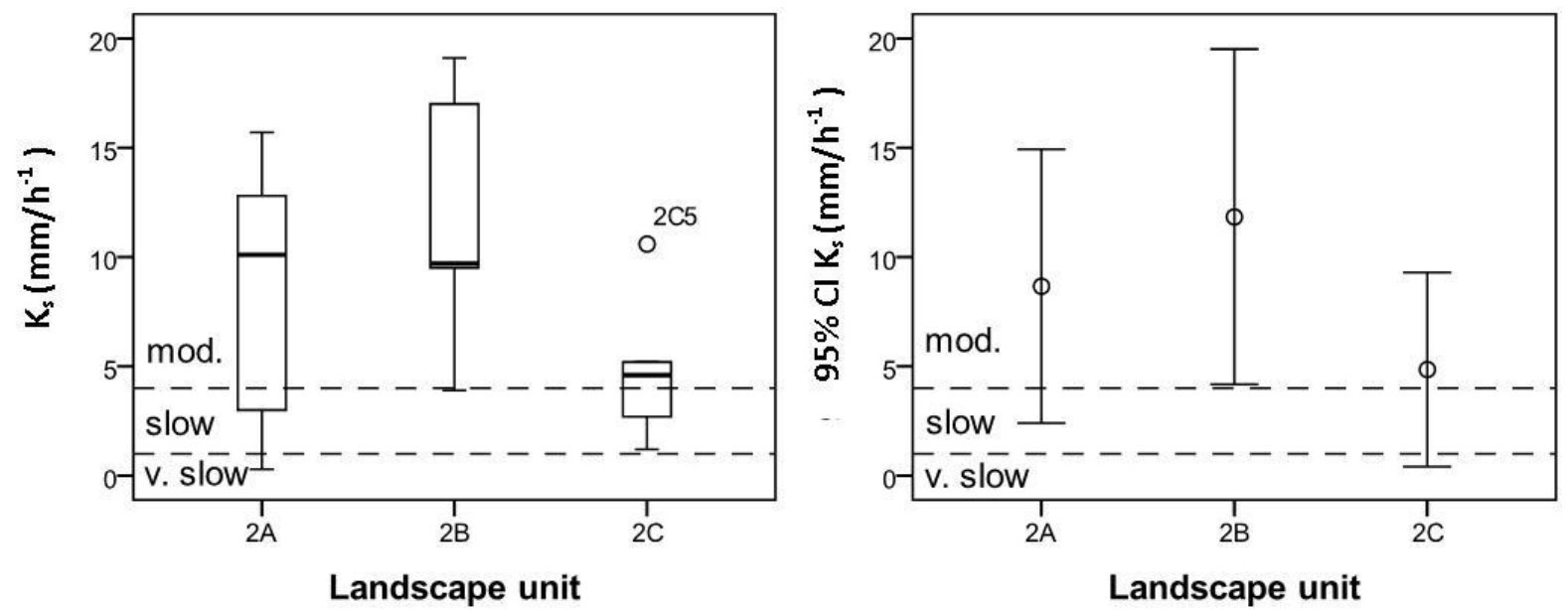

Figure 23 Mean $K_{s}$ at Mananui farm by landscape unit. Box and whisker plot shows the distribution of values and where they lay in relation to the $K_{s}$ classes. The second plot displays the mean for each landscape unit at the $95 \% \mathrm{Cl}$.
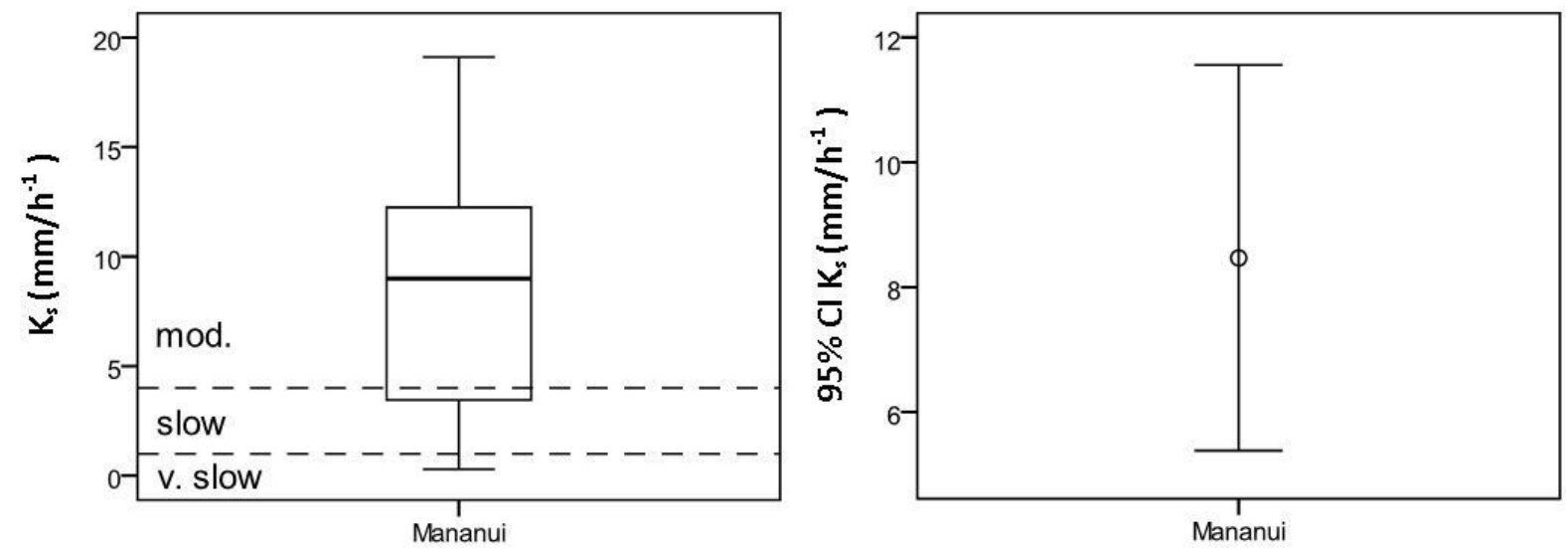

Figure 24 Mean $K_{s}$ over the entire Mananui farm displayed as a box and whisker plot and $95 \% \mathrm{Cl}$. 


\subsection{Bulk density and depth to slowly permeable layer}

\subsubsection{Bulk density}

The general trend at both study areas is an increase in bulk density $(\rho)$ with depth. At Takapau farms the first $6 \mathrm{~cm}$ of the A horizon had a mean $\rho$ of $1.10 \mathrm{~g} / \mathrm{cm}^{3}$, at $10-20 \mathrm{~cm} 1.42 \mathrm{~g} / \mathrm{cm}^{3}$, and at $40-90 \mathrm{~cm}$ (fragipan) $1.56 \mathrm{~g} / \mathrm{cm}^{3}$. The mean $\rho$ at Mananui farm was similar with $1.10 \mathrm{~g} / \mathrm{cm}^{3}, 1.37 \mathrm{~g} / \mathrm{cm}^{3}$, and $1.54 \mathrm{~g} / \mathrm{cm}^{3}$ respectively. Each bulk density core was extracted using the driving hammer technique (Chapter 4, section 4.2.4). As the carving method is considered more accurate due to less disturbance of the soil a correction factor of $+6 \%$ for the A-horizon samples and $+3.5 \%$ for the fragipan was used to adjust the data to an equivalent obtained by carving as suggested by Parfitt et al. (2010). The original bulk density data can be found in appendix A.

Table 17 Summary statistics for bulk density at Takapau farms

\begin{tabular}{|l|c|c|c|c|c|}
\hline \multicolumn{1}{|c|}{ Depth (cm) } & $\mathbf{n}$ & mean $\mathbf{( g / \mathbf { c m } ^ { 3 } )}$ & $\mathbf{S D}$ & $\mathbf{S E}$ & $\mathbf{9 5 \%}$ Cl of Mean \\
\hline 0-6 (A-horizon) & 30 & 1.10 & 0.12 & 0.02 & 1.06 to 1.14 \\
10-40 (A-horizon) & 18 & 1.42 & 0.22 & 0.05 & 1.31 to 1.53 \\
40-90 (fragipan) & 9 & 1.56 & 0.15 & 0.05 & 1.44 to 1.68 \\
\hline
\end{tabular}
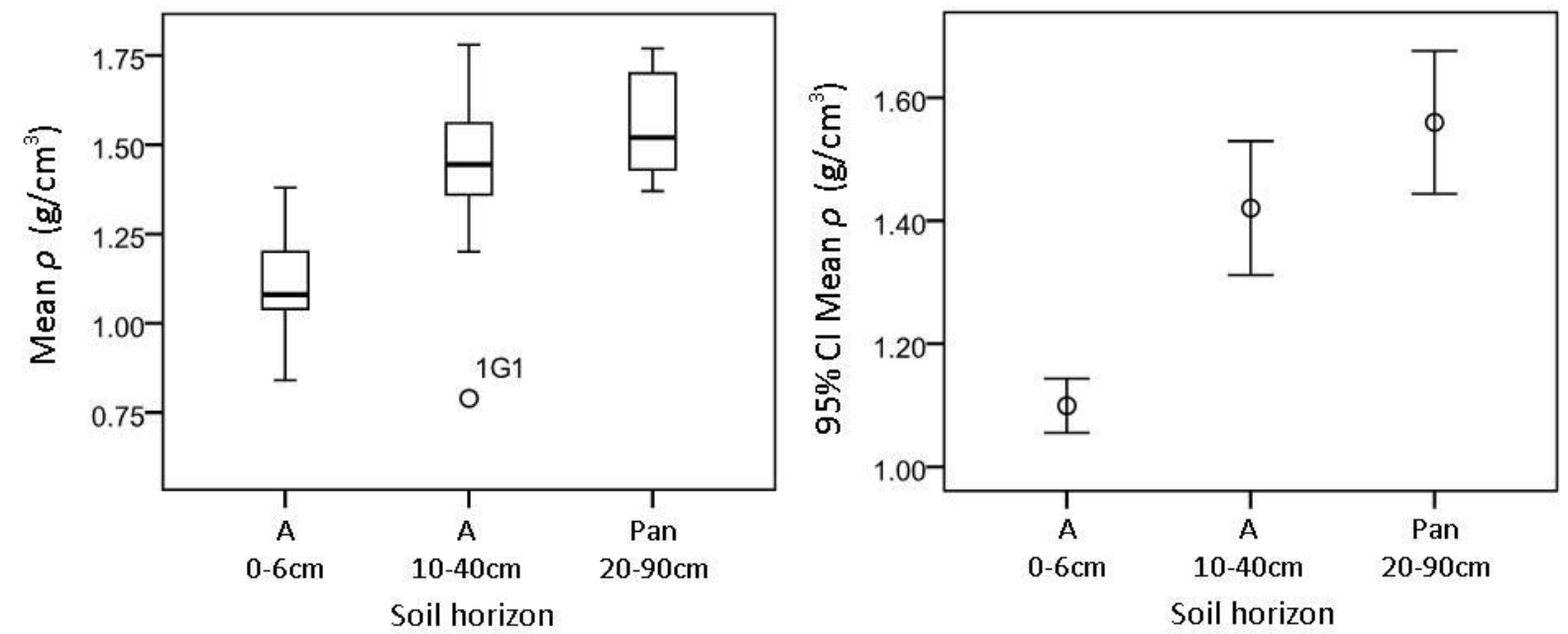

Figure 25 Box-and-whisker plot and 95\% confidence interval for mean bulk density at Takapau farms at different soil horizons.

Table 18 Summary statistics for bulk density at Mananui farm

\begin{tabular}{|l|c|c|c|c|c|}
\hline \multicolumn{1}{|c|}{ Depth $\mathbf{( c m )}$} & $\mathbf{n}$ & mean $\left(\mathbf{g} / \mathbf{c m}^{\mathbf{3}}\right)$ & $\mathbf{S D}$ & $\mathbf{S E}$ & $\mathbf{9 5 \%} \mathbf{C l}$ of Mean \\
\hline 0-6 (A-horizon) & 16 & 1.10 & 0.08 & 0.02 & 1.06 to 1.14 \\
10-40 (A-horizon) & 11 & 1.37 & 0.16 & 0.05 & 1.26 to 1.48 \\
40-90 (fragipan) & 3 & 1.54 & 0.17 & 0.10 & 1.12 to 1.96 \\
\hline
\end{tabular}



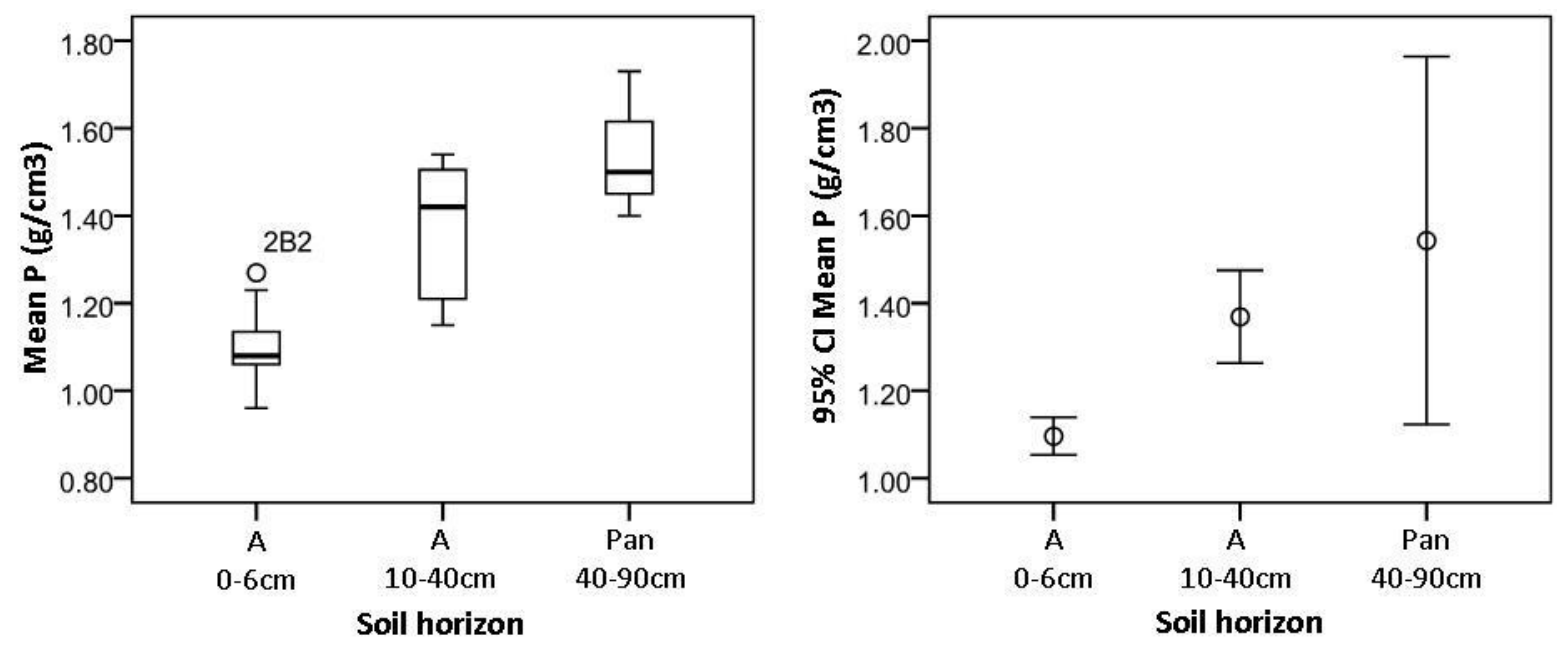

Figure 26 Box-and-whisker plot and 95\% confidence interval for mean bulk density at Mananui farm at different soil horizons.

\subsubsection{Depth to slowly permeable layer}

The NSD lists 'depth to slowly permeable layer' (DSLO). At Takapau farms it lists the DSLO as min $150 \mathrm{~cm}$, max $300 \mathrm{~cm}$, mid $225 \mathrm{~cm}$ for the Atua and Mangapakeha silt loam. However, bulk density and field pits have shown that in places the Atua and Mangapakeha pan can be as shallow as $17 \mathrm{~cm}$ and $10 \mathrm{~cm}$ respectively. The NSD lists the DSLO for the Matapiro silt loam as $\min 0 \mathrm{~cm}$, max $44 \mathrm{~cm}$, mid $22 \mathrm{~cm}$, which is generally consistent with the values recorded in the field. At Mananui farm the DSLO for Mangatahi sandy loam is $\min 150 \mathrm{~cm}$, $\max 300 \mathrm{~cm}$, mid $225 \mathrm{~cm}$. Again, the bulk density and field observations have shown that in places the Mangatahi pan can be as shallow as $12 \mathrm{~cm}$. For this reason the observations made in the field will be used to add greater detail to the values held in the NSD. The original DSLO data can be found in appendix B.

Table 19 Summary statistics for DSLO by soil series

\begin{tabular}{|l|c|c|c|c|c|c|c|c|}
\hline \multicolumn{1}{|c|}{ Depth $\mathbf{( c m )}$} & $\mathbf{n}$ & $\begin{array}{c}\mathbf{m i n} \\
(\mathbf{c m})\end{array}$ & $\begin{array}{c}\mathbf{m a x} \\
\mathbf{( c m})\end{array}$ & $\begin{array}{c}\text { med } \\
(\mathbf{c m})\end{array}$ & $\begin{array}{c}\text { mean } \\
(\mathbf{c m})\end{array}$ & SD & SE & $\mathbf{9 5 \%} \mathbf{C l}$ of Mean \\
\hline Atua & 9 & 17 & 60 & 28 & 35.0 & 16.8 & 5.59 & 22.11 to 47.89 \\
Mangatahi & 16 & 12 & 46 & 25 & 24.6 & 8.6 & 2.14 & 20.00 to 29.12 \\
Matapiro & 12 & 20 & 35 & 30 & 28.9 & 5.6 & 1.61 & 25.21 to 22.29 \\
Maungapakeha & 6 & 10 & 30 & 22.5 & 22.0 & 7.9 & 3.22 & 13.74 to 30.26 \\
\hline
\end{tabular}




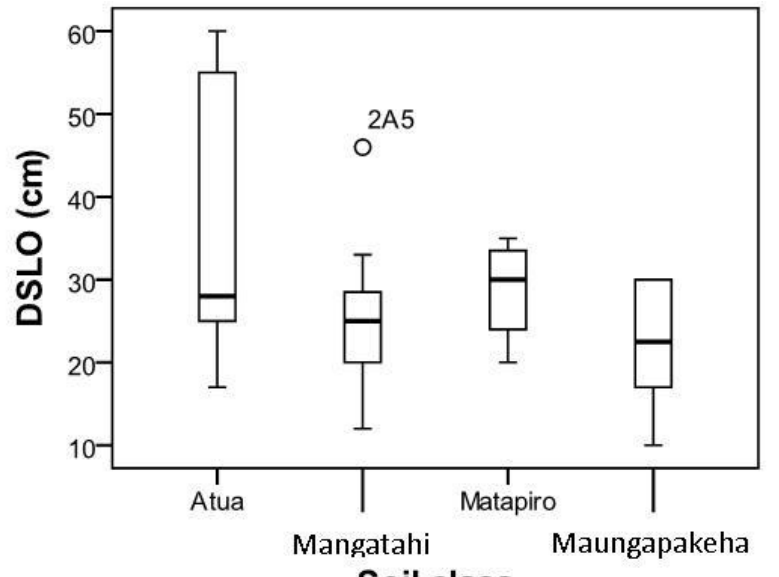

Soil class

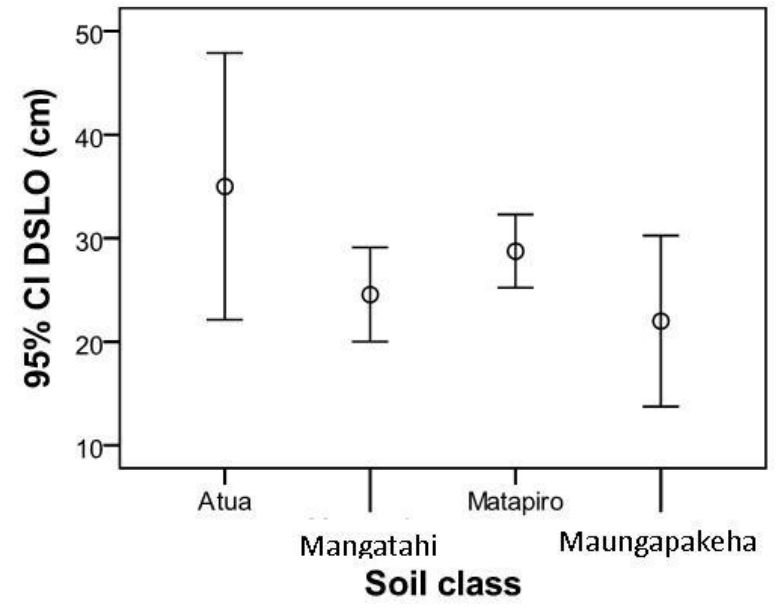

Soil class

Figure 27 Box-and-whisker plot and 95\% confidence interval for DSLO by soil series

\subsection{The effects of trees}

This section displays the results and statistical analysis from the macrocarpa shelterbelt and isolated poplar trees followed by a discussion of the likely reasons for such results. The data sets in this section were examined for normality using the Shapiro-Wilk test together with a visual inspection of the histogram. All data was assessed as normally distributed (Tables 20 and 21) and the ANOVA and parametric $t$-tests were used to examine whether there were any significant differences in mean hydraulic conductivity and bulk density values at 1,5 , and $10 \mathrm{~m}$. Note that the data for this experiment was gathered during a wet spring period (Sep 2010). The extremely wet conditions on both farms caused problems with the Guelph Permeameter (discussed below) which might have resulted in underestimates of hydraulic conductivity.

\subsubsection{Macrocarpa (Cupressus macrocarpa) shelterbelt}

\section{a) Results and statistical analysis}

The macrocarpa shelterbelt was planted along the boundry between Mr Folley's and Mr Chapman's farms. It runs in a northeast-southwest direction for approximately $1.2 \mathrm{~km}$ through the loess downland area and varies in height between 12 to 15 metres (Figure 30). Hydraulic conductivity and bulk density measurements were taken in the A-horizon at 1, 5 and $10 \mathrm{~m}$ from the base of the trees. At $1 \mathrm{~m}$ the sample area lay inside a boundary fence which excluded livestock (cattle and sheep). At 5 and $10 \mathrm{~m}$ the same measurements were taken again although these fell outside the fence and were thus affected by animal treading (surface compaction) and grazing. The results showed mean $K_{s}$ decreased with distance from the trees. There was a 78\% decrease in mean $K_{s}$ between 1 and $5 \mathrm{~m}$, and an $81 \%$ reduction between 1 and $10 \mathrm{~m}$. This means the soil beneath the trees were 4.5 and 5.5 times more conductive than the pasture soil at 5 and $10 \mathrm{~m}$ respectively (Table 20). Comparing mean 
$K_{s}$ between samples at 1,5 and $10 \mathrm{~m}$ using the ANOVA test gave a P-value of 0.00 indicating the differences are highly significant at the $5 \%$ significance level. Mean bulk density increased by $9.4 \%$ between 1 and $5 \mathrm{~m}$, and $12 \%$ between 1 and 10m (Table 21). Comparing the $\rho$ values using ANOVA gave a P-value of 0.068 indicating the differences are not significant at the $5 \%$ significance level. However, at the $10 \%$ level the differences become significant indicating there is a trend in the data suggesting a slight increase in surface compaction away from the trees.

Table 20 Summary statistics and test of normality of mean hydraulic conductivity at 1,5 and $10 \mathrm{~m}$ from macrocarpa shelterbelt and poplars.

\begin{tabular}{|l|c|c|c|c|c|c|c|}
\hline Tree & $\begin{array}{c}\text { Distance } \\
\text { from tree }\end{array}$ & $\mathbf{n}$ & $\begin{array}{c}\text { mean } \boldsymbol{K}_{\mathbf{s}} \\
\left(\mathbf{m m} / \mathbf{h}^{-1}\right)\end{array}$ & SD & SE & $\begin{array}{c}\mathbf{9 5 \%} \text { Cl of } \\
\text { Mean }\end{array}$ & $\begin{array}{c}\text { Shapiro-Wilk } \\
\text { (Sig.) }\end{array}$ \\
\hline \multirow{3}{*}{ Macrocarpa } & $1 \mathrm{~m}$ & 5 & 8.10 & 1.62 & 0.72 & 6.09 to 10.11 & 0.286 \\
& $5 \mathrm{~m}$ & 5 & 1.80 & 1.06 & 0.47 & 0.49 to 3.11 & 0.287 \\
& $10 \mathrm{~m}$ & 5 & 1.46 & 1.05 & 0.47 & 0.16 to 2.76 & 0.062 \\
\hline \multirow{3}{*}{ Poplar } & $1 \mathrm{~m}$ & 4 & 3.53 & 3.96 & 1.98 & -2.78 to 9.83 & 0.135 \\
& $5 \mathrm{~m}$ & 4 & 3.10 & 3.75 & 1.88 & -2.87 to 9.07 & 0.103 \\
& $10 \mathrm{~m}$ & 4 & 1.13 & 0.43 & 0.21 & 0.45 to 1.80 & 0.260 \\
\hline
\end{tabular}

Table 21 Summary statistics and test of normality for mean bulk density at 1, 5 and $10 \mathrm{~m}$ from macrocarpa shelterbelt and poplars.

\begin{tabular}{|l|c|c|c|c|c|c|c|}
\hline Tree & $\begin{array}{c}\text { Distance } \\
\text { from tree }\end{array}$ & $\mathbf{n}$ & $\begin{array}{c}\text { mean } \boldsymbol{\rho} \\
\left(\mathbf{g} / \mathbf{c m}^{\mathbf{3}}\right)\end{array}$ & SD & SE & $\begin{array}{c}\mathbf{9 5 \%} \text { Cl of } \\
\text { Mean }\end{array}$ & $\begin{array}{c}\text { Shapiro-Wilk } \\
\text { (Sig.) }\end{array}$ \\
\hline \multirow{3}{*}{ Macrocarpa } & $1 \mathrm{~m}$ & 5 & 0.96 & 0.03 & 0.02 & 0.88 to 1.03 & 0.637 \\
& $5 \mathrm{~m}$ & 5 & 1.06 & 0.10 & 0.04 & 0.94 to 1.18 & 0.890 \\
& $10 \mathrm{~m}$ & 5 & 1.09 & 0.05 & 0.02 & 1.03 to 1.15 & 0.563 \\
\hline \multirow{3}{*}{ Poplar } & $1 \mathrm{~m}$ & 4 & 0.95 & 0.36 & 0.18 & 0.37 to 1.52 & 0.135 \\
& $5 \mathrm{~m}$ & 4 & 1.08 & 0.10 & 0.05 & 0.92 to 1.23 & 0.103 \\
& $10 \mathrm{~m}$ & 4 & 0.99 & 0.11 & 0.05 & 0.81 to 1.16 & 0.260 \\
\hline
\end{tabular}



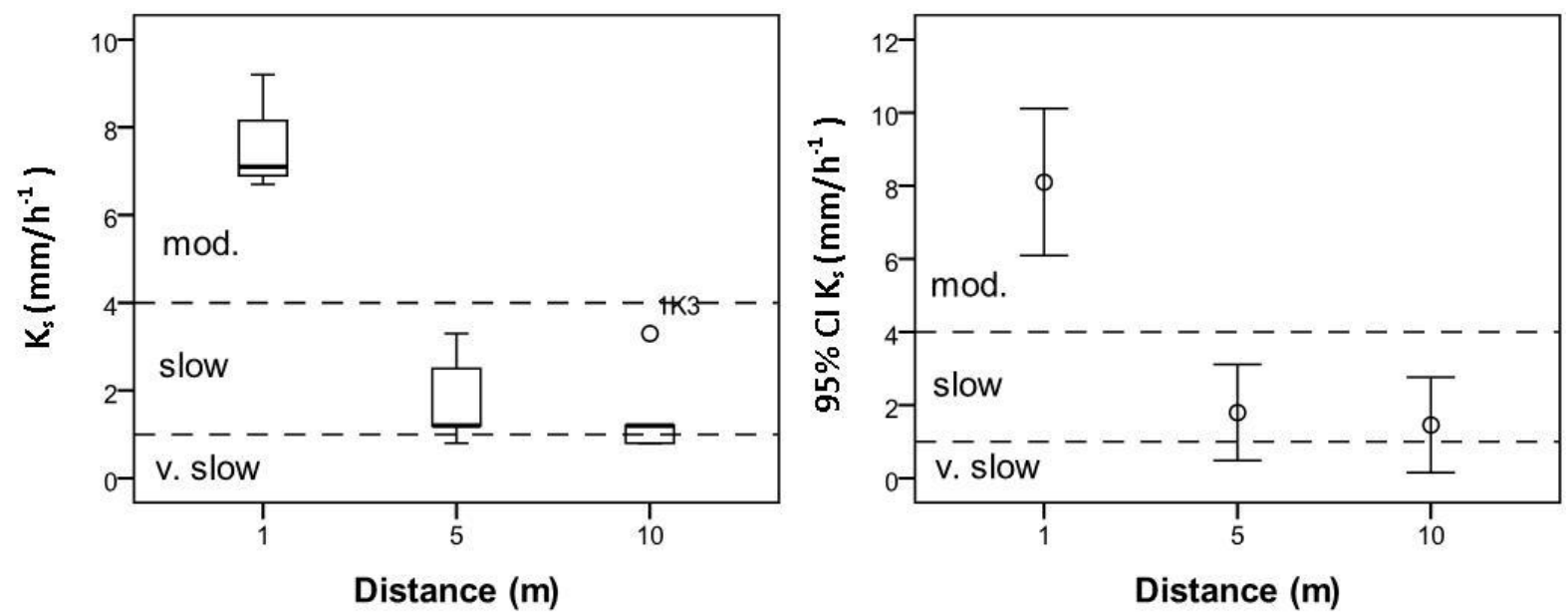

Figure 28 Box-and-whisker plot and $95 \%$ confidence interval for mean hydraulic conductivity at 1, 5 and $10 \mathrm{~m}$ spacing from macrocarpa shelterbelt.
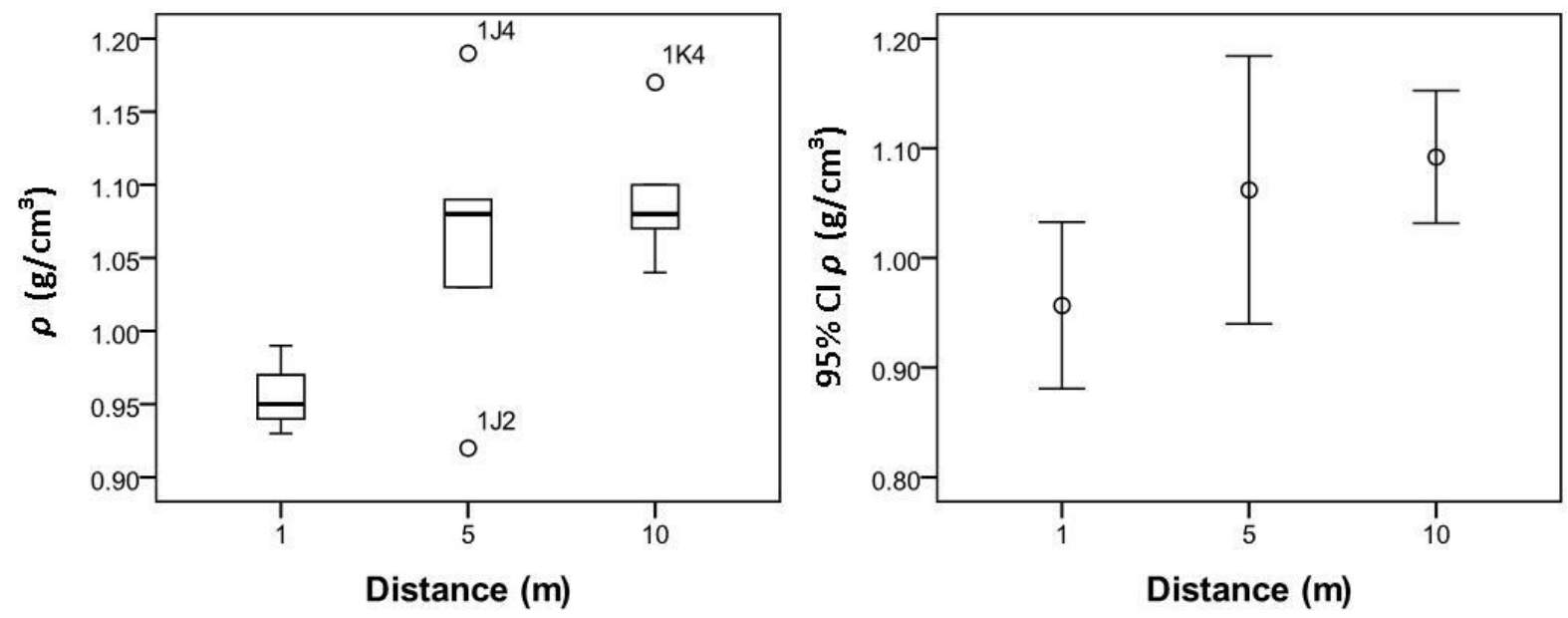

Figure 29 Box-and-whisker plot and $95 \%$ confidence interval for mean bulk density at 1, 5 and $10 \mathrm{~m}$ spacing from macrocarpa shelterbelt.

\section{b) Discussion of macrocarpa results}

The differences between 1 and $10 \mathrm{~m}$ can be attributed to the positive effects of trees (increased macroflow, protection against erosion, drying of the soil) and negative effects of livestock (grazing, soil compaction and erosion). This field work was undertaken during a particularly wet period when the soil on the farm was either saturated, or near saturated. This made vehicle access to most of the farm difficult. Through the processes of wet-canopy evaporation, root abstraction and leaf transpiration trees are able to dry the soil and indeed, under the trees (Figure 30) the soil was noticeably drier when compared to the same soil 5 and $10 \mathrm{~m}$ away. Unfortunately the soil moisture probe being used malfunctioned so soil moisture was not measured directly. As an alternative, soil 
moisture was derived indirectly through bulk density calculations based on USDA (2010) (outlined in Chapter 4 section 4.2.4).

Using this method, calculations implied at $1 \mathrm{~m}$ from the tree $23 \%$ of available pore space was filled with water. This contrasted with $80 \%$ and $85 \%$ water content at $5 \mathrm{~m}$ and $10 \mathrm{~m}$ respectively. In addition, increased macroflow around the roots would further increase the hydraulic conductivity of the soil. The decreasing $K_{s}$ at distance from the trees was exacerbated by livestock accumulating near the fence for shelter. Livestock can compact the soil decreasing permeability and graze and trample any vegetation which might increase infiltration and protect against erosion (Chapter 2, section 2.2). This effect can be clearly seen in Figure 31 which shows a loss in soil height of 6 to $12 \mathrm{~cm}$ which has exposed the tree roots outside the fence. The lack of grassy vegetation until about $6 \mathrm{~m}$ from the trees is probably a combination of livestock effects and competition for water from the shelterbelt itself.
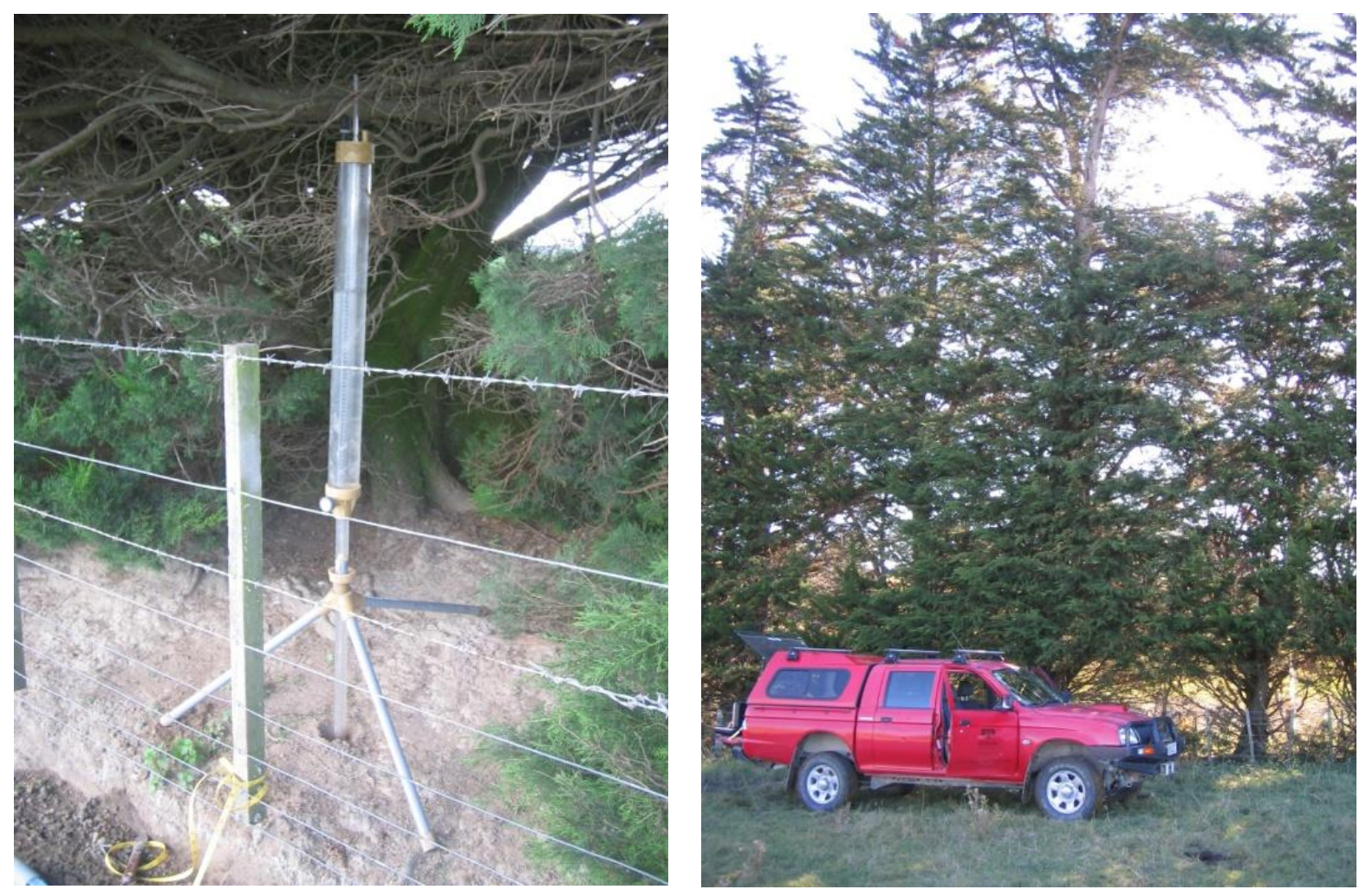

Figure 30 Measuring $K_{s}$ at $1 \mathrm{~m}$ from trunk of tree (left); height of trees at southern end of shelterbelt (right). 


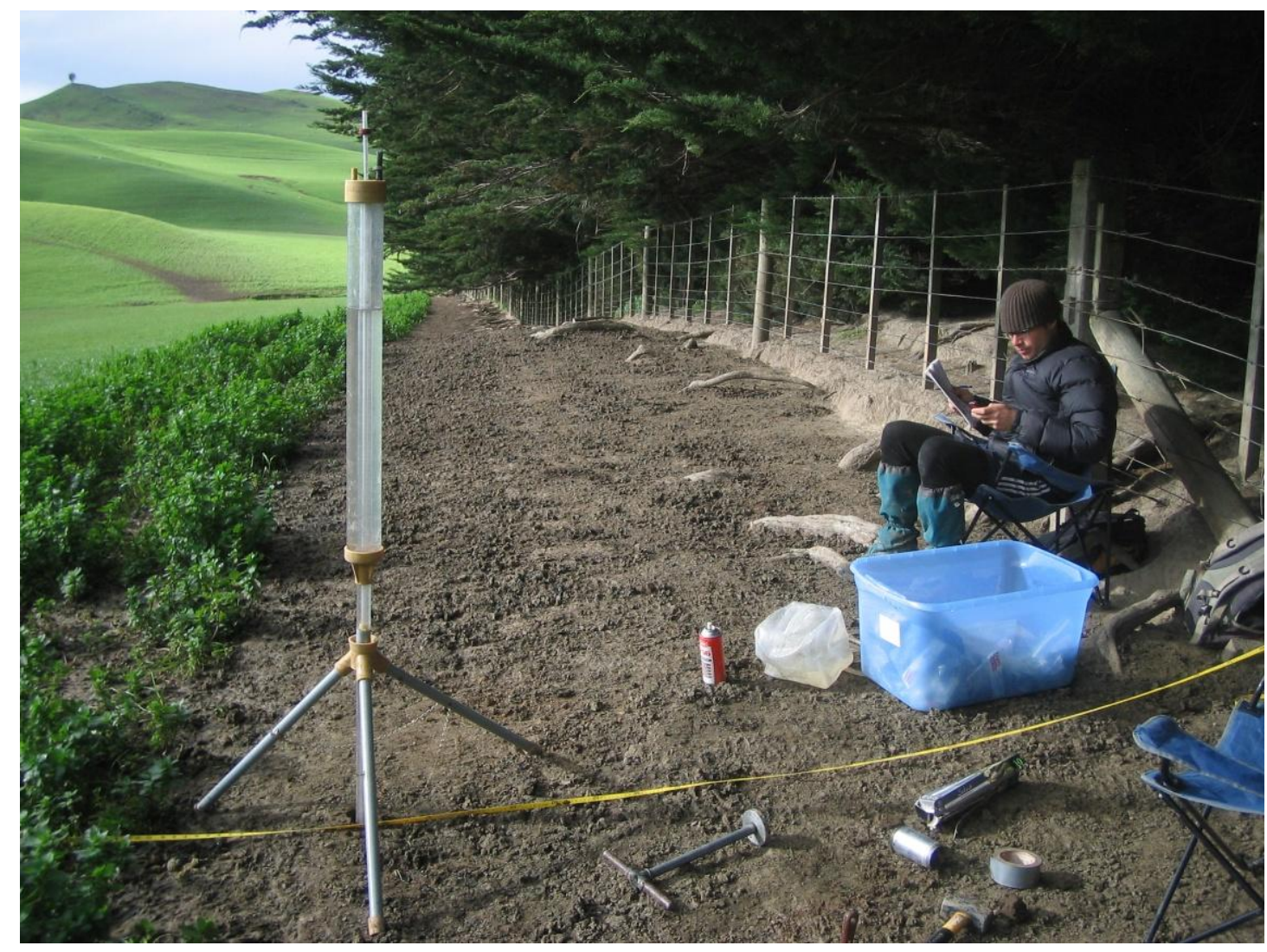

Figure 31 Measuring $K_{s}$ and bulk density at $5 \mathrm{~m}$ from the base of the macrocarpa shelterbelt. Note soil erosion and exposed roots outside of fence, and lack of vegetation until approximately $6 \mathrm{~m}$ from the fence.

\subsubsection{Poplars (Populus spp.)}

\section{a) Results and statistical analysis}

At Mananui farm 15 to 16 year old poplars had been planted in the gullies for stock shelter and aesthetic reasons. As at Takapau, measurements were taken at 1, 5 and $10 \mathrm{~m}$ from the base of the trees. The results were an overall $69 \%$ decrease in mean $K_{s}$ between 1 and $10 \mathrm{~m}$, meaning the soil at $1 \mathrm{~m}$ from the poplars was 3.1 times more conductive than the soil in pasture at $10 \mathrm{~m}$ (Table 20). The mean bulk density increased by $9 \%$ between 1 and 10m (Table 21). However, the ANOVA test found no statistical difference at the $5 \%$ significance level between $K_{s}$ and $\rho$ values at 1,5 and $10 \mathrm{~m}$ (P-value $0.542,0.709$ respectively). A visual inspection of the data found there was little difference in mean $K_{s}$ values between 1 and $5 \mathrm{~m}$ which could indicate that roots still have a significant effect at $5 \mathrm{~m}$. The Populus genus is characterised by wide reaching horizontal roots which can reach up to $30 \mathrm{~m}$ from the trunk (Pregitzer and Friend 1996). Therefore, the 1 and $5 \mathrm{~m}$ values were grouped together and then compared to the mean value at $10 \mathrm{~m}$ using the parametric t-test. At the $5 \%$ significance this produced a $K_{s}$ P-value of 0.031 meaning there was a statistical difference in hydraulic conductivity between the 1 to $5 \mathrm{~m}$ grouped data and $10 \mathrm{~m}$ values. For bulk density it produced a P-value of 0.274 
which is not significant meaning there is no statistical difference in surface compaction between sites. The similar bulk densities at all three distances can be attributed to livestock access to all areas.
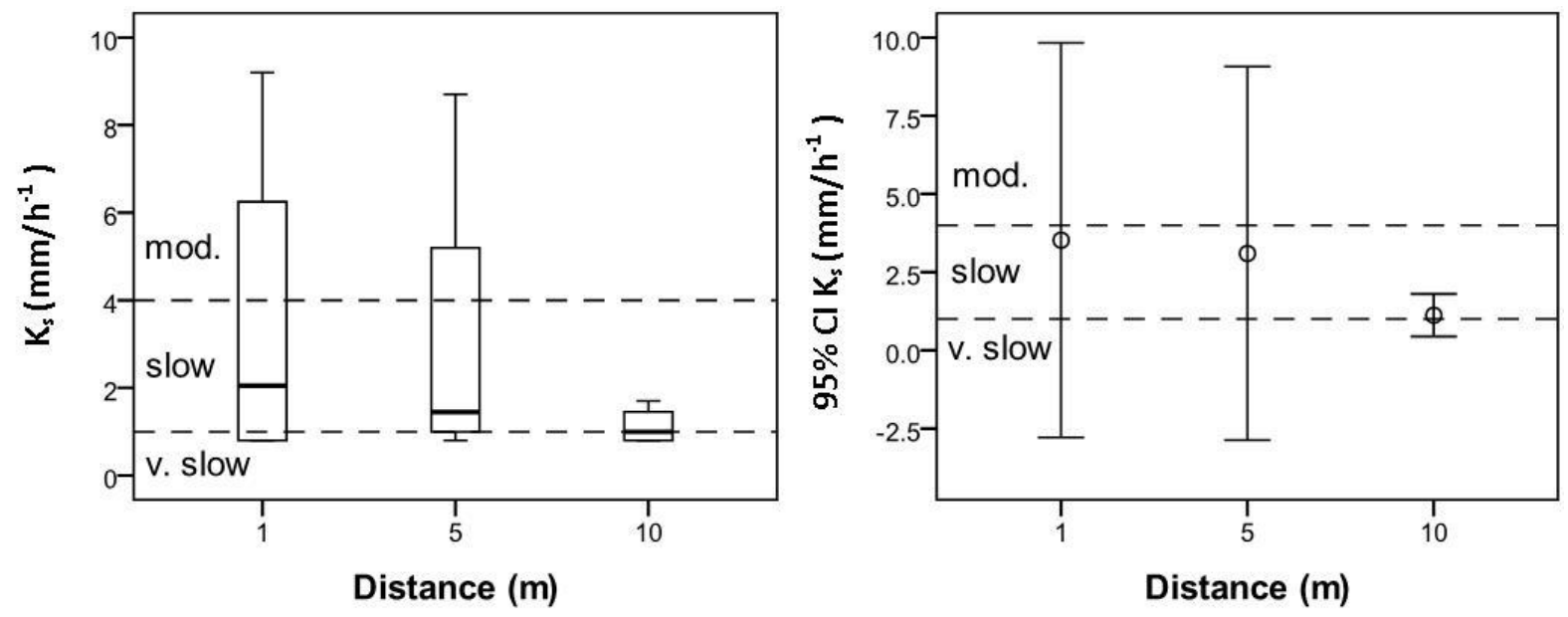

Figure 32 Box-and-whisker plot and 95\% confidence interval for mean hydraulic conductivity at 1, 5 and 10m spacing from poplar trees.
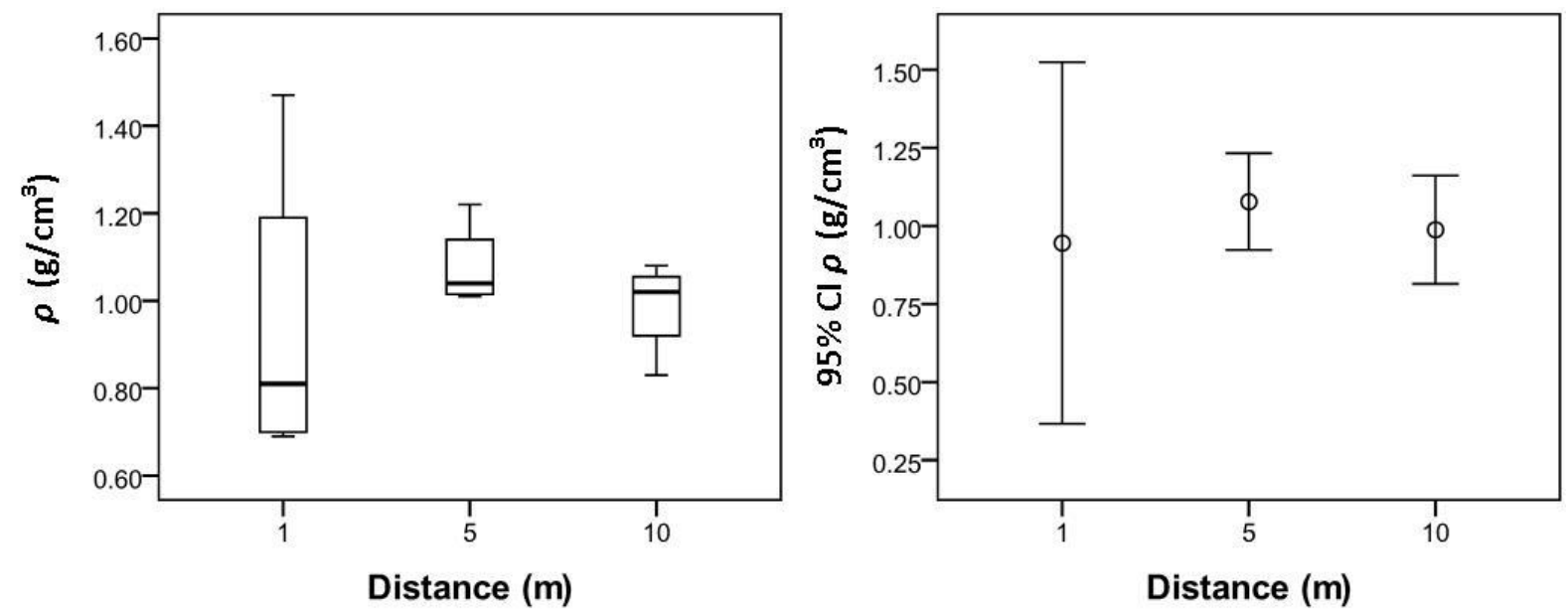

Figure 33 Box-and-whisker plot and 95\% confidence interval for mean bulk density at 1, 5 and 10m spacing from poplar trees.

\section{b) Discussion of poplar results}

Like Takapau, these measurements were taken during the wet spring period when the soils available pore space was filled on average to $82 \%$ capacity (compared to $36 \%$ during the dry period). Unlike Takapau, cattle and sheep were free to congregate underneath the trees which had resulted in extensive pugging around the base (Figure 35). Finding an appropriate tree to sample from was difficult due to the very wet conditions at the farm. The poplars were positioned within gullies which are natural drainage areas and in many places water was pooling at the base of the trees because 
the water table was high. This caused an artefact in the measurement as water would fill the borehole from the surrounding soil as well as the Guelph Permeameter reservoir. To mitigate the problem transects were positioned to extend slightly uphill where there was better drainage to avoid the water logged soil. The greater slope angle (elevation head) at 5 and $10 \mathrm{~m}$, coupled with the heavy treading at $1 \mathrm{~m}$ could explain why the differences in hydraulic conductivity between 1 and $10 \mathrm{~m}$ were not as high as observed at the macrocarpa shelterbelt. Another reason is the macrocarpas were planted close together creating a dense root network whereas the poplars were planted 15 to $20 \mathrm{~m}$ apart and thus could be assumed to have a less extensive root network. Due to wetness which created farm access issues, the only measurements taken during the spring were those at the poplars. Overall, mean $K_{s}$ during the wet period was $2.59 \mathrm{~mm} / \mathrm{h}^{-1}$ (slow) when compared to the mean $K_{s}$ over the drier summer period $8.46 \mathrm{~mm} / \mathrm{h}^{-1}$ (moderate). The summer period measured $K_{s}$ at hill slopes only with no values recorded at trees. Considering that in general, trees have higher conductivity rates than pasture (Table 1), one could assume that the tree values recorded during the spring are an underestimate due to the borehole problem mentioned above. A search of the literature found no reference to the borehole problem. However, during wet conditions a smear layer can increase the wall resistance to water flow in fine texture soils (Salverda and Dane 1993). As the sample sites had tiny proportions of clay and the well prep brush was used to remove the smear layer, it is likely that the error associated with the GP was due to invading water from the surrounding soil rather than the smear layer itself. For this reason as well as vehicle access to the farm further field work is recommended during drier antecedent soil conditions.
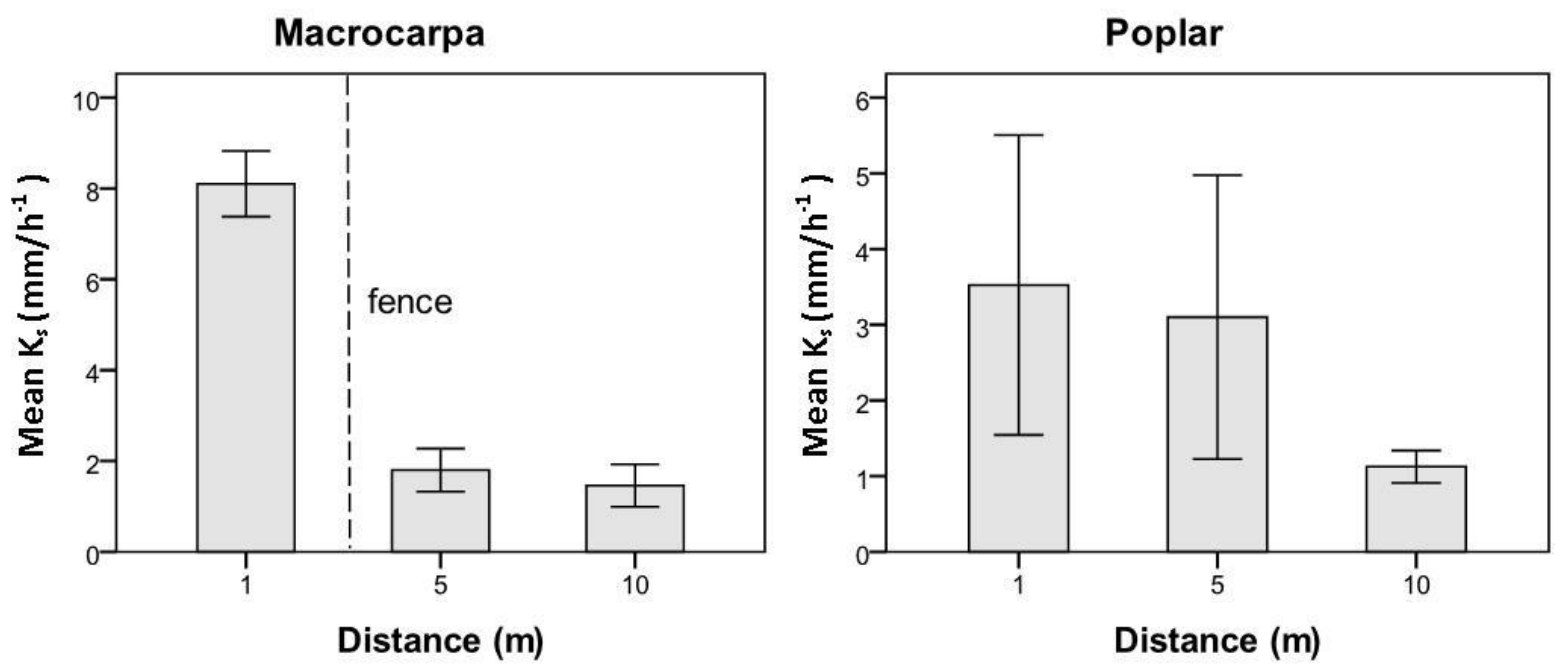

Figure 34 Saturated hydraulic conductivity near a macrocarpa shelterbelt and poplars at distances of 1, 5, and $10 \mathrm{~m}$ from the base of the trees. Bars give one standard error of the mean. 


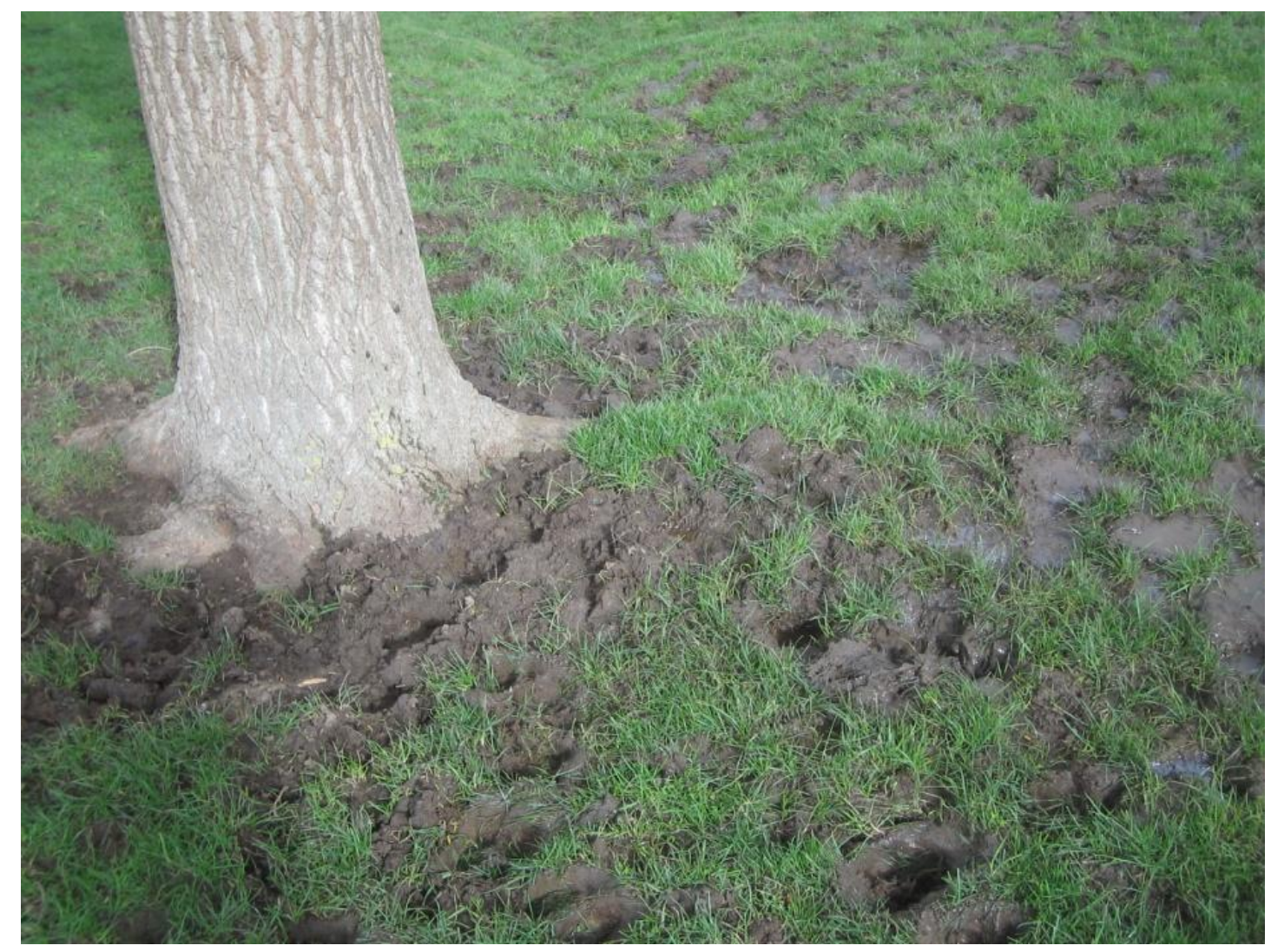

Figure 35 Extensive pugging at the base of a poplar. Note water pooling at surface.

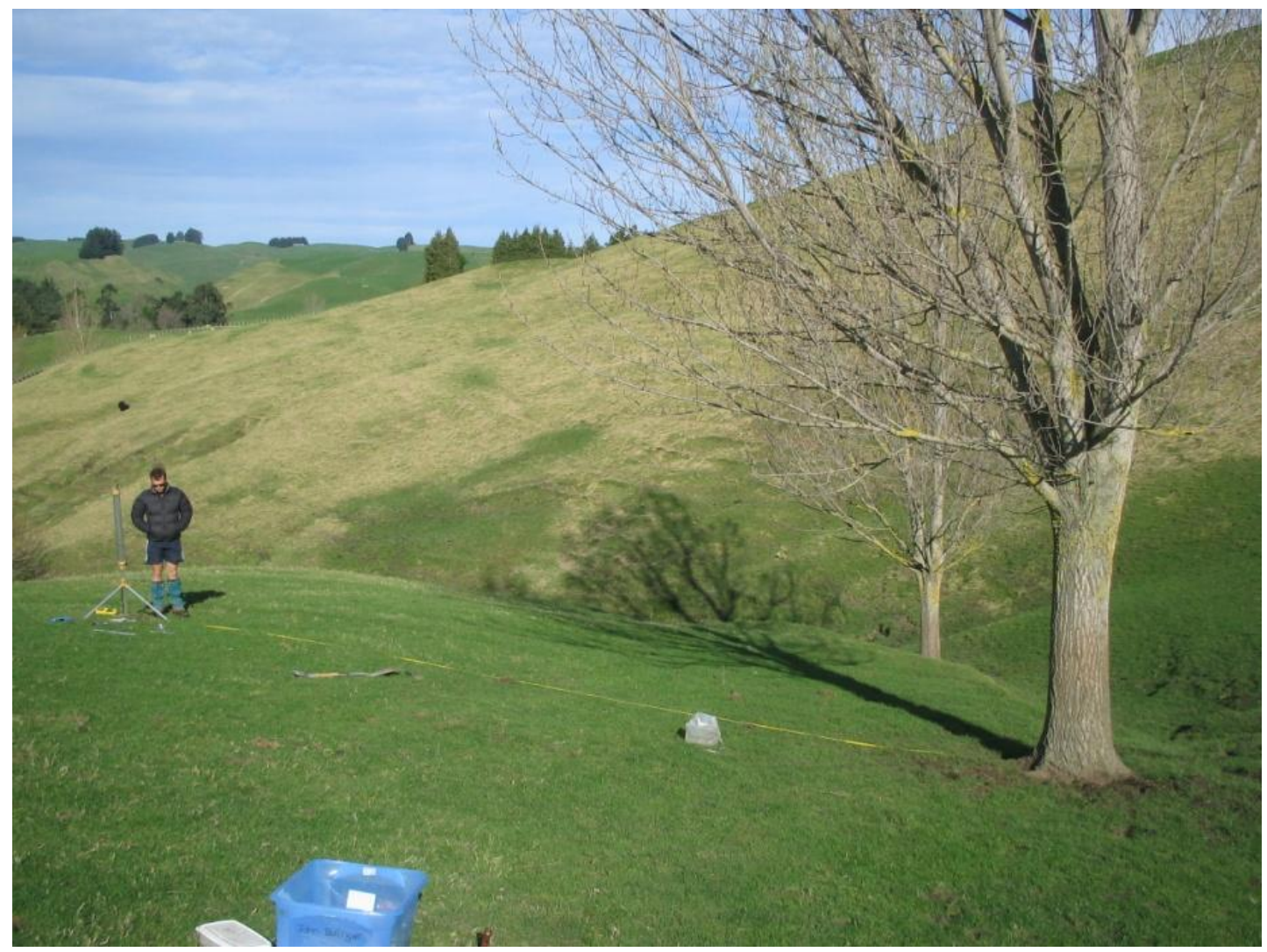

Figure 36 Measuring $K_{s}$ at $10 \mathrm{~m}$ mark from the trunk of a poplar 


\subsubsection{Summary of tree results}

The magnitude of increases in $K_{s}$ near trees at the study sites lie towards the lower end of the published values for forest versus pasture topsoil (Table 1). The lower values may be due to lower density of trees at the study sites compared to the published findings. Also, many species of tree have roots that extend horizontally beyond $10 \mathrm{~m}$, which includes the Macrocarpa and Populus genus's (Pregitzer and Friend 1996). Therefore their roots may have been affecting $K_{s}$ at both 5 and $10 \mathrm{~m}$. Furthermore, the wet conditions and resultant borehole problems as well as surface compaction from livestock will have also contributed to the lower values. The sample size in this study was small and further research with more replicates of trees of different ages, species, and density, as well as stock in/exclusion is merited. Additional sampling of soil $\mathrm{pH}$, structure, and worm abundance may also offer insights into the affects of soil acidity on $K_{s}$.

\subsection{Main findings from the experimental results}

Achieving objectives 1 and 2 formed the basis of the experimental design (Chapter 4). The following points summarise the main findings from the experimental results.

- Objective 1 - The National Soil Database information with the classes ( $m=$ measured directly) and ( $r$ = estimated from other soil properties) compared well with the measured field data and are suitable to inform modelling at the farm scale. The soils with these classes are the Matapiro, Takapau, Tukituki, and Mangatahi loams. The classes $(u=$ unknown level of accuracy) and ( $u f=$ estimated from General Soil Survey Data) compared poorly to the measured field data. The soils with these classes were the Atua and Mangapakeha silt loams. Any soil information from these classes would need to be ground truthed and corrected before they were used for reliable hydrological modelling at the farm scale. For this reason the additional soil $K_{s}$ and depth measurements taken in the field will be used to better represent both study areas.

- The land use data from the NZLRI broadly matched the land use classes observed on site. However, for greater accuracy additional digitizing to better represent the spatial position of landscape features was undertaken for the POLYSCAPE modelling in Chapter 6.

- Objective 2 - A limited study into the effects of tree shelter belts showed mean $K_{s}$ decreased with distance from the trees. At Takapau farms the macrocarpa shelterbelt had the greatest difference in conductivity with mean $K_{s}$ reduced by $86 \%$ between 1 and $10 \mathrm{~m}\left(8.1 \mathrm{~mm} / \mathrm{h}^{-1}\right.$, $\left.1.5 \mathrm{~mm} / \mathrm{h}^{-1}\right)$ and $13 \%$ increase in mean bulk density respectively $\left(0.96 \mathrm{~g} / \mathrm{cm}^{3}, 1.09 \mathrm{~g} / \mathrm{cm}^{3}\right)$. The high $K_{s}$ values at $1 \mathrm{~m}$ can be attributed to greater infiltration around the roots and stock 
exclusion from the shelterbelt. At Mananui farm poplar trees were positioned in gullies for aesthetics and stock shade. In these areas there was a $69 \%$ decrease in mean $K_{s}$ between 1 and $10 \mathrm{~m}\left(3.5 \mathrm{~mm} / \mathrm{h}^{-1}, 1.1 \mathrm{~mm} / \mathrm{h}^{-1}\right)$. However, there was no statistical difference in mean bulk density at the $95 \% \mathrm{Cl}$ due to livestock congregating underneath the trees. These results were used to set tree buffer assumptions in the POLYSCAPE modelling.

- In theory the field saturated technique using the Guelph Permeameter should not be affected by antecedent soil moisture; however near saturated soils appeared to retard $K_{s}$ values when comparing results obtained during drier soil conditions (see section 5.5.2). For this reason it is advisable to take these measurements during drier antecedent conditions.

- Further research with more replicates of trees of different ages, species, and density, as well as stock in/exclusion is merited. Additional sampling of soil $\mathrm{pH}$, structure, and worm abundance may also offer insights into the affects of soil acidity on $K_{s}$. 


\section{Chapter 6 - Flood modelling and POLYSCAPE}

The aim of Chapter 6 is to complete objectives 3, 4 and 5 as listed in Chapter 1:

3. Collect elevation, rainfall, evaporation, and soil moisture data from Hawkes Bay Regional Council and NIWA's National Climate Database (Cliflo).

4. To maximise flood mitigation benefits, calculate the optimal or near optimal locations for natural buffer placement using the flood mitigation tool within POLYSCAPE. Compare model output using six Digital Elevation Models (DEMs) of differing resolutions. These include two national scale DEMs $(25 \mathrm{~m})$ created by GeographX and Landcare Research, and four DEMs $(25 \mathrm{~m}, 10 \mathrm{~m}, 5 \mathrm{~m}, 1 \mathrm{~m})$ created from Light Detection and Ranging (LiDAR) data. This is to determine both the limits of DEM resolution appropriate for effective prediction of flood buffering effects at the farm scale, and to show the differences between the same resolution DEMs from different data sources.

5. Explore the flood mitigating effectiveness of natural buffers by simulating runoff response for nine different land use and rainfall scenarios. The land use layers include the farm under current land use (existing buffers); the farm with existing buffers removed; and the farm with additional strategically placed buffers. The rainfall simulations include a representative "wet" and "dry" record and the same records modified for a $1^{\circ} \mathrm{C}$ and $2^{\circ} \mathrm{C}$ change following national guidance (MfE 2010) to reflect potential climate change impacts.

First, as background for this chapter some fundamental concepts of rainfall-runoff modelling are briefly introduced (section 6.1) followed by commonly used flood and inundation models in New Zealand (section 6.2); Second, the POLYSCAPE toolbox is described with an emphasis on the flood mitigation tool (section 6.3); Third, the optimum locations for natural buffers are determined using different resolution DEMs with an assessment of DEM accuracy; and finally the chapter concludes by predicting runoff response under three rainfall scenarios and three land use scenarios giving a total of nine combinations using the flood mitigation tool within POLYSCAPE.

\subsection{General principles of hydrological modelling}

\subsubsection{Classifying rainfall-runoff models}

The two main purposes of hydrological modelling are to increase system understanding and to inform a number of hydrological management issues such as flood forecasting and inundation, integrated basin management, and prediction of the effects of change (Ibbitt et al. 2004). Although 
there is a need for good quantitative rainfall-runoff predictions for these problems, the degree to which current models can satisfy this demand is limited. This is because many of the processes that influence catchment runoff occur under the ground. Therefore, the application of hydrological models is constrained by the available measurement techniques and resulting data accuracy (Beven 2005). As a consequence, Beven (2005) states it is hard to predict hydrological response in any arbitrary catchment using data on topography, soils, and land use alone and refers to the "prediction in ungauged catchments problem" as outlined in Blöschl (2005). Many models rely on local calibration using measured rainfall input to compare both predicted and measured flow output in order to improve predictions. While in the past it was considered adequate to use an "optimised" model to make predictions, current approaches recognize the inherent uncertainties associated with model input, definition, and calibration. These issues are especially important when making hydrological predictions during more extreme conditions (e.g. floods and drought), and when trying to model flow response due to land use change (Beven 2005). For this reason, a number of techniques are in development for assessing model uncertainty including fuzzy modelling techniques (Bardossy 2005), "top down" approaches to modelling (Bai et al. 2009) and assessment in uncertainty in model calibration and prediction (Gupta et al. 2005). As mentioned above, part of this uncertainty arises from the model definition itself. A model by nature is a conception of reality. It represents a simplification of a complex system where only the components thought to be most significant to a problem are represented within the model. In general, the best models are considered to be those that achieve the greatest realism with the least amount of parameter and model complexity (Mulligan and Wainwright 2004). Hydrological models can broadly be classified by their degree of spatial representation. The most fundamental distinction in such a classification is between lumped and distributed models.

\section{a) Lumped versus distributed models}

Lumped hydrological models simplify a catchment into a single unit and relate precipitation input into flow output without explicitly considering the spatial patterns of the processes and characteristics of the catchment (Beven 2005). Early lumped models related flow output to rainfall input, catchment area, and a runoff coefficient (effectively a model parameter, see section 6.1.2). The main difficulty in applying this method was choosing the value of the coefficient, which represented local conditions within a catchment. This is especially difficult considering that catchment characteristics change depending on antecedent conditions. The effect of antecedent conditions on flow output is a non-linear problem in that rainfall under wet antecedent conditions will produce considerably greater flow than the same total rainfall under drier antecedent conditions (Beven 2005). This non-linearity problem is solved in part by the use of "lumped continuous 
simulation models" such as the Explicit Soil Moisture Accounting models (ESMA) e.g. the Stanford Watershed Model (Crawford and Lindsay 1966). ESMA models have several storage elements to represent different processes within a catchment (e.g. interception, upper \& lower soil moisture, groundwater etc) which are controlled by different parameters. The parameters must be estimated or calibrated for each area. The temporal changes in antecedent conditions are accounted for by continuously calculating the changes in storage in the model, but at the expense of introducing a considerable number of parameters (Beven 2005). This style of model can be made "semidistributed" by applying it within the study area's sub-catchments. Flow outputs from each subcatchment are then added together via a river routing algorithm to derive outflow for the entire catchment. This helps account for areas where spatial characteristics might be important e.g. large changes in rainfall with elevation, or extensive forest versus pasture cover (Beven 2005).

A "fully distributed" model attempts to predict the response from all the elements in a spatial discretisation of a catchment area. One common way of discretising is to break the catchment into grid cells based on raster digital elevation data and control volumes (Peckham 2009). Each element can have its own inputs and parameters. The more complex models include the prediction of flux in four dimensions ( 3 spatial and the temporal) and can potentially have thousands of parameters that must be defined (Beven 2005). In order to define all these parameters, some quantification of the variability in soil water, flow, and evapotranspiration rates for each element is required. In this way even the most complex models are effectively "lumped" at the sub-catchment element scale and therefore no model is ever "fully" distributed (Beven 2005). A further way to categorise hydrological models is to the degree in which they describe process.

\section{b) Empirical versus physically based models}

Empirical models are based on analysing observed data such as rainfall and flow output. They are usually based on the simplest mathematical function that best fits the observed relationships between variables. Empirical models are generally characterised by high predictive power but low descriptive depth and for this reason are only valid for the catchment where data was collected from (Mulligan and Wainwright 2004). Furthermore, if the length of record used for the calibration does not contain any data from extreme events then any predictions made during such events should be treated with caution. This is a particular problem in ungauged catchments and those that have short hydrological records (Beven 2001). The SCS method is an example of an empirical model that is frequently used for runoff prediction (AghaKouchak 2011).

Physically based models represent the physical processes in a catchment as observed in the real world. Typically, they contain representations of surface and subsurface flow, evapotranspiration, 
and channel flow, but can be much more complicated. Although distributed models have good descriptive depth, they are often characterized by poor predictive power i.e. they don't agree with observations (Mulligan and Wainwright 2004). This is because representing more complexity introduces more parameters that cannot be easily measured directly, or are calibrated on indirect information. Thus, distributed models generally have more degrees of freedom when representing a catchment, but this can result in greater prediction uncertainty. In practice there is a continuum of models that can be broadly defined as physically based, but are calibrated to observed data to provide greater predictive power (Beven 2005). A simple example of a physically based model is the application of Richards equation for soil moisture dynamics (AghaKouchak 2011).

\section{c) Deterministic versus stochastic models}

A final classification of rainfall-runoff models is into models that are either deterministic or stochastic. In deterministic models a single set of input data will produce a single prediction for all its output. The majority of hydrological models are deterministic even though the uncertainties associated with such predictions are now well understood. Stochastic models allow for the uncertainties in the input by creating some variance at different time steps for the output (Beven 2005).

\subsubsection{Assumptions and boundary conditions}

To conceptualise a model from reality a set of assumptions have to be made. Some assumptions will be wrong but are necessary for the process of modelling. Mulligan and Wainwright (2004) claim the key is to know which assumptions are wrong and to make sure they are not important for the purpose of the modelling. Furthermore, any assumptions must be well understood and clearly stated in reference to the conditions in which they are valid, and more importantly, the conditions in which they are invalidated (Mulligan and Wainwright 2004).

In any model spatial and temporal boundaries must be set to identify the times and spaces of interest and the associated data required to support the modelling process. The 'boundary conditions' for data represents processes outside the spatial extent of the model (e.g. catchment, or sub-catchment) while the 'initial conditions' for data represents processes within the spatial extent but before the temporal, or time period of interest (Mulligan and Wainwright 2004). Rainfall and evaporation data typically falls outside the spatial area of interest and so are boundary conditions. Antecedent soil moisture is a result of earlier rainfall events but is still within the spatial confines of the catchment so are initial conditions. In addition to initial and boundary conditions are 'parameters' which are the numbers assigned to a model that make it specific to a particular 
catchment. These can range from the amount of water able to be stored in the soil and vegetation, to the hydraulic conductivity of soils (see chapter 3 ). These parameters are often best guesses based where possible on quantified measurements (Ibbitt et al. 2004).

\subsubsection{Calibration}

Model calibration is the process where the input parameters are modified so the output matches an observed set of data. There is no general "best way" to calibrate a model because there are many different sources of error which cannot be easily separated. Often there is no way of estimating the different sources of error independently. One common method attempts to lump all sources of error into a single "modelling" error, and then applies a statistical approach to calibrate the model (Krzysztofowicz and Kelly 2000; Young 2002). This statistical approach requires a "likelihood function" whose form is derived from the assumptions made about the sources of error. This is an objective approach in that the validity of the likelihood function can be tested (at least approximately) by comparing the results with the likelihood function against the actual modelled results to see if the error assumptions are justified (Beven 2005). This method is just one of the many available. For more information and techniques see Beven $(2001,2005)$ and Gupta et al. (2005).

\subsection{Rainfall-runoff models in New Zealand}

In New Zealand the most commonly used flood and inundation models are TOPNET, MIKE 11 and MIKE 21. TOPNET was developed by the National Institute of Water and Atmospheric Research (NIWA) and is a semi-distributed, physically-based catchment model which is used to produce flood maps in association with flood risk zones. Flood return periods are derived from representative hydrographs which are calculated on the basis of extreme value analysis (e.g. Gumbel and EV1). TOPNET models a catchment as a series of sub-catchments connected by a branched river network and was developed by combining TOPMODEL (Beven et al. 1995) which represents small catchments, with a kinematic wave channel routing algorithm (Goring 1994). TOPNET drapes soil and land use data over a DEM and then assigns rainfall interception and soil moisture values for each vegetation and soil type from look up tables. Then an area weighted sum of these properties is assigned to each sub-catchment (Ibbitt et al. 2004). TOPMODEL assumes that soil water storage within the catchment is affected by topography. It utilises a topographical index, which measures the tendency for water to accumulate in valley bottoms rather than ridge tops, and the level of storage within the saturated zone (which varies with time) to help simulate subsurface and overland flow (Ibbitt et al. 2004). For more information see Ibbitt et al.(2004) and Bandaragoda et al.(2004). 
MIKE 11 and MIKE 21 are modelling packages developed by the Danish Hydraulic Institute (DHI) for simulating surface runoff, flow, floodplains, sediment transport and water quality in rivers and tidally influenced estuaries. The hydrodynamic module, MIKE 11 simulates unsteady flow within branched and looped river networks, and quasi two dimensional (2-D) flow on floodplains using one dimensional (1-D) implicit, dynamic wave routing based on the St. Venant equations for unsteady flow (Kamel 2008). It is usually used in conjunction with a GIS system, Digital Elevation Model (DEM), and river cross sections. MIKE 21 is two dimensional and can simulate the development of river bed and channel morphology due to changes in the hydraulic regime. Some of the simulated processes include bank erosion, scouring and shoaling brought about by human activities such as engineered structures and dredging or seasonal fluctuations in flow (DHI 2011). One dimensional models like MIKE 11 are computationally efficient for modelling large complex river channel systems, but are less accurate when simulating floodplain flows due to their assumption of 1-D flow. Two dimensional models like MIKE 21 are better suited to floodplain modelling but have higher requirements for hardware, data and computational time (Lawrence 2009). A common tactic is to combine both 1-D and 2-D models into one package where the 1-D component is used to model channel flow and the 2-D component the floodplain inundation such as the MIKE FLOOD toolbox (DHI 2011).

The reason POLYSCAPE was chosen over the TOPNET and MIKE modelling packages is because POLYSCAPE explicitly recognises the spatial placement of vegetation at the farm scale whereas TOPNET does not, and the MIKE packages are for river/floodplain modelling which is not an objective of this research. However, either modelling system could be combined with POLYSCAPE or similar approaches as part of a multi-scale modelling project. An additional reason for choosing POLYSCAPE is because it is being developed at Victoria University and so this research is also part of testing and refining it.

\subsection{POLYSCAPE}

POLYSCAPE is a semi-distributed, physically based land management toolbox that was developed to assist users to improve ecosystem services such as carbon sequestration, water quality, habitat connectivity, farm productivity, flood alleviation, and erosion reduction through targeted land management. The impact of land use changes on ecosystem services depends on their position within the landscape. As a rule, land use features should be sited in locations where they have the greatest benefit or highest value. However, changing the landscape to achieve a particular outcome, for example increasing agricultural productivity through conversion of forest to high yielding grassland, can have implications for other ecosystem services such as increased erosion and biodiversity loss. For this reason POLYSCAPE was developed to examine spatially explicit synergies 
and tradeoffs between ecosystem services and help users to decide whether they add, remove, or protect an existing feature in the landscape. Furthermore, local stakeholders often have detailed knowledge and landscape requirements which should be integrated into planning decisions. With this in mind, POLYSCAPE was designed as a negotiation tool, rather than a prescriptive tool, so local stakeholders can trial their own plans and build in their knowledge and landscape restrictions. POLYSCAPE can be applied at a range of scales from the farm scale up to catchments $10,000 \mathrm{~km}$ in size.

\subsubsection{Tool descriptions}

POLYSCAPE is a toolbox that operates within ESRI's ArcGIS versions 9.2 and above. Currently, POLYSCAPE (version 1.1) has 5 tools (algorithms) for investigating the effects of land use change on 1) flood risk; 2) erosion/sediment delivery; 3) habitat connectivity; 4) carbon sequestration; and 5) agricultural productivity. Further tools in development include water quality, amenity, and cultural valuation. In addition there is 6) a synergies and trade-off tool between the five ecosystem services, 7) a pre-processing tool, and 8) an editing tool for stakeholders to make their own adjustments to both input and output. All algorithm calculations and valuations are produced at the resolution of a raster based Digital Elevation Model (DEM). This research utilises the flood mitigation and preprocessing tools only and compares model output between six DEMs of varying resolution $(1,5,10$, $25 \mathrm{~m}$ ). The flood mitigation algorithm is based on recent research results from Carroll et al. (2004), Jackson et al. (2008), Marshall et al. (2009), and Wheater (2005).

POLYSCAPE can identify areas which have high potential for change. For example, when considering flood mitigation one might consider installing a pond or tree buffer strip in areas where large amounts of flow accumulate to reduce runoff. Furthermore, POLYSCAPE identifies areas of high existing value such as highly productive pasture, or wetlands with high biodiversity and flood alleviation benefits, and colours them as worthy for protection. This is achieved through the production of colour-coded "traffic-light" impact maps. The default colour system uses green to show areas where change is considered desirable, amber zones are marginal areas, and red highlights areas of existing high value where there is a high risk associated with any change. Bright red/green suggests high existing value, or opportunity for change respectively, whereas duller red/green indicates still significant, but less pronounced value or opportunity (Jackson et al. 2011).

The flood mitigation algorithm works as follows. Features within the landscape that have high storage and/or permeability are assumed to mitigate flooding by acting as "sinks" for overland flow and slower near-surface flow; either storing the water, or slowing it down by routing through subsurface pathways. How effective these features are for controlling runoff depends on their position 
within the landscape with areas with negligible upland contributing area far less effective than locations with large amounts of low permeability upland contributing area. The flood mitigation layer accordingly characterises features within the landscape by their permeability and storage capacity as defined by soil and land use data (Jackson et al. 2011). Then "using a novel algorithm based on modifying flow accumulation according to permeability/storage, it then discretises units within the landscape according to similarity of their hydraulic properties and spatially explicit topographical routing" (Jackson et al. 2011).

The flood mitigation algorithm can be used in two ways. The simplest ignores temporal effects by removing flow that enters "sink" areas from the flow accumulation data. Jackson et al. (2011) writes that "all land use or soil types that provide this mitigation are treated as of high existing value. Areas where a large amount of unmitigated flow routes directly to waterways are treated as priority areas for change". The default parameters for defining high accumulation flow thresholds can also be changed to represent the characteristics of a particular catchment. The results from this modeling are contained in section 6.4.

The second way to apply the algorithm is more complex in that it can value land under different rainfall events (e.g. design flood rainfall input, known return period rainfall events) and antecedant soil conditions. It does this by routing water through hydrological response units within the landscape (i.e. cells with defined storage and hydraulic conductivity values) through a cascading 'fill and spill' approach. This requires more data (or assumptions) on soil water holding capacity and hydraulic conductivity (Jackson et al. 2011). This research utilises both the ground truthed national soil data and results from field studies. Results can be found in section 6.5.

\subsection{Using POLYSCAPE to determine the optimum locations for flood mitigation}

The flood mitigation benefits of natural buffers are strongly influenced by their location within the landscape. Using the flow accumulation algorthm mentioned above, optimum and near optimum locations for natural buffers were determined. As input, the algorithm requires a stream network, a hydrologically consistent DEM (consistent with the stream network and with sinks removed) and land use data. The soil data such as hydraulic conductivity can be estimated from land use although in this case the field measurements and national data (NSD) were used. The land use information was drawn from the national land use data (NZLRI) and improved by manual digitization in GIS from field studies. The pre-processing tool generated the hydrologically consistent DEM from a "standard" DEM (Jackson et al. 2011). To test how the resolution of the underlying DEM affects the accuracy of the model output, six DEMs of differing resolutions were used (Objective 5). These included two 
national scale DEMs $(25 \mathrm{~m})$ created by GeographX and Landcare Research, and four DEMs $(25 \mathrm{~m}$, $10 \mathrm{~m}, 5 \mathrm{~m}, 1 \mathrm{~m}$ ) created from Light Detection and Ranging (LiDAR) data. This is to determine the required DEM resolution for effective prediction of flood buffering effects at the farm scale. The following section describes the origins of each DEM (section 6.4.1) before displaying the modelled results from the comparisons (section 6.4.2).

\subsubsection{DEM origins and information}

\section{a) GeographX 25m DEM - version 2}

The GeographX 25m DEM was first created in 2000 and then edited and re-released as version 2 in 2003. The source data came from the Land Information New Zealand (LINZ) NZMS260 1:50k topographical database. The accuracy of cell values in the DEM is only as accurate as the source data used to create it. The horizontal and vertical accuracy cited for NZMS260 is +/- $22 \mathrm{~m}$ for the horizontal points and $+/-10 \mathrm{~m}$ for the vertical points (GeographX 2003). There are four known issues with the GeographX 25m DEM. The first is localized sinks and spikes caused by spot height errors in the original LINZ source data. The second is unconstrained bathymetry with enclosed water surfaces such as lakes appearing as shallow concave surfaces. The third is surface ripples on steep slopes such as Mt Taranaki when hill-shading is applied. The fourth and most important issue in regards to this research is explained by GeographX (2003):

"The $25 \mathrm{~m}$ elevation model is not suitable for detailed hydrological analysis. The cell resolution is not fine enough, nor is the vertical accuracy sufficient to accurately define drainage patterns on areas of low relief. In order to adapt this dataset for such analysis, it would first be necessary to "burn" known hydrology into the elevation model surface."

\section{b) Landcare Research $25 \mathrm{~m}$ DEM - version 2}

The Landcare Research 25m DEM version 2 was created by Barringer et al. (2002), and like the GeographX DEM, the source data was the LINZ topographical database. The second version of the Landcare DEM improved on the first version by changing the interpolation algorithm to interpolate from up to four contour or spot heights instead of two. Additional changes include assigning pixel height based on interpolation within the pixel, tracking distances from the nearest contours using float point precision and allowing diagonal steps, and using float point precision for elevations within the DEM. Barringer et al. (2002) states the aim when producing this DEM was minimisation of absolute elevation error and speed of interpolation rather than hydrological correctness, slope continuity, or some other performance goal which suggests that like the GeographX DEM, it is not suitable for detailed hydrological analysis. Barringer et al. (2002) tested the DEM against a high 
resolution reference DEM $(2.5 \mathrm{~m})$ created from LiDAR data in a small area of the Southern Alps. They found on average, their $25 \mathrm{~m}$ DEM overestimated elevation by approximately $6 \mathrm{~m}$. Errors in the DEM are most likely to be found at the local scale in valley bottoms (Barringer et al. 2002).

\section{c) LiDAR derived DEMs (25m, 10m, $5 \mathrm{~m}, 1 \mathrm{~m})$}

Four DEMs were created from LiDAR data supplied by Hawkes Bay Regional Council. The Airbourne Laser Scanning (ALS) data covers the Ruataniwha Plains and was acquired from a fixed wing aircraft in October 2006 and January 2010 by AAM Pty Limited. The vertical accuracy of the data set is +/$0.15 \mathrm{~m}$, and the horizontal accuracy is $+/-0.30 \mathrm{~m}$, however the definition of ground underneath trees may be less accurate than this.

The DEMs were created in ArcMap using the Spatial Analyst extension. The DEMs were produced by Inverse Distance Weighting (IDW) interpolation using 12 points with a variable search radius of $40 \mathrm{~m}$. The DEMs produced from the $40 \mathrm{~m}$ search radius produced a coverage that contained values for every cell within the extent apart from a small area within the large reservoir dam at the northern end of Takapau farms.

\subsubsection{Comparing output between different resolution DEMs}

Figure 37 compares output from the flood mitigation tool using an improved land use layer and hydrological DEMs of differing resolutions. As explained in section 6.4, the map is colour coded via a flow accumulation algorithm. The lower and upper area thresholds for high and very high prioritisation of change vary depending on cell size with the $1 \mathrm{~m}$ and $5 \mathrm{~m}$ DEMs having a lower threshold of 100 cells contributing flow, and an upper threshold of 600 cells. All DEMs of greater resolution $(10 \mathrm{~m}, 25 \mathrm{~m})$ have a lower threshold of 5 contributing cells and an upper threshold of 20 cells. How accurately the DEMs represent flow pathways within the Takapau landscape is shown in Figure 37 . At $1 \mathrm{~m}$ and $5 \mathrm{~m}$ both major and minor pathways including the main stream channels are represented in high detail. At $10 \mathrm{~m}$ the stream channels along with the major and minor pathways are represented in reasonable detail suggesting that a 10m DEM is still appropriate within the study area. However, at $25 \mathrm{~m}$ resolution the drainage patterns are represented poorly as the grid size is too coarse. When visually comparing output between all three $25 \mathrm{~m}$ DEMs the LiDAR derived DEM performed considerably better than the DEMs created from LINZ topographic data. This is probably due to methodological error and/or inaccuracies within the underlying LINZ source data such as

localised spot height error. Overall, the Landcare DEM performed marginally better than the GeographX DEM however both are unsuitable for defining drainage patterns at the farm scale. 
Although there are recognised errors associated with LiDAR data (mostly due to vegetation cover), it is the most accurate dataset available for the study area. For this reason the $1 \mathrm{~m}$ high resolution DEM was used as a reference to quantify the differences in elevation between the other five DEMs (Figure 38). The maps in Figure 38 were calculated using the raster calculator in ESRI's ArcGIS with Table 22 displaying the summary statistics. As expected the $5 \mathrm{~m}$ and $10 \mathrm{~m}$ DEMs closely matched the elevation values at $1 \mathrm{~m}$ with a mean difference of $+0.04 \mathrm{~m}$ and $+0.005 \mathrm{~m}$ respectively. At $25 \mathrm{~m}$ the LiDAR derived DEM had a very slight bias of $-0.09 \mathrm{~m}$ compared to the Landcare and GeographX DEMs which had a positive bias of $+12.3 m$ and $+12.9 m$ respectively.

Table 22 Differences in elevation between a high resolution reference DEM $(1 \mathrm{~m})$ and five DEMs of varying resolution. Calculations were made using the raster calculator in ArcGIS.

\begin{tabular}{|l|c|c|c|c|c|}
\hline DEM resolution & Count $(\mathbf{n})$ & Minimum & Maximum & Mean & SD \\
\hline 5m LiDAR & 479048 & -6.0 & 17.2 & 0.04 & 0.86 \\
10m LiDAR & 119644 & -8.6 & 2.6 & 0.005 & 0.39 \\
25m LiDAR & 19173 & -12.7 & 16.0 & -0.09 & 3.26 \\
25m Landcare & 19152 & -17.7 & 47.4 & 12.3 & 7.24 \\
25m GeographX & 19173 & -11.7 & 45.5 & 12.9 & 6.65 \\
\hline
\end{tabular}




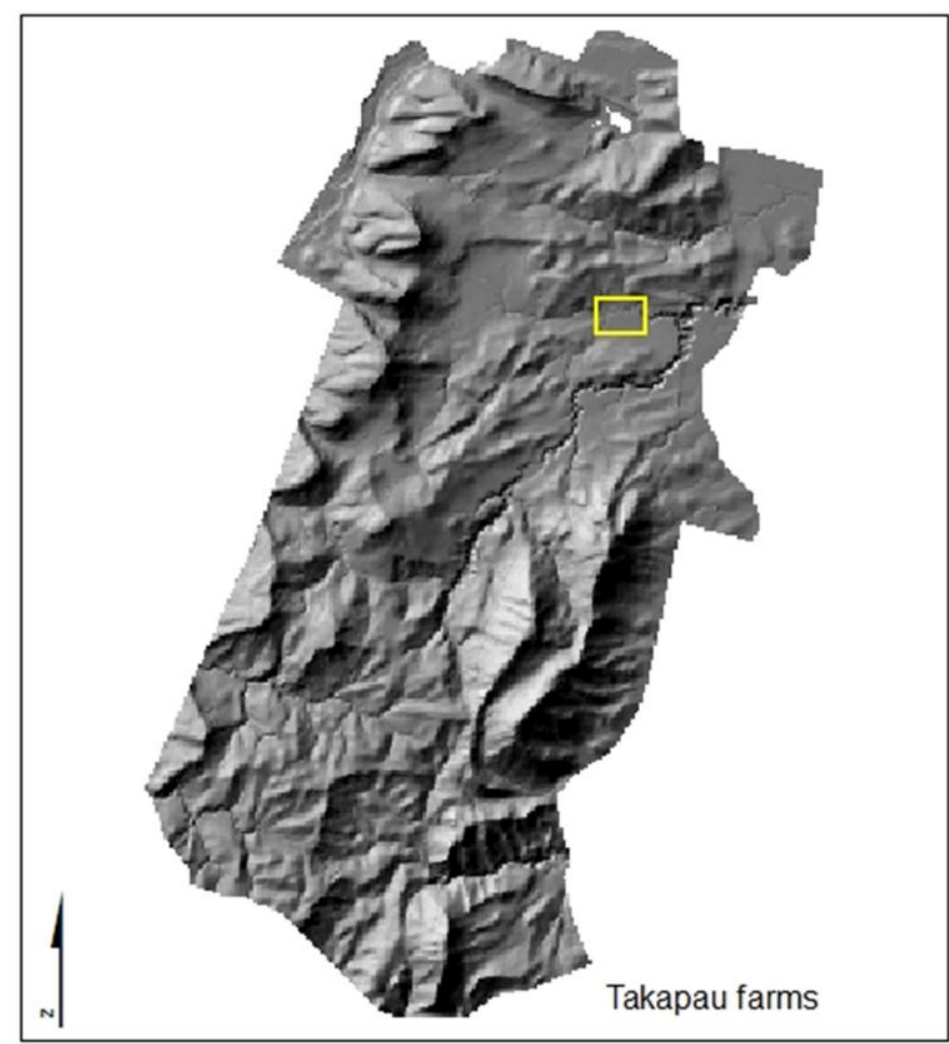

Sink area (flood mitigating)

Negligible flow $(a)<500 \mathrm{~m}^{2}(\mathrm{~b})<3125 \mathrm{~m}^{2}$

Moderate flow (a) $500 \mathrm{~m}^{2}$ (b) $3125 \mathrm{~m}^{2}$

High flow (a) $>300000 \mathrm{~m}^{2}(\mathrm{~b})>12500 \mathrm{~m}^{2}$
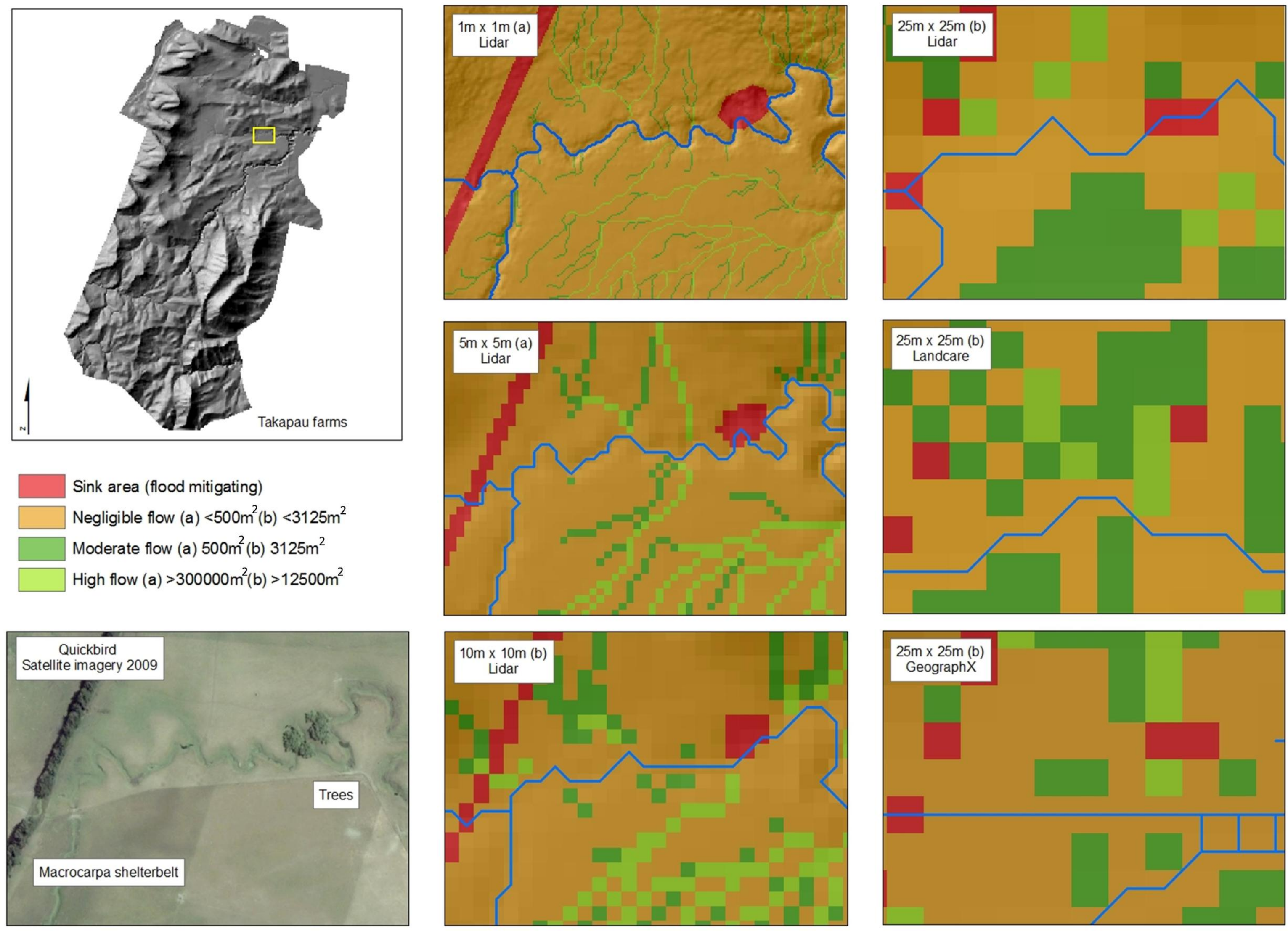
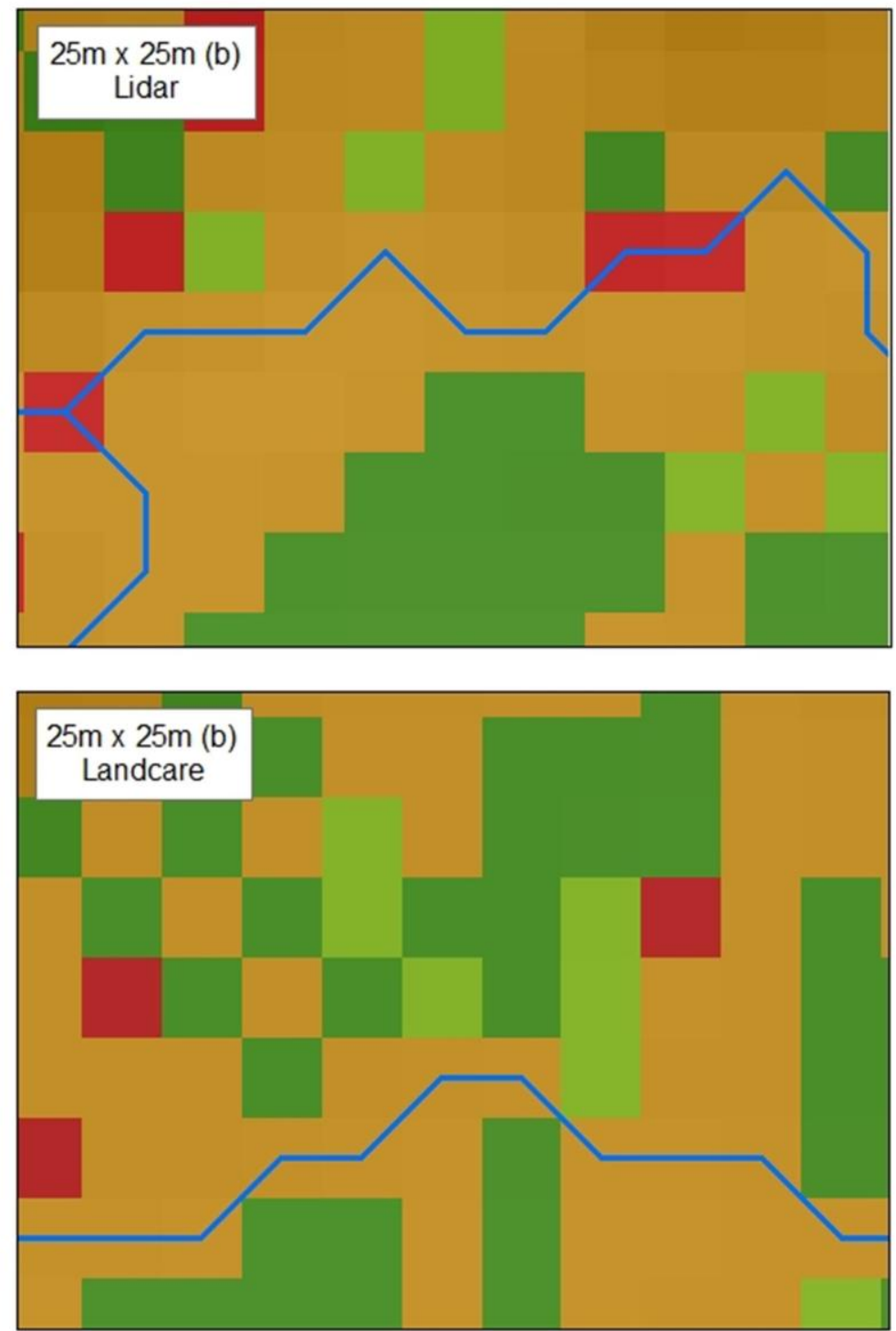

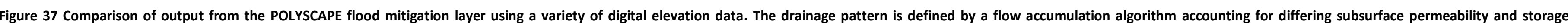

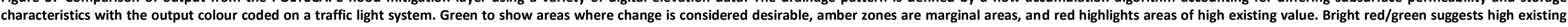
value, or opportunity for change respectively, whereas duller red/green indicates still significant, but less pronounced value or opportunity. 

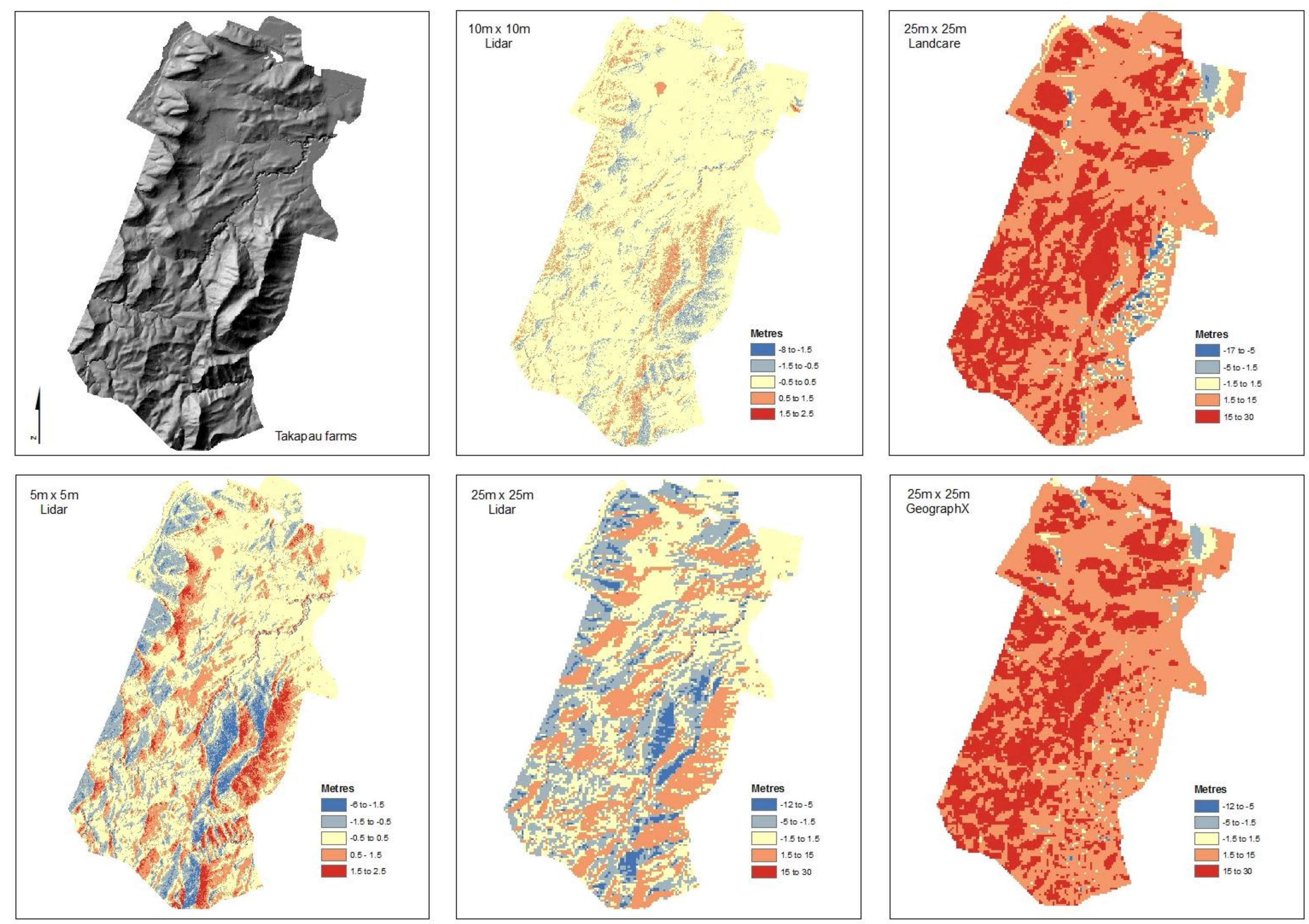

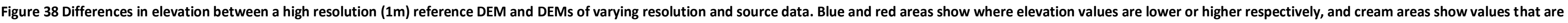
within $-/+1.5 m$ 


\subsection{Predicting the impacts of land use change using POLYSCAPE}

The flood mitigation tool within POLYSCAPE was used to test the flood mitigating effectiveness of natural buffers by simulating quickflow generation for nine different land use and rainfall scenarios. The land use layers include the farm under current land use (existing buffers); the farm with existing buffers removed; and the farm with additional strategically placed buffers. The rainfall simulations include a representative "wet" and "dry" record and the same records modified for a $1^{\circ} \mathrm{C}$ and $2^{\circ} \mathrm{C}$ change following national guidance (MfE 2010) to reflect potential climate change impacts. The following section describes the approach taken to make the predictions (section 6.5.1) followed by a description of the soil parameters (section 6.5.2) and different land use/rainfall scenarios used for the simulations (section 6.5.3). The chapter concludes with the predicted effects from the simulations including stated uncertainties and level of reliability (section 6.5.4).

\subsubsection{Defining model parameters}

This section defines the hydraulic conductivity, depth to slowly permeable layer (DSLO), and profile total available water (PAW) values to be used for the modelling at Takapau farms. The values were either taken from the "_MOD" class within the National Soil Database (NSD), or from the values calculated from field measurements (Table 23). The _MOD values within the NSD are the estimated modal value for a particular class and are calculated using class range (_CLASS) and variability (_VAR) and are considered to approximate the most common value.

\section{a) Hydraulic conductivity}

For all soils within the study area hydraulic conductivity values were assigned from field measurements. This is because the NSD simply assigns a $K_{s}$ class which covers a range of rates (e.g. moderate $=4$ to $71 \mathrm{~mm} / \mathrm{h}^{-1}$ ) whereas the field measurements are at finer resolution showing variation within that moderate class. As the Takapau, Okawa, and Taihape loams were not measured directly, mean $K_{s}$ for the entire Takapau farm sub-catchment was used to define their hydraulic conductivity. Additional assumptions include percolation through the B-horizon (slowly permeable layer). The values chosen were $0.05 \mathrm{~mm} / \mathrm{h}^{-1}$ for pasture, $0.5 \mathrm{~mm} / \mathrm{h}^{-1}$ for trees, and $1 \mathrm{~mm} / \mathrm{h}^{-1}$ for ponds, and were based on the experience and recommendations of B.M Jackson (personal communication). However, these are only "best guesses" and the winter month results were found to be somewhat sensitive to these parameters. The lack of data for B-horizon percolation rates is an issue that should be addressed in future research. 


\section{b) Depth to slowly permeable layer (DSLO)}

The depth to slowly permeable layer (DSLO) values were assigned to soils and ponds from both NSD and field measurements. To decide which value to use the NSD and field values were compared to see if they were significantly different. If the two values varied significantly then the field value was chosen. If the two were similar $(+/-10 \mathrm{~cm})$ then the NSD value was chosen. The degree of accuracy within the NSD can be determined by a field called "EST_values". These describe the origin of the value and to what extent they can be relied upon for accuracy. The NSD Matapiro silt loam values are derived from direct measurements of the soil (class $\mathrm{m}$ ) which explains why they compared well with the values measured for this research. The Takapau and Taihape loams have NSD values estimated from relationships with other soils (class $r$ ) but the estimate is considered reliable. As mentioned above, these soils were not measured during the field period and so the NSD values were used. The Maungapakeha silt loam values were also estimated from relationships with other soils but with an unknown level of accuracy (class $\mathrm{u}$ ). This could explain why the field measurements were significantly different and thus were favoured to best represent DSLO. Furthermore, the NSD values for the Atua silt loam were estimated from General Soil Survey Data (scale 1:253,440) (class uf), which in general is considered less reliable than the ' $u$ ' class above. The unreliability of this class was reflected in the field DSLO values being significantly shallower than those listed in the NSD. The depth of the ponds was set at $1 \mathrm{~m}$ and was derived from visual assessments from the field studies.

\section{c) Profile total available water (PAW)}

Profile total available water (PAW) is the minimum and maximum values of profile total available water for the soil profile to a depth of $0.9 \mathrm{~m}$, or to the potential rooting depth (whichever is the lesser) and, expressed as mm of water. The PAW values for all but the Atua and Maungapakeha silt loams were taken from the NSD. PAW for the aforementioned soils was recalculated using mean DSLO values from the field investigations.

Table 23 Hydraulic conductivity, depth to slowly permeable layer, profile total available water values assigned to soil types.

\begin{tabular}{|l|c|c|c|}
\hline Soil series/type & $\boldsymbol{K}_{\boldsymbol{s}}\left(\mathrm{mm}^{\mathrm{m}} \mathbf{h}^{-\mathbf{1}}\right)$ & $\mathbf{D S L O}(\mathbf{m})$ & PAW $(\mathbf{m m})$ \\
\hline Matapiro silt loam & $7^{\mathrm{b}}$ & $0.22^{\mathrm{a}}$ & $45^{\mathrm{a}}$ \\
Atua silt loam & $6^{\mathrm{b}}$ & $0.35^{\mathrm{b}}$ & $39^{\mathrm{b}}$ \\
Maungapakeha silt loam & $6^{\mathrm{b}}$ & $0.22^{\mathrm{b}}$ & $75^{\mathrm{a}}$ \\
Takapau stony loam & $9^{\mathrm{b}}$ & $2.25^{\mathrm{a}}$ & $120^{\mathrm{a}}$ \\
Okawa sandy loam & $9^{\mathrm{b}}$ & $0.52^{\mathrm{a}}$ & $120^{\mathrm{a}}$ \\
\hline
\end{tabular}

a - value assigned from NSD $\quad b$ - value assigned from field study 


\subsubsection{Rainfall simulations}

\section{a) Rainfall under current conditions (rainfall simulation 1)}

The rainfall and evaporation data used for the simulations was downloaded from NIWA's 'National Climate Database' (Cliflo). The simulations were based on two representative time periods: a "wet" period (May 92 to Jun 93), and a "dry" period (Sep 08 to Sep 09). The two climate records were selected by examining monthly and annual rainfall records from the Ruataniwha Plains over the period 1983-2010. The nearest climate station with the necessary data for the wet period was Waipukurau Aero located $12.6 \mathrm{~km}$ to the east, and for the dry period Waipawa Ews located $30 \mathrm{~km}$ away to the north-west. The highest rainfall peak during the dry period was $15.7 \mathrm{~mm}$ which fell within one hour in March 2009. The highest rainfall event in the wet period was $109.4 \mathrm{~mm}$ recorded over 32 hours in July 1992. The wet period was characterised by wet antecedent soil conditions while the dry period had high soil moisture deficit. Each was used to explore the amount of quickflow generated under the different land use scenarios.

\section{b) Climate change and rainfall intensity (rainfall simulations 2 \& 3)}

The IPCC in its Fourth Assessment (Christensen et al. 2007) declared more intense rainfall due to climate change is "very likely over most areas" of Australia and New Zealand. This is because a warmer atmosphere can hold more moisture (about $8 \%$ more for every $1^{\circ} \mathrm{C}$ increase in temperature). MfE (2008) state this value is widely accepted as a reasonable upper limit for heavy rainfall changes. To calculate mean temperature changes over New Zealand NIWA (2008) downscaled global projections and calculated an average increase of $1^{\circ} \mathrm{C}$ by 2040 , and $2^{\circ} \mathrm{C}$ by 2090 . This equates to an increase in maximum rainfall intensity of $8 \%$ and $16 \%$ respectively. These values were used in conjunction with an equation (listed on the following page) for the present day rainfall record giving a total of three rainfall simulations of varying intensity.

With an increase in heavy rainfall, overall low rainfall events decrease. This is because the available atmospheric water has already fallen during the heavy events leaving less moisture behind for low intensity rainfall. Ultimately this results in heavier rainfall, but overall fewer rain days. The rainfall records were modified ${ }^{2}$ using the methodology outlined in MfE (2010). First, the number of rain days (i.e. daily total at least $0.1 \mathrm{~mm}$ ) was reduced by decreasing the probability of a rain-day by $1.75 \%$ per $1^{\circ} \mathrm{C}$ increase in annual-average temperature. This reduction in low rainfall days helps to balance the increased rainfall extremes mentioned above.

\footnotetext{
${ }^{2}$ This modification utilised an existing code at Victoria University.
} 
Thus, if:

$$
\begin{aligned}
& N W=\text { number of rain days } \\
& N T=\text { total number of days in a year (i.e. } 365.25 \text { ) } \\
& \Delta T=\text { warming }
\end{aligned}
$$

Then the number of rain days will change from NW to NW $-0.0175 * \Delta T * N T$.

This corresponds to about six fewer rain days per year for a $1^{\circ} \mathrm{C}$ warming. This reduction is done by ranking all rain-days and setting the calculated number $(0.0175 * \Delta T * N T)$ of lowest rainfall days to zero rainfall. After applying these steps the rainfall percentiles $(P)$ were calculated from the adjusted daily data. Note that the percentiles were calculated over rain days only; i.e., ignoring dry days. The percentile values were then changed according to the formula:

Equation 14 Change in daily rainfall $\left(\right.$ in $\%$ per $\left.{ }^{\circ} \mathrm{C}\right)=6.15 *[1 .-\ln (100-\mathrm{P}) / 2.3]$

This formula gives zero change at percentile $\mathrm{P}=90,+8 \%$ per ${ }^{\circ} \mathrm{C}$ change at $\mathrm{P}=99.5$, and about $-6 \%$ per ${ }^{\circ} \mathrm{C}$ change at $\mathrm{P}=0$. For $\mathrm{P}>99.5$, the change is capped at $+8 \%$ per degree Celsius of local warming (taken as the change in annual-average temperature). As stated above, the $8 \%$ per ${ }^{\circ} \mathrm{C}$ value is widely recognised as the rate at which the water vapour saturation level increases in the atmosphere (the Clausius-Clapeyron relationship), and is the upper limit recommended in the MfE (2008) Guidance Manual for adjusting return periods of extreme rainfall. Lastly, these $\%$ changes in rainfall were applied to the original rainfall record.

The results from this modelling show a general increase in rainfall intensity in moderate to large rainfall events with Table 24 displaying results from the largest events from both wet and dry records. While intensity increased during the larger events, there were fewer small events with total rainfall throughout the year actually lower due to the lack of atmospheric moisture issue mentioned above. This is illustrated below in Table 25 and Figures 39 to 42.

Table 24 Change in rainfall quantities for the largest event in both wet and dry periods, and \% change between the original record, and a $1^{\circ} \mathrm{C}$ and $2^{\circ} \mathrm{C}$ increase in atmospheric temperature.

\begin{tabular}{|l|c|c|c|}
\hline Largest rainfall event & $\begin{array}{c}\text { Original rainfall } \\
(\mathbf{m m})\end{array}$ & $\begin{array}{c}\mathbf{1}^{\mathbf{}} \mathbf{C} \text { rainfall } \\
(\mathbf{m m})\end{array}$ & $\begin{array}{c}\mathbf{2}^{\circ} \mathbf{C} \text { rainfall } \\
(\mathbf{m m})\end{array}$ \\
\hline Wet period (over $30 \mathrm{hrs})$ & 109.4 & $113.8(3.9 \%)$ & $117.4(6.8 \%)$ \\
Dry period (over $1 \mathrm{hr})$ & 15.7 & $17(7.6 \%)$ & $18.2(13.7 \%)$ \\
\hline
\end{tabular}


Table 25 Total cumulative rainfall for the wet and dry periods and \% change between the original record, and a $1^{\circ} \mathrm{C}$ and $2^{\circ} \mathrm{C}$ increase in atmospheric temperature.

\begin{tabular}{|l|c|c|c|}
\hline Total cumulative rainfall & $\begin{array}{c}\text { Original rainfall } \\
\mathbf{( m m )}\end{array}$ & $\begin{array}{c}\mathbf{1}^{\mathbf{}} \mathbf{C} \text { rainfall } \\
\mathbf{( m m})\end{array}$ & $\begin{array}{c}\mathbf{2}^{\circ} \mathbf{C} \text { rainfall } \\
\mathbf{( m m})\end{array}$ \\
\hline Wet period & 1164 & $1143(-1.8 \%)$ & $1107(-4.9 \%)$ \\
Dry period & 640 & $622(-2.8 \%)$ & $586(-8.4 \%)$ \\
\hline
\end{tabular}

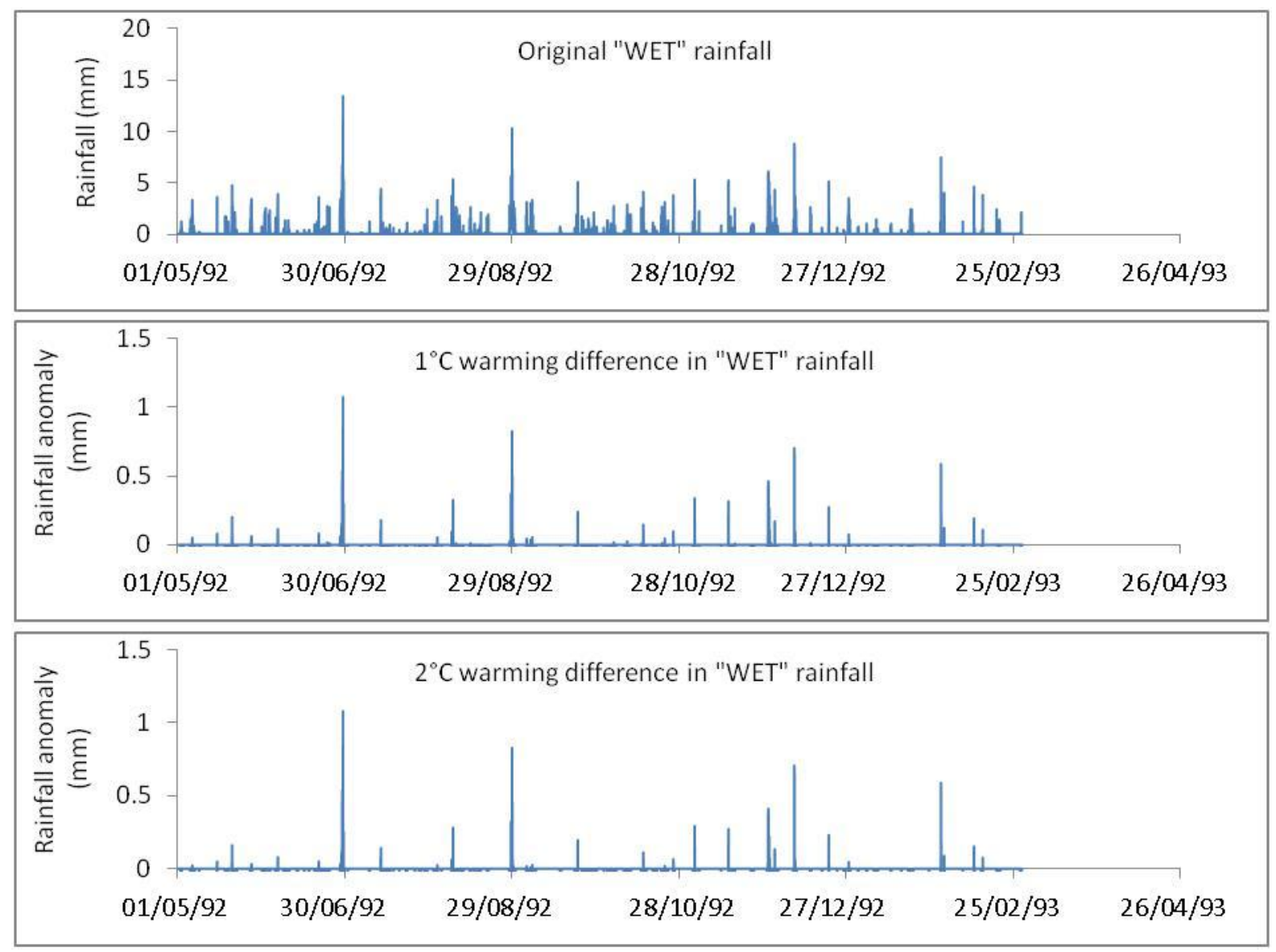

Figure 39 Original "wet" rainfall followed by the differences in rainfall quantity between the original record and the $1^{\circ} \mathrm{C}$ and $2^{\circ} \mathrm{C}$ record. 


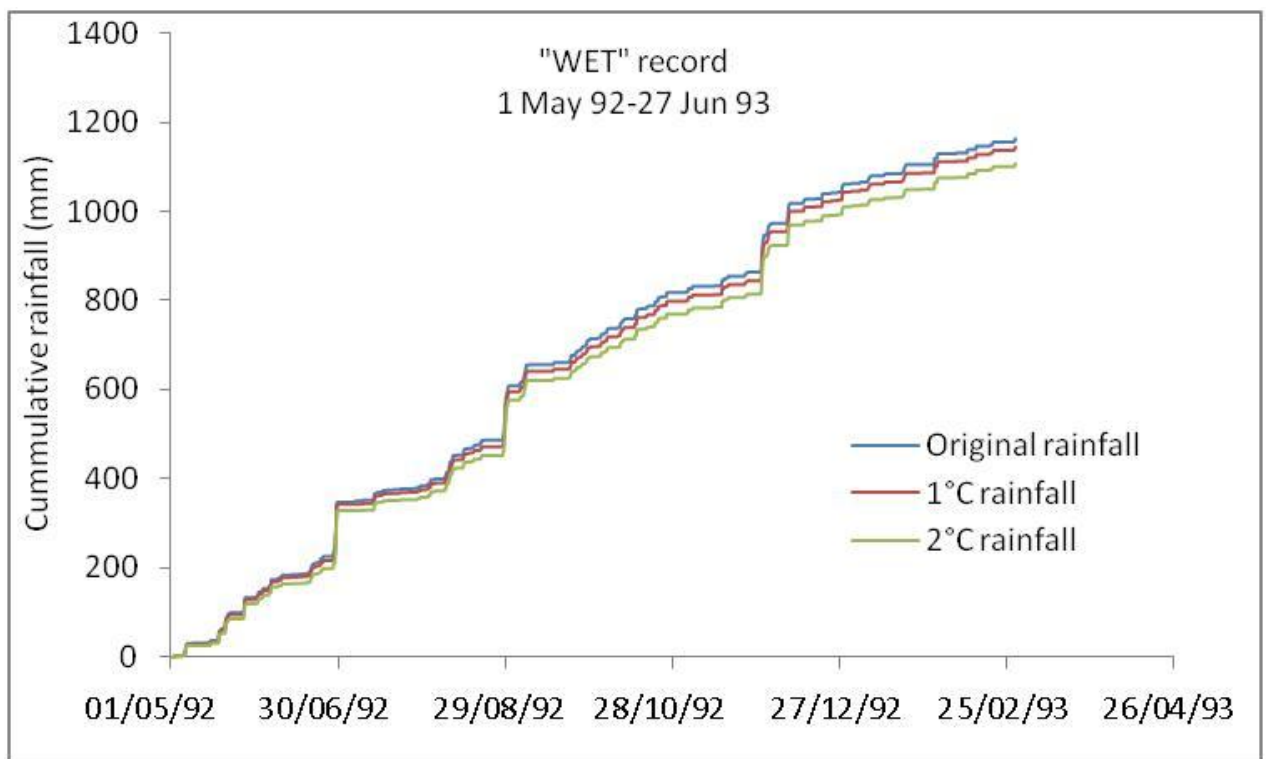

Figure 40 Cumulative "wet" rainfall for the original record and the $1^{\circ} \mathrm{C}$ and $2^{\circ} \mathrm{C}$ increase in atmospheric temperature.

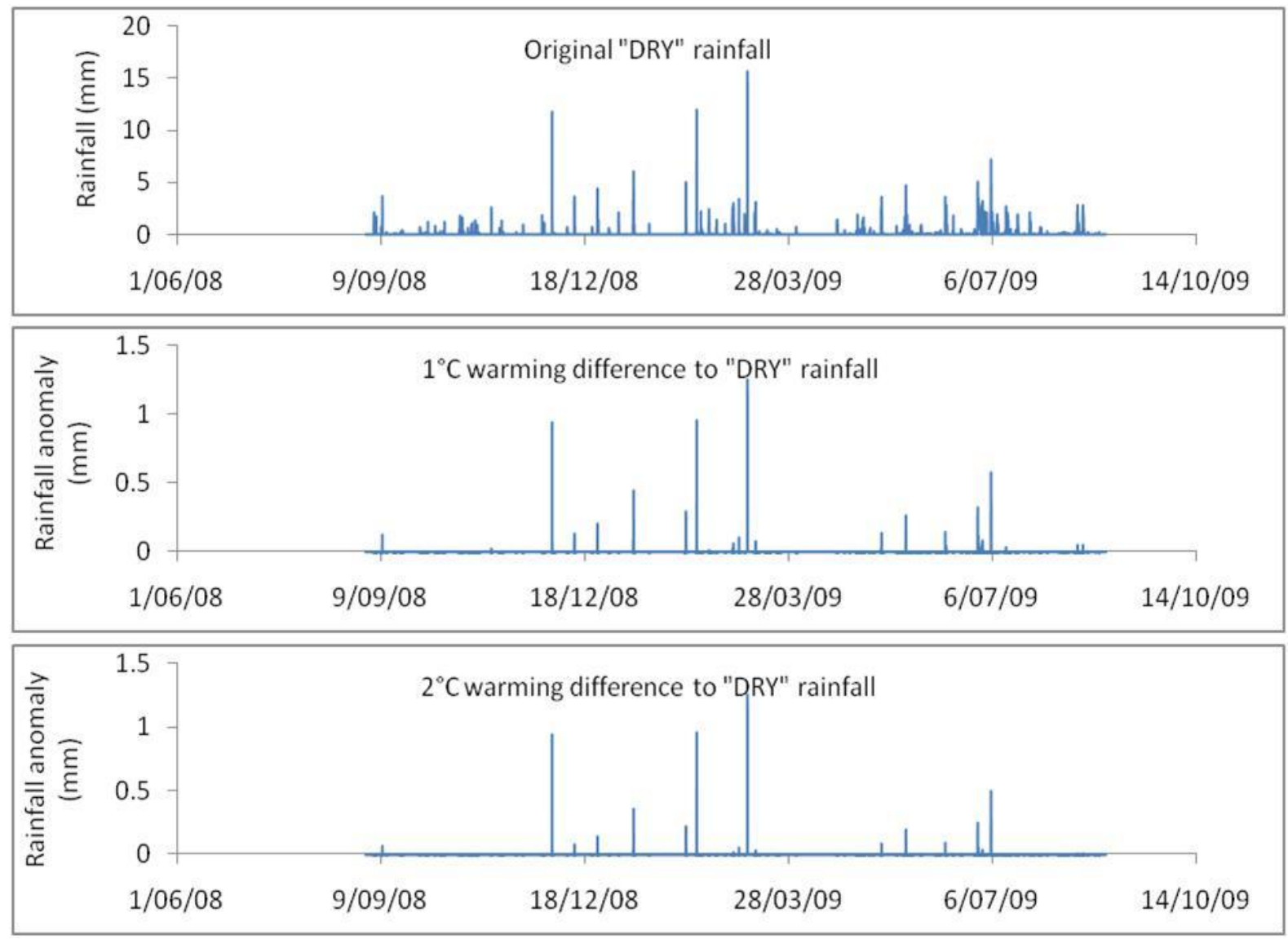

Figure 41 Original "dry" rainfall followed by the differences in rainfall quantity between the original and the $1^{\circ} \mathrm{C}$ and $2^{\circ} \mathrm{C}$ record. 


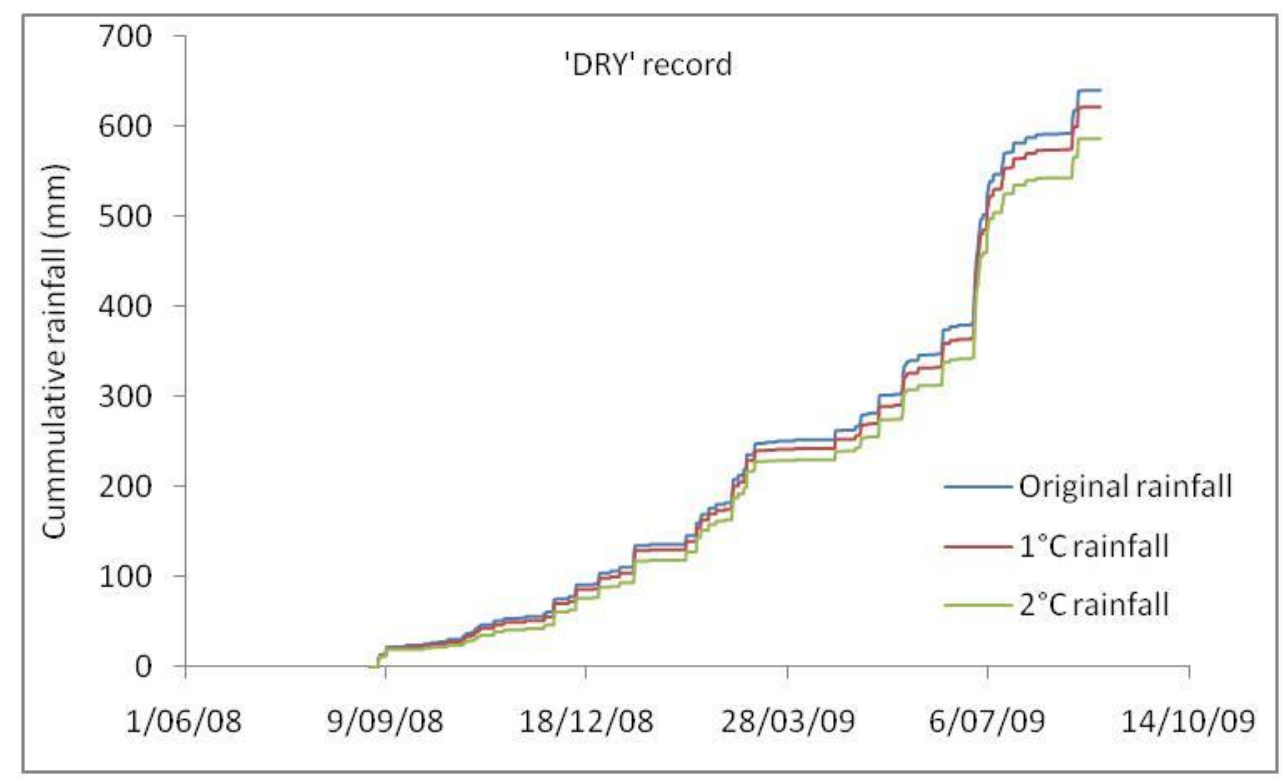

Figure 42 Cumulative "dry" rainfall for the original record and the $1^{\circ} \mathrm{C}$ and $2^{\circ} \mathrm{C}$ increase in atmospheric temperature.

\subsubsection{Land use scenarios}

The total area of Takapau farms is $12.6 \mathrm{~km}^{2}$. Three different land use scenarios were created with varying ratios of buffers (ponds and trees) to pasture (Figure 43). Scenario 1 represents Takapau farms under current land use conditions where existing natural buffers cover $0.9 \mathrm{~km}^{2}(7.1 \%)$ of available land area. Scenario 2 removes all existing buffers apart from the large reservoir 10.05 $\mathrm{km}^{2} / 0.4 \%$ ) at the northern end of the farm with the remaining land covered entirely in pasture. Scenario 3 includes the existing buffers plus an additional $0.4 \mathrm{~km}^{2}$ (3.2\%) of targeted planting to give a total buffer area of $1.3 \mathrm{~km}^{2}(10.3 \%)$. Trees were chosen rather than ponds as the landscape already had a large number of constructed farm ponds (n33). The locations for the trees were determined using the flow accumulation algorithm in order to maximize flood mitigation benefits.

The model was run using the $5 \mathrm{~m}$ DEM. This means the landscape was broken into $5 \mathrm{~m}$ cells and so the influence of an individual tree was $5 \mathrm{~m}^{2}$. The tree cells had hydraulic conductivity values 5 times greater than the same soil in pasture. It also assumes that the tree areas are fenced off from stock. The $1 / 5$ ratio was taken from the results gained from the macrocarpa shelterbelt. These are conservative values in that these results are at the lower end of published values and the influence of trees on soil properties is likely to extend beyond the $5 \mathrm{~m}$ mark. 


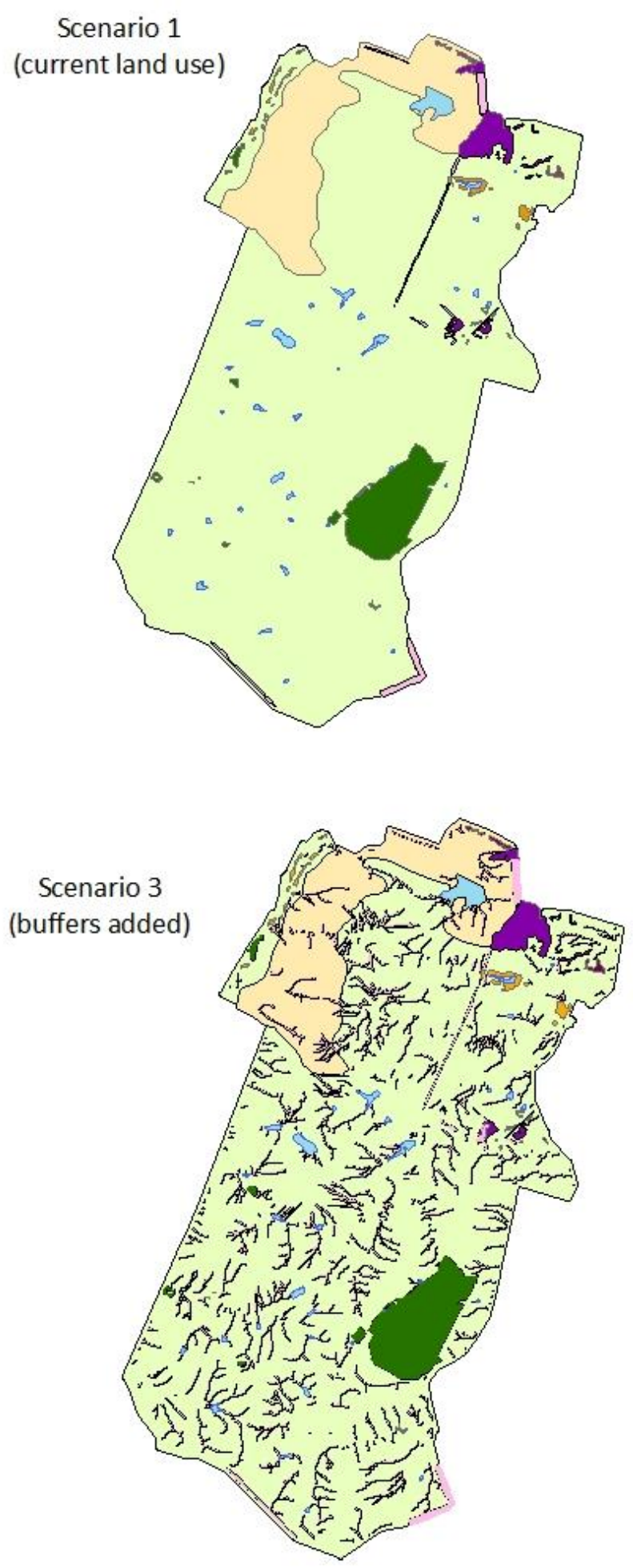

Scenario 2

(buffers removed)

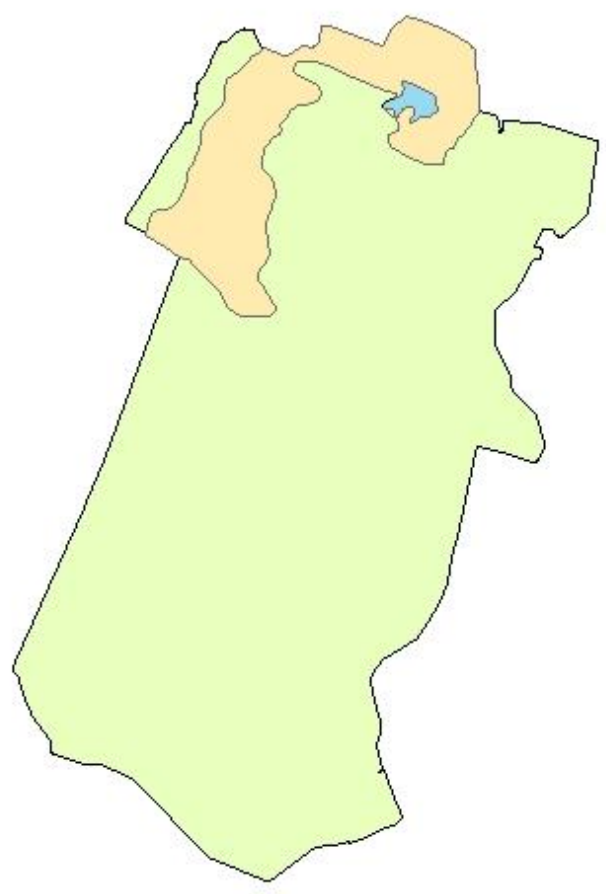

Deciduous Hardwoods

High Producing Exotic Grassland Indigenous Forest

Lake and Pond

Low Producing Grassland

Macrocarpa shelterbelt

Other Exotic Forest

Pine Forest - Open Canopy

Figure 43 The three land use scenarios used in the POLYSCAPE modelling. Scenario 1 is the farm under current land use. Scenario $\mathbf{2}$ is with buffers removed and Scenario $\mathbf{3}$ is with strategically positioned buffers added. 


\subsubsection{Prediction methodology}

The predictions were made using a common six-step approach as outlined in O'Connell et al. (2006:100):

1. Select an appropriate model to represent the changes in hydrological functioning due to the proposed land use management. The flood mitigation tool within POLYSCAPE.

2. Calibrate POLYSCAPE and run simulations in its state to prior to change. Land use scenario 1 simulates flow using the existing buffers under present day conditions.

3. Alter the model's parameters to reflect the change. Land use scenario 2 removes all existing buffers (trees and ponds); and land use scenario 3 adds new strategically placed buffers (trees).

4. Run simulations using the altered parameters. All three land use scenarios were run using a representative 'wet and dry' rainfall record, followed by the same records forced by $a 1^{\circ} \mathrm{C}$ and $2^{\circ} \mathrm{C}$ increase in atmospheric warming to reflect potential climate change impacts.

5. Estimate the effects of the change on the discharge hydrograph, based on the differences between the runoff responses in the step 4 'changed' simulations and the step 2 'unchanged' simulations. For results see section 6.6.

6. Estimate uncertainty bounds, with a stated reliability level, for the predicted effects. As there are no flow records to validate the model, the quickflow generated is a simulation and therefore should be treated as indicative only. Any future modelling would benefit greatly from continuous flow gauging in smaller farm catchments. Trying to disentangle flow from farms out of flow records from larger catchments can be difficult and time consuming, if not impossible without supplementary information.

\subsection{Experimental results}

The flood mitigation tool identified sinks/buffers within the landscape that have high storage or permeability. Under current land use conditions (scenario 1) $7 \%$ of the farm area is classified as providing mitigation and protects $56.4 \%$ of the landscape. In scenario 2 the existing sinks are removed (apart from the large reservoir in the north of the property) and the area of land protected falls to $2.2 \%$. Scenario 3 includes the current land use with an extra $3.2 \%$ of flood prone land planted in trees for a total of $10.3 \%$ buffer cover. This scenario mitigated/protected $85.8 \%$ of flood prone land which is an encouraging result for a relatively small increase in planted area (Table 26). 
Table 26 Ratio of pasture versus buffer cover resulting in amount of flood prone land protected/mitigated.

\begin{tabular}{|l|c|c|c|}
\hline $\begin{array}{l}\text { Land use scenarios } \\
\text { (total land area 12.6km })\end{array}$ & Pasture cover & Buffer cover & $\begin{array}{c}\text { Flood prone land } \\
\text { protected/mitigated }\end{array}$ \\
\hline Scenario 1 (current land use) & $11.7 \mathrm{Km}^{2}(92.9 \%)$ & $0.9 \mathrm{Km}^{2}(7.1 \%)$ & $6.6 \mathrm{Km}^{2}(56.4 \%)$ \\
Scenario 2 (buffers removed) & $12.6 \mathrm{Km}^{2}(99.6 \%)$ & $0.05 \mathrm{Km}^{2}(0.4 \%)$ & $0.5 \mathrm{Km}^{2}(2.2 \%)$ \\
Scenario 3 (buffers added) & $11.3 \mathrm{Km}^{2}(89.7 \%)$ & $1.3 \mathrm{Km}^{2}(10.3 \%)$ & $10.8 \mathrm{Km}^{2}(85.8 \%)$ \\
\hline
\end{tabular}

The cumulative amount of quickflow (overland and rapid subsurface flow) from the three land use scenarios was modelled using the three rainfall simulations creating a total of 9 model runs for each rainfall record (wet and dry). For each rainfall record the top three rainfall events are graphed with an accompanying table displaying the total amount of quickflow generated under the various land use scenarios.

\subsubsection{Wet period}

The highest rainfall event $\left(22^{\text {nd }} \mathrm{Jul} 92\right.$ ) produced the most quickflow in all 9 model runs with runoff greatest under the $2^{\circ} \mathrm{C}$ simulation. As expected, total quickflow was highest when all existing natural buffers were removed and smallest with the addition of strategically placed trees. The largest rainfall events occurred in winter and spring with the amount of quickflow generated dependent on antecedent soil moisture. In the largest event it rained for $32 \mathrm{hrs}$ with a peak of $13 \mathrm{~mm}$ at $19 \mathrm{hrs}$. By this time the soil had become saturated and the additional water was discharged as quickflow (Table 27 , Figure 44$)$. During the second largest event peak rainfall $(13.4 \mathrm{~mm})$ occurred close to the start and was absorbed by the buffers. Although the subsequent rainfall was lighter, it soon overwhelmed the remaining storage resulting in quickflow (Table 28, Figure 45). The third largest rainfall lasted for $4 \mathrm{hrs}$ with a total of $13.4 \mathrm{~mm}$ falling. In this event the buffers were able to temporarily store water as soil antecedent levels were low and thus quickflow was kept to a minimum (Table 29, Figure 46). When averaging quickflow generation from the three largest events using all three rainfall simulations then scenarios 1 and 3 reduced quickflow by $30 \%$ and $44 \%$ compared to the landscape with buffers removed (scenario 2).

Although the buffers were overwhelmed during the large rainfall events, total cumulative quickflow for the entire 'wet' period was still considerably lower under scenarios 1 and 3 . When averaging the results from all three rainfall simulations, scenario 1 reduced total quickflow by $36 \%$ compared to scenario 2. Scenario 3 performed best with a 51\% reduction in total quickflow compared to scenario 2 (Table 30, Figure 47). Although the reductions in quickflow were not huge during the wet period, any reduction is still beneficial as it lowers overall soil erosion and runoff quantities which helps to improve farm productivity and water quality. 
Table 27 Total quickflow generated by the different land use scenarios over $32 \mathrm{hrs}$ during the largest 'wet' rainfall event

\begin{tabular}{|l|c|c|c|}
\hline \multicolumn{1}{|c|}{ Largest rainfall event } & \multicolumn{3}{|c|}{ Total quickflow during event (mm) } \\
(21/07/92) & Original rainfall & With $1^{\circ}$ C increase & With $2^{\circ}$ C increase \\
\hline Scenario 1 (current land use) & 80.3 & 84.7 & 88.0 \\
Scenario 2 (buffers removed) & 104.5 & 108.9 & 112.3 \\
Scenario 3 (buffers added) & 71.6 & 75.8 & 78.8 \\
\hline
\end{tabular}

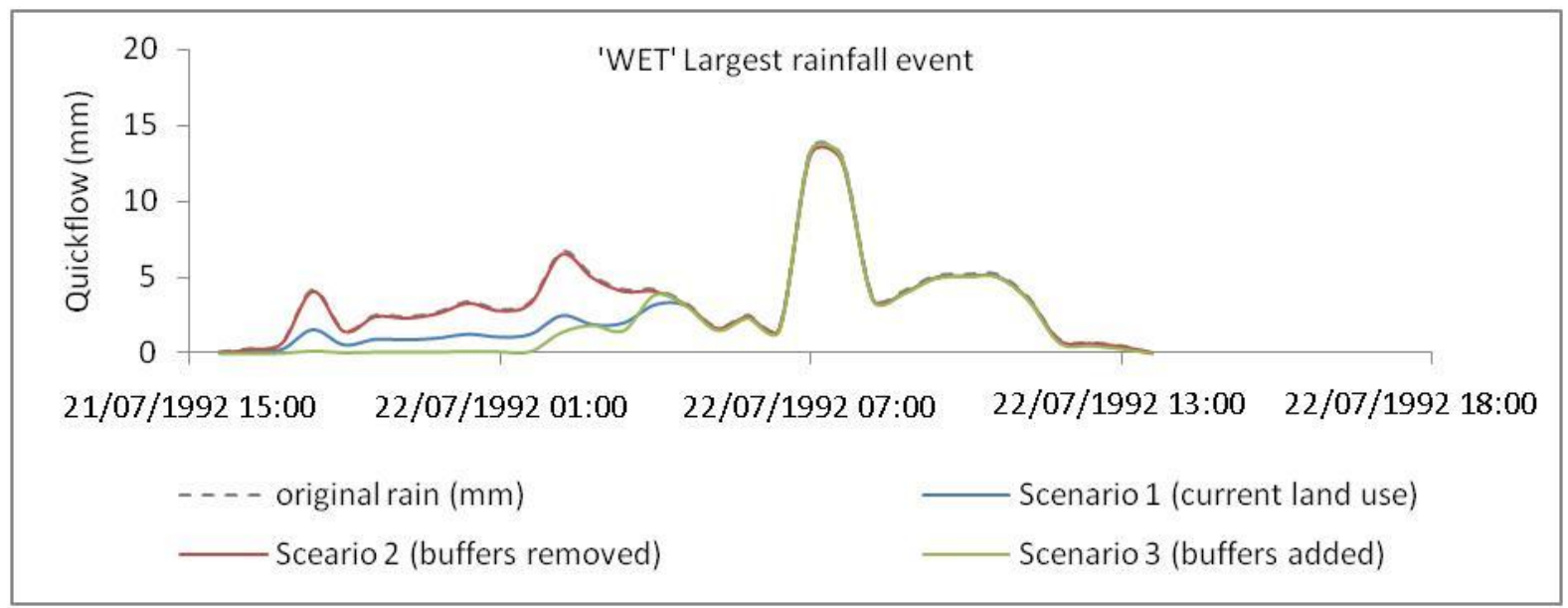

Figure 44 Hydrograph showing 'original' rainfall and quickflow response from the different land use scenarios during the largest 'wet' rainfall event.

Table 28 Total quickflow generated by the different land use scenarios over $42 \mathrm{hrs}$ during the $2^{\text {nd }}$ largest 'wet' rainfall event

\begin{tabular}{|l|c|c|c|}
\hline \multicolumn{1}{|c|}{$\mathbf{2}^{\text {nd }}$ largest rainfall event } & \multicolumn{3}{|c|}{ Total quickflow during event (mm) } \\
\hline Scenario 1 (current land use) & Original rainfall & With $1^{\circ}$ C increase & With $2^{\circ}$ C increase \\
Scenario 2 (buffers removed) & 41.9 & 25.2 & 21.8 \\
Scenario 3 (buffers added) & 58.5 & 50.3 & 46.6 \\
\hline
\end{tabular}

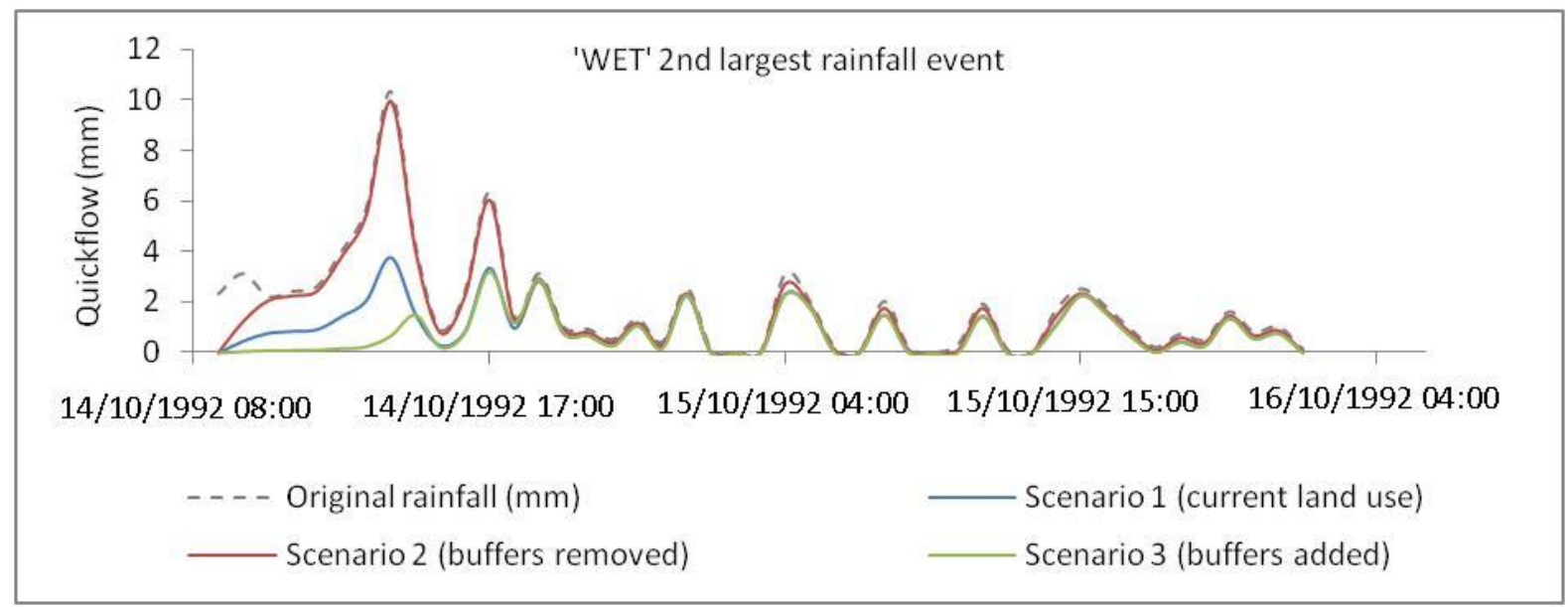

Figure 45 Hydrograph showing 'original' rainfall and quickflow response from the different land use scenarios during the $2^{\text {nd }}$ largest 'wet' rainfall event. 
Table 29 Total quickflow generated by the different land use scenarios over 4hrs during the 3rd largest 'wet' rainfall event

\begin{tabular}{|l|c|c|c|}
\hline \multicolumn{1}{|c|}{$3^{\text {rd }}$ largest rainfall event } & \multicolumn{3}{|c|}{ Total quickflow during event (mm) } \\
\hline Scenario 1 (current land use) & Original rainfall & With $1^{\circ}$ C increase & With $2^{\circ}$ C increase \\
Scenario 2 (buffers removed) & 4.2 & 2.4 & 0.0 \\
Scenario 3 (buffers added) & 11.2 & 6.4 & 0.0 \\
\hline
\end{tabular}

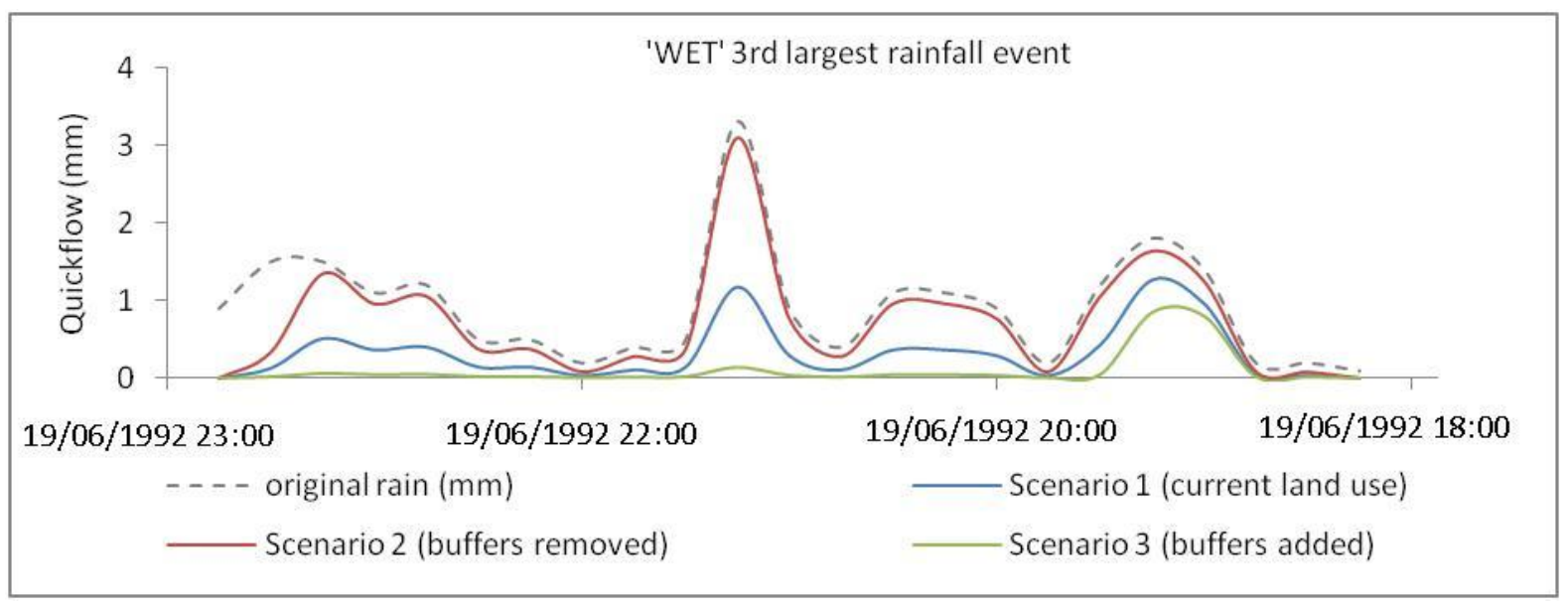

Figure 46 Hydrograph showing 'original' rainfall and quickflow response from the different land use scenarios during the $3^{\text {rd }}$ largest 'wet' rainfall event.

Table 30 Cumulative 'wet' quickflow under various land use scenarios and rainfall simulations for the entire 'wet' period.

\begin{tabular}{|c|c|c|c|}
\hline & \multicolumn{3}{|c|}{ Cumulative quickflow (mm) } \\
\hline & Original rainfall & With $1^{\circ} \mathrm{C}$ increase & With $2^{\circ} \mathrm{C}$ increase \\
\hline Scenario 1 (current land use) & 144 & 136 & 129 \\
\hline Scenario 2 (buffers removed) & 227 & 213 & 196 \\
\hline Scenario 3 (buffers added) & 108 & 103 & 101 \\
\hline
\end{tabular}



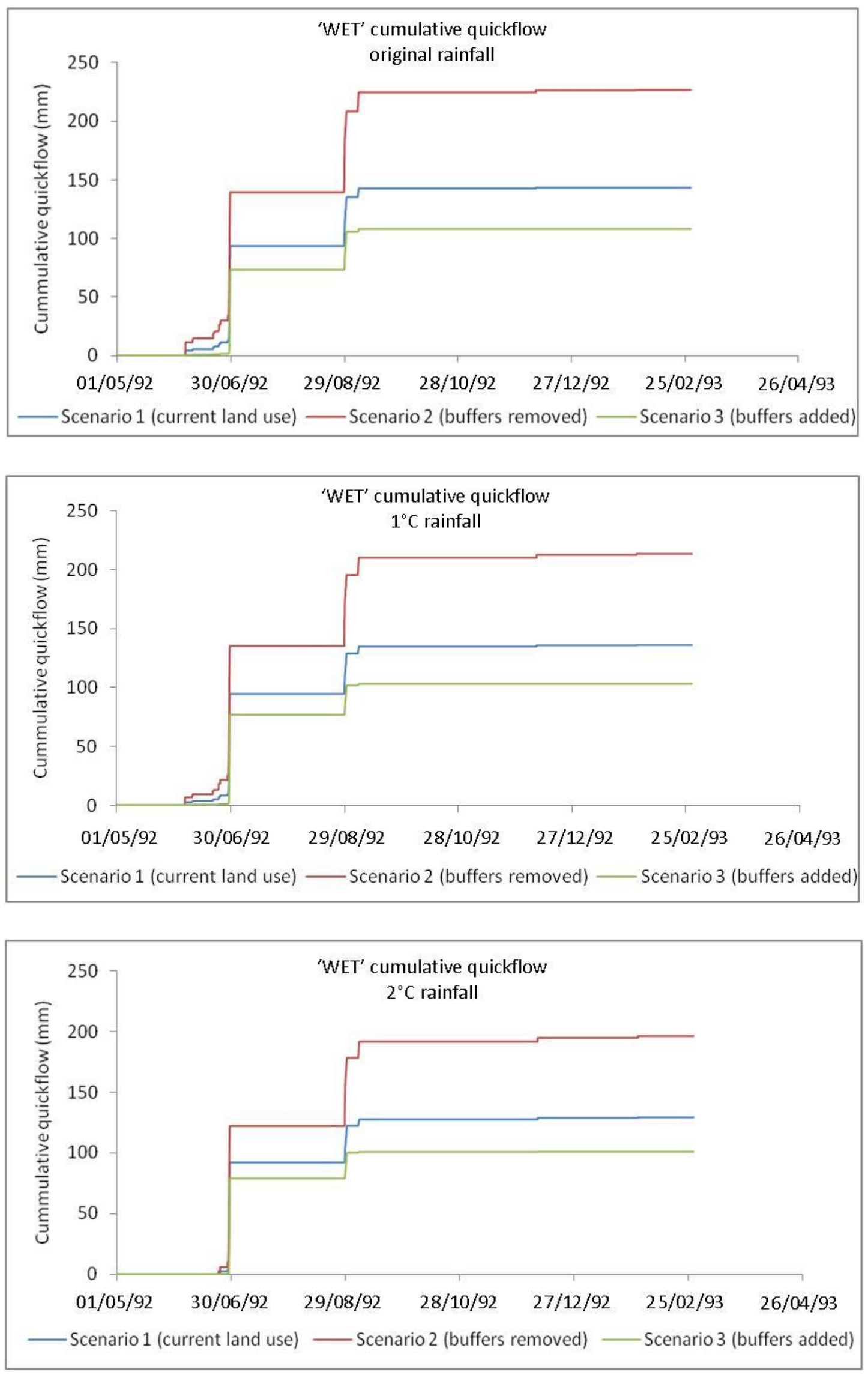

Figure 47 Cumulative quickflow from the different land use and rainfall scenarios over the entire 'wet' rainfall period. 


\subsubsection{Dry period}

Like the wet period, the highest rainfall event during the dry period ( $7^{\text {th }}$ Mar 09) produced the most quickflow in all 9 model runs with runoff greatest under the $2^{\circ} \mathrm{C}$ simulation. Again, total quickflow was highest when all existing natural buffers were removed and smallest with the addition of strategically placed trees (Table 31, Figure 48). The largest rainfall events occurred in summer when soil moisture levels were low with the bulk of the rain $(15.7 \mathrm{~mm}, 12 \mathrm{~mm}, 11.8 \mathrm{~mm})$ falling within one hour. This characteristic is typical of convective rainfall which is quite common in Hawkes Bay during the summer months. The dry soil conditions at the time of the rainfall had a dramatic effect on the impact of the natural buffers. In all three events scenario 3 performed very well with the majority of rainfall absorbed by the soil or stored in the ponds. Very little quickflow was generated with the sum of all three events equalling $0.8 \mathrm{~mm}$. The current land use (scenario 1 ) generated more quickflow with a total of $3.2 \mathrm{~mm}$. When the buffers were removed (scenario 2 ) the amount of total quickflow increased significantly to $8.5 \mathrm{~mm}$. When averaging quickflow generation from the three largest events using all three rainfall simulations then scenarios 1 and 3 reduced quickflow by $87.3 \%$ and 95.6\%. This is an important outcome as most of the damage caused by flooding occurs during the largest events.

A similar trend was observed with total cumulative quickflow for the entire 'dry' period much lower under scenarios 1 and 3. When averaging the results from all three rainfall simulations, scenarios 1 and 3 reduced total quickflow by $55 \%$ and $82 \%$ respectively compared to scenario 2 . What is particularly interesting is the extra $27 \%$ reduction between scenarios 1 and 3 for a relatively small increase in planted area (3.1\%) (Table 34 and Figure 50). 
Table 31 Total quickflow generated by the different land use scenarios during the largest 'dry' rainfall event

\begin{tabular}{|l|c|c|c|}
\hline \multicolumn{1}{|c|}{$\begin{array}{c}\text { Largest rainfall event } \\
\text { (7/03/09) }\end{array}$} & \multicolumn{3}{|c|}{ Total quickflow during event (mm) } \\
\hline Scenario 1 (current land use) & 3.2 & $1^{\circ} \mathrm{C}$ & $2^{\circ} \mathrm{C}$ \\
Scenario 2 (buffers removed) & 8.5 & 3.7 & 4.2 \\
Scenario 3 (buffers added) & 0.4 & 9.7 & 10.9 \\
\hline
\end{tabular}

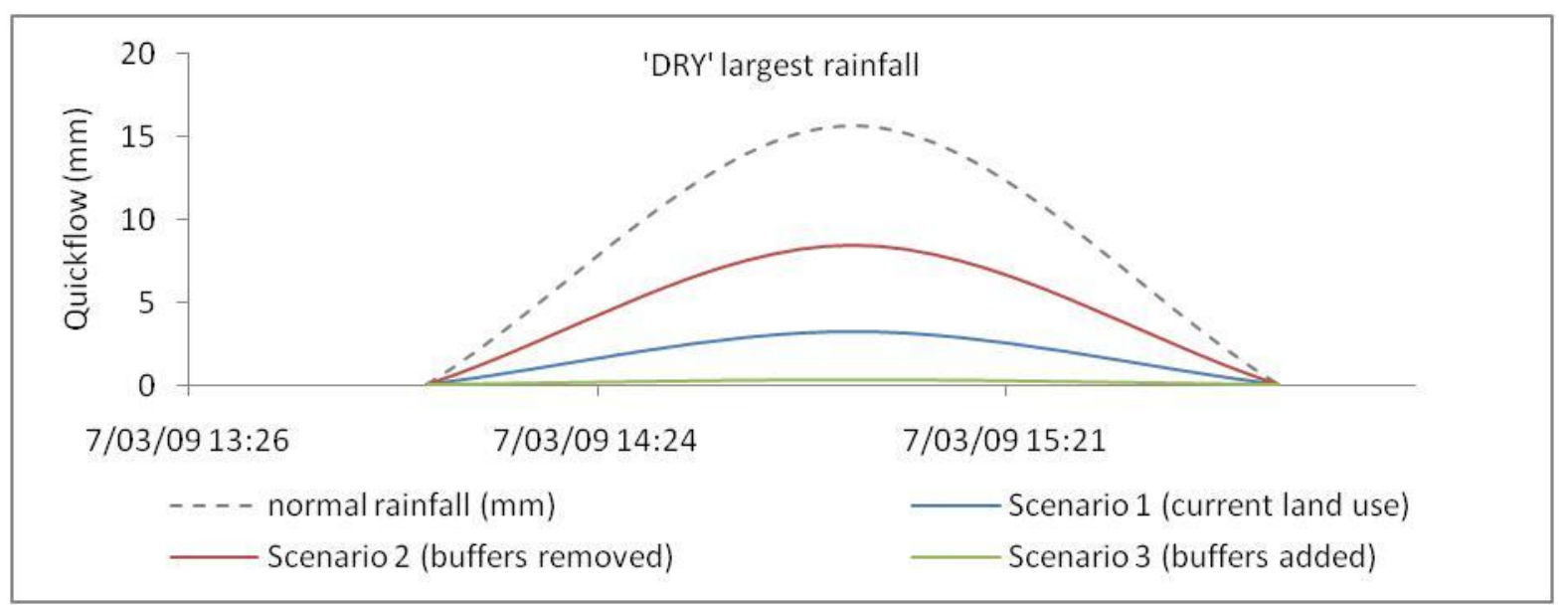

Figure 48 Hydrograph showing 'original' rainfall and quickflow response from the different land use scenarios during the largest 'dry' rainfall event.

Table 32 Total quickflow generated by the different land use scenarios during the $2^{\text {nd }}$ largest 'dry' rainfall event

\begin{tabular}{|l|c|c|c|}
\hline \multicolumn{1}{|c|}{$\mathbf{2}^{\text {nd }}$ largest rainfall event } & \multicolumn{3}{|c|}{ Total quickflow during event (mm) } \\
(10/02/09) & Original rainfall & With $1^{\circ} \mathrm{C}$ increase & With $2^{\circ} \mathrm{C}$ increase \\
\hline Scenario 1 (current land use) & 1.9 & 2.2 & 2.6 \\
Scenario 2 (buffers removed) & 4.9 & 5.8 & 6.7 \\
Scenario 3 (buffers added) & 0.2 & 0.3 & 0.3 \\
\hline
\end{tabular}

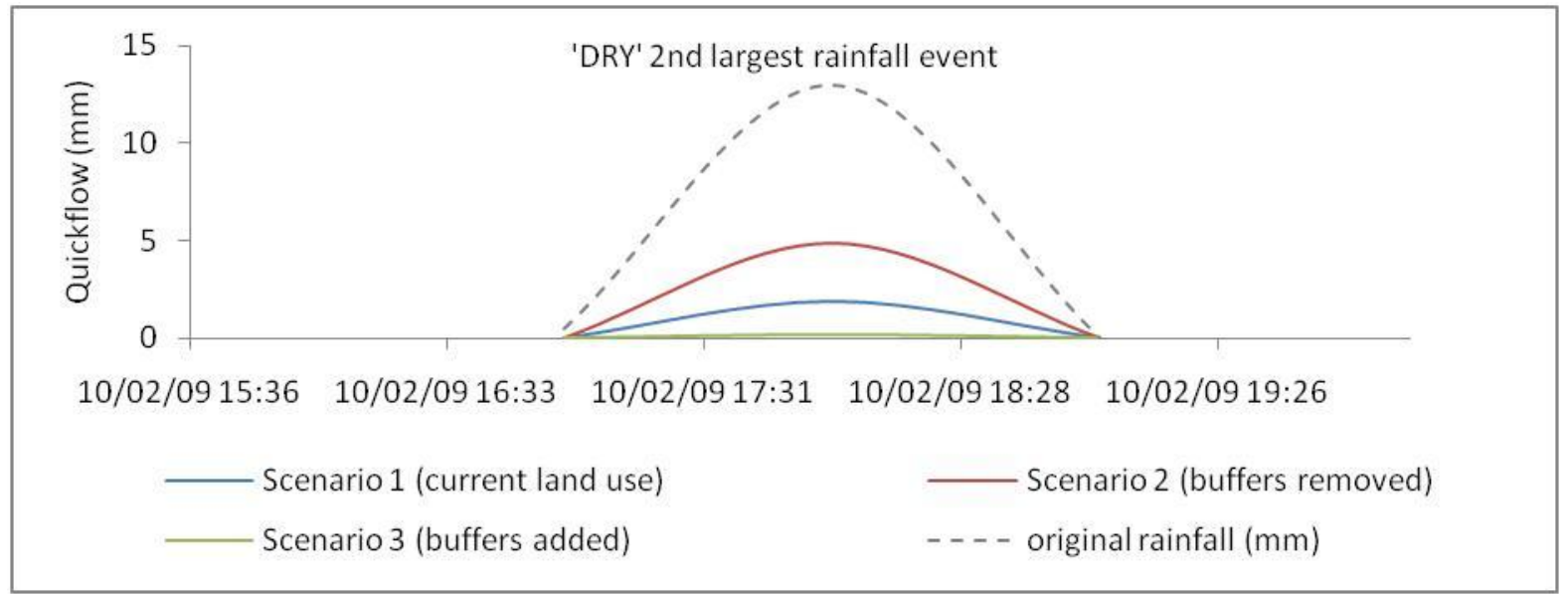

Figure 49 Hydrograph showing 'original' rainfall and quickflow response from the different land use scenarios during the $2^{\text {nd }}$ largest 'dry' rainfall event. 
Table 33 Total quickflow generated by the different land use scenarios during the $3^{\text {rd }}$ largest 'dry' rainfall event

\begin{tabular}{|c|c|c|c|}
\hline \multicolumn{1}{|c|}{$3^{\text {rd }}$ largest rainfall event } & \multicolumn{3}{|c|}{ Total quickflow during event (mm) } \\
(1/12/08) & Original rainfall & With $1^{\circ}$ C increase & With $2^{\circ}$ C increase \\
\hline Scenario 1 (current land use) & 1.8 & 2.1 & 2.5 \\
Scenario 2 (buffers removed) & 4.7 & 5.6 & 6.5 \\
Scenario 3 (buffers added) & 0.2 & 0.3 & 0.3 \\
\hline
\end{tabular}

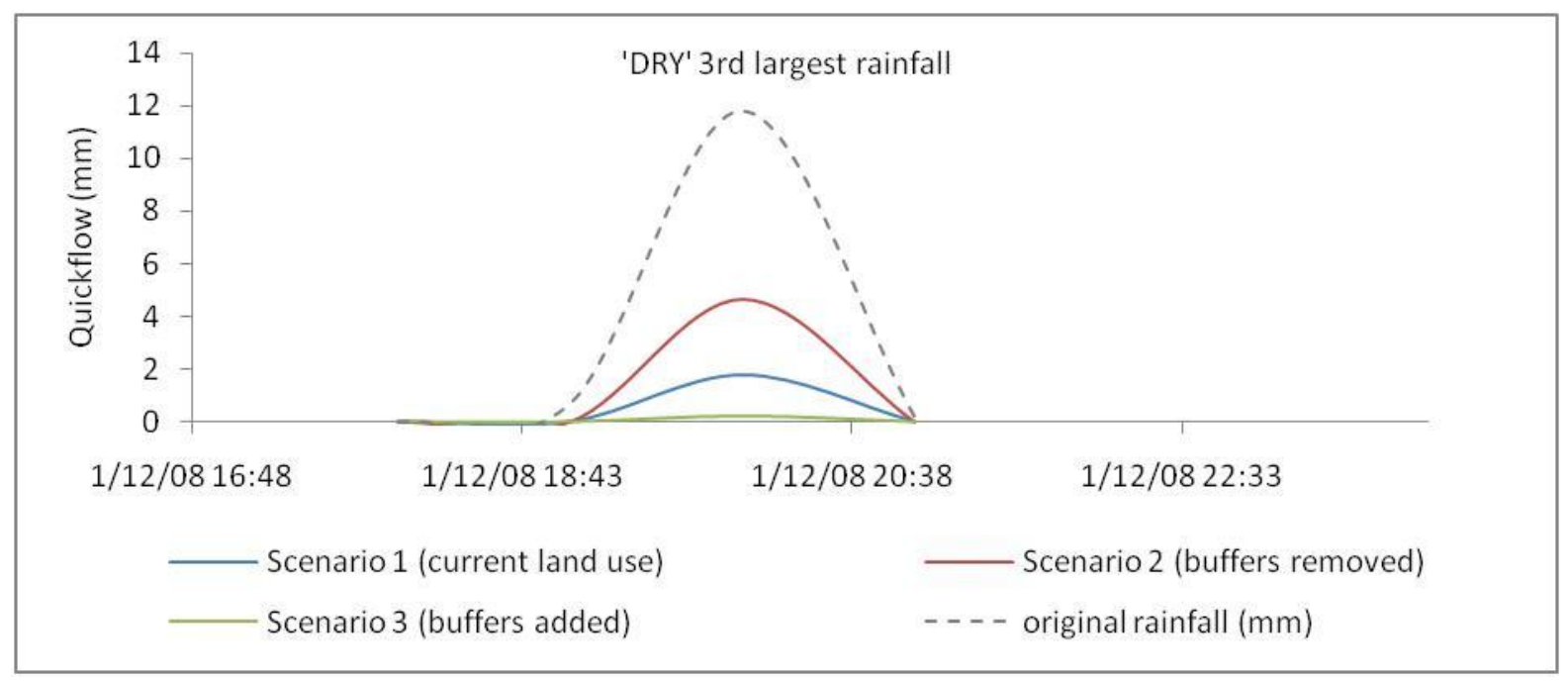

Figure 50 Hydrograph showing 'original' rainfall and quickflow response from the different land use scenarios during the $3^{\text {rd }}$ largest 'dry' rainfall event.

Table 34 Cumulative 'dry' quickflow under various land use scenarios and rainfall simulations for the entire 'dry' period.

\begin{tabular}{|c|c|c|c|}
\hline & \multicolumn{3}{|c|}{ Cumulative quickflow (mm) } \\
\hline & Original rainfall & With $1^{\circ} \mathrm{C}$ increase & With $2{ }^{\circ} \mathrm{C}$ increase \\
\hline Scenario 1 (current land use) & 43 & 48 & 39 \\
\hline Scenario 2 (buffers removed) & 101 & 100 & 89 \\
\hline Scenario 3 (buffers added) & 22 & 19 & 11 \\
\hline
\end{tabular}



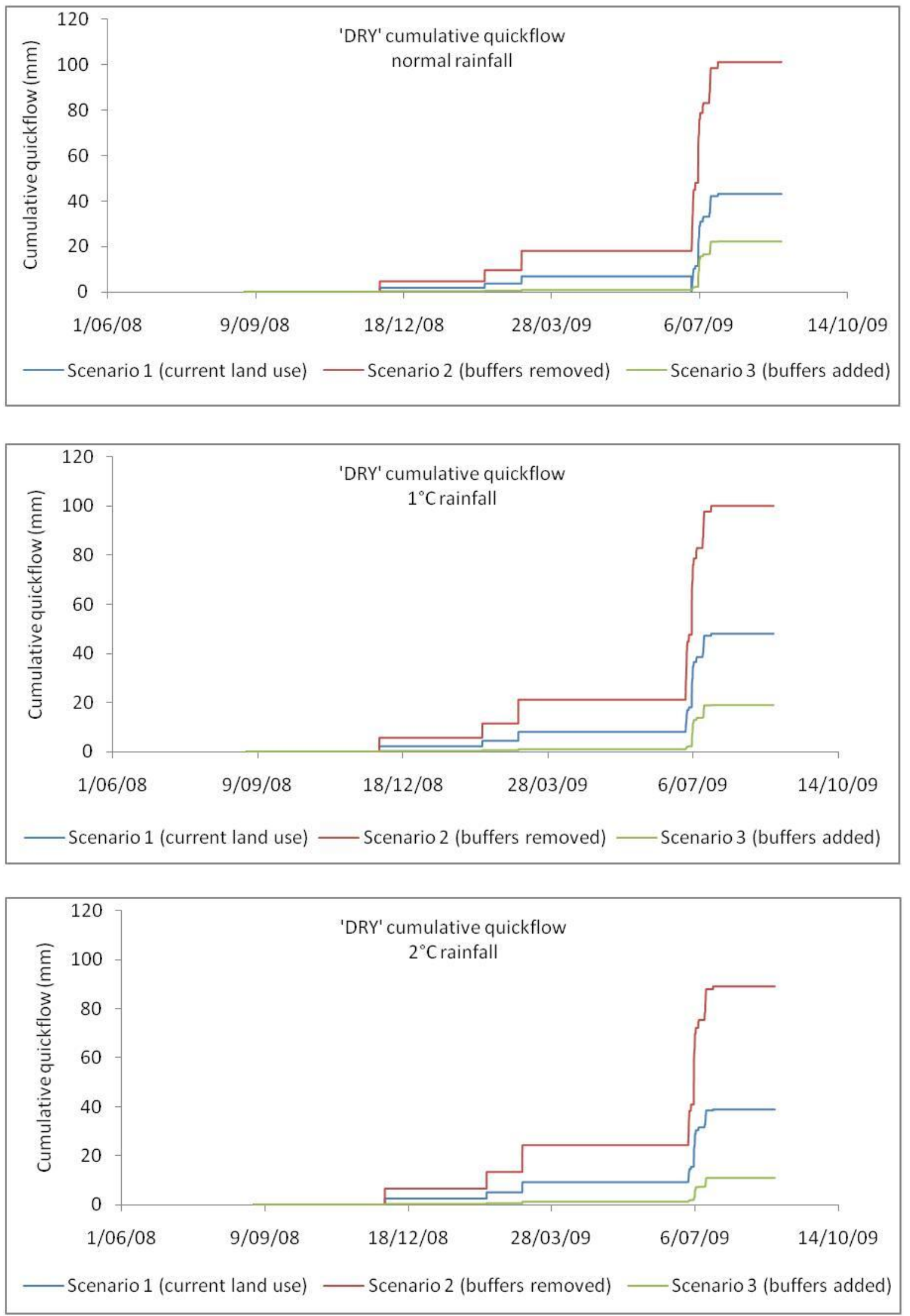

Figure 51 Cumulative quickflow from the different land use and rainfall scenarios over the entire 'wet' rainfall period. 


\subsection{Model uncertainty}

Modelling results are always subject to a degree of uncertainty. These include uncertainty in the model structure and the data used to force, calibrate and validate the model (O'Connell et al. 2006). Apart from the well-known general problems associated with rainfall-runoff modelling (see section 6.1.3), POLYSCAPE and indeed all other catchment models, have not fully represented all the mechanisms that effect runoff generation. Some of these include:

- Macroflow created by worm holes or soil cracking under very dry soil conditions;

- Diurnal and seasonal thermal/moisture cycling, including freeze thaw and shrinking/ swelling soil;

- Compacted soil caused by farm animals and vehicles;

- Natural vertical preferential flow path development;

- Rainfall impact and crust formation and degradation; and

- Artificial drainage such as tile and mole drains.

As well as these processes, a number of assumptions had to be made in regards to the data input (see section 6.5.1). Ideally for calibration purposes flow data from the study area would be used to help calibrate the model. Unfortunately the Takapau catchment is ungauged with the nearest flow gauging at the Tukituki River. This flow data was not suitable as the Tukituki River drains a very large catchment area. Although flow can be correlated for ungauged catchments, time constraints and the fact that the land use and buffers at Takapau farms were not representative of the broader area meant the rainfall was modelled as a simulation only. Any future research would benefit greatly from flow gauging in small catchments. A further source of error relates to the rain and evaporation data which was not measured at the farm with the gauges approximately $12.6 \mathrm{~km}$ to the east (wet record) and $30 \mathrm{kms}$ to the northwest (dry record). Lastly, the soil properties were assigned from the NSD and point measurements from 47 sample sites. Additional sampling would better represent the study area. However, there is a lack of nationally available information on a number of variables which influence flow predictions. For this reason any further research should consider the hydraulic conductivity of various species of trees in different soils including their ability to modify the Bhorizon. In addition, there are no percolation rates for the B-horizon listed in the NSD. As a consequence of the issues mentioned above, these results are speculative and further data is needed to reliably estimate uncertainty. 


\subsection{Summary of modelling results}

- The results from the modelling indicate that the capacity of natural buffers to reduce quickflow and thus mitigate flooding is strongly influenced by soil antecedent conditions. The model was run using a representative 'wet' and 'dry' rainfall record. The 'wet' record was characterised by large amounts of rain which kept the soil relatively wet. In these conditions the buffers had little extra capacity to store water when subjected to large rainfall events. The buffers performed better in small to medium events with significant reductions in total cumulative quickflow equalling $35 \%$ for scenario 1 , and $51 \%$ for scenario 3. Any reduction in quickflow is beneficial as it lowers soil erosion and runoff quantities which improves farm productivity and water quality.

- Although the 'dry' rainfall record had some large events, they were spaced far apart which kept the soil conditions drier. In these conditions rain from the three largest events was absorbed by the buffers with big reductions in quickflow of $87.3 \%$ for scenario 1 , and $95.6 \%$ for scenario 3. Total cumulative quickflow during the 'dry' period saw reductions of $55 \%$ and $82 \%$ for scenarios 1 and 3 . This suggests that buffers occupying a relatively small area of land can have very significant benefits for flood mitigation, especially when sited in areas of high flow accumulation.

- The current modelling results are speculative because they are based on many assumptions and incomplete data. Any future modelling would benefit from more specific vegetation and soil information, as well as direct flow gauging to help calibrate the model. 


\section{Chapter 7 - Discussion and conclusion}

\subsection{Discussion}

The ongoing development of floodplains combined with an expected increase in rainfall intensity due to climate change is increasing society's vulnerability to destructive flooding (Smith and Ward 1998). Traditionally industrialized countries have utilised engineered solutions to keep flood waters away from existing development. In New Zealand a commonly used flood protection solution is stopbanks. For stopbanks to be effective they have to be protected from erosion by the river. This protection is provided by bank-edge works such as rock linings, willow trees, groynes, and river berms which maintain channel position. Protection is also provided by active channel management which includes bed re-contouring and gravel extraction. Finally, bridges have to be upgraded to reduce the risk of debris dams forming so they don't restrict flow and therefore preserve the security of the flood protection system (WRC 2001). All of these measures incur significant and ongoing maintenance costs and may not be adequate to contain large floods on their own. An alternative 'Sustainable Flood Management' approach works in conjunction with engineered solutions. In particular 'Natural Flood Management' using trees and upland water retention such as wetlands has proven effective (see WWF (2002) for large scale examples). With this in mind, it might be cost effective in the long term to target flood producing land in the upper catchments rather than continually upgrade and maintain expensive engineered structures downstream.

Before such strategies can be robustly implemented there needs to be quantifiable data collected on the flood attenuation effectiveness of natural buffers under varying soil and climatic conditions. It has been suggested that the best way to achieve this is through a combination of field studies and multiscale hydrological modelling (O'Connell et al. 2006). With this goal in mind this thesis first reviewed the existing literature for evidence of proven flood attenuation benefits from natural buffers (Chapter 2). Secondly, the national scale land, soil and elevation data to be used as input for the hydrological modelling was 'ground truthed' for accuracy (Chapters 3-5). Thirdly, as trees were proposed as flood buffers the soil hydraulic properties of two species of tree commonly found on New Zealand farms were measured and results compared to pasture from the same location (Chapter 5). Lastly, hydrological modelling was undertaken with two objectives in mind. The first sought to establish the minimum DEM resolution required to get useful output from the POLYSCAPE model and when this was defined, identify areas of strategic importance both for protection and change. The second sought to quantify the flood mitigating effectiveness of natural buffers using a rainfall/soil moisture record which contained both significant rainfall events and periods of high soil 
moisture deficit. The remainder of this chapter summarises the main findings from each chapter and discusses directions for future research.

\subsubsection{Do natural buffers work?}

\section{a) Flooding}

There is substantial evidence from both New Zealand and abroad that show that natural buffers such as trees and wetlands can significantly increase storage and reduce flood peaks at the small catchment scale. Studies (including this research) comparing hydraulic conductivity between trees and pasture show that in general, forest soils are significantly more conductive and have greater storage than pasture soils. Further studies measuring streamflow from New Zealand suggest that targeted afforestation in smaller upland catchments can significantly decrease and delay flood peaks as they pass downstream in small to medium size events. In general, the greatest changes in storm runoff occur during the period of canopy closure which suggests that forest growth can cause a rapid change within a short period of time. Further research into the degree of resistance and infiltration offered by different species of riparian and floodplain vegetation, including contoured filter strips, would help to optimise their placement for flood mitigation.

Some quantitative data exists to support the restoration of wetlands and the reconnection of floodplains for managing flood waters. A worldwide review by Bullock and Acreman (2003) found that most lowland wetlands reduce or delayed floods by acting as spillways during peak rainfall events. However, just over half of the headwater wetlands mitigated floods with the remainder actually increasing flood peaks. Therefore, some data must be collected to identify a wetlands functional role before it is used for flood mitigation.

Although small catchment studies have shown that different land use types can either amplify or dampen the effects of extreme flood events, there is little evidence of the cumulative effects of subcatchment flood peaks as they converge downstream at the broader catchment scale. This does not mean there is no effect, but rather that the evidence has been hard to distinguish given other sources of natural variability e.g. climate and landscape heterogeneity (O'Connell et al. 2006). Currently the predominant thinking is in larger flood events (>10-year) when heavy rain falls in the lower, middle and upper catchments, then the cumulative effect of natural buffers would normally be small. However, if rainfall is heavy but localised, then natural buffers can still be effective. Ultimately, generalizations about buffer effectiveness should be discouraged because every catchment is unique. The propagation of a flood wave downstream is moderated by a complex interaction of catchment characteristics. These include: catchment geometry, channel network, 
rainfall pattern, hydraulic properties of soil/geology, area of contributing sub-catchments, and the timing and distance apart of tributaries. To better understand how local scale flood effects combine to affect flooding at larger scales new multiscale monitoring and modelling research is required. Disentangling land use flow signatures from large catchment flow data is difficult and time consuming because large catchment flow data is influenced by many other variables. Therefore, the multiscale modelling objective would benefit greatly from more continuous flow gauging in smaller contributing catchments along with gauging at the larger catchment scale.

\section{b) Erosion and sediment yield}

An associated benefit of decreasing rapid runoff is a significant reduction in erosion rates and sediment yield. By restricting the supply of sediment to river channels and flood plains, valuable topsoil and upland storage areas are maintained. Additional benefits include improved water quality, farm productivity, recreation and biodiversity. Results from New Zealand suggest afforesting or reverting close to $100 \%$ of small catchments can reduce average sediment yields by at least $50 \%$ and in most cases greater than $80 \%$. Most of the results were from either completely forested or deforested catchments. However, evidence shows that targeting areas where flow accumulates can significantly reduce sediment and runoff quantities at the plot scale. International studies have shown that contoured vegetative filter strips can reduce surface runoff and sediment loss by $18-60 \%$ and $50-90 \%$ respectively. To optimize the effectiveness of filter strips, livestock (especially cattle) should be excluded as they compact the surface soil exacerbating runoff rates.

\section{c) Experimental results from this study}

Modelling results from this study suggest overland flow is generated when the A-horizon layer is saturated. At Takapau farms the A-horizon is shallow (mean depth $27 \mathrm{~cm}$ ) and overlies a much less permeable subsoil (fragipan). Consequently, this top layer provides limited storage during rainfall events and swiftly becomes saturated since water is unable to percolate quickly to lower depths. One of the aims of this research was to examine whether trees and ponds can be used effectively as a flood mitigation measure. There is now substantial evidence from the literature that indicates that hydraulic conductivity rates in tree areas are generally much higher than in grazed pasture areas, a conclusion supported by this research. Thus, strategically located trees are likely to be useful in reducing rapid runoff. However, these areas must be able to store water for a sufficiently long period of time to be effective at reducing flood risk. Therefore more detailed knowledge of water storage and transmission in tree areas is required. In particular, where A-horizons are shallow and hence storage capacity low, the effect of different species of trees on the B-horizon soil properties is of great importance. 
Modelling results indicate that the capacity of natural buffers to reduce quickflow and thus mitigate flooding is strongly influenced by soil antecedent conditions. When the soil was relatively wet (as in winter) then the buffers had little extra capacity to store water when subjected to large rainfall events. When the soil was relatively dry (as in summer) then the buffers performed well during heavy rainfall with large decreases in quickflow. Future climate change projections for Hawkes Bay predict lower total rainfall yields, but higher rainfall intensity (NIWA 2008). These conditions will make the soil drier which could increase its storage capacity (albeit after an initial wetting up period). In this way natural buffers could be more effective for future flood mitigation, especially during sub-tropical storms which strike New Zealand during the summer. At the other extreme lower rainfall yield in the east of New Zealand might result in more frequent droughts. By increasing farm storage using natural buffers the water which would otherwise runoff can be utilised to help maintain farm productivity and other ecosystem services. Perhaps one of the biggest advantages when utilising natural buffers is the large amount of flood prone land that can be protected by a relatively small area in buffers. These areas are especially effective when sited in areas of high flow accumulation.

\subsubsection{Implementing Natural Flood Management techniques}

Now that it has been established that natural buffers work (although the extent of their effectiveness in large events is debatable and location specific), the challenge is to implement these techniques amongst land users. A large proportion of flood producing land is owned and managed by farmers with regulatory authority assigned to regional councils. Trying to convince a farmer to retire land in the interest of protecting downstream communities might not be a strong enough argument on its own. Demonstrating that such management has many co-benefits which can improve overall farm productivity provides a more convincing argument. Many of these benefits are well known with regional councils providing incentive schemes and information on farming best practice, especially in relation to riparian management. Riparian management includes fencing and planting around the margins of streams and wetlands. In addition to vast improvements in water quality, soil erosion, biodiversity, and amenity value, are increases in farm productivity. As farming is a business any opportunities that increase efficiency and profitability are seen as beneficial for farmers. Productivity is often improved by fencing out areas which are awkward to manage or hazardous to stock. The hazards to stock include exposure to liver fluke within streams, stock death by drowning, falling down steep banks, and getting bogged in mud. Stream bank fencing also provides cleaner water which causes less wear and tear on farm infrastructure such as irrigation and farm pumps. But perhaps the greatest benefit to farmers from clean water is the ability to produce a higher quality product because livestock are healthier when water is not contaminated by 
pathogens. This provides a 'clean green' marketing advantage when selling produce from farms managed in a sustainable way. Additional benefits for land users include enhanced environment for recreational pursuits such as fishing, swimming, or shooting. Downstream neighbours also enjoy cleaner water as sediment, dissolved chemicals and organic pollutants into water is minimised (TRC 2011; Stace 2004).

An important consideration for farmers when retiring land is the loss of potentially productive pasture. However, TRC (2011) claims $1 \mathrm{~km}$ of stream retired to a width of $5 \mathrm{~m}$ on both banks amounts to 1 ha of land, which is enough to support less than two dairy cows, or a dozen sheep. The problem with only fencing riparian areas is that once floodwaters reach the stream it is hard to delay its movement downstream unless it drains into a wetland/reservoir with significant storage. For vegetative strips to be effective they should ideally be set back from the stream so water can move as slower subsurface flow. This requires fencing and planting along ephemeral channels on hillsides which are source areas during flood events (Figure 52). If the cost of retiring this additional land does not match the productivity benefits of grazing it, communities or local government could compensate a farmer for any perceived losses in productivity. Indeed, such options are already being investigated in the UK by the Scottish Government (2011), and DEFRA (2003). Rather than abandoning the land totally, a compromise might include restricting stock access using temporary fencing during seasonally wet periods. Regrettably, such an approach would probably have little flood buffering benefit as plantings would be grazed leaving nothing but grasses, and soil would still be subject to surface compaction (albeit under drier soil conditions). Excluding stock during wet periods would still have other ecosystem benefits such as reducing soil erosion and improving water quality. The argument for establishing a "sustainable" style of farming could be improved if a multidisciplinary, highly instrumented 'research' farm was established (e.g. a Landcorp farm). In such a study changes in land use could be driven by 'best practice' principles and the results recorded over a long time scale (e.g. 20 years). The best practice principles and environmental indicators for measurement could include:

i) Establishing tree filter strips in areas of flow accumulation. Measure changes in soil properties and have gauges set up to measure rainfall, evaporation, soil moisture, and overland flow. The gauges should be positioned both uphill and downhill from the filter strip so the effects from the trees can be isolated.

ii) Measure changes in soil quality (structure, carbon and nutrient levels, worm abundance) and erosion rates throughout the farm. 
iii) Measure changes in water quality (turbulence, pathogens, nutrient levels etc) and stream morphology (streambed sediment size, channel morphology).

iv) Measure changes in terrestrial and aquatic biodiversity (species abundance, diversity, richness, habitat connectivity).

v) Record and analyze farm productivity (grass growth, stocking rates, stock health, quality of product, overall farm return).
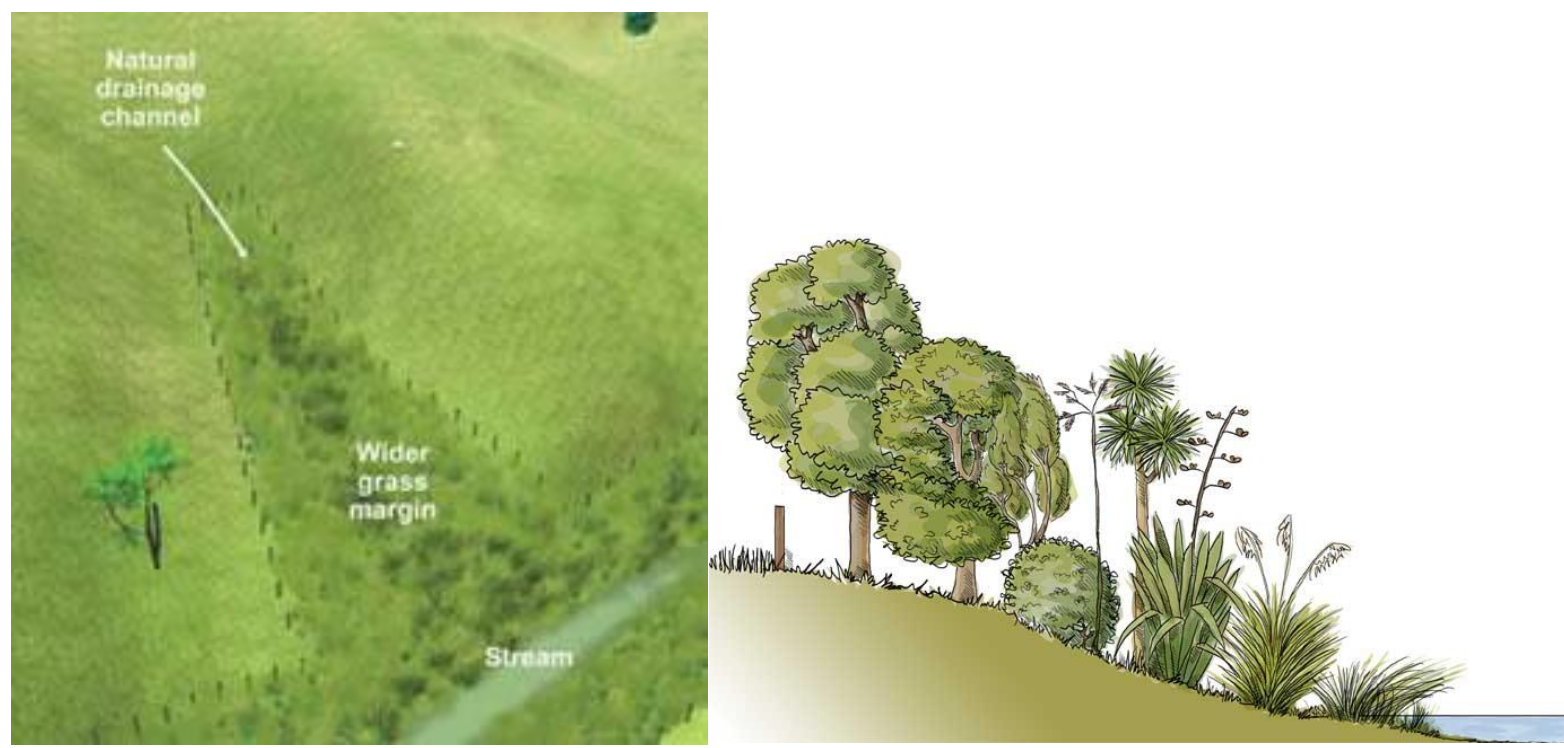

Figure 52 (left) Vegetative buffer zone along an ephemeral stream channel (ECan 2005); (right) an example of a planting profile using endemic plants (WRC 2009)

\section{a) Land management models}

As part of the Motueka Integrated Catchment Management programme Davie (2004) reviewed different hydrological modelling frameworks for use in a multiscale and multidiscipline land management programme. Davie (2004) reviewed five models, or sets of models that have some capacity to assess the accumulative effects of incremental changes in land and water management. The models included NIWA's TOPNET, the Catchment Modelling Toolkit developed in Australia, and the SWAT, DHVSM, PLM, and BASINS models from the USA. Davie (2004:21) concluded that "the five modelling systems were all capable of reproducing hydrological data to a certain extent... and that the ability of any model to accurately predict past events is largely dependent on the quality of data used as inputs". Although flooding, erosion and drought are important, there are also other landscape functions which need to be considered in any land management decision. There are many approaches which assess the impacts of land use on different landscape functions. Some of these include land use effects on ecological integrity (Aalders 2008; HillPlan 2010; Jin et al. 2009; SERDP 2011), agricultural productivity (Flach 2011; Smit et al. 2008; Tabeau et al. 2006; van Noordwijk 
2002) soil erosion and water quality (Brunner et al. 2008; Gitas et al. 2009; Grismer 2011; Wigmosta et al. 2009), and flooding (Barredo and Engelen 2010; Friesecke 2005; Simonovic 2011). The POLYSCAPE toolbox falls within this set of approaches, including algorithms which can quantify the synergies and/or tradeoffs between many different land use scenarios. The current tools can assess how land use change affects flood risk, erosion/sediment delivery, habitat connectivity, carbon sequestration, and agricultural productivity. Further tools in development include water quality, amenity, and cultural valuation. While the modelling of land use effects still has a way to go, progress in this area is being made worldwide.

\subsubsection{Is the national scale land, soil and elevation data appropriate for hydrological modelling at the farm scale?}

Any output from a model is only as accurate as the data input. This research tested the accuracy of national datasets in elevation, land use and soil type. The National Soil Database information with the classes $(m)$ and $(r)$ compared well with the measured field data and are suitable for modelling at the farm scale. The classes $(u)$ and ( $u f$ ) compared poorly to the measured field data. Any soil information from the $u$ and $u f$ classes would need to be ground truthed and corrected before they were used for hydrological modelling at the farm scale. The land use data from the New Zealand Land Resource Inventory broadly matched the land use classes observed on site. However, for greater accuracy additional digitizing to better represent the spatial position of landscape features at Takapau farms was necessary. The coarsest resolution Digital Elevation Model deemed appropriate for hydrological modelling at the farm scale was $10 \mathrm{~m}$. Of the three $25 \mathrm{~m}$ DEMs tested, one was created from LiDAR data while the other two were national DEMs created from LINZ topographic data. Although the LiDAR DEM performed marginally better than the Landcare and GeographX DEMs, all three are unsuitable for defining drainage patterns at the farm scale.

An important factor in the wide scale application of POLYSCAPE or indeed any flood risk prediction model is the cost associated with obtaining the necessary data to accurately apply the model. Fortunately the Hawkes Bay region generally has good soil information and therefore the need for additional soil sampling is less. This is important because field work (such as measuring hydraulic conductivity) is time consuming and expensive. If financial resources are limited then there are techniques to infer soil properties indirectly from other more easily measured properties (e.g. pedotransfer functions to calculate hydraulic conductivity), which might prove appropriate. Perhaps the largest potential cost however, is creating a DEM of sufficient resolution to obtain meaningful results from any modelling. At Takapau farms the coarsest resolution deemed appropriate is $10 \mathrm{~m}$. The finest resolution DEM currently available for the entire country is the Landcare $25 \mathrm{~m}$ DEM. 
Clearly, there is a need to create a finer resolution DEM from methods other than the expensive (but highly accurate) LiDAR source data. As many regional authorities have high resolution aerial photographs one promising technique might be digital aerial photogrammetry. Photogrammetry can generate high resolution DEMs (e.g. $5 \mathrm{~m}$ ) by means of automated image matching procedures (Farrow and Murray 1992; Heipke 1995; Mitchell and Chadwick 1999; Schenk 1999; Fabris and Pesci 2005). Other sources of data include the Shuttle Radar Topography Mission (SRTM) which obtained a near global scale DEM from data obtained by the space shuttle Endeavour in 2000. It used the same concept as photogrammetry but with satellite images to generate a global DEM of $90 \mathrm{~m}$, and a United States DEM of 30m (Keeratikasikorn and Trisirisatayawong 2008). This was succeeded by the ASTER project which is capable of producing a global DEM of $30 \mathrm{~m}$ and a $15 \mathrm{~m}$ DEM at the local scale (Hirano et al. 2003). The ASTER data and global DEM is a joint operation between NASA and Japan's Ministry of Economy, Trade and Industry (METI) and can be freely downloaded from the NASA website. Both the SRTM and ASTER DEMs are of coarse resolution at the global scale. However, these techniques can create finer DEMs at the local/national scale albeit subject to inherent errors (which for satellites is atmospheric interference). Currently, satellite imagery combined with photogrammetry techniques provides the most cost effective method for producing national scale DEMs of sufficient resolution for hydrological analysis (Hayakawa et al. 2008).

\subsection{Conclusion}

This research explored the flood mitigating effectiveness of natural buffers (trees and ponds) under varying rainfall and land use scenarios using a flood risk model from the POLYSCAPE toolbox. The modelling results suggest that the capacity of natural buffers to reduce quickflow is strongly influenced by soil antecedent conditions. In very wet soil conditions the buffers had little extra capacity to store water when subjected to large rainfall events. In contrast, the buffers were much more effective in drier soil conditions with the optimised buffer scenario able to absorb the majority of peak rainfall from the largest events. For this reason natural buffers could prove very effective at mitigating intense rainfall during drier summer periods e.g. sub-tropical storms. Although the buffers storage capacity was overwhelmed during a few peak events in wet soil conditions, the total amount of quickflow generated throughout the year was substantially less compared to the scenario where the buffers were removed. This is valuable because any reduction in quickflow will reduce soil erosion and therefore help maintain landscape storage capacity and other important ecosystem services.

The ability of any model to make practical predictions is largely dependent on the quality of data input. This research has highlighted the need for further targeted data collection to reliably estimate 
uncertainty. In particular, where A-horizons are shallow and hence storage capacity low, the effect of different species of trees on the B-horizon soil properties is of great importance. Furthermore, to improve predictions at the farm scale requires flow gauging in these catchments for calibration of the model, and to help isolate the effects of different land use at both the farm and wider catchment scale. Although the results from the modelling are speculative, the outcome is never the less encouraging. Results from both the model simulations and field measurements of hydraulic conductivity suggest that strategically placed ponds and small scale planting can be used to improve the infiltration and water storage capacity of extensive areas of grazed pasture. This will likely reduce runoff and erosion rates and thereby improve stream water quality and farm productivity at both the farm and wider catchment scale. Considering that flooding is the most frequent and costly natural hazard worldwide, natural buffers with their low maintenance costs and recognized ecosystem co-benefits could offer a cost effective and sustainable solution as part of future flood management planning. 


\section{References}

Aalders, I. 2008. Modeling land-use decision behavior with Bayesian belief networks Ecology and Society $13(1): 1-22$.

Adams, W.M., and M.R. Perrow. 1999. Scientific and institutional constraints on floodplain restoration. In Floodplains: Interdisciplinary approaches special publications 163, edited by S. Marriot, J. Danielander and R. Hey. London: Geological Society.

AghaKouchak, A. 2011. Basic definitions - Hydrologic modelling 2011 [cited 8/02/11 2011]. Available from http://www.aghakouchak.com/resources/hm/basic def $\mathrm{hm}$.

Alegre, J.C, and M.R Rao. 1996. Soil and water conservation by contour hedging in the humid tropics of Peru. Agricultural, Ecosystems and Environment 57:17-25.

Amoozegar, A. 1989. Comparison of the Glover solution with the simulataneous-equations approach for measuring hydraulic conductivity. Soil Science Society of America Journal 53:1362-1367.

Anderson, B.G, I.D Rutherford, and A.W Western. 2006. An analysis of the influence of riparian vegetation on the propagation of flood waves. Environmental Modelling and Software 21:1290-1296.

Arcement, G.J., and V.R. Schneider. 1990. Guide for selecting Manning's roughness coefficients for natural channels and flood plains. Washington, DC: U.S. Geological Survey Water supply paper 2339.

Aubertin, G.M. 1971. Nature and extent of macropores in forest soils and their influence on subsurface water movement. In Research Paper NE-192. Upper Darby: USDA, Forest Service.

Augusto, L, M.P Turpault, and J Ranger. 2000. Impact of forest trees on feldspar weathering rates. Geoderma 96:215-237.

Bagarello, V, M lovino, and W.D Reynolds. 1999. Measuring hydraulic conductivity in a cracking clay soil using the guelph permeameter. Transactions of the ASABE 42 (4):957-964.

Bai, Y, T Wagener, and P Reed. 2009. A top-down framework for watershed model evaluation and selection under uncertainty. Environmental Modelling \& Software 24 (8):901-916.

Bandaragoda, C., D.G. Tarboton, and R. Woods. 2004. Application of TOPNET in the distributed model intercomparison project Journal of Hydrology 298:178-201.

Bardossy, A. 2005. Fuzzy sets in rainfall/runoff modeling. In Encyclopedia of Hydroloic Sciences, edited by M. G. Anderson and J. J. McDonnell: John Wiley \& Sons Ltd.

Bargh, B. 1977. Output of water, suspended sediment, phosphorus and nitrogen from a small forested catchment. New Zealand Journal of Forestry 7:162-71.

Bargh, B. 1978. Output of water, suspended sediment, phosphorus and nitrogen from a small agricultural catchment. New Zealand Journal of Agricultural Research 21:29-38.

Barredo, J.I., and G. Engelen. 2010. Land use scenario modeling for flood risk mitigation. Sustainability 2:1327-1344.

Barringer, J.R.F, D Pairman, and S.J McNeill. 2002. Development of a high-resolution digital elevation model for New Zealand. Wellington: Landcare Research.

Bartens, J, S.D Day, R.J Harris, J.D Dove, and T.M Wynn. 2008. Can Urban Tree Roots Improve Infiltration through Compacted Subsoils for Stormwater Management? Journal of Environmental Quality 37:2048-2057.

Batey, T. 2001. Soil profile description and evaluation. In Soil and Environmental Analysis - Physical Methods, edited by K. A. Smith and C. E. Mullins. New York: Marcell Dekker Inc.

Baumgartl, T, and R Horn. 1991. Effect of aggregate stability on soil compaction. Soil and Tillage Research 19:203-213.

Beavis, S, and M Howden. 1996. National Landcare Program (NLP) Project: Effects of farm dams on water resources: Bureau of Resource Sciences.

Beims, U, F Jenn, K Knodel, M Liese, R Nagare, C Nitsche, M Porzig, and H.-J Voigt. 2007. Methods for characterizing the Hydrologic and Hydraulic Conditions. In Environmental Geology - 
Handbook of Field Methods and Case Studies edited by K. Knodel, G. Lange and H.-J. Voigt. Berlin: Springer.

Berglund, E.R, A Ahyoud, and M Tayaa. 1981. Comparison of soil and infiltration properties of range and afforested sites in northern Morocco. Forest Ecology and Management 3:295-306.

Beven, K, and P Germann. 1982. Macropores and water flow in soils. Water Resources research 18 (5):1311-1325.

Beven, K.J. 2001. Rainfall-runoff modelling: the primer. Chichester: John Wiley \& Sons Ltd.

Beven, K.J. 2005. Rainfall-runoff modeling: Introduction In Encyclopedia of Hydrological Sciences, edited by B. G. Anderson: John Wiley \& Sons Ltd.

Beven, K.J., R. Lamb, P. Quinn, R. Romanowicz, and J. Freer. 1995. Topmodel. In Water Resources Publications, edited by V. P. Singh: Highland Ranch.

Black, R. 1998. Sediment yields from Pakuratahi and Tamingmingi catchments (from unpublished LR contract reports to Carter Holt Harvey). As cited in Blaschke, Hicks, and Meister (2008).

Blaschke, P, D Hicks, and A Meister. 2008. Quantification of the flood and erosion reduction benefits, and costs, of climate change mitigation measure in New Zealand. Report prepared by Blaschke and Rutherford Environmental Consultants for MfE. Wellington: Ministry for the Environment.

Blöschl, G, and M Sivapalan. 1995. Scale issues in hydrological modelling: A review. Hydrological Processes 9:251-290.

Blöschl, G. 2005. Rainfall-runoff modeling of ungauged catchments. In Encyclopedia of Hydrological Sciences, edited by A. G. Anderson: John Wiley \& Sons.

Blunt, M.E, and M Hilpert. 2001. Pore scalel modeling. Advances in Water Resources 24:231-478.

Bonell, M. 1993. Progress in the understanding of runoff generation dynamics in forest. Journal of Hydrology 150:217-275.

Bonnell, M, A.J Pearce, and M.K Stewart. 1990. The identification of runoff production mechanisms using environmental isotopes in a tussock grassland catchment, eastern Otago, New Zealand. Hydrological Processes 4:15-34.

Bosch, J. M., and J. D. Hewlett. 1982. A review of catchment experiments to determine the effect of vegetation changes on water yield and evapotranspiration. Journal of Hydrology 55 (1-4):323.

Bouwer, H. 1986. Intake rate: Cylinder Infiltrometer. In Methods of soil analysis Part 1: Physical and Mineralogical methods, edited by A. Klute. Madison: Agronomy Monograph No. 9. American Society of Agronomy.

Bowden, W.B, B.D Fahey, J Ekanayake, and D.L Murray. 2001. Hillslope and wetland hydrodynamics in a tussock grassland, South Island, New Zealand. Hydrological Processes 15:1707-30.

Brassington, Rick. 2007. Field hydrogeology. 3 ed. Michigan University: John Wiley.

Brown, Alice E., Lu Zhang, Thomas A. McMahon, Andrew W. Western, and Robert A. Vertessy. 2005. A review of paired catchment studies for determining changes in water yield resulting from alterations in vegetation. Journal of Hydrology 310 (1-4):28-61.

Brown, K.R. 1968. The influence of herbage height at treading and treading intensity on the yields and botanical composition of a perennial ryegrass - white clover pasture. New Zealand Journal of Agricultural Research 11:131-137.

Brunner, A.C., S.J. Park, G.R. Ruecker, and P.L.G. Vlek. 2008. Erosion modelling approach to simulate the effect of land management options on soil loss by considering catenary soil development and farmers perception. Land Degradation \& Development 19:623-635.

Buchan, D , A Meister, and N Giera. 2006. Bridging the gap between environmental knowledge and research, and desired environmental outcomes to achieve sustainable land management, edited by B. Bell: Ministry of Agriculture and Forestry.

Bullock, A, and M Acreman. 2003. The role of wetlands in the hydrological cycle. Hydrology and Earth Systems Sciences 7 (3):358-389. 
Burch, G.J, R.K Bath, I.D Moore, and E.M Loughlin. 1987. Comparative hydrological behaviour of forested and cleared catchments in south-eastern Australia. Journal of Hydrology 90:19-42.

Burt, T.P, T.P Butcher, N Coles, and A.D Thomas. 1983. The natural history of Slapton Ley Nature Reserve XV: hydrological processes in the Slapton Wood catchment. Field Studies 5:731-752.

Buttle, J.M, and D.A House. 1997. Spatial variability of saturated hydraulic conductivity in shallow macroporous soils in a forested basin. Journal of Hydrology 203:127-142.

Campbell, D, and R Jackson. 2004. Hydrology of wetlands. In Freshwaters of New Zealand, edited by J. Harding, P. Mosley, C. Pearson and B. Sorrell. Christchurch: New Zealand Hydrological Society \& New Zealand Limological Society

Campbell, G.S, A Stobbs, L Ternan, and A Williams. 1996. Localised impact of Sitka Spruce (Picea sitchensis (Bong) Carr.) on soil permeability. Plant and Soil 182:157-169.

Carroll, Z. L., S. B. Bird, B. A. Emmett, B. Reynolds, and F. L. Sinclair. 2004. Can tree shelterbelts on agricultural land reduce flood risk? Soil Use and Management 20 (3):357-359.

Chandler, D.G, and M.F Walter. 1998. Runoff responses among common land uses in the Uplands of Matalom, Leyte, Philippines. Vol. 41: American Society of Agricultural Engineers.

Chandler, K.R, and N.A Chappell. 2008. Influence of individual oak (Quercus robur) trees on saturated hydraulic conductivity. Forest Ecology and Management 256:1222-1229.

Chaney, K, and R.S Swift. 1984. The influence of organic matter on aggregate stability of some British soils. Journal of Soil Science 35:223-230.

Chappell, N.A, and S.W Franks. 1996. Property distributions and flow structure in the Slapton Wood catchment. Field Studies 8:559-575.

Chappell, N.A, and J.L Ternan. 1997. Ring permeametry: Design, operations and error analysis. Earth Surface Processes and Landforms 22:1197-1205.

Chappell, N.A, J.L Ternan, and K Bidin. 1999. Correlation of physicochemical properties and suberosional landforms with aggregate stability variations in a tropical Ultisol disturbed by forestry operations. Soil and Tillage Research 50:55-71.

Chell, J. 2007. Measurement of saturated hydraulic conductivity of Pontbren soils and preliminary modelling analysis Imperial College, London.

Christensen, J.H., B. Hewitson, A. Busuioc, A. Chen, X. Gao, I. Held, R. Jones, R.K. Kolli, W-T. Kwon, R. Laprise, R.V. Magaña Rueda, L. Mearns, C.G. Menéndez, J. Räisänen, A. Rinke, A. Sarr, and P. Whetton. 2007. Regional climate projections. In Climate change 2007: the physical science basis. Contribution of Working Group I to the Fourth Assessment Report of the Intergovernmental Panel on Climate Change edited by S. Solomon, D. Qin, M. Manning, Z. Chen, M. Marquis, K. B. Averyt, M. Tignor and H. L. Miller: Cambridge University Press, Cambridge, United Kingdom and New York, NY, USA.

Claridge, G. 1980. Studies of water quantity and quality at Taita and their possible significance to the Nelson situation. In Proceedings of a seminar on land use in relation to water quantity and quality, Nelson 1979 Nelson Catchment Board.

Climo, W.J, and M Richardson. 1984. Factors affecting the susceptibility of three soils in the Manawatu to stock treading. New Zealand Journal of Agricultural Research 27:247-253.

Clothier, B.E. 2001. Infiltration. In Soil and Environmental Analysis - Physical Methods, edited by K. A. Smith and C. E. Mullins. New York: Marcel Decker Inc.

Clothier, B.E, and I White. 1981. Measurementt of sorptivity and soil water diffusivity in the field. Soil Science Society of America Journal 45:241-245.

Cooke, J.G. 1988. Sources and sinks of nutrients in a New Zealand hill pasture catchment II. Phosphorus Hydrological Processes 2:123-133.

Cooke, J.G, and A.B Cooper. 1988. Sources and sinks of nutrients in New Zealand hill pasture catchment III. Nitrogen. Hydrological Processes 2:135-149.

Costalles, E.F. 1979. Infiltration rates of soils as influenced by some land-use types in the Benguet pine watershed. . Sylvatrop 4 (4):255-260. 
Crawford, N.H., and R.K. Lindsay. 1966. Digital simulation in hydrology's Stanford watershed model 4. In Technical report no. 39: Stanford University.

Danalatos, N.G, C.S Kosmas, P.M Driessen, and N Yassoglou. 1994. Estimation of the draining soil moisture characteristic from standard date as recorded in routine soil surveys. Geoderma 64:155-165.

Daniels, R.B, and J.W Gilliam. 1996. Sediment and chemical load reduction by grass and riparian filters. Soil Science Society of America Journal 60:246-251.

Darby, S. 1999. Effect of riparian vegetation on flow resistance and flood potential. Journal of Hydraulic Engineering (May 1999):443-454.

Darcy, Henry. 1856. Les Fontaines Publiques de la Ville de Dijon ("The Public Fountains of the Town of Dijon"). Dalmont, Paris.

David, T.S, J.H.C Gash, F Valente, J.S Pereira, M.I Ferreira, and J.S David. 2006. Rainfall interception by an isolated evergreen oak tree in a Mediterranean savannah. Hydrological Processes 20 (13):2713-2726.

Davie, J.T. 1996. Modelling the influence of afforestation on hillslope storm runoff. In Advances in hillslope processes, edited by M. G. Anderson and S. M. Brooks. Chichester: John Wiley \& Sons.

Davie, T, and B Fahey. 2005. Forestry and water yield - current knowledge and future work. New Zealand Journal of Forestry 49 (4):3-8.

Davie, T. 2004. Review of different hydrological modelling frameworks for usage in the Motueka Integrated Catchment Management programme of research In Motueka Integrated Catchment Management (Motueka ICM) Programme Report Series. Lincoln: Landcare Research.

Davies, S.H., R.A. Vertessey, and R.P. Silberstein. 1999. The sensitivity of a catchment model to soil hydraulic properties obtained by using different measurement techniques. Hydrological Processes 13:677-688.

Davis, S.H, R.A Vertessy, and R.P Silberstein. 1999. The sensitivity of a catchment model to soil hydraulic properties obtained by using different measurement techniques. Hydrological Processes 13:677-688.

Davoren, A. 1978. A survey of New Zealand's peat resources. In Water and Soil Technical Publication No.14. Hamilton: University of Waikato.

DEFRA. Managed Realignment: Land Purchase, Compensation and Payment for Alternative Beneficial Land Use. Department for Environment, Food and Rural Affairs 2003 [cited 17/02/11.

Available from

http://www.defra.gov.uk/environment/flooding/policy/guidance/realign.htm.

DHI. 2011. MIKE by DHI software. DHI Water \& Environment 2011 [cited 7/02/11 2011]. Available from http://www.mikebydhi.com/.

Dirksen, C, and S Matula. 1994. Automatic atomized water spray system for soil hydrauliic measurements. Soil Science Society of America Journal 58:319-325.

Dirksen, Christian. 2001. Unsaturated hydraulic conductivity. In Soil and Environmental Analysis Physical Methods, edited by K. A. Smith and C. E. Mullins. New York: Marcell Decker Inc.

DOC. 2007. The economic values of Whangamarino Wetland: Department of Conservation.

Dons, A. 1986. The effect of large-scale afforestation on Tarawera River flows. New Zealand Journal of Hydrology 25:61-73.

Dons, A. 1987. Hydrology and sedimentary regime of a pine, native forest and pasture catchment in the central North Island New Zealand Journal of Forestry (17):161-78.

Drewry, J.J, R.P Littlejohn, and R.J Paton. 2000. A survey of soil physical properties on sheep and dairy farms in southern New Zealand New Zealand Journal of Agricultural Research 43 (2):251-258.

Duncan, M. J. 1995. Hydrological impacts of converting pasture and gorse to pine plantation, and forest harvesting, Nelson, New Zealand. Journal of Hydrology (New Zealand) 34 (1):15-41. 
Durner, W, and K Lipsius. 2005. Determining soil hydraulic properties. In Encyclopedia of Hydrological Sciences, edited by M. G. Anderson: John Wiley \& Sons.

ECan. 2005. A guide to managing waterways on Canterbury farms. Christchurch: Environment Canterbury.

Edmond, D.B. 1958. The influence of treading on pasture - a preliminary study. New Zealand Journal of Agricultural Research 1:319-328.

Edmond, D.B. 1974. Effects of sheep treading on measured pasture yield and physical conditions of four soils. New Zealand Journal of Agricultural Research 2:39-43.

Elkateb, T, R Chalaturnyk, and P.K Robertson. 2003. An overview of soil heterogeneity: quantification and implications on geotechnical field problems. Canadian Geotechnical Journal 40:1-15.

Elliot, A.H, Y.Q Tian, J.C Rutherford, and W.T Carlson. 2002. Effect of cattle treading on interrill erosion from hill pasture:modelling concepts and analysis of rainfall simulator data. Australian Journal of Soil Research 40:963-976.

Elrick, D.E, and W.D Reynolds. 1989. Water flux components and their measurement. Proceedings of applied soil physical stress environments, January 22-26, National Agricultural Research Council, Islamabad.

Elrick, D.E, and W.D Reynolds. 1992. Methods for analyizing constant-head permeameter data. Soil Science Society of America Journal 56:320-323.

Elrick, D.E, W.D Reynolds, and K.A Tan. 1989. Hydraulic conductivity measurements in the unsaturated zone using improved well analysis. Ground Water Monitoring \& Remediation 9:184-193.

Everitt, S. 2006. Guidelines for the design, construction, maintenance and safety of small flood detention dams. Whakatane: Prepared for Environment Bay of Plenty by Waterline Engineering Consultants.

Fabris, M., and A. Pesci. 2005. Automated DEM extraction in digital aerial photogrammetry: precisions and validation for mass movement monitoring. Annals of geophysics 48 (6):973988.

Fahey, B, W.B Bowden, J Smith, and D.L Murray. 1998. Hillslope-wetland hydrological linkages in the headwaters of a tussock grassland catchment at Glendhu, South Island, New Zealand. In Hydrology, Water Resources and Ecology in Headwaters. Proceedings of the HeadWater '98 Conference held at Meran/Merano, Italy, April 1998. IAHS Publ. 248.

Fahey, B.D. 1999. Pre-harvest sediment yields: a comparison between pasture and forest. . In Environmental Working Group meeting notes, LIRO.

Fahey, B.D, M.J Duncan, and J Quinn. 2004. Impacts of forestry. In Freshwaters of New Zealand, edited by M. P. Harding J, Pearson C, Sorrell B NZ Hydrological Society and NZ Limnological Society.

Fahey, B.D, and R.J Jackson. 1997. Hydrological impacts of converting native forests and grasslands to pine plantations, South Island, New Zealand. Agricultural and Forestry Meteorology (84):69-82 (cited by Fahey et al, 2004).

Fahey, B.D, and L. K. Rowe. 1992. Land use impacts. In Waters of New Zealand, edited by M. P. Mosley: New Zealand Hydrological Society.

Fahey, B.D, A.J Watson, and J Payne. 2001. Water loss from plantations of Douglas-fir and radiata pine on the Canterbury Plains, South Island Journal of Hydrology (NZ) 30 (1):1-15.

Fallow, D.J, D.E Elrick, W.D Reynolds, N Baumgartner, and G.W Parkin. 1994. Field measurent of hydraulic conductivity in slowly permeanle materials using early-time infiltration measurements in unsaturated media. In Hydraulic conductivity and waste contaminant transport in soil, edited by D. E. Daniel and S. J. Trautwein. Philedelphia: American Society for Testing and Materials.

Farrow, J., and K. Murray. 1992. Digital photogrammetry - options and opportunities. International Archives of the Photogrammetry, Remote Sensing and Spatial Information Sciences 26:150166. 
Felton, G.K, and J.L Nieber. 1991. Four soil moisture characteristic curve functions evaluated for numerical modeling of sand. Transactions-American Society of Agricultural Engineers 34:417422.

Flach, K.W. Modeling of soil productivity and related land classification. United States Department of Agriculture 2011 [cited. Available from http://www2.alterra.wur.nl/internet/webdocs/ilripublicaties/publicaties/pub40/pub40-h13.pdf.

Florence, R.G. 2004. Ecology and Silviculture of Eucalypt Forests. Collingwood: CSIRO Publishing. Fogel, R. 1983. Root turnover and productivity of coniferous forests. Plant and Soil 71:75-85.

Friend, A.L, G Scarascia-Mugnozza, J.G Isebrands, and P.E Heilman. 1990. Quantification of two-yearold hybrid poplar root systems: morphology, biomass, and $14 \mathrm{C}$ distribution ${ }^{1}$. Tree Physiology 8:109-119.

Friesecke, F. 2005. Flood risk management - Flood prevention by land consolidation in the Rhine catchment area. In From Pharaohs to Geoinformatics, FIG Working Week 2005 and GSDI-8. Cairo, Egypt April 16-21, 2005.

Gardiner, Duane, T, and Raymond Miller, W. 2004. Soils in our environment. 10 ed. Upper Saddle River, New Jersey: Pearson Education Inc.

GeographX. 2003. Metadata Geographx 25m New Zealand Map Grid Digital Elevation Model version 2. Wellington: Geographx.

Gerrard, John. 2003. Fundamentals of soils. London, UK; New York, USA: Routledge.

Ghosh, S.N. 2006. Flood control and drainage engineering. Third ed. Brookfield: Balkema Publishers.

Gibbs, H.S. 1980. New Zealand soils - An introduction. Wellington: Oxford University Press.

Giertz, S, B Junge, and B Diekkruger. 2005. Assessing the effects of land use change on soil physical properties and hydrological processes in the sub-humid tropical environment of West Africa. Physics and Chemistry of the Earth 30:485-496.

Gitas, I.Z., K. Douros, C. Minakou, G.S. Silleos, and C.G. Karydas. 2009. Multi-temporal soil erosion risk assessment in N.Chalkidiki using a modified usle raster model. EARSeLe Proceedings 8 (1):40-52.

Glover, R.E. 1953. Flow from a test-hole located above ground water level. In Theory and problems of water percolation: engineering monograph No.8, edited by C. N. Zangar. Denver: Bureau of Reclamation, Us Dept. Of Interior.

Goring, D.G. 1994. Kinematic shocks and monoclinal waves in the Waimakariri, a steep, braided, gravel-bed river. In Proceedings of the International Symposium on Waves: Physical and Numerical Modelling, University of British Columbia, Vancouver, Canada, 21-24 August.

Gradwell, M.W. 1968. Compaction of pasture top soils under winter grazing. In Proceedings of the 9th International Conference of the Soil Science Society. Adelaide, S.A.

Graham, R.C, J.O Ervin, and H.B Wood. 1995. Aggregate stability under oak and pine after four decades of soil development. Soil Science Society of America Journal 59:1740-1744.

Greenwood, P.B, and R.M McNamara. 1992. An analysis of the physical condition of two intensively grazed Southland soils. Proceedings of the New Zealand Grassland Association 54:71-75.

Griffiths, E. 2004. Soils of the Ruataniwha Plains - a guide to their management. Napier: Grifftech \& Hawke's Bay Regional Council.

Grismer, M.E. 2011. Erosion Modeling for Land Management -Scaling from plots to forest catchments in the Tahoe Basin. UCD 2011 [cited 17/02/11 2011]. Available from http://www.ierstahoe.com/pdf/research/Grismer Erosion\%20Modeling scaling.pdf.

Gupta, H.V, K.J Beven, and T Wagener. 2005. Model calibration and uncertainty estimation. In Encyclopedia of Hydrological Sciences, edited by M. G. Anderson: John Wiley \& Sons Ltd.

Haverkamp, R, and J.Y Parlange. 1986. Predicting the water retention curve from particle size distribution: 1. Sandy soils without organic matter. Soil Science 142:325-339.

Hayakawa, Y.S., T. Oguchi, and Z. Lin. 2008. Comparison of new and existing global digital elevation models: ASTER G-DEM and SRTM-3. Geophysical Research Letters 35:L17404, 5 PP., doi:10.1029/2008GL035036 
Hayashi, M, and W.L Quinton. 2004. A constant-head well permeameter method for measuring fieldsaturated hydraulic conductivity above an impermeable layer. Canadian Journal of Soil Science 84:255-264.

He, Y.H, H Sun, and K.M Chen. 2000. Options for improving productivity of sloping agricultural land in China: experiences of project on appropriate technologies for soil conserving farming systems. Katmandu, Nepal: ICIMOD.

He, Y.H, Y Tang, H Sun, and K.M Chen. 2001. Effects of contour hedgerow on surface flow and soil erosion control in Arid valley of Jinsha river. Paper presented at the International Symposium on Mountain Agriculture in the Hindu Kush Himalayan Region, at Kathmandu, Nepal.

Heathwaite, A.L, T.P Burt, and S.T Trudgill. 1990. Land-use controls on sediment production in a lowland catchment, South-west England. In Soil Erosion on Agricultural Land, edited by J. Boardman, I. D. L. Foster and J. A. Dearing. Chichester, UK: John Wiley \& Sons Ltd.

Heipke, C. 1995. State-of-the-art digital photogrammetric workstations for topographic applications. Photogrammetric Engineering \& Remote Sensing 61 (1):49-56.

Hennessy, K, B Fitzharris, B.C Bates, N Harvey, S.M Howden, L Hughes, J Salinger, and R Warrick. 2007. Australia and New Zealand. In Climate Change 2007: Impacts, Adaptation and Vulnerability. Contribution of Working Group II to the Fourth Assessment Report of the Intergovernmental Panel on Climate Change, edited by M. L. Parry, O. F. Canziani, J. P. Palutikof, P. J. van der Linden and C. E. Hanson. Cambridge, UK: Cambridge University Press.

Hicks, D.M. 1990. Suspended sediment yields from pasture and exotic forest basins. In Paper presented to New Zealand Hydrological Society Symposium, Taupo.

Hicks, D.M, J Hill, and U Shankar. 1996. Variation of suspended sediment yields around New Zealand: The relative importance of rainfall and geology. In Proceedings of a symposium on erosion and sediment yield Exeter: IAHS Publication 236.

HillPlan. 2011. Decision support tools to link ecology and land management: Development of HillPlan. The Macaulay Land Use Research Institute 2010 [cited 17/02/11 2011]. Available from http://www.macaulay.ac.uk/hillplan/.

Hirano, A., R. Welch, and H. Lang. 2003. Mapping from ASTER stereo image data: DEM validation and accuracy assessment Journal of Photogrammetry and Remote Sensing 57:356-370.

Holden, J, and T.P Burt. 2003. Hydraulic conductivity in upland blanket peat; measurement and variability. Hydrological Processes 17:1227-1237.

Hooghoudt, S.B. 1934. In Dutch. Bijdrage tot de kennis van enige natuurkundige grootheden van de grond. Verslagen Landbouwkundig Onderzoek 40B:215-345.

Hoover, M.D. 1949. Hydrologic characteristics of South Carolina Piedmont forest soils. Soil Science Society of America Proceedings 14:353-358.

Hornbeck, J.W, M.B Adams, E.S Corbett, E.S Verry, and J.A Lynch. 1993. Long-term impacts of forest treatments on water yield: a summary for northeastern USA. Journal of Hydrology 150 (24):323-44.

Ibbitt, R, A McKerchar, and R Woods. 2004. Catchments, streamflow and the use of models. In Freshwaters of New Zealand, edited by J. Harding, M. Mosley, C. Pearson and B. Sorrell. Wellington: New Zealand Hydrological Society.

Iwata, S, T Tabuchi, and B.P Warkentin. 1995. Soil-water interactions: mechanisms and applications. 2 ed. New York: Marcel Decker Inc.

Jackson, B.M, T Pagella, F Sinclair, B Orellana, B Reynolds, A Henshaw, N Mclntyre, H Wheater, and A Eycott. 2011. Polyscape: a GIS mapping toolbox providing efficient and spatially explicit landscape scale valuation of multiple ecosystem services.

Jackson, B.M., H.S. Wheater, N.R. Mcintyre, J. Chell, O.J. Francis, Z. Frogbrook, M. Marshall, B. Reynolds, and I. Solloway. 2008. The impact of upland land management on flooding: insights from a multiscale experimental and modelling programme. Journal of Flood Risk Management 1 (2):71-80. 
Jackson, J.L. 1973. Catchment hydrology and some of its problems. In Proceedings soil and plant water symposium, Palmerston North: DSIR Information Series 16.

Jackson, R. 1998. Sediment yields from Ashley Forest catchments (from unpublished project reports, FRI). As cited in Blaschke, Hicks, and Meister (2008).

Jackson, R.J. 1987. Hydrology of an acid wetland before and after draining for afforestation, western New Zealand. In Symposium on forest hydrology and watershed managment. Vancouver, Canada.

Jaiyeoba, I.A. 2001. Soil rehabilitation through afforestation: Evaluation of the performance of eucalyptus and pine plantations in a Nigerian savanna environment. Land Degradation and Development 12:183-194.

James, A.L, and N.T Roulet. 2007. Investigating hydraulic conectivity and its association with threshold change in runoff response in a temperate forested watershed Hydrological Processes 21:3391-3408.

Jin, N., D.S. Chapman, and K. Hubacek. 2009. Adaptive land-use management in dynamic ecological system Applications of Evolutionary Computing 5484:152-161.

Johnson, R, M Watson, and E McQuat. 2008. The way forward for natural flood manangement in Scotland: Mountain Environments Ltd \& Scottish Environment LINK.

Jones, J.A. 1997. Global Hydrology: Processes, resources and environmental management: Addison Wesley Longman Limited.

Jury, W.A. 1985. Spatial variability of soil physical pararmeters in solute migration: A critical literature review. In EPRI Topical Report EA4228. Palo Alto: Electric Power Research Institute.

Kamel, A.H. 2008. Application of a hydrodynamic MIKE 11 model for the Euphrates River in Iraq. Slovak Journal of Civil Engineering:1-7.

Katul, G, P Todd, D.E Pataki, Z.J Kabala, and R Oren. 1997. Soil water depletion by oak trees and the influence of root water uptake on the moisture content spatial statistics. Water Resources research 33 (4):611-623.

Keeratikasikorn, C, and I Trisirisatayawong. 2008. Reconstruction of 30m DEM from 90m DEM with bicubic polynomial interpolation method. The International Archives of the Photogrammetry, Remote Sensing and Spatial Information Sciences XXXVII (Part B1):791-794.

Kelliher, F.M, T.A Black, and D.T Price. 1986. Estimating the Effects of Understory Removal From a Douglas Fir Forest Using a Two-Layer Canopy Evapotranspiration Model Water Resources research 22 (13):1891-1899.

Klute, A, and C Dirksen. 1986. Hydraulic conductivity and diffusivity: Laboratory methods. In Methods of Soil Analysis, Part 1, Physical and Minerological Methods, edited by A. Klute. Madison, WI: Agronomy Monograph No. 9. American Society of Agronomy.

Kool, J.B, J.C Parker, and M Van Genuchten. 1987. Parameter estimation for unsaturated flow and transport models - A review. Journal of Hydrology 91:255-293.

Krausse, M.K, C Eastwood, and R.R Alexander. 2001. Muddied Waters: Estimating the economic cost of soil erosion and sedimentation in New Zealand. Palmerston North: Landcare Research New Zealand.

Krzysztofowicz, R., and K.S. Kelly. 2000. Hydrologic uncertainty processor for probabalistic river stage forecasting Water Resources Research 36 (11):3265-3277.

Kundzewicz, Z.W. 2002. Non-structural flood protection and sustainability. Water International 27 (1):3-13.

Lauren, J.G, R.J Wagnet, J Bouma, and J.H.M Wosten. 1988. Variability of Saturated Hydraulic Conductivity in A Glossaquic Hapludalf With Macropores. Soil Science 145 (1):20-28.

Lawrence, M.O. 2009. Quasi two-dimensional river flood modelling for the Budalangi floodplains, School of Engineering, Moi University, Eldoret.

Lee, D.M, W.D Reynolds, D.E Elrick, and B.E Clothier. 1985. A comparison of three field methods for measuring saturated hydraulic conductivity. Canadian Journal of Soil Science 65:563-573. 
Leeds, R, L.C Brown, M.R Sulc, and L Van Lieshout. Vegetative Filter Strips: Application, Installation and Maintenance 2010 [cited 30/08/2010. Available from http://ohioline.osu.edu/aexfact/0467.html.

Lilly, A. 1994. The determination of field-saturated hydraulic conductivity in some Scottish soils using the Guelph permeameter. Soil Use and Management 10:72-78.

Loster, T. 1999. Flood trends and global change: Geoscience Research Group, Munich Reinsurance Company. http://www.iiasa.ac.at/Research/RMS/june99/papers/loster.pdf.

Lowe, A. 1998. Sediment yields from Tairua and Riverhead forest catchments (from unpublished reports, FRI). As cited in Blaschke, Hicks, and Meister (2008).

Lowe, D.J, and J.D Green. 1987. Origins and development of the lakes. In Inland Waters of New Zealand, edited by A. B. Viner. Wellington: DSIR Science Information Publishing.

Maclaren, P. 1996. Environmental effects of planted forests in New Zealand. In Bulletin 198: Forest Research Instutute.

Marshall, M. R., O. J. Francis, Z. L. Frogbrook, B. M. Jackson, N. Mclntyre, B. Reynolds, I. Solloway, H. S. Wheater, and J. Chell. 2009. The impact of upland land management on flooding: results from an improved pasture hillslope. Hydrological Processes 23 (3):464-475.

Maxted, J.R, C.H McCready, and M.R Scarsbrook. 2005. Effects of small ponds on stream water quality and macroinvertebrate communities New Zealand Journal of Marine and Freshwater Research 39:1069-1084.

McConchie, J.A. 2000. From floods to forecasts: the hydrology of Wellington. In Dynamic Wellington, edited by J. A. McConchie, D. R. Winchester and R. P. Willis: Victoria University of Wellington.

McCulloch, J.S.G , and M Robinson. 1993. History of forest hydrology. Journal of Hydrology 150:189216.

McDonald, M.A, J.R Healy, and P.A Stevens. 2002. The effects of secondary forest clearance and subsequent land-use on erosion losses and soil properties in the Blue Mountains of Jamaica. Agriculture, Ecosystems and Environment 92 (2):1-19.

McDonnell, J. 1990. A rationale for old water discharge through macropores in a steep, humid catchment Water Resources research 26 (11):2821-2832.

McKerchar, A.I. 1980. Hydrological charecteristics of land use catchments in the Nelson area. In Proceedings of a seminar on land use in relation to water quantity and quality, Nelson 1979: Nelson Catchment Board.

McKergow, L, K Costley, and G Timpany. 2008. Contour grass filter strips: hydrology and water quality. Hamilton: NIWA.

McLaren, R.G, and K.C Cameron. 1996. Soil Science - Sustainable production and environmental protection. 2 ed. Auckland: Oxford University Press.

Meissner, M. 2003. Best practices on flood prevention, protection and mitigation: http://www.floods.org/PDF/Intl BestPractices EU 2004.pdf.

MfE. 2008. Climate change effects and impacts assessment: A guidance manual for local government in New Zealand. Retrieved from: www.mfe.govt.nz/publications/climate/: Ministry for the Environment,.

MfE. 2010. Tools for estimating the effects of climate change on flood flow. A guidance manual for local government in New Zealand Retrived from: http://www.mfe.govt.nz/publications/climate/climate-change-effects-on-floodflow/index.html: Ministry for the Environment,.

Milne, J.D.G, B Clayden, P.L Singleton, and A.D Wilson. 1991. Soil description handbook. Lower Hutt: DSIR Land Resources.

Min, S., X. Zhang, F.W. Zwiers, and G.C. Hegrel. 2011. Human contribution to more-intense precipitation extremes. Nature 470:378-381.

Mitchell, H.L., and R.G. Chadwick. 1999. Digital photogrammetric concepts applied to surface deformation studies. Geomatica 53 (4):405-414. 
Molchanov, A.A. 1960. The Hydrological Role of Forests. Translated by Isreal Prog. For. Sci. Trans. Acad. Sci. USSR Inst. For., Jerusalem.

Morris, J., T. Hess, and H. Posthumus. 2011. Agriculture's role in flood adaptation and mitigation: policy issues and approaches. Food, Agriculture and Natural Resources Policy Analysis Network 2010 [cited 20/02/2011 2011]. Available from http://www.fanrpan.org/documents/d00871/.

Mosley, M. 1979. Streamflow generation in a forested watershed, New Zealand. Water Resources research 15:795-806.

Mualem, Y. 1986a. Hydraulic conductivity of unsaturated soils: Prediction and formulas. In Methods of Soil Analysis, Part 1, Physical and Mineralogical Methods, edited by A. Klute. Madison, WI: American Society of Agronomy.

Mulholland, B, and M.A Fullen. 1991. Cattle trampling and soil compaction on loamy sands. Soil Use and Management 7:189-193.

Mulholland, Murray. 2006. The effect of land use change on the flood hydrology of pumice catchments. Environment Waikato Technical Report 2006/35: Environment Waikato.

Mulligan, M, and J Wainwright. 2004. Modelling and model building. In Environmental Modelling: Finding simplicity in complexity, edited by J. Wainwright and M. Mulligan: John Wiley \& Sons Ltd.

Munoz-Carpena, R, C.M Regalado, J Alvarez-Benedi, and F Bartoli. 2002. Field evaluation of the new phillip-dunne permeameter for measuring saturated hydraulic conductivity. Soil Science 167 (1):9-24.

Muys, B, N Lust, and P Granval. 1992. Effects of grassland afforestation with different tree species on earthworm communities, litter decomposition and nutrient status. Soil Biology and Biochemistry 24:1459-1466.

Nandagiri, L, and R Prasad. 1997. Relative performences of textural models in estimating soil moisture characteristic. Journal of Irrigation and Drainage Engineering 123:211-214.

Neirynck, J, S Mirtcheva, G Sioen, and N Lust. 2000. Impact of Tilia platyphyllos Scop., Fraxinus excelsior L., Acer pseudoplatanus L., Quercus robur L. and Fagus sylvatica L. on earthworm biomass and physico-chemical properties of a loamy topsoil. Forest Ecology and Management 133:275-286.

Nguyen, M. L., G. W. Sheath, C. M. Smith, and A. B. Cooper. 1998. Impact of cattle treading on hill land 2. Soil physical properties and contaminant runoff. New Zealand Journal of Agricultural Research 41 (2):279-290.

Nilsson, S.I, H.G Miller, and J.D Miller. 1982. Forest growth as a possible cause of soil and water acidification: an examination of the concepts. Oikos 39:40-49.

Nisbet, T.R., and H. Thomas. 2006. The role of woodland in flood control: a landscape perspective. In Water and the landscape: the landscape ecology of freshwater ecosystems, edited by B. Davies and S. Thompson. Oxford.

NIWA. 2011. Climate change scenarios for New Zealand. National Institute of Water \& Atmospheric Research 2008 [cited 10/02/11 2011]. Available from http://edit.niwa.co.nz/ourscience/climate/information-andresources/clivar/scenarios?SQ BACKEND PAGE=main\&safe edit=yes\&page=30638\#extrem es.

Noguchi, S, Y Tsuboyama, R.C Sidle, and I Hosoda. 1999. Morphological Characteristics of Macropores and the Distribution of Preferential Flow Pathways in a Forested Slope Segment. Soil Science Society of America Journal 63:1413-1423.

NZIER. 2004. Economic impacts on New Zealand of climate change-related extreme events: focus on freshwater floods: Report to Climate Change Office, New Zealand Institute of Economic Research,Wellington, http://www.climatechange.govt.nz/resources/reports/economicimpacts-extreme-eventsjul04/economic-impacts-extreme-events-jul04.pdf. 
O'Connell, E., J. Ewen, G. O'Donnell, and P. Quinn. 2006. Is there a link between agricultural land-use management and flooding? Paper read at General Assembly of the European-GeosciencesUnion, Apr 02-07, at Vienna, Austria.

Ogtrop, F.F, A.Y Hoekestra, and F van der Meulen. 2005. Flood managemnet in the Lower Incomata River Basin, Mozambique: Two alternatives Journal of American Water Resources Association June 2005.

Oosterbaan, R.J, and H.J Nijland. 1994. Determining the saturated hydraulic conductivity. In Drainage Principles and Applications edited by H. P. Ritzema. Wageningen, Netherlands: Institute for Land Reclamation and Improvement (ILRI)

Or, D, and J.M Wraith. 2000. Soil water content and water potential relationships. In Handbook of Soil Science, edited by M. E. Sumner: CRC Publishing.

Paige, G.B, and D Hillel. 1993. Comparison of Three Methods for Assessing Soil Hydraulic Properties. Soil Science 155:175-189.

Parfitt, R.L, C Ross, L.A Schipper, J.J Claydon, W.T Baisden, and G Arnold. 2010. Correcting bulk density measurements made with driving hammer equipment. Geoderma (157):46-50.

Parkin, G.W, D.E Elrick, R.G Kachanoski, and R.G Gibson. 1995. Unsaturated hydraulic conductivity measured by TDR under a rainfall simulator. Water Resources research 31:447-454.

Parkin, G.W, D.E Elrick, and W.D Reynolds. 1999. Recent advantages in using ring infiltrometers and TDR to measure hydraulic properties of unsaturated soils. In Proceedings of the international workshop on characterization and measurement of the hydraulic properties of unsaturated porous media, edited by M. Van Genuchten, F. J. Leij and L. Wu. University of California: Riverside.

Parkyn, S, and B Wilcock. 1992. Impacts of agricultural land use. In Waters of New Zealand, edited by M. P. Mosley: New Zealand Hydrological Society.

Pearce, A.J, C.L O'Loughlin, R.J Jackson, and X.B Zhang. 1987. Reforestation: on-site effects on hydrology and erosion, eastern Raukumara Range, New Zealand In Proceedings Symposium on Forest Hydrology and Watershed Mangement.

Peckham, S.D. 2009. Geomorphometry and spatial hydrologic modelling. Developments in Soil Science 33:579-602.

Perroux, K.M, and I White. 1988. Designs for disk permeameters. Soil Science Society of America Journal 52:1205-1215.

Phillip, J.R. 1985. Reply to "Comments on 'Steady infiltration from spherical cavaties.'". Soil Science Society of America Journal 49:788-789.

Phoon, Kok-Kwang, Thiam-Soon Tan, and Pui-Chih Chong. 2007. Numerical simulation of Richards equation in partially saturated porous media: under-relaxation and mass balance Geotechnical and Geological Engineering 25 (5):525-541.

Pitard, F.F. 1993. Pierre Gy's Sampling Theory and Sampling Practice. Heterogeinity, sampling correctness and statistical process control. 2 ed: CRC Press, USA.

Pollock, K. Hawke's Bay region - Facts and figures, Te Ara - the Encyclopedia of New Zealand 2010 [cited 23/07/2010. Available from http://www.teara.govt.nz/en/hawkes-bay-region/15.

Pregitzer, K.S, and A.L Friend. 1996. The structure and function of Populus root systems. In Biology of Populus and its implications for management and conservation edited by R. F. Stettler: NRS Research Press.

Pritchett, W.L, and R.F Fisher. 1987. Properties and management of forest soils. Second ed. New York: John Wiley and Sons.

Quinn, J, and M Stroud. 2002. Water quality and sediment and nutrient export from New Zealand hill land catchments of contrasting land use. New Zealand Journal of Marine and Freshwater Research 36:409-29.

Radcliffe, D.E, and T.C Rasmussen. 2000. Soil water movement. In Handbook of soil science, edited by M. E. Sumner: CRC Press. 
Rawls, W.J, T.J Gish, and D.L Brakensiek. 1991. Estimating soil water retention from soil physical properties and characteristics. In Advances in Soil Science, edited by B. A. Stewart. New York: Springer-Verlag.

Reenes, L. 1976. Field and laboratory studies of the movement and reactions of Phosphorus in soils. $\mathrm{PhD}$ thesis, Massey University. As cited in Blaschke, Hicks, and Meister (2008)

Reynolds, W.D, B.T Bowman, R.R Brunke, C.F Drury, and C.S Tan. 2000. Comparison of Tension Infiltrometer, Pressure Infiltrometer, and Soil Core Estimates of Saturated Hydraulic Conductivity. Soil Science Society of America Journal 64:478-484.

Reynolds, W.D, and D.E Elrick. 1986. A method for simultaneous in situ measurement in the vadose zone of field saturated hydraulic conductivity, sorptivity and the conductivity-pressure head relationship Ground Water Monitoring Review 6 (1):84-95.

Reynolds, W.D, and D.E Elrick. 1990. Ponded Infiltration From a Single Ring: I. Analysis of Steady Flow. Soil Science Society of America Journal 54:1233-1241.

Reynolds, W.D, D.E Elrick, and B.E Clothier. 1985. The constant head well permeameter: Effect of unsaturated flow. Soil Science 139:172-180.

Reynolds, W.D, S.R Vieira, and G.C Topp. 1992. An assessment of the single-head analysis for the constant head well permeameter. Canadian Journal of Soil Science 72:489-501.

Richards, L.A. 1931. Capillary conduction of liquids through porous mediums. Physics 1 (5):318-333.

Riggs, H.C. 1985. Streamflow characteristics. Vol. 22, Developments in water science: Elsevier.

Robb, C. 1992. HRFMP Phase 1 - Hutt River Flood Control Scheme Review. Topic No.4 River channel capacity, edited by C. Robb. Wellington: Rivers Department, Wellington Regional Council.

Robinson, $\mathrm{M}$, and $\mathrm{K}$ Beven. 1983. The effect of mole drainage on the hydrological response of a swelling clay soil. Journal of Hydrology 64:205-223.

Robinson, M., A. L. Cognard-Plancq, C. Cosandey, J. David, P. Durand, H. W. Fuhrer, R. Hall, M. O. Hendriques, V. Marc, R. McCarthy, M. McDonnell, C. Martin, T. Nisbet, P. O'Dea, M. Rodgers, and A. Zollner. 2003. Studies of the impact of forests on peak flows and baseflows: a European perspective. Forest Ecology and Management 186 (1-3):85-97.

Rowe, L. K, R Jackson, and B Fahey. 2003. Land use and water resources: Hydrological effects of different vegetation covers: Contract report to Ministry for Environment, Landcare Research.

Rowe, L. K., and A. J. Pearce. 1994. Hydrology and related changes after harvesting native forest catchments and establishing Pinus-Radiata plantations 2 . The native forest water-balance and changes in streamflow after harvesting. Hydrological Processes 8 (4):281-297.

Rowe, L.K, R Jackson, and B Fahey. 2002. Land use and water resources: Hydrological effects of different vegetation covers: Contract report to Ministry for Environment, Landcare Research.

Sahin, V, and M.J Hall. 1996. The effects of afforestation and deforestation on water yields. Journal of Hydrology 178 (1-4):293-309.

Salverda, A.P, and J.H Dane. 1993. An examination of the Guelph permeameter for measuring the soil's hydraulic properties. Geoderma 57:405-421.

Scarf, F. 1970. Hydrological effects of cultural changes at Moutere experimental basin. New Zealand Journal of Hydrology 9:142-62.

Schaap, M.G. 2005. Models for Indirect Estimation of Soil Hydraulic Properties. In Encyclopedia of Hydrological Sciences, edited by M. Anderson: John Wiley \& Sons.

Schenk, H.J, and R.B Jackson. 2002. The global biogeography of roots. Ecological Monographs 72:311-328.

Schenk, T. 1999. Digital Photogrammetry. TerraScienze 1:41-76.

Schouten, C.J. 1976. Origin and output of suspended and dissolved material froma catchment in Northland, New Zealand, with particular reference to man-induced changes: Publication 23, Physical Geography and Soil Science Laboratory, University of Amsterdam.

Schuyt, K, and L Brander. 2004. Living waters: The economic values of the world's wetlands. Amsterdam: WWF. 
Scott, R.S. 1963. The effect of mole drainage and winter pugging on grassland production. Proceedings of the New Zealand Grassland Association 25:119-127.

Selby, M.J. 1972. Relationships between land use and erosion in the central North Island. New Zealand Journal of Hydrology 11:73-87.

Selby, M.J. 1976. Slope erosion due to extreme rainfall: a case study from New Zealand. Geografiska Annaler 58a (131-8).

Selby, M.J, and P.J Hosking. 1973. The erodibility of pumice soils of the North Island. New Zealand Journal of Hydrology 12:32-56.

SERDP. 2011. Ecological models 2011 [cited 17/02/11 2011]. Available from http://www.esd.ornl.gov/programs/SERDP/EcoModels/models.html.

Shah, N., T.R. Nisbet, and H. Thomas. 2009. Rural flooding: The potential role of forestry: Centre for Forestry and Climate Change.

Simonovic, S.P. 2011. Computerized decision support for flood management: Red River basin case study. internationalfloodnetwork.org 2011 [cited 17/02/11 2011]. Available from http://www.internationalfloodnetwork.org/AR2006/AR09Simonovic.pdf.

Singleton, P.L, and B Addison. 1999. Effects of cattle treading on physical properties of three soils used for dairy farming in the Waikato, North Island, New Zealand. Australian Journal of Soil Research 37:891-902.

Sivapalan, M. 2003. Process complexity at hillslope scale, process simplicity at the watershed scale: is there a connection? Hydrological Processes 17:1037-1041.

Sklash, M.G, M.K Stewart, and A.J Pearce. 1986. Storm runoff generation in humid headwater catchments 2. A case study of hillslope and low-order stream response. Water Resources research 22:1273-1282.

Smit, H.J., M.J. Metzger, and F. Ewert. 2008. Spatial distribution of grassland productivity and land use in Europe. Agricultural Systems 98 (3):208-219.

Smith, K, and R Ward. 1998. Floods - Physical processes and human impacts. New York: John Wiley \& Sons.

Smith, P.J. 1987. Variation of water yield from catchments under grass and exotic forest, east Otago. New Zealand Journal of Hydrology (26):175-84.

Soilmoisture. 2800k1 Operating Instructions 2008 [cited 8/07/10. Available from http://www.soilmoisture.com/PDF\%20Files/82800k1.pdf.

Stace, C. 2011. Riparian management. Environment Bay of Plenty Regional Council 2004 [cited 8/02/11 2011]. Available from http://boprc.govt.nz/media/29125/LandManagement090526-Factsheet02.pdf.

Stednick, J.D. 1996. Monitoring the effects of timber harvest on annual water yield. Journal of Hydrology 176 (1-4):79-95.

Stephens, D.B, and S.P Neuman. 1982. Free surface and saturated-unsaturated analysis of borehole infiltration tests above the water table. Advances in Water Resources 5:111-116.

Stokes, S. 2006. Foley Bros. Takapau Farms Environmental Plan. Napier: Hawke's Bay Regional Council.

Sun, H, Y Tang, K.M Chen, and Y.H He. 1999. Effect of contour hedgerow system on erosion control on slope lands. Soil and Water Conservation 19 (6):1-6.

Sun, H, Y Tang, K.M Chen, and Y.Z Zhang. 2001. Effect of contour hedgerow intercropping on reducing runoff in sloping cropland. Soil and Water Conservation 21 (2):48-51.

Sun, $\mathrm{H}, \mathrm{Y}$ Tang, and J Xie. 2008. Contour hedgerow intercropping in the mountains of China: a review. Agroforestry Systems 73 (1):65-76.

Swales, A, and T Hume. 1998. Bare ground percentages before and after logging (from unpublished NIWA contract report to Carter Holt Harvey). As cited in Blaschke, Hicks, and Meister (2008).

Tabeau, A., B. Eickhout, and H. van Meijl. 2006. Endogenous agricultural land supply: estimation and implementation in the GTAP model Presented at the 9th Annual Conference on Global Economic Analysis, Addis Ababa, Ethiopia. 
Ternan, J.L, A.G Williams, and K Solman. 1987. A preliminary assessment of soil hydraulic properties and their implications for agro forestry management in Grenada, West Indies. In Forest Hydrology and Watershed Management. IAHS Publication No. 167, edited by R. H. Swanson, P. Y. Bernier and P. D. Woodard. Wallingford: IAHS.

The Scottish Government. 2011. CR/2010/14 Flood Protection Work 2011 [cited 17/02/11 2011]. Available from http://www.scotland.gov.uk/Topics/Research/About/EBAR/researchopportunities/cr201014.

Thomas, H, and T.R Nisbet. 2006. An assessment of the impact of floodplain woodland on flood flows. Water and Environmental Journal 21 (2):114-126.

Thompson, S.K. 2002. Sampling. New York: John Wiley \& Sons.

Tietje, O, and M Tapkenhinrichs. 1993. Evaluation of Pedo-Transfer Funstions. Soil Science Society of America Journal 57:1088-1095.

Tonkin \& Taylor Ltd. 2009. Prefeasibility study of water augmentation opportunities - Ruataniwha Plains Prepared for Hawkes Bay Regional Council.

Townend, J, M.J Reeve, and A Carter. 2000. Water release characteristic. In Soil and Environmental Analysis - Physical Methods, edited by K. A. Smith and C. E. Mullins. New York: Marcell Decker Inc.

TRC. 2010. Sustainable land management programme: Wetlands, edited by L. M. Section. Stratford: Taranaki Regional Council.

TRC. 2011. Why manage streambanks? Taranaki Regional Council 2011 [cited 8/02/11 2011]. Available from http://www.trc.govt.nz/assets/Publications/information-sheets-andnewsletters/land-management-information-sheets/riparian-management-informationsheets/22benefits-of-rip-man09.pdf.

USDA. 2010. 4. Bulk density test. United States Department of Agriculture 2010 [cited 16/12/10 2010]. Available from http://soils.usda.gov/sqi/assessment/files/chpt4.pdf.

USDA. Saturated Hydraulic Conductivity in Relation to Soil Texture. United States Department of Agriculture 2010 [cited 4/06/2010. Available from http://www.mo10.nrcs.usda.gov/references/guides/properties/sathydcond.html.

Van Genuchten, M. 1980. A close-form equation for predicting the hydrraulic conductivity of unsaturated soils. Soil Science Society of America Journal 44:892-898.

Van Genuchten, M, F.J Leij, and L Wu. 1992. Indirect methods for estimating the hydraulic properties of unsaturated soils. Riverside: University of California.

Van Genuchten, M, F.J Leij, and L Wu. 1999. Characterization and measurement of the hydraulic properties of saturated porous media. Riverside: University of California.

van Noordwijk, M. 2002. Scaling trade-offs between crop productivity, carbon stocks and biodiversity in shifting cultivation landscape mosaics: the FALLOW model. Ecological Modelling 149:113-126.

Van Roon, M. 1983. Water quality in the Waitemata Harbour and catchment. In Technical Report: Auckland Regional Authority.

Vereecken, H, J Maes, J Feyen, and P Darius. 1989. Estimating the soil retention characteristics from texture, bulk density, and carbon content. Soil Science 148:389-403.

Viaene, P, H Vareecken, J Diels, and J Feyen. 1994. A statistical analysis of six hysteresis models for the moisture retention characteristic Soil Science 68:75-94.

Vieira, S.R, W.D Reynolds, and G.C Topp. 1988. Spatial variability of hydraulic properties in highly structured clay soil. Paper read at Proc. Symp. Validation of flow and transport models for the unsaturated zone, Ruidoso, New Mexico. Res. Rep. 88-SS-04, New Mex. State Univ., Las Cruces, NW.

Wagner, B, V.R Tarnawski, V Hennings, U Müller, G Wessolek, and R Plagge. 2001. Evaluation of pedo-transfer functions for unsaturated soil hydraulic conductivity using an independent data set Geoderma 102 (3-4):275-297. 
Wang, Z.Q. 2000. Preliminary discussion on ecological environment construction in the gullied rolling loess region in northern Shaanxi. Soil and Water Conservation, China 8:26-28.

Waugh, J.R. 1980. Hydrological effects of the establishment of forests. In Proceedings of a seminar on land use in relation to water quality, Nelson 1979: Nelson Catchmnet Board.

Wedd, M.W. Determination of Particle Size Distributions Using Laser Diffraction 2003 [cited 8/07/10. Available from http://www.erpt.org/0320/Wedd-01.pdf.

Western, A.W, R.B Grayson, and J.F Costello. 2005. Principles of Hydrological Measurements. In Encyclopedia of Hydrological Sciences, edited by M. G. Anderson: John Wiley \& Sons.

Wheater, H. S. 2005. Flood hazard and management: a UK perspective. Paper read at Discussion Meeting on Extreme Natural Hazards, Oct 26-27, at London, ENGLAND.

White, Robert. 2006. Principles and practice of soil science. The soil as a natural resource. Malden, USA; Oxford, UK; Carlton, Australia: Blackwell Publishing.

Wigmosta, M.S., L.J. Lane, and A.M. Coleman. 2009. Hydrologic and erosion models to assess land use and management practices affecting soil erosion. Journal of Hydrologic Engineering 14 (1):27-41.

Wilson, G.V, and P.M Jardine. 1989. Spatial Variability of Saturated Hydraulic Conductivity of the Subsoil of Two Forested Watersheds. Soil Science Society of America Journal 53:679-685.

Wood, H.B. 1977. Hydrologic differences between selected forested and agricultural soils in Hawaii. Soil Science Society of America Journal 41:132-136.

Woods, R. 2005. Hydrological concepts of variability and scale. In Encyclopedia of Hydrological Sciences, edited by M. G. Anderson: John Wiley \& Sons.

Woodward-Clyde. 1998. Ruataniwha Plains flood hazard study. Napier: prepared for Hawke's Bay Regional Council.

Wosten, J.H.M, Y.A Pachepsky, and W.J Rawls. 2001. Pedotransfer functions: bridging the gap between available basic soil data and missing soil hydraulic characteristics. Journal of Hydrology 251:123-150.

WRC. 2001. Hutt River Floodplain Management Plan (HRFMP). Wellington: Wellington Regional Council, Flood Protection Group.

WRC. 2011. Planting for results. Wellington Regional Council 2009 [cited 16/02/11 2011]. Available from http://www.gw.govt.nz/planting-for-results-2/.

Wullschleger, S.D., F.C. Meinzer, and R.A. Vertessy. 1998. A review of whole-plant water use in trees. Tree Physiology 18 (8-9):499-512.

WWF. 2002. WWF Background Paper. Managing floods in Europe: The anwsers already exist. More intelligent river basin management using wetlands can alleviate future flooding events.

WWF. 2007. Flood Planner - A manual for the natural management of river floods: WWF Scotland Publication.

Xiao, Q., and E.G. McPherson. 2002. Rainfall interception by Santa Monica's municipal urban forest. Urban Ecosystems 6:291-302.

Xu, F, Q.G Cai, S.A Wu, G.Y Zhang, S.W Ding, and C.F Cai. 2000. A study on soil nutrient loss by slope eco-engineering in the Three Gorges Reservoir Region Taking the contour hedgerows as an example. Geographical Research 19:303-310.

Yeates, G.W, and B Boag. 1995. Relation between macrofaunal populations and soil physical properties in two agroforestry trials. Acta Zoologica Fennica 196:275-277.

Yin, D.X, H.B Tang, Q Zhu, and R.R Li. 2001. Research on alley cropping technology integrated terracing slopeland. Soil and Water Conservation 15:84-87.

Yin, D.X, C.H Zhou, and H.B Tang. 1996. Study on hedgerow cropping technology integrated with gradually terracing land in China. Guizhou Agricultural Science 5:1-5.

Young, P.C. 2002. Advance in real-time flood forecasting. Philosophical Transactions of the Royal Society of London B360:1433-1450.

Youngs, E.G. 2001. Hydraulic conductivity of saturated soils. In Soil and Environmental Analysis Physical Methods, edited by K. A. Smith and C. E. Mullins. New York: Marcell Decker Inc. 
Zegwaard, K.E, M.R Balks, and P.L Singleton. 1998. The effect of cattle trampling and pugging on selected soil properties. In Proceedings of the New Zealand Soil Society Conference 1998.

Zhang, Z.F. 2010. Effective Hydraulic Conductivity of Unsaturated Isotropic Soils with Multidimensional Heterogeneity. Soil Science Society of America Journal 74:734-743.

Zhou, X.K, G.L Sun, and Q.G Cai. 1997. Amorpha fruticosa-a kind of shrubs for vegetation hedge on the terraced field wall in the loess region. Shanxi Science Technology Soil Water

Conservervation 2:32-34. 


\section{Appendix A - Original and adjusted bulk density}

As the carving method is considered more accurate due to less disturbance of the soil a correction factor of $+6 \%$ for the A-horizon samples and $+3.5 \%$ for the fragipan was used to adjust the data to an equivalent obtained by carving as suggested by Parfitt et al. (2010).

Table A1. Original and adjusted bulk density at Takapau farms.

\begin{tabular}{|c|c|c|c|}
\hline Takapau farms & Depth (cm) & $\begin{array}{l}\text { Original bulk density } \\
\qquad\left(\mathrm{g} / \mathrm{m}^{3}\right)\end{array}$ & $\begin{array}{l}\text { Adjusted bulk density } \\
\qquad\left(\mathrm{g} / \mathrm{m}^{3}\right)\end{array}$ \\
\hline 1/A1 & $0-6$ & 1.14 & 1.21 \\
\hline 1/A1 & $20-25$ & 1.48 & 1.57 \\
\hline 1/A1 & $40-46$ & 1.35 & 1.40 \\
\hline $1 / A 2$ & $0-6$ & 0.99 & 1.05 \\
\hline $1 / \mathrm{A} 2$ & $25-31$ & 1.36 & 1.44 \\
\hline 1/A3 & $0-6$ & 1.06 & 1.12 \\
\hline 1/A3 & $20-26$ & 1.17 & 1.24 \\
\hline 1/A3 & $40-46$ & 1.68 & 1.73 \\
\hline 1/B1 & $0-6$ & 1.13 & 1.20 \\
\hline 1/B1 & $30-36$ & 1.36 & 1.44 \\
\hline 1/B2 & $0-6$ & 0.98 & 1.04 \\
\hline 1/B3 & $0-6$ & 0.79 & 0.84 \\
\hline $1 / C 1$ & $0-6$ & 1.21 & 1.29 \\
\hline $1 / C 1$ & $15-20$ & 1.33 & 1.41 \\
\hline $1 / C 1$ & $35-41$ & 1.68 & 1.78 \\
\hline $1 / C 2$ & $0-6$ & 1.10 & 1.16 \\
\hline $1 / C 2$ & $35-40$ & 1.37 & 1.45 \\
\hline $1 / C 2$ & $80-86$ & 1.71 & 1.77 \\
\hline $1 / \mathrm{C} 3$ & $0-6$ & 1.31 & 1.38 \\
\hline $1 / C 3$ & $35-41$ & 1.40 & 1.48 \\
\hline $1 / \mathrm{C} 3$ & $70-75$ & 1.64 & 1.70 \\
\hline 1/D1 & $0-6$ & 0.93 & 0.99 \\
\hline 1/D2 & $0-6$ & 0.96 & 1.01 \\
\hline 1/D3 & $0-6$ & 1.08 & 1.14 \\
\hline 1/E1 & $0-6$ & 1.03 & 1.10 \\
\hline 1/E1 & $20-26$ & 1.41 & 1.49 \\
\hline 1/E1 & $40-45$ & 1.44 & 1.49 \\
\hline $1 / \mathrm{E} 2$ & $0-6$ & 1.16 & 1.23 \\
\hline 1/E2 & $40-45$ & 1.57 & 1.63 \\
\hline 1/E3 & $0-6$ & 1.11 & 1.17 \\
\hline 1/E3 & $35-41$ & 1.63 & 1.73 \\
\hline $1 / F 1$ & $2-7$ & 0.99 & 1.05 \\
\hline $1 / F 2$ & $2-7$ & 1.00 & 1.06 \\
\hline $1 / F 2$ & $40-46$ & 1.32 & 1.37 \\
\hline 1/F3 & $2-7$ & 0.88 & 0.93 \\
\hline 1/G1 & $0-6$ & 1.17 & 1.24 \\
\hline
\end{tabular}




\begin{tabular}{|l|c|c|c|}
\hline $1 / \mathrm{G} 1$ & $20-26$ & 0.74 & 0.79 \\
$1 / \mathrm{G} 2$ & $0-6$ & 0.99 & 1.05 \\
$1 / \mathrm{G} 2$ & $22-28$ & 1.38 & 1.46 \\
$1 / \mathrm{G} 2$ & $55-61$ & 1.38 & 1.43 \\
$1 / \mathrm{G} 3$ & $0-6$ & 1.13 & 1.20 \\
$1 / \mathrm{G} 3$ & $30-36$ & 1.47 & 1.56 \\
$1 / \mathrm{H} 1$ & $0-6$ & 1.02 & 1.08 \\
$1 / \mathrm{H} 1$ & $25-31$ & 1.13 & 1.20 \\
$1 / \mathrm{H} 2$ & $0-6$ & 1.00 & 1.06 \\
$1 / \mathrm{H} 2$ & $60-66$ & 1.47 & 1.52 \\
$1 / \mathrm{H} 3$ & $0-6$ & 1.02 & 1.08 \\
$1 / \mathrm{H} 3$ & $20-26$ & 1.29 & 1.36 \\
$1 / 11$ & $0-6$ & 1.14 & 1.20 \\
$1 \mathrm{1} / 1$ & $20-26$ & 1.47 & 1.56 \\
$1 \mathrm{1} / 2$ & $0-6$ & 1.02 & 1.08 \\
$1 \mathrm{1} / 2$ & $10-15$ & 1.17 & 1.24 \\
$1 \mathrm{1} / 3$ & $0-6$ & 1.08 & 1.15 \\
$1 \mathrm{I} / 3$ & $10-16$ & 1.29 & 1.37 \\
\hline
\end{tabular}

Table A2 Original and adjusted bulk density at Manaui farms.

\begin{tabular}{|c|c|c|c|}
\hline Mananui farm & Depth (cm) & $\begin{array}{l}\text { Original bulk density } \\
\qquad\left(\mathrm{g} / \mathrm{m}^{3}\right)\end{array}$ & $\begin{array}{l}\text { Adjusted bulk density } \\
\qquad\left(\mathrm{g} / \mathrm{m}^{3}\right)\end{array}$ \\
\hline 2/A1 & $0-5$ & 1.06 & 1.12 \\
\hline 2/A1 & $32-37$ & 1.34 & 1.42 \\
\hline $2 / A 2$ & $0-5$ & 1.08 & 1.15 \\
\hline 2/A2 & $26-31$ & 1.42 & 1.51 \\
\hline 2/A3 & $0-5$ & 0.99 & 1.05 \\
\hline 2/A3 & $15-20$ & 1.14 & $1.2 \mathrm{C}$ \\
\hline 2/A4 & $0-5$ & 1.01 & 1.07 \\
\hline $2 / A 4$ & $28-33$ & 1.45 & 1.54 \\
\hline 2/A5 & $0-5$ & 0.94 & $1.0 \mathrm{C}$ \\
\hline 2/A5 & $20-25$ & 1.15 & 1.22 \\
\hline 2/A5 & $46-51$ & 1.36 & $1.4 \mathrm{C}$ \\
\hline 2/A5 & $70-75$ & 1.67 & 1.73 \\
\hline 2/A6 & $2-7$ & 1.02 & 1.08 \\
\hline 2/A6 & $40-45$ & 1.45 & $1.5 \mathrm{C}$ \\
\hline 2/B1 & $0-5$ & 0.96 & 1.02 \\
\hline 2/B1 & $10-15$ & 1.08 & 1.15 \\
\hline 2/B1 & $25-30$ & 1.32 & $1.4 \mathrm{C}$ \\
\hline 2/B2 & $0-5$ & 1.20 & 1.27 \\
\hline 2/B3 & $0-5$ & 1.02 & 1.08 \\
\hline 2/B4 & $0-5$ & 1.01 & 1.07 \\
\hline 2/B5 & $0-6$ & 1.01 & 1.08 \\
\hline 2/B5 & $15-21$ & 1.08 & 1.15 \\
\hline 2/B5 & $35-41$ & 1.45 & 1.54 \\
\hline $2 / C 1$ & $0-6$ & 0.91 & $0.9 €$ \\
\hline
\end{tabular}




\begin{tabular}{|l|c|c|c|}
\hline $2 / C 1$ & $20-26$ & 1.35 & 1.43 \\
$2 / C 2$ & $0-5$ & 1.16 & 1.23 \\
$2 / C 3$ & $0-5$ & 1.06 & 1.12 \\
$2 / C 4$ & $0-6$ & 1.10 & 1.17 \\
$2 / C 5$ & $0-6$ & 1.01 & 1.07 \\
$2 / C 5$ & $28-34$ & 1.41 & $1.5 \mathrm{C}$ \\
\hline
\end{tabular}

Table A3 Original and adjusted bulk density at the macrocarpa shelterbelt on Takapau farms.

\begin{tabular}{|c|c|c|c|}
\hline Takapau farms & $\begin{array}{c}\text { Distance from } \\
\text { Macrocarpa }(\mathbf{m})\end{array}$ & $\begin{array}{c}\text { Original bulk density } \\
\left(\mathbf{g} / \mathbf{m}^{\mathbf{3}}\right)\end{array}$ & $\begin{array}{c}\text { Adjusted bulk density } \\
\left(\mathrm{g} / \mathbf{m}^{\mathbf{3}}\right)\end{array}$ \\
\hline 1/M1 & 1 & 0.93 & 0.98 \\
1/M2 & 1 & 0.90 & 0.95 \\
1/M3 & 1 & 0.88 & 0.94 \\
$1 / \mathrm{J} 1$ & 5 & 1.02 & 1.08 \\
1/J2 & 5 & 0.87 & 0.92 \\
1/J3 & 5 & 0.97 & 1.03 \\
1/J4 & 5 & 1.12 & 1.18 \\
1/J5 & 5 & 1.03 & 1.09 \\
1/K1 & 10 & 1.02 & 1.08 \\
1/K2 & 10 & 0.98 & 1.04 \\
1/K3 & 10 & 1.04 & 1.10 \\
1/K4 & 10 & 1.10 & 1.16 \\
1/K5 & 10 & 1.01 & 1.08 \\
\hline
\end{tabular}

Table A4 Original and adjusted bulk density at the poplar trees on Mananui farm.

\begin{tabular}{|c|c|c|c|}
\hline Mananui farm & $\begin{array}{c}\text { Distance from Poplar } \\
(\mathbf{m})\end{array}$ & $\begin{array}{c}\text { Original bulk density } \\
\left(\mathbf{g} / \mathbf{m}^{\mathbf{3}}\right)\end{array}$ & $\begin{array}{c}\text { Adjusted bulk density } \\
\left(\mathbf{g} / \mathbf{m}^{\mathbf{3}}\right)\end{array}$ \\
\hline 2/P1 & 1 & 0.86 & 0.92 \\
2/P2 & 1 & 1.39 & 1.47 \\
2/P3 & 1 & 0.65 & 0.69 \\
2/P4 & 1 & 0.67 & 0.71 \\
2/E1 & 5 & 1.15 & 1.22 \\
2/E2 & 5 & 0.96 & 1.01 \\
2/E3 & 5 & 0.95 & 1.00 \\
2/E4 & 5 & 1.00 & 1.06 \\
2/D1 & 10 & 1.02 & 1.08 \\
2/D2 & 10 & 0.97 & 1.03 \\
2/D3 & 10 & 0.95 & 1.00 \\
2/D4 & 10 & 0.78 & 0.83 \\
\hline
\end{tabular}




\section{Appendix B - Depth to slowly permeable layer}

Table B1 Depth to slowly permeable layer (fragipan) as measured at Takapau and Mananui farms

\begin{tabular}{|c|c|c|c|}
\hline Farm & ID & Soil series & $\begin{array}{c}\text { Depth to slowly } \\
\text { permeable layer }(\mathrm{cm})\end{array}$ \\
\hline Takapau & 1/A1 & Matapiro & 20 \\
\hline Takapau & $1 / \mathrm{A} 2$ & Matapiro & 25 \\
\hline Takapau & $1 / \mathrm{A3}$ & Matapiro & 32 \\
\hline Takapau & 1/B1 & Maungapakeha & 17 \\
\hline Takapau & 1/B2 & Maungapakeha & 25 \\
\hline Takapau & 1/B3 & Maungapakeha & 20 \\
\hline Takapau & 1/C1 & Matapiro & 30 \\
\hline Takapau & $1 / \mathrm{C} 2$ & Matapiro & 33 \\
\hline Takapau & 1/C3 & Matapiro & 32 \\
\hline Takapau & 1/D1 & Maungapakeha & 5 \\
\hline Takapau & 1/D2 & Maungapakeha & 10 \\
\hline Takapau & 1/D3 & Maungapakeha & 10 \\
\hline Takapau & 1/E1 & Matapiro & 35 \\
\hline Takapau & $1 / \mathrm{E} 2$ & Matapiro & 23 \\
\hline Takapau & 1/E3 & Matapiro & 30 \\
\hline Takapau & 1/F1 & Matapiro & 35 \\
\hline Takapau & $1 / F 2$ & Matapiro & 28 \\
\hline Takapau & 1/F3 & Matapiro & 20 \\
\hline Takapau & $1 / \mathrm{G} 1$ & Atua & 55 \\
\hline Takapau & $1 / G 2$ & Atua & 30 \\
\hline Takapau & 1/G3 & Atua & 23 \\
\hline Takapau & $1 / \mathrm{H} 1$ & Atua & 60 \\
\hline Takapau & $1 / \mathrm{H} 2$ & Atua & 28 \\
\hline Takapau & $1 / \mathrm{H} 3$ & Atua & 25 \\
\hline Takapau & $1 / I 1$ & Atua & 17 \\
\hline Takapau & $1 / 12$ & Atua & 30 \\
\hline Takapau & $1 / 13$ & Atua & 20 \\
\hline Mananui & 2/A1 & Mangatahi & 33 \\
\hline Mananui & $2 / A 2$ & Mangatahi & 29 \\
\hline Mananui & $2 / A 3$ & Mangatahi & 20 \\
\hline Mananui & 2/A4 & Mangatahi & 27 \\
\hline Mananui & $2 / A 5$ & Mangatahi & 18 \\
\hline Mananui & 2/A6 & Mangatahi & 28 \\
\hline Mananui & 2/B1 & Mangatahi & 26 \\
\hline Mananui & 2/B2 & Mangatahi & 33 \\
\hline Mananui & 2/B3 & Mangatahi & 25 \\
\hline Mananui & 2/B4 & Mangatahi & 17 \\
\hline Mananui & 2/B5 & Mangatahi & 20 \\
\hline Mananui & $2 / C 1$ & Mangatahi & 18 \\
\hline Mananui & $2 / C 2$ & Mangatahi & 11 \\
\hline Mananui & $2 / C 3$ & Mangatahi & 20 \\
\hline Mananui & $2 / C 4$ & Mangatahi & 10 \\
\hline Mananui & $2 / \mathrm{C5}$ & Mangatahi & 25 \\
\hline
\end{tabular}

